Department for Innovation, Universities \& Skills
$\mathrm{E} \cdot \mathrm{S} \cdot \mathrm{R} \cdot \mathrm{C}$

ECONOMIC \& S OCIA L

RESEARCH

$\mathrm{COUNCI}$

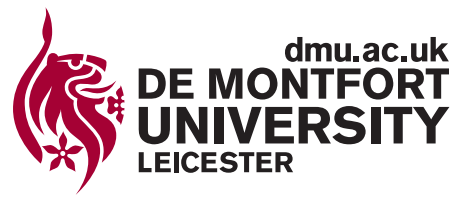

British Indian

and Chinese

Student, Graduate

and Academic

International

Entrepreneurship

Stella Mascarenhas-Keyes

Higher Education Directorate

Department for Innovation, Universities and Skills

DIUS Research Report 0820 


\title{
British Indian and Chinese Student, Graduate and Academic International Entrepreneurship
}

\author{
Stella Mascarenhas-Keyes \\ Higher Education Directorate \\ Department for Innovation, Universities and Skills
}

DIUS Research Report 08-20

(c) Crown Copyright 2008

The views expressed in this report are the authors' and do not necessarily reflect those of the Department for Innovation, Universities and Skills 


\section{Acknowledgements}

I would like to thank the many people and organisations in the UK and China who helped with this project. In particular, I would like to thank the following members of the steering group: David Ridley (Economic \& Social Research Council), Peter Hogarth and Paul Robson (UKTI), Adrian Day (Higher Education Funding Council for England); Daniel Cameron (London Development Agency), Kai Laing (graduate entrepreneur), Richard Roberts (Barclays Bank), Professor Paul Hannon and Dr Luke Pittaway (National Council for Graduate Entrepreneurship), Charles Ritchie (Department for Innovation, Universities and Skills) and George Bramley (Department for Business, Enterprise and Regulatory Reform); Professor Yaojun Li of Manchester University, and analysts at BERR and DIUS for the provision of various statistics; policy colleagues at DIUS, BERR, UKTI, RDAs and British officials in China for agreeing to interviews and discussing emergent findings; the ESRC, DIUS and BERR for co-funding this project; the large number of students, graduates and academics and ethnic minority organisations for agreeing to interviews; to Chinese scholars' associations for allowing me to attend events; audiences at seminars at a number of universities and conferences for comments on emergent findings; Liz Frost from De Montfort University who undertook multiple administrative tasks associated with the project with great diligence and efficiency, and Nicola Smith, Jane Brearley and Liam Shrivastava for additional admin support; and last, but by no means least, Professor Monder Ram, Director of the Centre for Research on Ethnic Minority Entrepreneurship, Leicester Business School, De Montfort University, for suggesting I undertake this research, for chairing the steering group, and for unstinting support, advice and guidance throughout this project.

\section{Stella Mascarenhas-Keyes}

\section{April 2008}

Dr. Stella Mascarenhas-Keyes is a Government Social Researcher in the Higher Education Directorate at the Department for Innovation, Universities and Skills (DIUS). She has also worked at the Small Business Service, Department for Trade \& Industry which is now known as the Department for Business, Enterprise and Regulatory Reform (BERR). The research project on which this report is based was undertaken under the Economic and Social Research Council Knowledge Transfer Placement Fellowship. It involved a year long secondment to the Centre for Research on Ethnic Minority Entrepreneurship, Leicester Business School, De Montfort University, Leicester. The study was co-funded by the ESRC, DIUS and BERR. The author is solely responsible for the report and none of the views or recommendations reflects those of Government.

Dr. Mascarenhas-Keyes holds a Ph.D in Social Anthropology, an M.A. in Higher and Professional Education, and a B.Sc in Psychology. Prior to joining the civil service, she held a number of posts including university lecturer, educational developer and researcher. Her previous research has focussed on international migration, ethnicity and higher education.

Dr. Mascarenhas-Keyes can be contacted at: stella.mascarenhas-keyes@dius.gsi.gov.uk 


\section{Notes and glossary}

1. The names of all individuals and universities have been changed to protect confidentiality. All named individuals in this report, with a very few exceptions, have been interviewed.

2. For Chinese, Christian first names have been used as this is a common practice among Chinese living abroad.

3. The following acronyms are used in the report:

BI: $\quad$ British Indian

BC: $\quad$ British Chinese

WB: White British

$\mathrm{BI}$ and $\mathrm{BC}$ are UK domiciled. In most cases they have British citizenship but some retain citizenship of India or China.

4. Overseas Indian/Overseas Chinese: citizens of India/China who do not have domiciliary rights to UK. They are usually in the UK on student or temporary work visas.

5. The terms Indian, Chinese and White are used when the data is taken from secondary sources which use this terminology. The category 'White' is predominantly White British, but does also include White Irish and White Other.

6. Some studies such as ASBS 2003 ethnic boost report (see note 8 below) use the term 'non-ethnic minority'. However, as the overwhelming majority of the category 'non-ethnic minority' are White British, for convenience, this term is used.

7. ASBS: Annual Small Business Survey (carried out by BERR)

8. ASBS 2003 ethnic boost report: Ethnic minority businesses in England: Report of the Annual Small Business survey 2003 Ethnic Boost published by DTI 2006d

9. BERR: Department of Business, Enterprise and Regulatory Reform

10. DCMS: Department for Culture, Media and Sport

11. DfEE: Department for Education and Employment

12. DIUS: Department for Innovation, Universities and Skills

13. DTI: Department for Trade \& Industry

14. FE: Further Education

15. GEM: Global Entrepreneurship Monitor

16. HEFCE: Higher Education Funding Council for England

17. HEA: Higher Education Academy

18. HEl: Higher Education Institution

19. HEIF: Higher Education Innovation Fund

20. HESA: Higher Education Statistical Agency

21. HSE: Household Survey of Entrepreneurship (carried out by BERR)

22. ICUK: Innovation China UK

23. NCGE: National Council for Graduate Entrepreneurship

24. OECD: Organisation for Economic Co-operation and Development

25. ONS: Office of National Statistics

26. PSA: Public Sector Agreement

27. RDA: Regional Development Agency

28. SBS: Small Business Service (formerly an executive agency of the DTI)

29. SET: Science, Engineering and Technology

30. SIES: Student Income and Expenditure Survey

31. SPEED: Student Placements for Entrepreneurs in EDucation

32. STEM: Science, technology, engineering and mathematics

33. UKBI: UK Business Incubation

34. UKIERI: UK-India Education and Research Initiative

35. UKTI: UK Trade and Investment, part of BERR and Foreign \& Commonwealth Office 36. UK-IPO: UK Intellectual Property Office, DIUS

37. 2008 Enterprise Strategy Paper: BERR 2008a Enterprise: unlocking the UK's talent 38. 2008 Innovation White Paper: DIUS 2008: Innovation Nation: Unlocking Talent 


\section{Table of contents}

\section{Contents}

CHAPTER 1: BACKGROUND, RESEARCH AIMS AND POLICY CONTEXT...................... 1

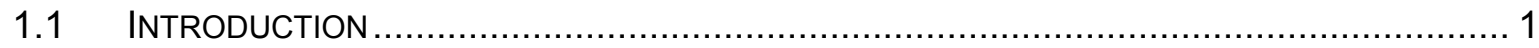

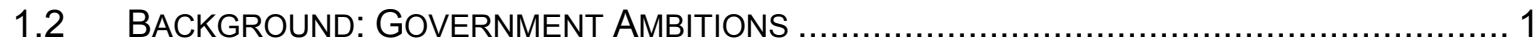

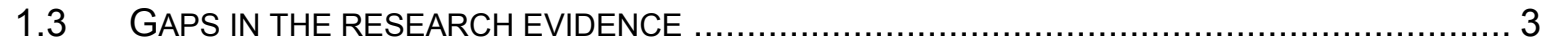

1.4 RESEARCH AIMS, METHOdOLOGY AND THEORETICAL APPROACH ............................ 3

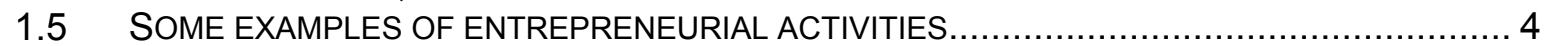

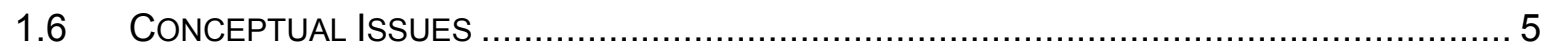

1.7 THE POLICY CONTEXT: DRIVERS OF PRODUCTIVITY AND ENABLERS OF ENTERPRISE.... 6

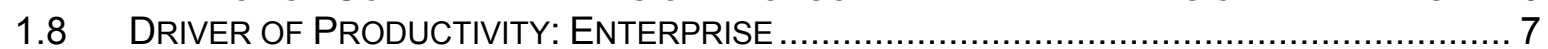

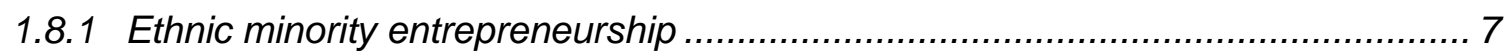

1.8.2 Student, graduate and academic entrepreneurship ...................................... 9

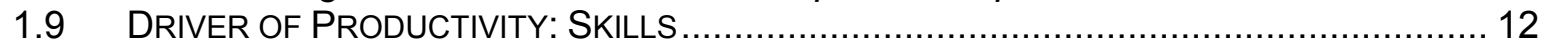

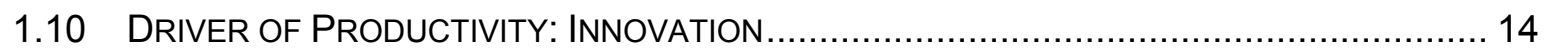

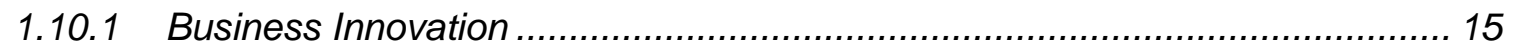

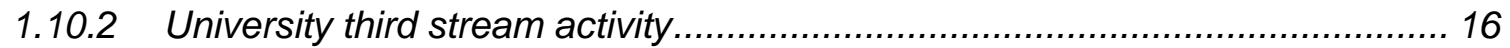

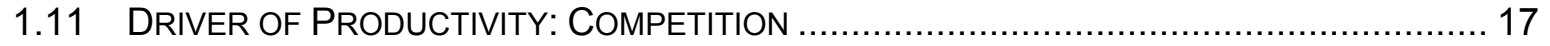

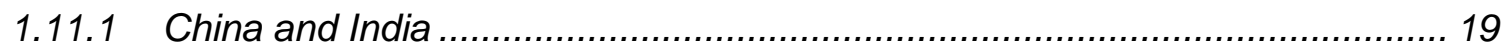

1.11.2 Social and Cultural Barriers to International entrepreneurship......................20

1.12 THE IMPACT OF THE DRIVERS OF PRODUCTIVITY AND ENABLERS OF ENTERPRISE ........ 22

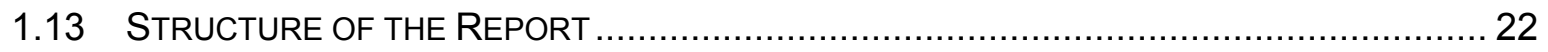

CHAPTER 2: BRITISH INDIAN AND BRITISH CHINESE: DEMOGRAPHY. SKILLS

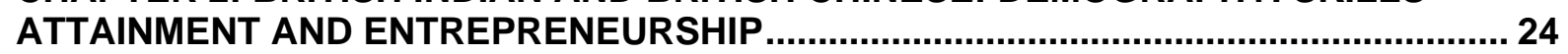

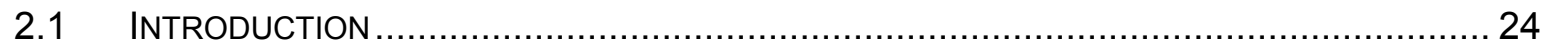

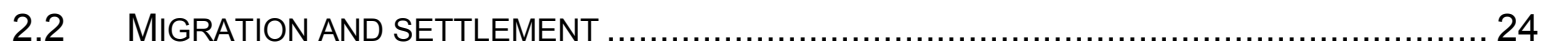

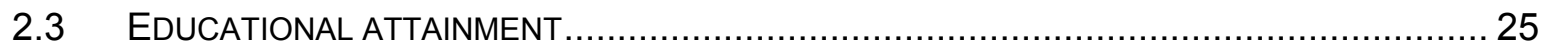

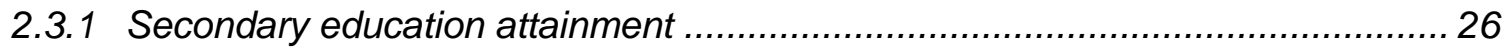

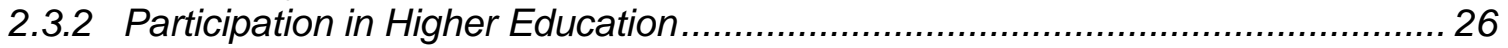

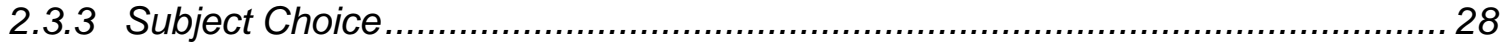

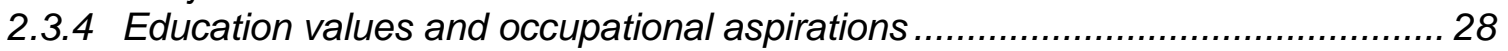

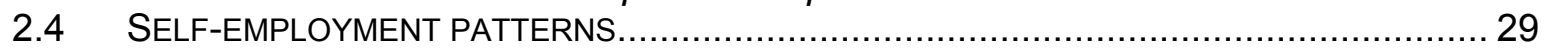

2.5 SELF-EMPLOYMENT AMONG FIRST AND SECOND GENERATION INDIAN AND CHINESE... 31

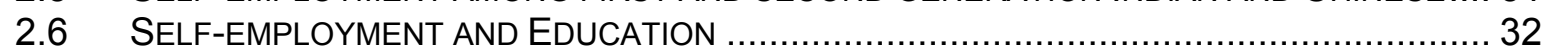

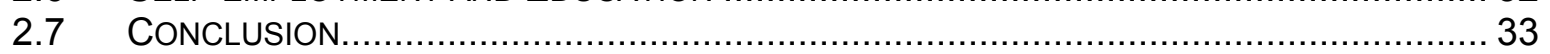

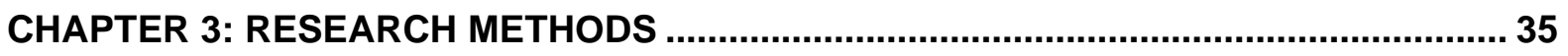

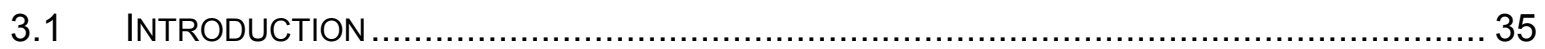

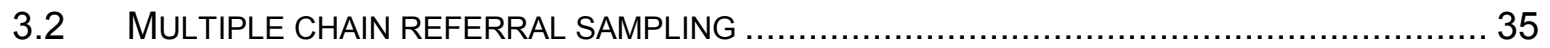

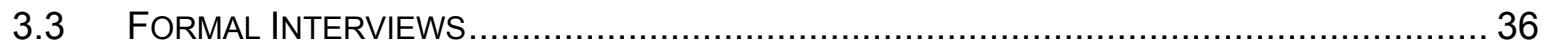

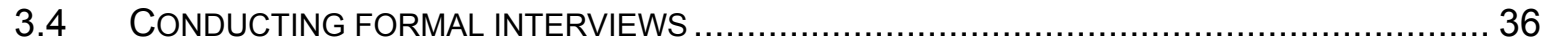

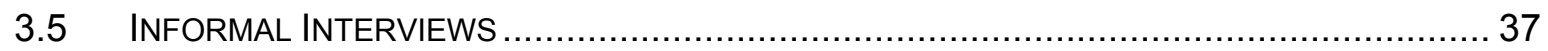

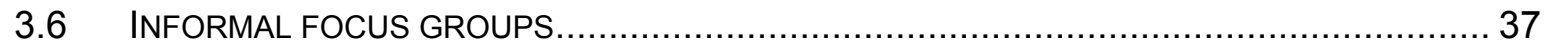

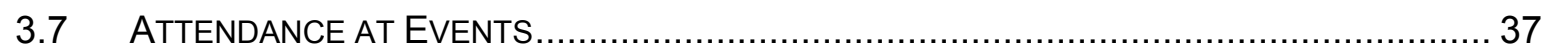

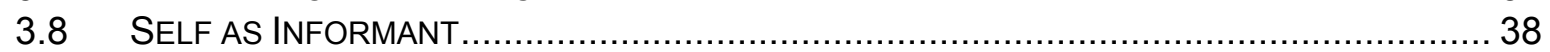

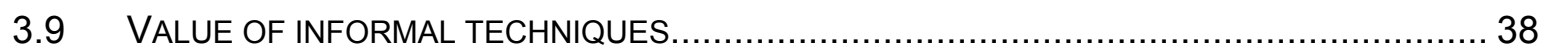

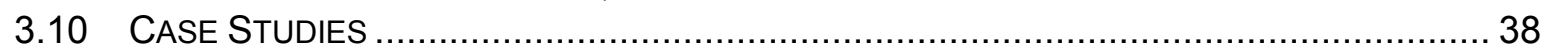

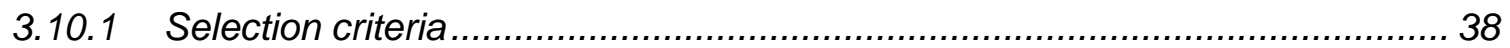

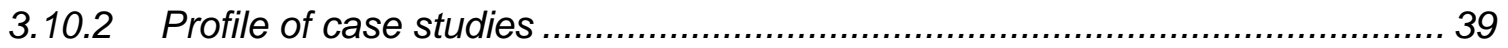




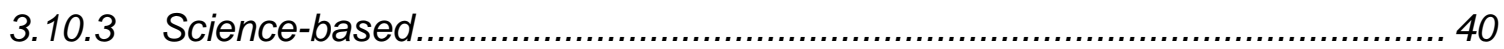

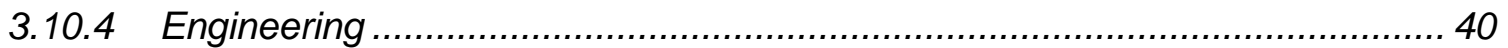

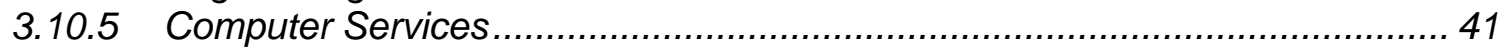

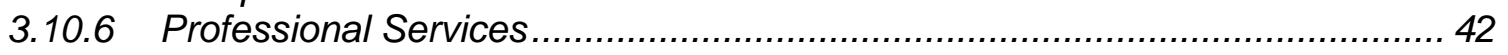

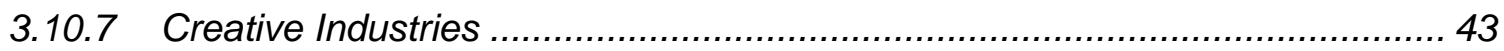

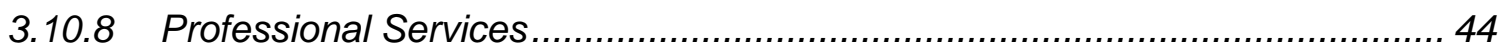

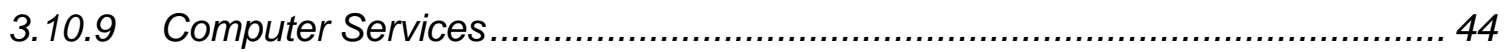

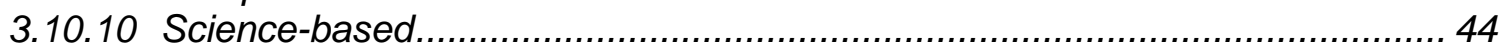

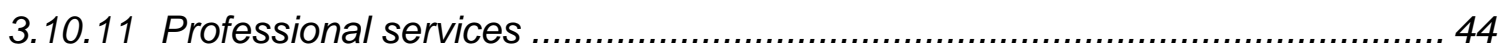

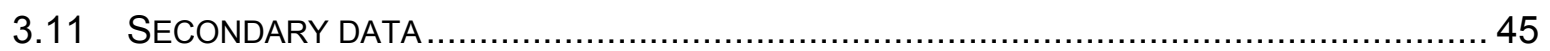

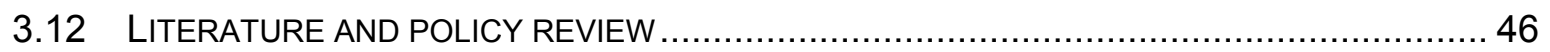

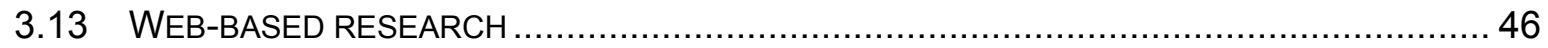

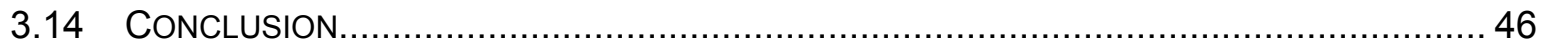

CHAPTER 4: CHARACTERISTICS OF BUSINESSES OF STUDENTS \& GRADUATES . 48

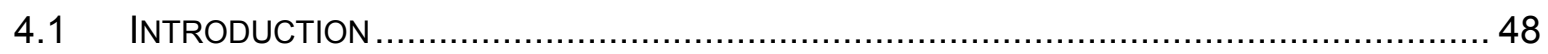

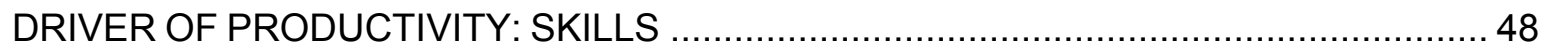

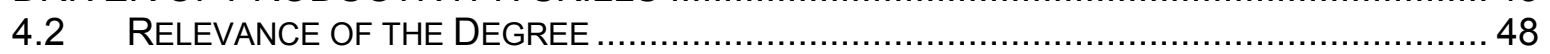

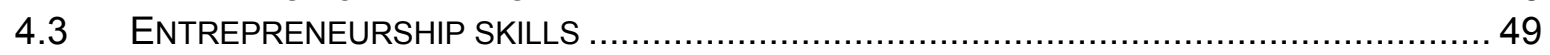

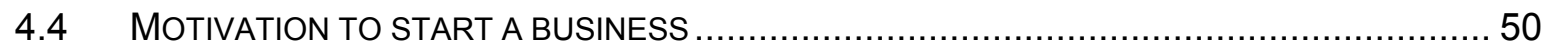

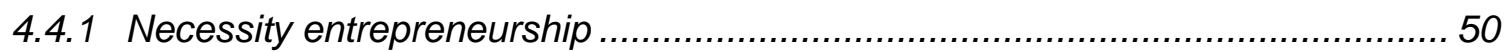

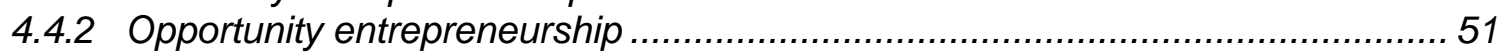

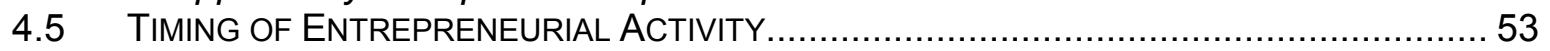

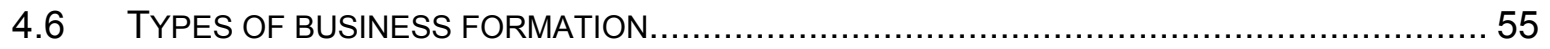

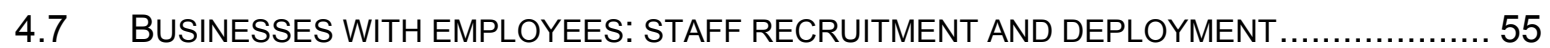

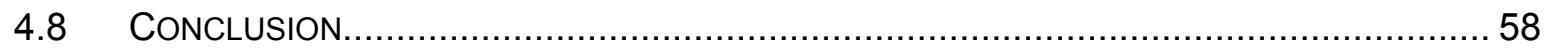

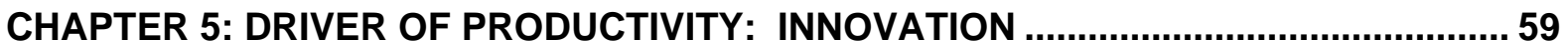

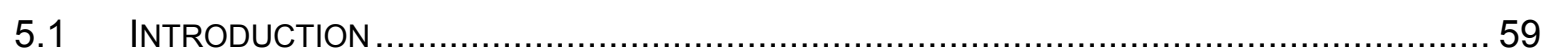

5.2 EUROPEAN AND INTERNATIONAL RESEARCH COLLABORATION INITIATIVES ................. 59

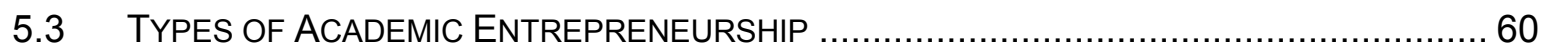

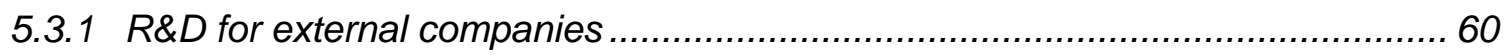

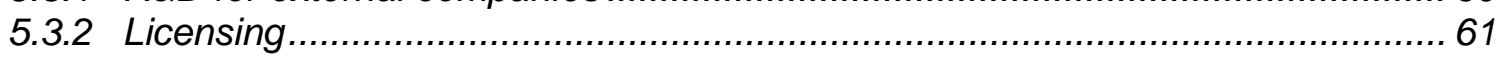

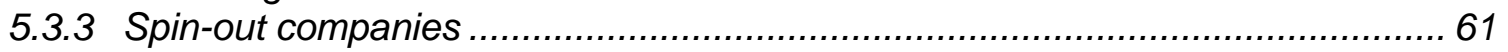

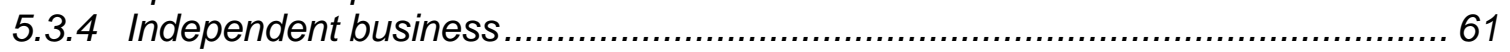

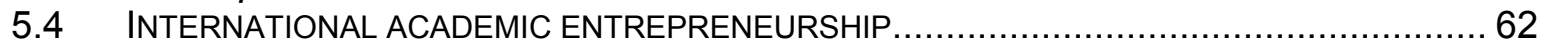

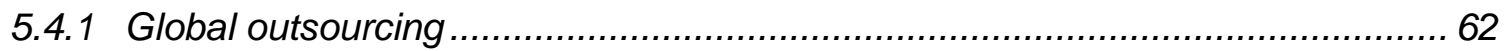

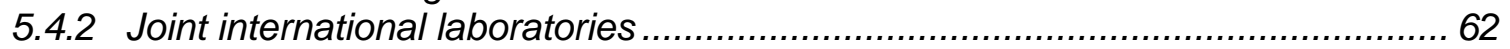

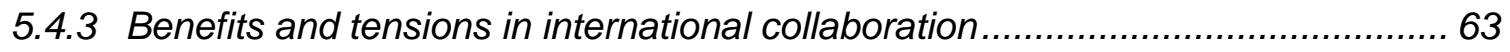

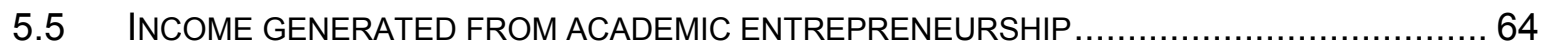

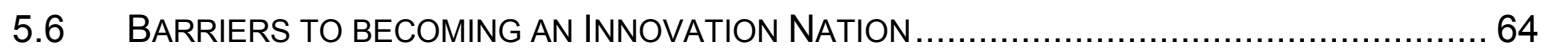

5.6.1 Lack of awareness of the commercial potential of research ............................... 65

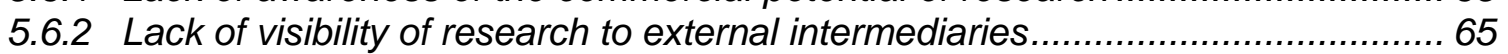

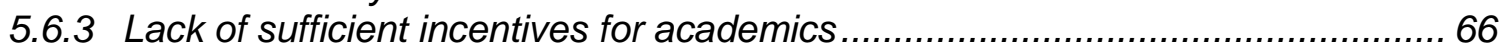

5.6.4 Potential Curtailment of R\&D contracts ....................................................... 66

5.6.5 Lack of sufficient recognition of the innovation potential of non-research students

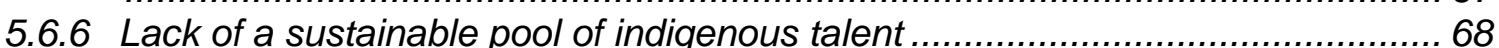

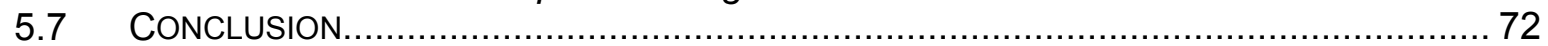

CHAPTER 6: DRIVER OF PRODUCTIVITY: COMPETITION - THE VALUE OF

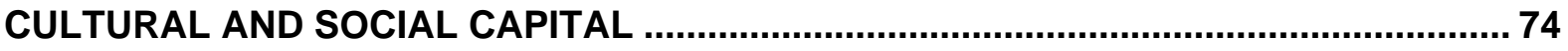

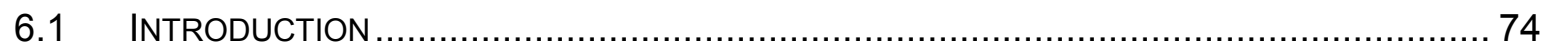

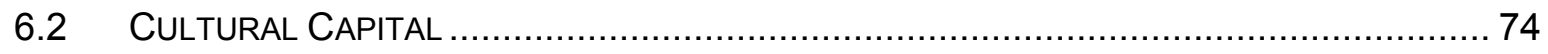

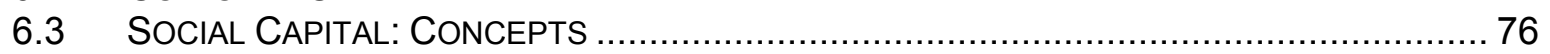




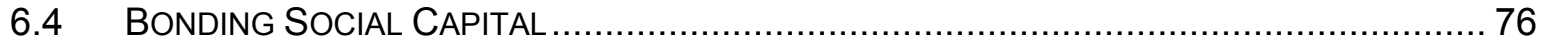

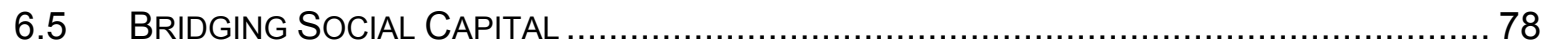

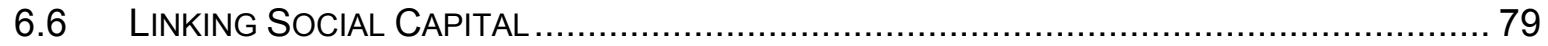

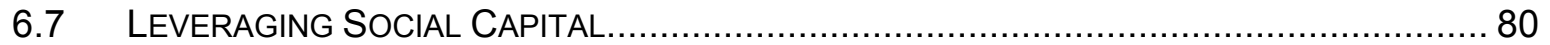

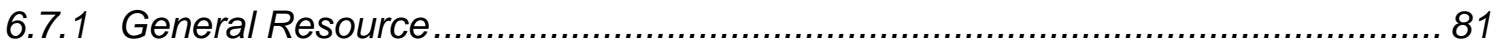

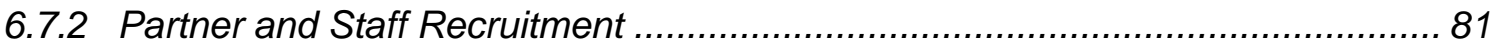

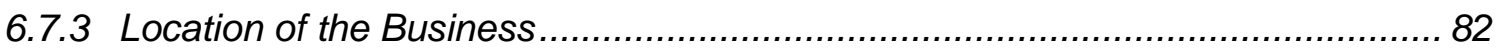

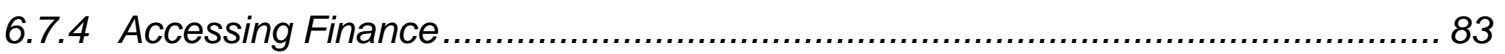

6.7.5 Collaborative activities including research ................................................. 83

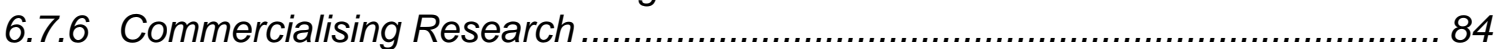

6.8 OPPORTUNITIES FOR DEVELOPING NETWORKS FOR INTERNATIONALISATION ............... 85

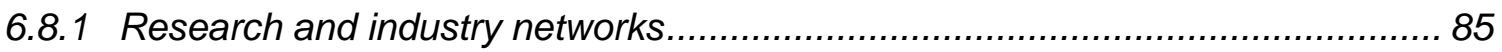

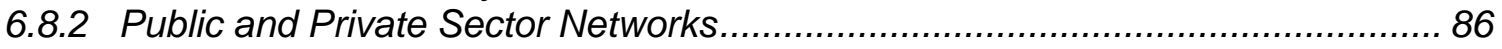

6.8.3 Networks with current international students, staff and parents ....................... 87

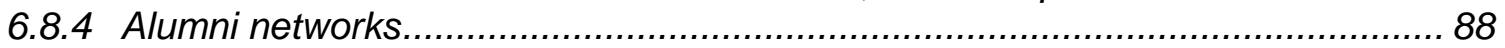

6.8.5 Employment of overseas students and graduates .................................... 88

6.9 POSSIBLE CURTAILMENT OF NETWORKING OPPORTUNITIES ................................. 88

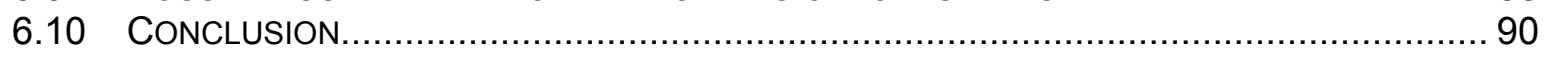

CHAPTER 7: ENABLER OF ENTERPRISE: ACCESS TO FINANCE ............................. 92

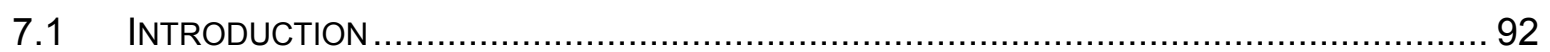

7.2 GRADUATE BUSINESSES: LEVELS OF START UP FINANCE AND SOURCES OF FINANCE ...92

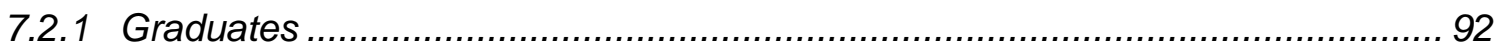

7.2.2 Ethnic minority businesses, including Indian and Chinese .............................. 93

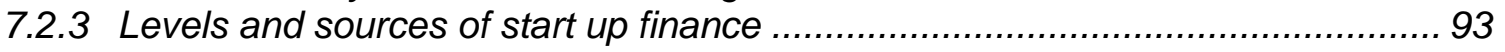

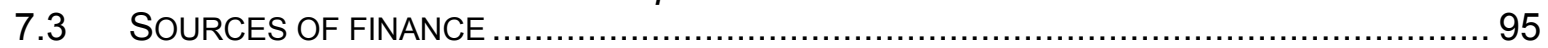

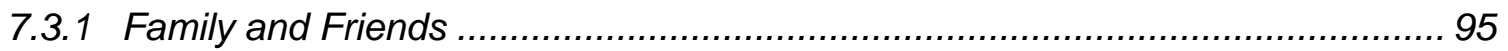

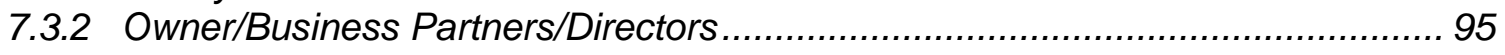

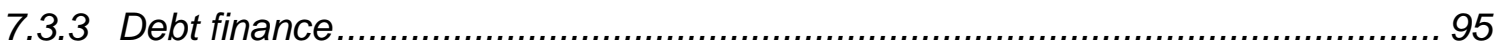

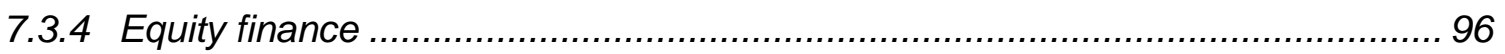

7.4 DEALING WITH MARKET FAILURES.

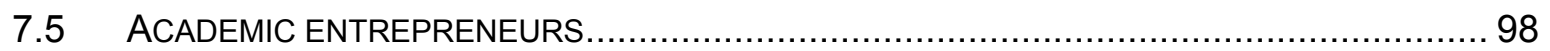

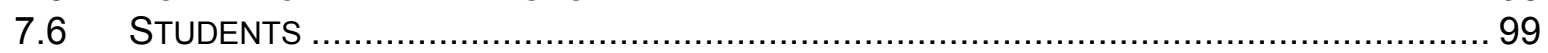

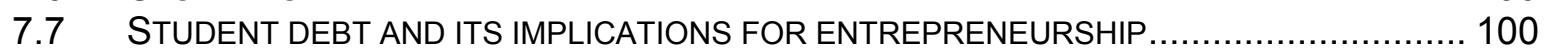

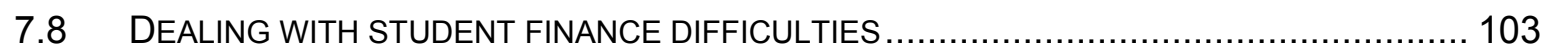

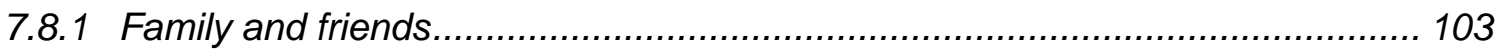

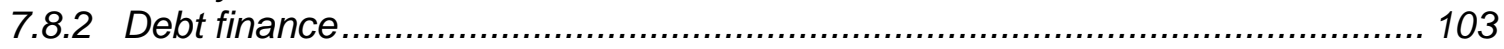

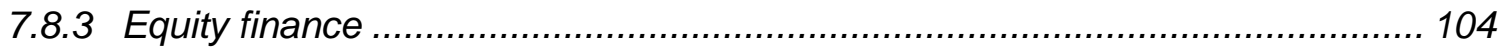

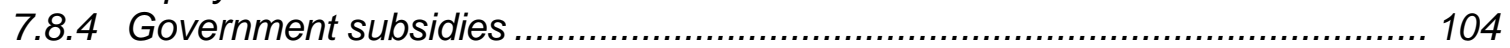

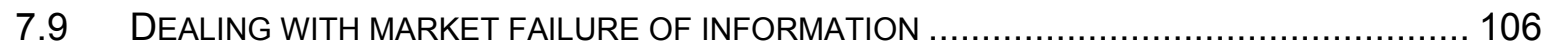

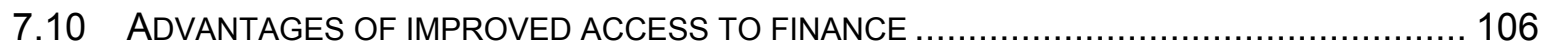

7.10.1 Potential increase in volume of start-ups ............................................ 106

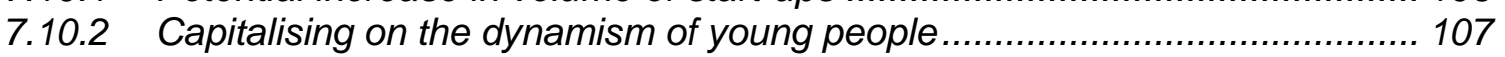

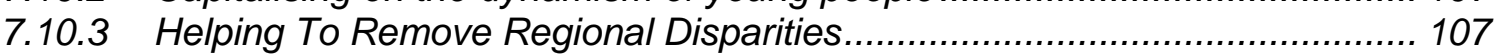

7.10.4 Reducing unemployment or under-employment ................................... 107

7.10.5 Stopping the dispersal of student groups of nascent entrepreneurs ............. 108

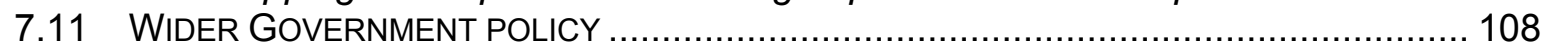

7.11.1 Lack of sustained and comprehensive policy on investment........................ 108

7.11.2 Lack of a holistic approach to university entrepreneurship ......................... 109

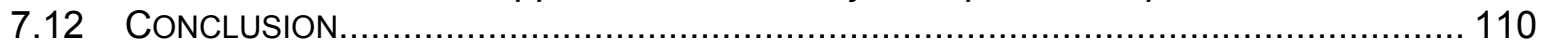

CHAPTER 8: ENABLER OF ENTERPRISE: KNOWLEDGE AND SKILLS PROVISION BY

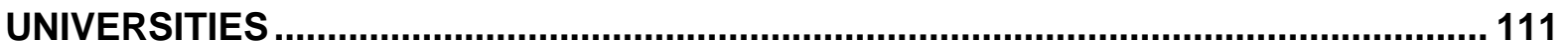

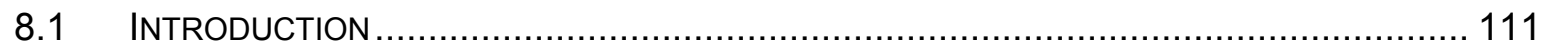

8.2 ENTREPRENEURSHIP EDUCATION: IN-CURRICULA AND EXTRA-CURRICULA ................. 111 


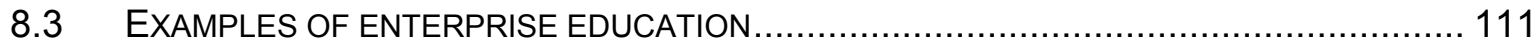

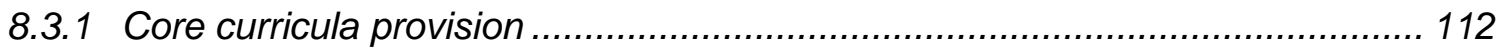

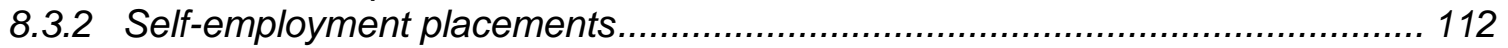

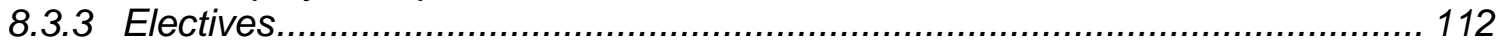

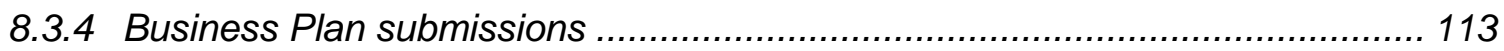

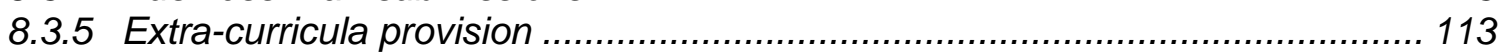

8.3.6 Involvement of multi-national companies................................................. 113

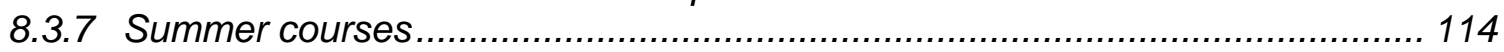

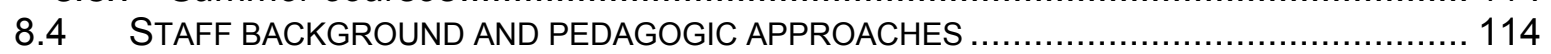

8.5 STUDENT ENTERPRISE CLUBS AND BUSINESS PLAN COMPETITIONS ...................... 115

$8.6 \quad$ LIMITATIONS OF ENTERPRISE EDUCATION PROVISION ...................................... 116

8.6.1 Lack of take up of entrepreneurship education opportunities ......................... 116

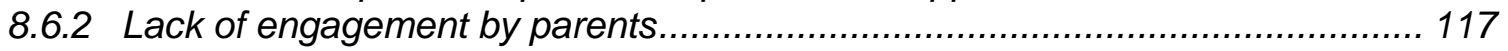

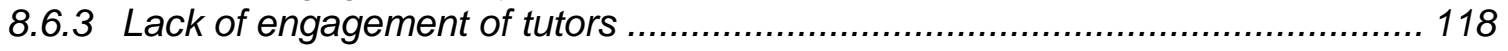

8.7 NATIONAL COUNCIL FOR GRADUATE ENTREPRENEURSHIP .................................. 119

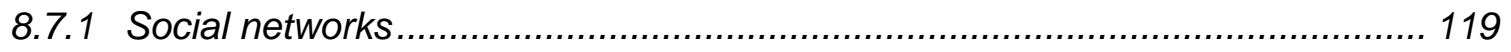

8.7.2 Rallies, business support programmes and competitions............................. 119

8.7.3 Enhancing female entrepreneurship .................................................. 120

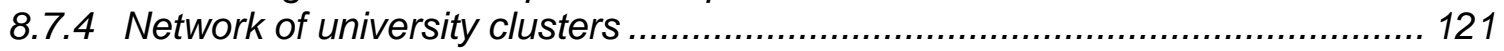

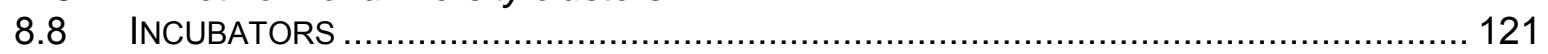

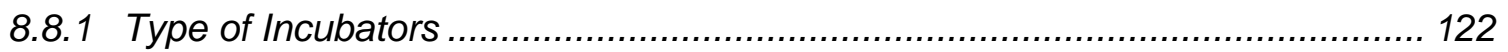

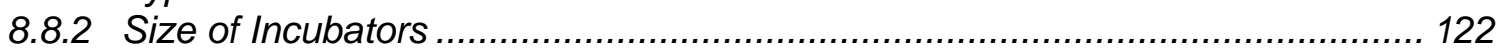

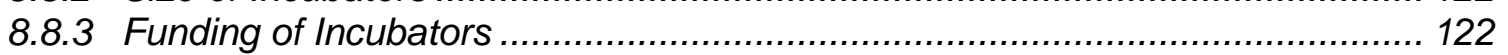

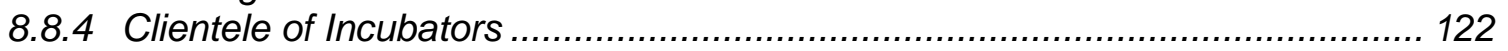

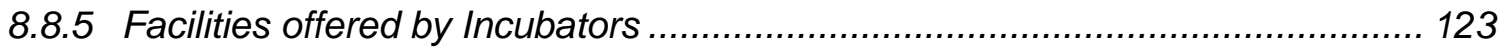

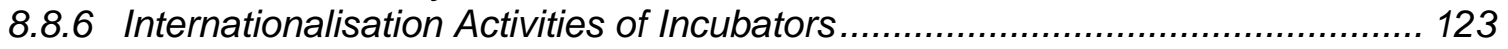

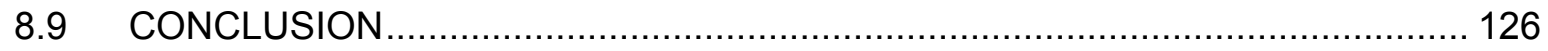

CHAPTER 9: ENTREPRENEURSHIP SUPPORT OUTSIDE UNIVERSITIES ................... 128

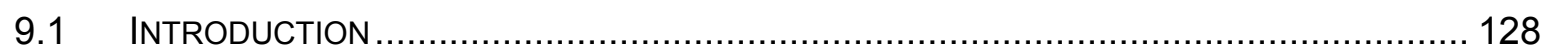

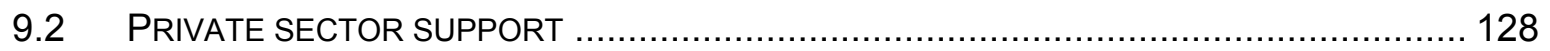

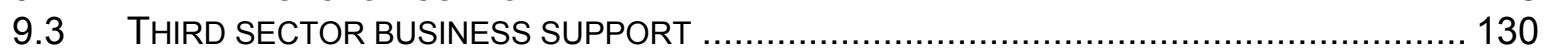

9.3.1 UK Ethnic Minority Organisations ..................................................... 130

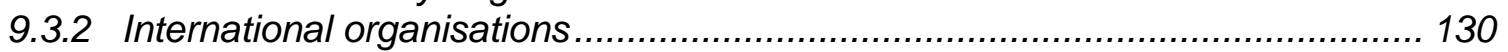

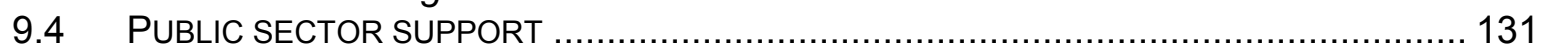

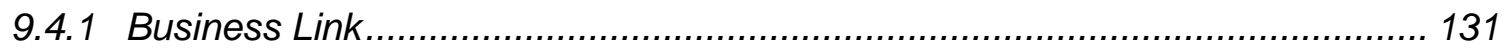

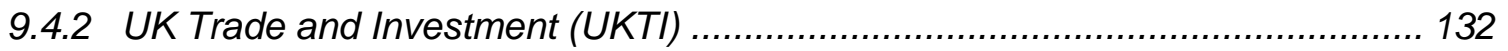

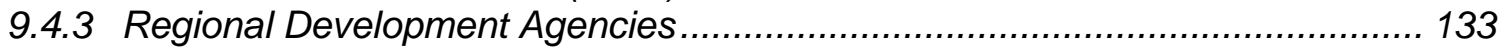

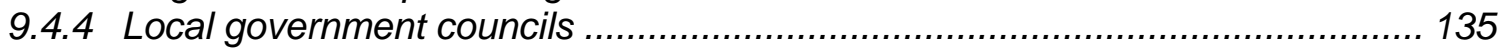

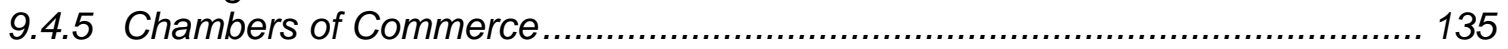

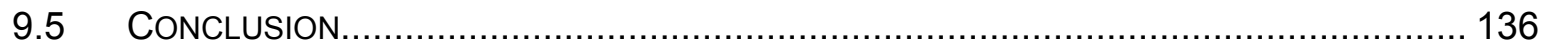

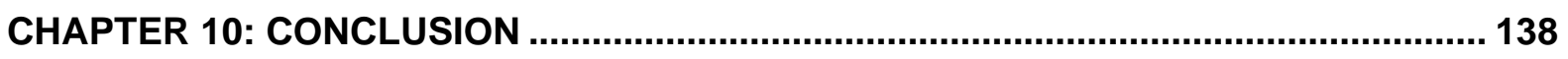

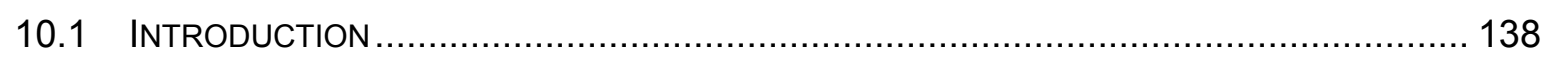

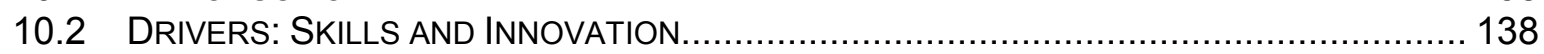

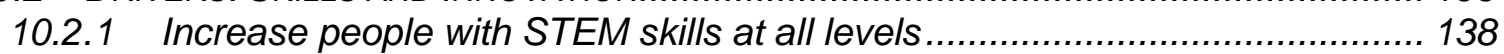

10.2.2 Promote multi-disciplinary collaboration .................................................. 138

10.2.3 Recognise and support the innovative capability of non-research students.. 139

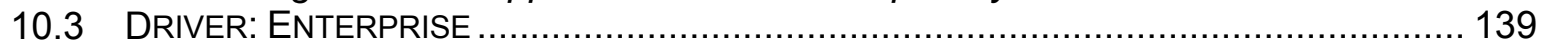

10.3.1 Promote more entrepreneurship among BI and BC students and graduates 139

10.3.2 Capitalise on student ambition ........................................................... 140

10.4 ENABLERS OF ENTERPRISE: CULTURE, KNOWLEDGE \& SKILLS, AND ACCESS TO

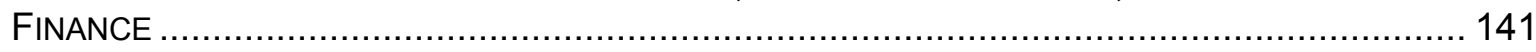

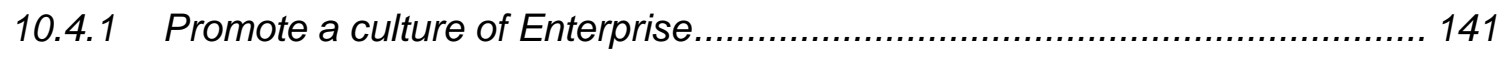


10.4.2 Support knowledge and skills acquisition and international entrepreneurship

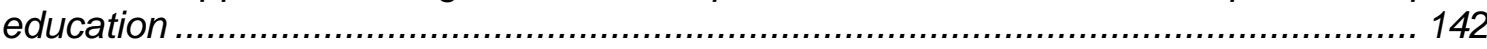

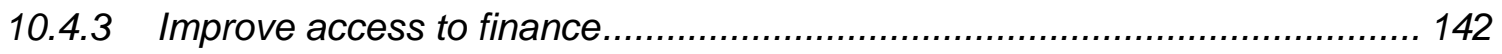

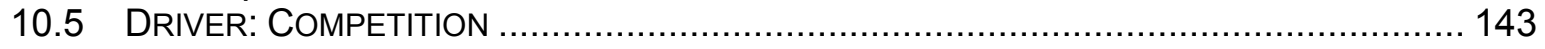

10.5.1 Value the competitive advantage provided by $B I$ and $B C$......................... 143

10.5.2 Universities can be the seedbeds of international entrepreneurship............. 144

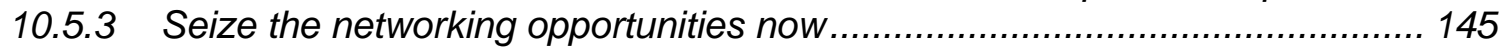

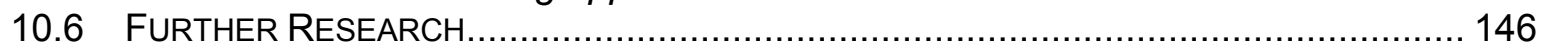

\section{Lists of charts and tables}

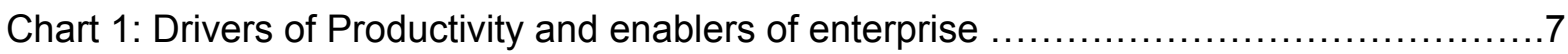

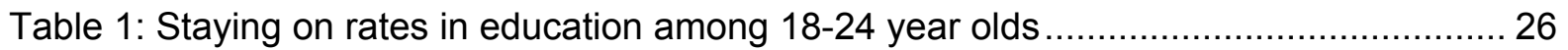

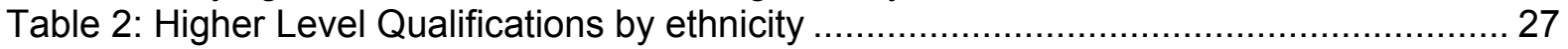

Table 3: British Indian and Chinese Enrolments by Level and Mode of Study at UK HEIs.. 27

Table 4: Indian, Chinese and WB businesses: number of employees ............................... 30

Table 5: Inter-generation comparison of the rate of self-employment among Indian and

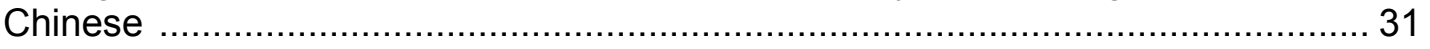

Table 6: Proportion of self-employed Indian and Chinese in the first and second

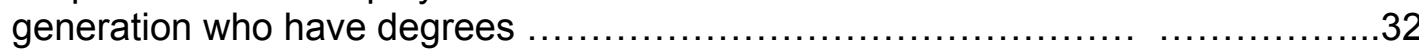

Table 7: Rate of self-employment by ethnicity and gender among graduates and total

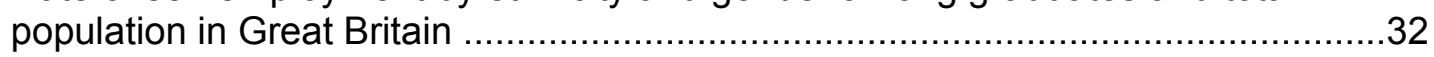

Table 8: Amount of finance required by graduates to start a business .....................94 


\section{EXECUTIVE SUMMARY}

\section{INTRODUCTION}

This report is based on qualitative research undertaken in 2007 and is set in the context of the British Government's ambitions, as articulated in the 2008 Enterprise Strategy Paper and 2008 Innovation White Paper, to raise productivity, become the most enterprising economy in the world, and an Innovation Nation. The Government has identified five drivers of productivity: enterprise, competition, skills, innovation and investment and also five enablers of enterprise: culture, knowledge and skills, access to finance, regulatory framework and business innovation. Highly skilled people are a key resource in helping to fulfil Government ambitions. This report focuses on the international entrepreneurial ambitions and activities of higher education students, graduates and academics. Within this broad constituency, a sub-group, British Indian (BI) and British Chinese (BC), ${ }^{1}$ are selected for intensive examination as, in the decade between 1999 and 2009, it has been estimated that ethnic minorities will account for half the growth in the working-age population (Cabinet Office 2003). Using the concepts of drivers of productivity and enablers of enterprise, the report explores the patterns, characteristics, facilitators of, and barriers to, knowledge-based student, graduate and academic international entrepreneurship in these two communities. In particular, it explores the extent to which, as diaspora communities with extensive bilateral and multilateral social networks, British Indians and Chinese have a competitive advantage in the global economy, especially in penetrating the emerging economies of their ancestral countries of India and China. The research adds not only to the evidence base of these two communities, but at a generic level, to that of university-generated entrepreneurship.

A range of qualitative techniques were used in this research, supplemented by quantitative techniques, secondary analysis of national datasets, literature and policy reviews and webbased research. One hundred and fifty formal interviews were conducted, predominantly in the UK but also in China. A broad spectrum of people were interviewed including existing and potential $\mathrm{BI}, \mathrm{BC}$ as well as White British (WB) involved in entrepreneurship activities (providing 33 core case studies), local, regional and central Government officials, business support organisations and a range of university staff. Interviewees were identified through multiple chain referral sampling methodology which ensured a diversity of respondents from a cross-section of regions, universities, sectors, age range and gender. The formal interviews were supplemented by social anthropological techniques of informal interviews, participant observation and reflexivity. Quantitative data was obtained via a self-completion questionnaire completed by almost half of the case studies. The multiplicity of methods used, and the triangulation of data, add to the robustness of the study and help to identify significant patterns, themes and issues.

\section{KEY MESSAGES}

- $\mathrm{BI}$ and $\mathrm{BC}$ place a high value on education resulting in a greater proportion, relative to their share of the working age population, in higher education. Consequently, there is a higher proportion of $\mathrm{BI}$ and $\mathrm{BC}$ compared to WB with skill levels 4-8. They are concentrated in a narrow range of subjects and are over-represented in science, engineering and technology (SET). SET plays a key role in innovation and $\mathrm{BI}$ and $\mathrm{BC}$ can make an important contribution to the UK becoming an Innovation Nation.

- While the self-employment rates for the total BI and BC population were higher than WB in the 2001 census, recent evidence from the Labour Force Survey 2007

\footnotetext{
${ }^{1} \mathrm{BI}$ and BC refer to Indians and Chinese who are UK domiciled. The majority are British citizens.
} 
indicates that $\mathrm{BC}$ now show no statistically significant difference and that $\mathrm{BI}$ have a slightly lower rate than WB. For graduates, the census data for 2001shows that the self-employment rate was lower for $\mathrm{BI}$ and $\mathrm{BC}$ UK born graduates compared to WB graduates. The quality of enterprise has changed from a predominance of corner shops and retail outlets, restaurants and take-aways. Of those who engage in entrepreneurial activity, $\mathrm{BI}$ and $\mathrm{BC}$ students, graduates and academics use their high intellectual capital to engage in a cross-section of national and international knowledge-based entrepreneurial activities in a range of sectors and including licensing and start-ups. While some knowledge-based enterprises start in the UK and become global, others are born global overseas particularly in India and China.

- $\mathrm{BI}$ and $\mathrm{BC}$ graduates leverage their rich cultural and social capital endowment to better penetrate, than WB, the markets of the high growth economies of India and China. Not only do their networks comprise bonding, bridging and linking social capital, but as members of diaspora communities, such networks transcend geographical boundaries. These diverse bilateral and multilateral networks create a veritable spider's web which is leveraged in different ways to enhance the competitive advantage of graduate $\mathrm{BI}$ and $\mathrm{BC}$ in the global economy.

- There are extensive opportunities 'right under our noses' for the wider population to emulate $\mathrm{BI}$ and $\mathrm{BC}$ in the development and leveraging of networks. UK universities can be the seedbeds of international entrepreneurship if multiple networks are developed and sustained with the large numbers of international students, their parents and alumni, as well as with international academic staff. There is some evidence of emergent international entrepreneurship activities in the universities using personal as well as institutional networks but more needs to be done to extend these.

- The innovation and entrepreneurial potential of non-research undergraduate and postgraduate students is not fully recognised and supported across the HE sector, and by central and regional government. Yet, given their large volume and dynamism, such students can make a significant contribution to helping the UK become a more enterprising and innovative economy.

\section{MAIN FINDINGS}

\section{DRIVER: SKILLS}

- More BI and BC have higher level skills, and are over-represented in science, engineering and technology

$\mathrm{BI}$ and $\mathrm{BC}$ place a high value on education resulting in a greater proportion, relative to their share of the working age population, in higher education. Proportionately more, compared to WB, go on to further education or training after graduation. While there is take-up across the whole cross-section of subjects offered by HEls, $\mathrm{BI}$ and $\mathrm{BC}$ are concentrated in a narrow range of subjects, particularly medicine, science and technology, engineering, mathematics, business studies and law. A greater proportion of the $\mathrm{BI}$ and $\mathrm{BC}$ population compared to the White population have SET-related degrees. While this pattern is mirrored at masters' level, it is the Chinese who are over-represented at doctoral level. Chinese people are also more prevalent among SET academic staff. ${ }^{2}$

\footnotetext{
${ }^{2}$ The data on those with degrees is for UK domiciled. The data for masters and doctoral level, and for academic staff, appears to combine UK domiciled Chinese and overseas Chinese (Jones \& Elias 2005).
} 


\section{DRIVER: ENTERPRISE}

\section{- Self-employment rates for UK born BI and BC graduates are lower than WB}

graduates

The overall self-employment rates according to the 2001 census for $\mathrm{BI}$ and $\mathrm{BC}$ were higher than WB. However, recent evidence from the Labour Force Survey 2007 indicates that BC now show no statistically significant difference and that BI have a slightly lower rate than WB. This supports the findings from the 2001 census which showed that the rate among $\mathrm{BI}$ and $\mathrm{BC}$ was lower in the second generation compared to the first generation. A continuation of this trend probably accounts for the pattern evident in the Labour Force Survey data for 2007. In 2001, among UK born graduates the rate among BI and BC was lower than it was for WB graduates. Rates of self-employment do not tell us about the quality of businesses. First generation $\mathrm{BI}$ and $\mathrm{BC}$, including many foreign educated graduates, generally run low-value added businesses such as corner shops, newsagents, take-aways and restaurants. However, while there is no robust national quantitative data on the quality of self-employment among second generation BI and BC students, graduates and academics, this report provides qualitative data on their knowledge-based entrepreneurial activities in a wide range of sectors. The high level of skills of the $\mathrm{BI}$ and $\mathrm{BC}$ graduates, particularly in SET subjects, equip them with disciplinary knowledge to engage in knowledge-based national and international entrepreneurial and intrapreneurial activities. SET based innovation has been strongly promoted by the British Government and a comparatively higher proportion of $\mathrm{BI}$ and $\mathrm{BC}$, compared to $\mathrm{WB}$, have the skills to contribute to this driver of productivity. This is in terms of licensing, start-ups and business growth.

- The majority of $\mathrm{BI}$ and $\mathrm{BC}$, as well as WB, students and graduates with entrepreneurial ambitions are opportunity entrepreneurs

The majority of $\mathrm{BI}$ and $\mathrm{BC}$, as well as WB students and graduates with entrepreneurial ambitions are opportunity entrepreneurs. Some have turned their hobbies into a business and credentialised it with a degree. This also allows them in the future to expand the business in ways which will make more direct use of their disciplinary knowledge. Others have set up their business from the outset with knowledge derived from their higher education studies. For a few the degree is of generic relevance and enhances their selfefficacy. Necessity entrepreneurship was evident among those graduates who felt they had reached the glass ceiling in paid employment and setting up their own business was the best way to scale greater heights. Some students run a business while they are students and some graduates start a business immediately on graduation while others work for some time before entering self-employment or combine paid employment with self-employment. As a result of Government policies of widening participation, employer engagement and student financial reforms, there are now more students with employment experience which enhances early self-employment readiness.

- $\quad \mathrm{BI}$ and $\mathrm{BC}$ second generation graduate entrepreneurs are less likely to employ co-ethnics on the basis of ethnicity unless cultural capital is an asset

$\mathrm{BI}$ and $\mathrm{BC}$ second generation graduate entrepreneurs who employed staff used different recruitment strategies to the first generation. Unlike the first generation with low valueadded businesses such as corner shops, newsagents, take-aways and restaurants that generally employed co-ethnics and also used family help, BI and $\mathrm{BC}$ second generation graduate entrepreneurs recruit staff for their knowledge-based businesses on the basis of graduate level expertise rather than ethnicity. However, ethnicity plays a role in staff recruitment when cultural capital is an asset to the business. This is particularly relevant in penetrating overseas markets. BC employ co-ethnics with graduate level expertise in their 
UK-China international business where multi-linguistic capabilities and other aspects of cultural capital facilitate service delivery.

\section{ENABLERS OF ENTERPRISE}

\section{Access to Finance}

- Actual or perceived difficulties in getting finance for starting a business is a barrier to entrepreneurship, potentially more so for $\mathrm{BI}$ and $\mathrm{BC}$ students and graduates

Actual or perceived difficulties in getting finance for starting a business is a barrier to entrepreneurship. Students and recent graduates merit targeted interventions as most enter the labour market with sizeable student debt, in addition to little or no personal savings or collateral, and possibly low levels of financial literacy. Graduates who enter paid employment have the security of knowing that they will have a steady income from which to pay off their debts while those entering entrepreneurship do not have such an assured trajectory. While this may not deter the hard core entrepreneurs, it may be a sufficient deterrent for those who are ambivalent about the wisdom of taking a risk with entrepreneurship. As a greater proportion of $\mathrm{BI}$ and $\mathrm{BC}$ students and graduates compared to WB come from lower socio-economic backgrounds, family and friends may have less disposable income to channel into supporting student and graduate entrepreneurial ambitions.

\section{Culture of Enterprise}

- Some parents and academic tutors are unaware of or hold negative attitudes to student and graduate entrepreneurship

Enterprise education policy focuses on students but parents and tutors have been left out of the equation. Yet, parents, particularly in the case of $\mathrm{BI}$ and $\mathrm{BC}$, play an important role in influencing the subject, institution and career choices of their children, even when they have reached adulthood.

\section{Knowledge and Skills}

- A wide range of in-curricula and extra-curricula activities are available in universities but international entrepreneurship is not well catered for

A wide range of in-curricula and extra-curricula activities are available at universities. While much of it is provided via business schools, there is also evidence of discipline-based enterprise education, particularly in science subjects encouraged by Government funding in recent years. However, international entrepreneurship education is not a strong feature of enterprise education, although some examples can be found.

- There is over-subscription to business support programmes for students and graduates

Programmes such as SPEED (Student Placements for Entrepreneurs in EDucation), which gives students the option of setting up their own business rather than a work experience placement with an existing business, are only available at 13 universities. The programme, funded by the Government's Higher Education Innovation Fund, is over-subscribed.

Similarly, programmes for graduates such as the National Council for Graduate Entrepreneurship Flying Start programmes are over-subscribed. There are, therefore, potential missed opportunities for entrepreneurship development among unsuccessful but good applicants. 
- There is a range of private, third sector and public sector business support for entrepreneurship but the strength of links with universities varies

Private sector support by $\mathrm{BI}$ and $\mathrm{BC}$ as well as WB international businesses have emerged to fill the gap in provision by public and third sector provision. There is a range of public sector support including that provided by Business Link, UKTI, RDAs, chambers of commerce and city councils. However, there is considerable diversity in the strength of links and collaboration between public sector business support organisations and universities in the development of entrepreneurship activities and knowledge transfer of intellectual property. Third sector ethnic minority business support organisations have little or no links with universities. Some attention is needed to integrate intra-university and external provision via the Government's Business Support Simplification Programme.

\section{- Overseas students are not eligible for many business support activities}

Overseas students, including from India and China, are denied access to many business support activities despite high interest. While they can attend open extra-curricula events and engage in curricula activities, they are not eligible, for instance, to apply for the SPEED programme or the NCGE Flying Start programmes. Neither are they allowed to nurture their business aspirations in the incubators in some universities. This results in potential missed opportunities for developing international entrepreneurship and accruing some of the value in global value chains.

\section{DRIVER: INNOVATION}

- If Britain is to become an Innovation Nation, various barriers to innovation need to be removed

To realise the Government's ambition to become an Innovation Nation, it is essential that the barriers to innovation are removed or mitigated. The development of academic entrepreneurship in the UK is dependent on a talented pool of academics, particularly SET academics, who are also commercially savvy. This requires removing the barriers of ignorance of the commercial potential of research among existing academics, providing academics with incentives to value and engage in entrepreneurship and opening the eyes of new university recruits. There are also potential threats from overseas to maintaining a high level of R\&D work undertaken by universities. To sustain future academic entrepreneurship, capacity building of an indigenous pool of innovators, particularly SET based, is crucially important. There are many and growing incentives in China and India which may encourage nationals from these countries working in the UK to return home, potentially leaving a vacuum in the UK. The Government's attempts at capacity building through the promotion of science in schools and colleges are endorsed. However, more could be done to encourage postgraduate research take-up, particularly among BI who are over-represented in SET at undergraduate and masters level but not at doctoral level, and WB who are only very slightly over-represented at this level. The lack of sufficient recognition in the HE sector and by central and local government of the innovation and commercialisation potential of nonresearch undergraduate and postgraduate students has led to missed opportunities.

\section{DRIVER: COMPETITION}

- $\mathrm{BI}$ and $\mathrm{BC}$ leverage their rich endowment of cultural and social capital to help penetrate more quickly the markets of the high growth economies of their ancestral countries of India and China 
$\mathrm{BI}$ and $\mathrm{BC}$ leverage their rich endowment of cultural and social capital to help more quickly penetrate markets in their ancestral countries. Market entry is vitally important as these are fast growing economies, and any assets that people in the UK possess, should be capitalised to facilitate international entrepreneurship. BI and $\mathrm{BC}$, like other ethnic minorities in the UK with diaspora connections, can make a valuable contribution to the UK economy and to internationalisation. However, there are generational and class differences. While both the first and second generation possess cultural capital, students, graduates and academics in the second generation have a richer stock of such capital. They have high level linguistic competence in English which complements mother tongue competencies and they are also cognisant of the cultural mores of the British and of their compatriots. Such cosmopolitanism allows them to engage in the strategic manipulation of identity to foster and grow international entrepreneurship. Unlike first generation $\mathrm{BI}$ and $\mathrm{BC}$ who had a smaller endowment of social networks, students, graduates and academics of the second generation have a richer endowment. Not only does this comprise bonding, bridging and linking social capital, but as members of diaspora communities, such networks transcend geographical boundaries. Such diverse bilateral and multilateral networks create a veritable spider's web which can be leveraged in different ways to enhance the competitive advantage of $\mathrm{BI}$ and $\mathrm{BC}$ and contribute to raising UK productivity and enhancing its globalisation strategy.

\section{POLICY RECOMMENDATIONS}

Policy recommendations are proposed for what more can be done to ameliorate or eradicate barriers to international entrepreneurship but they require further consideration of impact, feasibility, cost and affordability which are beyond the scope of this study. They are offered here to promote discussion and debate to aid policy and practice formulation and implementation at different levels of governance: central, regional, local and institutional.

\section{- Promote universities as seedbeds of international entrepreneurship}

There are extensive opportunities 'right under our noses' to emulate $\mathrm{BI}$ and $\mathrm{BC}$ in the development and leveraging of networks. All universities in the UK, and more recently further education colleges, have benefited from Government initiatives to increase their intake of international students. While the magnitude of increase varies between universities and regions, nevertheless there is a widespread dispersal of international students, particularly Chinese and Indians, across the country. While the bonding social capital within these groups is enhanced through co-location in the UK, bridging and linking social capital which can be engineered to the advantage of the British economy, as well as mutual advantage of all parties, is only minimally occurring.

Various strategies need to be adopted to mitigate the loss of missed opportunities for network development. These include adopting pedagogic approaches which encourage British students to collaborate with international students; providing social events which take account of the commensality and other cultural practices of different groups of international students rather than following an ethnocentric approach of the 'British way of doing things'; capitalising on the loyalty that overseas Chinese and Indian students have to the alma mater; developing, sustaining and strategic leveraging of alumni networks for promoting international entrepreneurship; developing networks with the parents of international students particularly by making links when they come to visit their university children in the UK; and briefing by the Government of university staff and international students on changing immigration regulations affecting employment and self-employment in the period after graduation as well as regulations regarding business set-up while students. The large number of overseas academic staff, particularly Chinese in SET university departments, offer further opportunities for intensifying and widening networks. These can be leveraged when the academic staff return home, for instance, to develop collaborative research 
projects, joint laboratories and global outsourcing of parts of the research process. Opportunities for developing networks with students and staff from overseas need to be seized now as there are no guarantees that the current volume of students and staff from overseas will be sustained in the future.

Overseas students, whose fees and consumption of goods and services contribute a great deal to university income and the UK economy, should be given access to all entrepreneurship support activities. This is not only a matter of equity but it is likely to boost international entrepreneurship. Reciprocal 'soft landings' could be developed between UK university incubators and counterparts overseas to stimulate international entrepreneurship, particularly among alumni. The strategy adopted by $\mathrm{BC}$ and $\mathrm{BI}$ of employing nationals from the country that the firm wishes to penetrate can usefully be adopted by all British businesses. Greater opportunities to do this exist now as international students are allowed to work in England for two years after graduation. This could perhaps be facilitated through ring-fenced Knowledge Transfer Partnerships.

\section{- Encourage more BI and BC graduates into self-employment}

$\mathrm{BI}$ and $\mathrm{BC}$ graduates have a potent combination of high level intellectual capital and a rich endowment of cultural and social capital. They also come from communities with high entrepreneurial spirit, many of whose businesses are more innovative. Yet a comparatively lower proportion of them compared to WB graduates go into self-employment. More research is needed to ascertain why this is the case in order to develop strategies to encourage more into knowledge-based high value self-employment.

\section{- Increase provision in enterprise education to better cater for a diverse student population}

While the inclusion of enterprise education in universities is to be applauded, nevertheless, much more needs to be done to enhance provision at post-graduate level and for part-time students. About four fifths of provision is at undergraduate level and is for full-time students. Yet there are a considerable number of post-graduate students, and part-time students, whose volume has increased with the expansion and widening of participation in higher education. Hence, there is a need to increase provision targeted at these groups. Enterprise education needs to be tailored not only to meet the basic needs of new entrepreneurs but also the needs of experienced student entrepreneurs, some of whom are mature and parttime students, who need support to improve and grow their businesses. The large scale presence of international students, and their interest in entrepreneurship, should give a further impetus to the development of international entrepreneurship in enterprise education programmes. This could potentially help to foster more 'born global' businesses and promote collaboration between British and international students which may lead immediately or sometime in the future to joint business ventures and supply chain collaboration.

\section{- Promote a culture of entrepreneurship and improve enterprise education}

A cultural change in the neutral or negative perception of entrepreneurship needs to occur among many parents of students and graduates. This is particularly important for $\mathrm{BI}$ and $\mathrm{BC}$ as parents exert a great deal of influence on their children, even in early adulthood. A cultural change is also necessary among academic tutors who are likely to be the front line contact for students with entrepreneurial ambitions. Basic enterprise awareness training should be a component of the initial training of university academic staff as well as part of the CPD of all tutors. This will ensure that academic tutors, who are the front line contact for students with entrepreneurial ambitions, better support them and sign-post them to those with greater expertise. Embedding entrepreneurship education in the curriculum is likely to 
allay the fears of parents and tutors that students with entrepreneurial ambitions will drop out of their studies or achieve lower than expected grades.

\section{- Improve access to finance}

Various sources of finance exist but these may need to be tailored to become fit for purpose to foster student, graduate and academic entrepreneurship. Wealthier members of Indian and Chinese ethnic minority business and social organisations could be mobilised as extended family to provide business angel finance. As the Government is planning to work with the Business Angel Association to develop angel finance, this could be extended to working with ethnic minority organisations to identify the support they require to provide Angel finance for young graduate entrepreneurs from their community.

Access to debt finance could be enhanced in at least three ways. First, providing ringfenced, clearly visible loans for the target group. Second, modifying the Small Firms Loan Guarantee (SFLG) scheme so that Government guarantees a higher proportion of the loan than the current $75 \%$. Third, developing micro-finance schemes, including a micro-finance self help bank linkage scheme. Grant finance could be made available for students to help sustain initiatives such as SPEED, to pay for patent applications, and to provide proof of concept funds for academics interested in taking innovations to market. Targeted interventions are needed to deal with a range of market failures including information asymmetries, lack of sufficient financial literacy and discipline and lack of investment readiness.

\section{- Improve recognition and support of the innovation and commercialisation potential of undergraduate and non-research postgraduate students}

Improved recognition is necessary of the innovation and commercialisation potential of nonresearch undergraduate and postgraduate students. As the volume of such students is overwhelmingly higher than research students, there are potential missed opportunities for increasing the number of innovations entering the economy. Greater recognition and support of the innovation capacity of non-research students, not only from SET, but a crosssection of disciplines, would dovetail very well with the 2008 Innovation White Paper's wider definition of innovation. If successful, it is hoped that the network of university clusters that the Government has charged NCGE to establish (DIUS 2008, BERR 2008a) will help to address this issue.

\section{Further research}

- As this study is qualitative, it is illustrative of patterns and themes. The methodology used in this qualitative study suggests that there is potentially substantial international entrepreneurship ambition and activity that are 'under the radar'. Quantitative research is required to provide robust measures of the scale of these patterns and themes. It is important to establish whether the case studies given of student, graduate and academic international entrepreneurship intention and activities, as well as those of British university alumni, and businesses abroad, are the tip of the iceberg or the activities of a few extraordinary people. To limit expenditure, existing Government national surveys and regional or local university surveys could include relevant questions.

- There is a need for research into the barriers to accessing finance by students, graduates and academics, particularly the extent to which the perception and actuality of student debt is a deterrent to entrepreneurship. The forthcoming review of HE student reforms may provide a vehicle to do this. 
- Research is needed on the entrepreneurial ambitions of international students and staff, and particularly their interest in setting up solo or collaborative international entrepreneurial activities with British peers. Facilitators and barriers should be identified so that appropriate action can be taken.

- This study has focused on British Indians and British Chinese students, graduates and academics but further research among other ethnic minority groups would be useful to ascertain the extent to which the patterns identified for $\mathrm{BI}$ and $\mathrm{BC}$ are replicated, particularly the competitive advantage for international entrepreneurship afforded by their cultural and social capital.

- As this report has strongly recommended that universities should be recognised as the seedbeds of international entrepreneurship, a pilot action research project to test this out could be undertaken involving a couple of universities. 


\section{CHAPTER 1: BACKGROUND, RESEARCH AIMS AND POLICY CONTEXT}

\subsection{Introduction}

The British Government's ambitions, as set out in two documents published in March 2008, the Enterprise Strategy Paper (BERR 2008a) and the Innovation White Paper (DIUS 2008), are to raise productivity, become the most enterprising economy in the world, and an Innovation Nation. The Government has identified five drivers of productivity: enterprise, competition, skills, innovation and investment and also five enablers of enterprise: culture, knowledge and skills, access to finance, regulatory framework and business innovation. Highly skilled people are a key resource in helping to fulfil Government ambitions. This study focuses on the international entrepreneurial ambition and activities of higher education students, graduates and academics. Within this broad constituency, a sub-group, British Indian (BI) and British Chinese (BC), are selected for intensive research as, in the decade between 1999 and 2009, it has been estimated that ethnic minorities will account for half the growth in the working-age population (Cabinet office 2003). In particular, the study explores the extent to which, as diaspora communities with extensive bilateral and multilateral social networks, $\mathrm{BI}$ and $\mathrm{BC}$ have a competitive advantage in the global economy, especially in penetrating the emerging economies of their ancestral countries, India and China.

This chapter first highlights, in the background section, the broad remit of Government ambitions under which this research is subsumed. It identifies the gaps in the research evidence and how these are addressed through the aims of the research on which this report is based. To provide a flavour of the types of entrepreneurial activity engaged in by $\mathrm{BI}$ and BC students, graduates and academics, three examples are provided. The chapter then discusses in detail the drivers of productivity and enablers of enterprise with a specific focus on students, graduates and academics, and on BI and BC.

\subsection{Background: Government Ambitions}

The British Government aims to raise prosperity for all. Its long term objectives are:

“...to raise the rate of the UK's productivity growth over the economic cycle; and narrow the productivity gap with our major industrial competitors."3

A major concern is that there continues to be a productivity gap between the UK and comparator countries such as the USA, and also with Germany and France, although this had narrowed more recently (DTI 2003a, DTI 2003b, BERR 2007a) ${ }^{4}$. Enterprise, skills, innovation and the enhanced ability to compete in a globalised world are all expected to play key roles in achieving Government ambition as indicated below. The role of enterprise is highlighted in the 2008 Enterprise Strategy Paper, Enterprise: unlocking the UK's talent which states that the Government's renewed enterprise vision is:

"..to make the UK the most enterprising economy in the world and the best place to start and grow a business. The Government wants to see more people with the ambition to start, grow and innovate within business; having access to suitable business advice and finance and enabled by a strong regulatory environment" (BERR 2008a: 5)

\footnotetext{
${ }^{3}$ PSA Delivery Agreement 1 (H.M. Treasury 2007a).

${ }^{4}$ In 2006 the ranking of countries, on a GDP per hour worked basis, shows that the UK is ahead of Japan, similar to Canada and Italy but behind Germany, the USA and France. Source: National Statistics Online 2008.
} 
"Unlocking talent - enterprise talent - for people from all sections of society and in our small businesses, helping them to grow, is where the UK's long term prosperity is going to reside" (BERR 2008a: 3).

The Government, in its publication World Class Skills, notes that a major reason for the productivity gap is a weakness in the country's skills base. Hence it makes a commitment to "joining the world's 'premier league' for skills" and this will mean"...more graduates, translating more of the UK's world-class research and development ability into world-class businesses and jobs" (DfES 2007: 3-4).

This commitment is in response to Leitch (2006) who, in his report Prosperity for all in the Global Economy - World Class Skills, argues that the UK, as a developed economy, cannot compete globally on natural resources and low labour costs and that prosperity demands a more service-led economy and high value-added industry. As Porter \& Ketels argue "[T]he challenge to the UK is to make the transition from a location competing on relatively low costs of doing business to a location competing on unique value and innovation" (2003: 5). Part of that unique value resides in people, and as Leitch emphasises, in the 21st century, "...our natural resource is our people - and their potential is both untapped and vast" (2006:1).

Part of this natural resource is higher education students, graduates and academics. This population has been rising with Government policies focusing on the expansion and widening of participation in higher education (DfES 2003). This is reflected in higher education student numbers in England which increased by $287 \mathrm{k}$ since 1997 or around $18 \%$ to $1.9 \mathrm{~m}$ in $2006 / 07$ : full-time have risen by $20 \%$; part-time by $13 \%$; mature students by $12 \%$; undergraduates by $15 \%$ and postgraduates by $28 \% .{ }^{5}$ Ethnic minorities are an important part of the natural resource and these communities also include a large proportion of students, graduates and academics whose numbers expand year on year (see chapter 2). Ethnic minorities make up $8 \%$ of the UK population of about 60 million. Indians make up about $2 \%$ and have a population of approximately one million, while Chinese make up about $0.4 \%$ of the UK population which is equivalent to about a quarter of a million people (ONS 2005a).

High level skills are particularly relevant to innovation. The Government's 2008 Innovation White Paper, Innovation Nation: Unlocking talent emphasises that:

"Innovation is essential to the UK's future economic prosperity and quality of life. To raise productivity, foster competitive businesses, meet the challenges of globalisation and to live within our environmental and demographic limits, the UK must excel at all types of innovation" (DIUS 2008:4).

Students, graduates and academics play an important role as innovators, and universities and external institutions can provide support to capitalise on their innovations. Within the knowledge economy, universities are a valuable asset as noted by the Sainsbury Review:

"The change in the purpose and self-image of the university has been driven by the concept of the knowledge economy, an economy in which ideas and the ability to manipulate them are of more importance than the traditional factors of production. In this economy, a world class university looks an increasingly useful asset" (Sainsbury 2007:43).

In recent years, globalisation has moved to the centre of the policy agenda as the inter-connectedness of the world economy has increased (BERR 2008b). The current wave of globalisation is characterised by "...the speed and intensity of the political, economic,

\footnotetext{
${ }^{5}$ Department for Innovation, Universities and Skills analytical team 2008.
} 
social and technological forces that have collided to create it" (BERR 2008c:v). The Government's ambition is to ensure that "...the benefits of globalisation are felt as widely as possible and across all regions" (BERR 2008c:v). This report will explore how students, graduates and academics, and specifically British Indian and British Chinese whose presence in the UK is a result of earlier waves of globalisation, contribute to the development and distribution of these benefits.

\subsection{Gaps in the research evidence}

The report addresses one generic gap in the study of university generated entrepreneurship and three major specific gaps in the study of ethnic minority entrepreneurship in the UK. First, there is a dearth of research on graduate entrepreneurship in the UK (Hannon 2005) and also on student and academic entrepreneurship. The Government established the National Council for Graduate Entrepreneurship (NCGE) in 2004 and since its inception it has commissioned research reports and analysis of national datasets (e.g. Brooksbank \& Jones-Evans 2005, NCGE 2005, Hussain \& Scott 2006, FreshMinds 2006, Nabi et al. 2006, Harding 2007), mapping exercises to ascertain the scope of enterprise education provided by universities (Price et al. 2004, NCGE 2007) and critical reviews of such provision (Gibb 2005). Small scale surveys of student entrepreneurial ambitions and activities have been undertaken involving a few universities in one region in England (Robertson et al. 2004, Wilkinson 2005, Robertson \& Wilkinson 2006). None of the studies examine aspirations to, or actual engagements in, international entrepreneurship among current students, graduates and academics, including British Indian and British Chinese.

In relation to ethnic minority entrepreneurship, this report takes account of three issues. First, it eschews the notion that ethnic minorities can be regarded as a homogenous group as there are considerable differences between them (Modood et al. 1997), and in their selfemployment patterns (Mascarenhas-Keyes 2006, Virdee 2006, Ram \& Jones 2008). This report, therefore, focuses on two groups, British Indian and British Chinese. Second, it acknowledges that, as well as inter-group differences, there are intra-group differences affected by many factors including migration history, generation, gender and education. This acknowledgement testifies to the need to recognise the 'super diversity' which characterises the ethnic minority population in the UK (Vertovec 2006). Hence the report covers both male and female $\mathrm{BI}$ and $\mathrm{BC}$, the second generation ${ }^{6}$ and those studying for or with graduate qualifications. Third, as most studies of ethnic minority entrepreneurship focus on businesses set up in the UK and largely exclude transnational entrepreneurship (Ram \& Jones 2008), this study looks at entrepreneurship activities that are either 'born global', 'become global' or intend to 'become global'.

\section{$1.4 \quad$ Research Aims, Methodology and Theoretical Approach}

The specific aim of this research report is to illustrate the 'untapped and vast potential' of $\mathrm{BI}$ and BC higher education students, graduates and academics in relation to entrepreneurship, particularly international entrepreneurship. It explores some of the patterns and characteristics of these entrepreneurial activities, the role of facilitators such as diaspora networks, university enterprise education and external support services, and the barriers to entrepreneurship, including access to finance. It also explores the role that graduate $\mathrm{BI}$ and $\mathrm{BC}$ play as the facilitators of the international entrepreneurial activities of the wider population including students, graduates and academics. A general aim of this report is to also highlight the 'untapped and vast potential' of university generated entrepreneurship. Whilst identifying the unique value and competitive advantage to international entrepreneurship of highly skilled $\mathrm{BI}$ and $\mathrm{BC}$, the report also highlights how the lessons learnt can be extrapolated to the wider population of students, graduates and academics.

\footnotetext{
${ }^{6}$ The term is also used to include the third and subsequent generations who are much smaller in size.
} 
This report is based largely on qualitative research conducted in 2007 which involved about 150 interviews mainly in the UK and supplemented by a brief field trip to China. It includes 33 core case studies of students, graduates and academics involved in entrepreneurial activities as well as interviews with central, regional and local Government officials, academic and academic-related staff, visits to incubators and science parks as well as attendance at a range of conferences and other events including business plan competitions. More details of the research methodology are contained in chapter 3 . The data generated by the research is analysed used the 'mixed embeddedness' approach (Kloosterman et al. 1999, Zhou 2004, Ram \& Theodorakopoulos 2007). Thus, the report examines both the external political economy and institutional infrastructure in which $\mathrm{BI}$ and $\mathrm{BC}$ are embedded as well as the internal values and networks of the two ethnic groups.

\subsection{Some examples of entrepreneurial activities}

To set the scene, the following three examples ${ }^{7}$ out of many more discussed in this report (see chapter 2), are used here to illustrate the range of international entrepreneurial activities that $\mathrm{BI}$ and $\mathrm{BC}$ are engaged in, as well as how international students in collaboration with White British (WB) students can promote international entrepreneurship.

\section{Example 1: Graduate entrepreneurship}

Satinder and Sunita, a married second generation British Indian couple are in their late twenties. They have owned a health care business for 5 years which provides both conventional and complementary medical products and services. It has a turnover of between $£ 250,000$ - $£ 499,999$, employs 15 staff, 2 of whom work overseas. Their parents were first generation immigrants from India. Satinder's parents ran a corner shop and Sunita's parents a newsagents and post office. Satinder graduated in Pharmacy from Leeds University and is completing a doctorate at Warwick University focusing on the demand for, and value of, a holistic approach to healthcare. Sunita graduated in sociology from Leeds University. They are planning to expand in the UK and are currently exploring setting up franchises in India, Dubai and USA.

\section{Example 2: Academic entrepreneurship}

Philip is in the 40-50 year old age group. He is a Life Sciences first generation British Chinese from mainland China who came to UK to do his Ph.D. twenty years ago. He works at a British university where he runs a laboratory with 15 staff and research students. He has invented a medical device which provides early diagnosis of a fatal disease and he has a patent for this. He plans to undertake clinical trials in either China or India and manufacture the device in China. He plans to either start a spin off company in the UK or overseas, or licence the device to a multinational company. He is exploring various options with his university's technology transfer office.

\section{Example 3: Student entrepreneurship}

Lincoln, Morley, and Norman are White British males, and Ashok is an overseas Indian student. They are all 20 years old and studying for an undergraduate degree in automobile engineering. They have set up jointly a bio-ethanol business and to exemplify their business idea have converted a standard racing car to run on bio-ethanol. With the help of Ashok's social networks, they intend to promote their business in India with a view to eventually setting up a UK-India business.

\footnotetext{
${ }^{7}$ The names of all respondents have been changed in this report to protect anonymity. All Chinese people referred to in this report have been given Christian names. This is a common practice among the Chinese. Names of universities have also been changed.
} 
The three examples above highlight the value at this stage of clarifying the concepts used in this report and the following will be discussed in turn: ethnic minorities, UK domiciliary status, entrepreneurship, and international entrepreneurship.

First, the term 'ethnic minorities' in the UK includes BI and BC. This term is appropriate within a defined geographical context and, therefore, it is appropriate, for instance, to refer to Chinese as an ethnic minority within the UK because of their very small numbers. However, in discussions about international entrepreneurship which can involve Chinese in the UK as well as in China, and Indians in the UK as well as in India, they can no longer be subsumed under the term ethnic minority. Indeed, within this wider geographical context, the Chinese constitute a majority. For this reason, the term ethnic minority is minimally used in this report, and where it is used, it is because secondary data drawn on for this report uses this term. In such cases, the term 'ethnic minority' is used in a UK context. This report focuses on Indians and Chinese domiciled ${ }^{8}$ in the UK and who are referred to as $\mathrm{BI}$ and $\mathrm{BC}{ }^{9}$ They are drawn from the following categories: (i) overseas born Indian and Chinese with British passports and UK domiciled (ii) UK born second generation Chinese and Indian such as Satinder and Sunita (iii) overseas born Indian and Chinese with foreign citizenship but UK domiciled as in the case of Philip, who retains a Chinese passport and has lived in the UK for more than 20 years. ${ }^{10}$ For those who are not UK domiciled, the terms overseas Indian and overseas Chinese are used.

Second, overseas Indian and overseas Chinese students qua students are not subsumed under the term BI or BC. While they are not directly included in the remit of this study, nevertheless, they have some relevance to this study. International student recruitment to UK universities has expanded exponentially since the late 1990s following various British Government recruitment drives initiated under the Prime Minister's Initiatives $1 \& 2^{11}$. Complementing the overseas student recruitment is the recruitment of overseas academic staff that is particularly prominent in some university departments, especially science, engineering and technology (Metcalf et al. 2005, Strebler et al. 2006). For instance, in $2005-2006,37 \%$ of doctoral science, technology, engineering and mathematics students and about $20 \%$ of academic staff came from overseas (DIUS 2008). In England, the number of non-UK nationals who are permanent academic staff has risen from 4,000 in 1995-96 to around 10,000 in 2005-06. The proportion of professional and support staff who are non-UK nationals also increased throughout the three-year period between 2003-04 and 2005-06 (HEFCE 2007a). The case of Philip in example 2 above demonstrates that overseas Chinese students after graduation do take up academic posts and can eventually obtain UK domiciliary rights. Ashok, in example 3 , is currently an overseas Indian student but he may take advantage of the change in Government policy which allows overseas students to work in England for two years after graduation. ${ }^{12}$ He may eventually qualify for domiciliary status under different visa schemes pertaining to highly skilled migrants.

\footnotetext{
${ }^{8}$ Those who have UK domiciliary rights have long term rights to live in the UK and they fulfil various immigration criteria. They are distinguished from those who have residence status which is usually for a temporary period.

${ }^{9}$ The prefix 'British' in BI and BC is used for convenience to refer to UK domiciled Indians and Chinese. It is not a self-definition relating to national identity.

${ }^{10}$ The Chinese Government does not allow its citizens from mainland China who are domiciled overseas to hold Chinese citizenship in conjunction with any other. The Indian Government allows overseas domiciled Indians to hold dual citizenship and have a special Indian Overseas Citizen category.

${ }^{11}$ See British Council website: http://www.britishcouncil.org/eumd-pmi-history.htm

12 Overseas students are only able to remain in England for a year after graduation but from later in 2008 this has been extended to 2 years. This is similar to the system that has been in operation in Scotland for some time. Immigration rules are quite complex but there are opportunities to obtain UK domiciled status through selfemployment and paid employment.
} 
Third, entrepreneurship is commonly taken to mean the practice of starting a business but as seen from the three examples above, students, graduates and academics can engage in a wide range of entrepreneurial activities other than establish a start up ${ }^{13}$. Student entrepreneurship (as in example 3) refers to entrepreneurial activities engaged in while a student on undergraduate or non-research masters level degrees, and some of these may be at an embryonic stage or more developed. Graduate entrepreneurship (as in example 1) refers to entrepreneurial activities undertaken after graduation from undergraduate or nonresearch masters level degrees. Academic entrepreneurship (as in example 2) refers to activities undertaken by researchers, sometimes doctoral students, but more typically postdoctoral researchers and academic staff engaged in research. For instance, they may have done some research which has the potential to be commercialised as in the case of Philip. One of the first steps they will take is to apply for a patent or equivalent mechanism to protect their intellectual property (IP). The progression pathways to commercialisation include licensing and spin off companies in which the academic often retains a stake.

Sometimes academics leave a full-time university post and set up their own knowledgebased business. Academic entrepreneurial activity may also include research and development (R\&D) activities for external businesses. Academic entrepreneurs may engage in different kinds of entrepreneurial activities throughout their careers. Such activities are included under the term entrepreneurship in this report.

Fourth, the term internationalisation (sometimes blurred with the term globalisation) in enterprise policy discussions and interventions, and to some extent in the wider literature, tends to focus on exporting/importing (trade) and inward/outward investment (BERR 2008c). International trade is the exchange of goods and services across international boundaries or territories. Foreign direct investment (FDI) is an investment in enterprises operating outside of the economy of the investor. This report covers a much wider spectrum of internationalisation activities than trade and investment. It includes international research collaboration which can lead to the international commercialisation of innovations.

Furthermore, outward investment often refers to a firm established in the UK and subsequently setting up overseas. However, this report has examples (see chapter 3 ) of $\mathrm{BI}$ and BC who have not set up a business first in the UK but instead gone overseas first and, in some cases, later established the UK operation.

\subsection{The Policy Context: Drivers of Productivity and Enablers of Enterprise}

The above examples of entrepreneurship provide a hook to explore a range of policy issues in this chapter. As noted earlier, the Government's ambition is to raise productivity. The five drivers of productivity - enterprise (including entrepreneurship), competition (both domestic and global), skills, innovation, and investment - identified by various Government strategy papers (DTI 2003a, BERR 2008b) are discussed below with a particular focus on the first four as they are most relevant to this study. The 2008 Enterprise Strategy Paper suggests that there are five enablers of enterprise: culture, knowledge and skills, access to finance, regulatory framework and business innovation. The relationship between the drivers of productivity and the enablers of enterprise are depicted in the following diagram from the 2008 Enterprise Strategy Paper.

\footnotetext{
${ }^{13}$ See chapter 3 for examples.
} 
Figure LI: Enterprise enablers and productivity

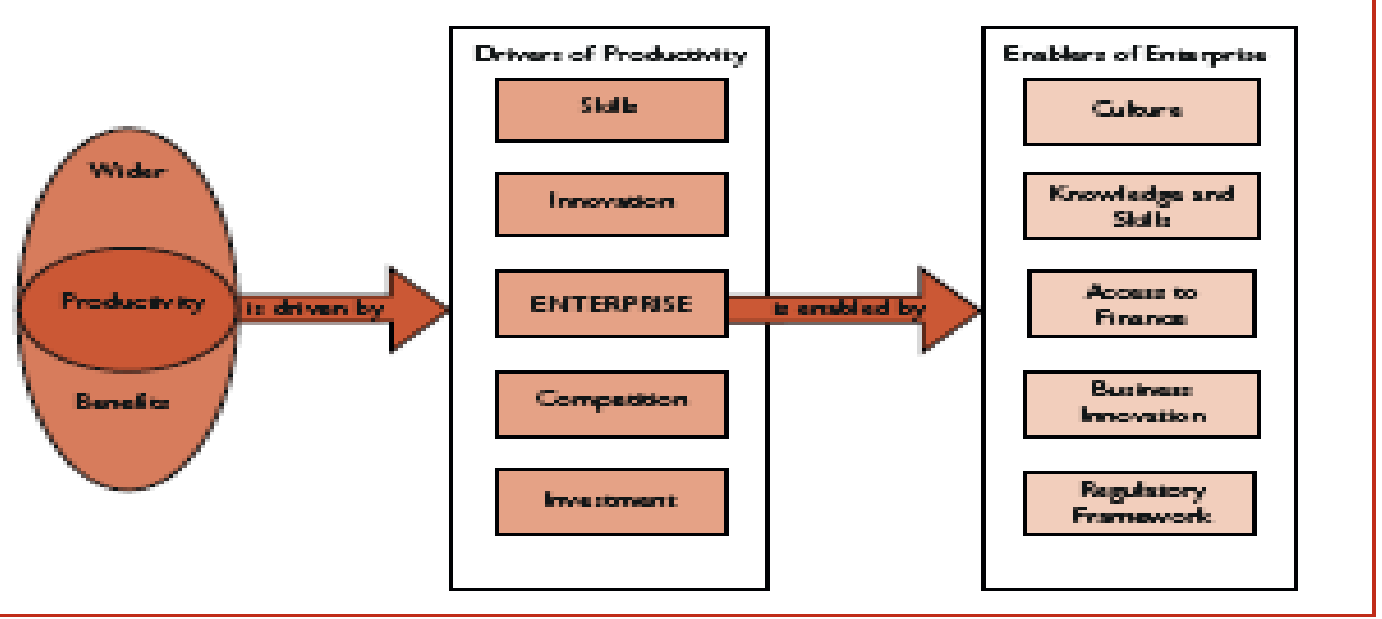

There are interdependencies between these drivers and enablers, but for the purposes of analysis they are discussed separately here. In the discussion on drivers and enablers below, the current position of student, graduates and academics, and of $\mathrm{BI}$ and $\mathrm{BC}$, is discussed and gaps in our knowledge identified. The discussion below also identifies some market failures. ${ }^{14}$

\subsection{Driver of Productivity: Enterprise}

As noted earlier, the Government's ambition is for the UK to become the most enterprising economy in the world and comprehensive statements of its policies and approaches are evident in the 2008 Enterprise Strategy Paper (BERR 2008a) and earlier action plan (DTI 2004a). Enterprise is commonly referred to as the identification and exploitation of new business opportunities and is closely linked to innovation (OECD 1998). ${ }^{15}$ The evidence on enterprise as a driver of productivity focuses on enterprise driving competition and innovation. This shows that most of the growth is from entry and exit of establishments in the market place and that entrepreneurs are essential to exploit the potential of novel innovations and R\&D expenditure (BERR 2008b). Entrepreneurship is important because it fosters both wealth creation and job creation. A range of indicators suggest that the UK has relatively low levels of enterprise (DTI 2003b) but there has been considerable progress over the last ten years (BERR 2008a). Small and medium sized businesses are the backbone of the UK economy. There were an estimated 4.6 million businesses in the UK at the start of 2006 , an increase of 125,000 (2.9\%) on the start of 2005 (BERR 2007b) and over 750,000 more than in 1997 (BERR 2008a). Almost all of these enterprises (99.3\%) were small, only 27,000 (0.6 per cent) were medium-sized and 6,000 (0.1\%) were large. ${ }^{16}$ The next two sections look at ethnic minority, and student, graduate and academic entrepreneurship.

\subsubsection{Ethnic minority entrepreneurship}

A significant proportion of ethnic minorities engage in entrepreneurship. Self-employment data is used as a proxy for entrepreneurship, although in a knowledge economy such data is found to be poor indicators of entrepreneurship (Brinkley 2008). Notwithstanding this, an

\footnotetext{
${ }^{14}$ Market failures when used in a policy context refers "...simply to circumstances in which there are significant potential economic benefits which the private sector would be unable or unlikely to achieve unaided" (DTI 2006b: 37). The common market failures are imperfect information and uncertainty; externalities, barriers to entry and public good (DTI 2003b).

${ }_{15}^{15}$ Cited in DTI 2003b.

${ }^{16}$ (BERR 2007b). Small (0-49 employees), Medium (50-249 employees) and Large (250 or more employees).
} 
analysis ${ }^{17}$ of the Census data for 2001 shows that the self-employment rate of all ethnic minorities is $12 \%$, which is only slightly lower than Whites at $12.5 \%$. However, this overall figure masks considerable variation in the self-employment rate of different ethnic minority groups. The highest self-employment rate is found among the Chinese ${ }^{18}(22 \%)$. Indian $(15 \%)$ is also higher than Whites. The higher rate of self-employment evident among Indian and Chinese also holds if disaggregated by gender, with both male and female having a higher self-employment rate than Whites. However, recent evidence from the Labour Force Survey 2007 indicates that BC now show no statistically significant difference and that $\mathrm{BI}$ have a slightly lower rate than WB. ${ }^{19}$ A study in 2005 of aspirations to entrepreneurship found they are higher among Indian and Chinese compared to WB: 15\% Indian and 14\% Chinese compared to $12 \%$ WB think about setting up a business (DTI 2007b). The vast majority of ethnic minorities engage in opportunity entrepreneurship. However, a higher proportion, about $16 \%$ of ethnic minority businesses compared to $9 \%$ of WB, engage in necessity entrepreneurship (DTI 2006d) ${ }^{20}$ because of various difficulties in obtaining paid employment (Ram \& Jones 1998, Virdee 2006).

Ethnic minority entrepreneurship makes an important contribution to productivity. There are more than 300,000 ethnic minority small and medium enterprises in the UK, which contribute at least $£ 20$ billion to the UK economy per year. ${ }^{21}$ In England alone, in 2004 ethnic minority businesses made up $5.8 \%$ of SMEs. ${ }^{22}$ Ethnic minority businesses have a significant presence in the capital city of London (LDA 2005). It is estimated that there are at least 100,000 Indian businesses and 20,000 Chinese businesses in England. ${ }^{23}$ There is a great deal of growth in ethnic minority businesses: they accounted for $11 \%$ of new business startups in 2004 which is an increase from 9\% in 2000 (Barclays Bank 2005). In 2004, it was estimated that there were 50,000 Black and minority ethnic ${ }^{24}$ business start-ups in England and Wales which is a 56\% increase from 2000 (Barclays Bank 2005). As the growth in the overall number of business start-ups in England and Wales was 28 percent higher than 2000 , the growth in the ethnic minority business start-up is, therefore, double the growth rate in total business start-ups (Barclays Bank 2005).

Ethnic minority entrepreneurship contributes not only to the wealth creation of the UK but also contributes to job creation. Ethnic minority businesses (EMBs) are more likely to have employees than WB businesses (DTI 2006d). EMBs employ almost a million people (about $7 \%$ of the total employment by SMEs). ${ }^{25}$ These official figures are probably an under-

\footnotetext{
${ }^{17}$ DTI SBS analysis of census data. The data is the self-employment rate out of all economically active aged 1674, England and Wales (see Mascarenhas-Keyes 2006).

${ }^{18}$ The terms Indian and Chinese are used here because these are the ones used in Census and Labour force Survey data. The overwhelming majority are likely to be UK domiciled. The overwhelming majority of Whites are White British.

${ }_{19}$ Analysis by BERR statistics team 2008. The Labour Force survey for 2007 shows that the rate for White

British is $9.4 \%$, while that for Chinese is $8.3 \%$ and Indian is $8.1 \%$. The pattern by gender is: for males WB $13.2 \%$, Indian $11.8 \%$ and Chinese $11.4 \%$. Among females the pattern is mixed: WB $5.2 \%$, Indian $3.9 \%$ and Chinese $5.6 \%$. Note that the data for the Labour Force Survey is for UK, and for the working age population i.e.16-65 for males and 16-59 for females. The census data is for England and Wales and all economically active aged 1674. While there are differences in geographical and age coverage between the two sources, they are unlikely to have a significant impact on the patterns.

${ }^{20}$ ASBS 2003 ethnic boost report. The report uses the terms 'ethnic minority businesses' and 'non-ethnic minority businesses'. The report does not have a category White British but as the overwhelming majority of the category 'non-ethnic minority' are White British, for convenience, this term is used. Separate figures are not available for $\mathrm{BI}$ and $\mathrm{BC}$.

${ }^{21}$ Department for Trade \& Industry Small Business Statistics Team estimates based on SBS's SME Statistics for the UK SME stats 2005, SBS Annual Small Business Survey 2005 and ONS Annual Business Inquiry 2004 (ONS 2005b). In Scotland, it is estimated that there are likely to be over 4,500 Minority Ethnic Businesses contributing an estimated $£ 500$ million to $£ 700$ million towards Scotland's GDP (Deakins et al. 2005).

${ }_{22}$ Annual Survey of Small Businesses 2004/5 (DTI 2006e). Analysis by DTI SBS statistics team.

${ }^{23}$ BERR Statistics Team estimate 2007.

${ }^{24}$ Barclays Bank use the term 'Black and Minority Ethnic' as do a number of other studies cited in this report.

${ }^{25}$ United Kingdom Survey of Small and Medium Sized Enterprise Finances 2004, cited in Fraser 2006.
} 
estimate as family members are often engaged in full or part-time work in family businesses but are not counted as 'employees' (Dhaliwal 2000, Ram et al. 2001a, Ram \& Jones 2002).

First generation ethnic minority businesses, including Indian and Chinese businesses, which tend to be embedded within the ethnic enclave economy are more likely to employ coethnics (Ashton et al. 2006). Data is lacking on graduate business and this report will explore the extent to which graduate $\mathrm{BI}$ and $\mathrm{BC}$ businesses, both domestic and international, employ co-ethnic workers or diversify their workforce.

Almost all Chinese and almost nine in ten Indian businesses are concentrated in the services sector compared to seven in ten Whites (DTI 2006d). Retailing is common among Bls, as in the case of Satinder and Sunita's parents, and restaurants and take-aways common among the Chinese. However, as we saw in the examples above and will see in the case studies (see chapter 3 ) and other examples provided in this report, $\mathrm{BI}$ and $\mathrm{BC}$ are diversifying into a broader range of sectors. This pattern of diversification is part of a trend of diversification among ethnic minorities in the UK. There are now significant increases in the proportion of ethnic minority businesses that are operating in the finance, property and catering sectors, IT and the creative industries (NEP 2005, Smallbone et al. 2005, Pollard et al. 2004, Ram et al. 2001b). Satinder and Sunita in example 1 above are illustrative of these patterns of business diversification apparent among second generation ethnic minorities, with many graduates setting up knowledge intensive businesses. Further details on ethnic minority entrepreneurship are provided in chapter 2.

\subsubsection{Student, graduate and academic entrepreneurship}

An analysis of international trends in entrepreneurship shows that not only do the majority of entrepreneurs in high-income, affluent countries have some form of higher education but that graduates also stand much greater chance of success, and are more likely to develop large businesses with high growth potential than their less well educated counterparts.

(FreshMinds 2006). For the UK, Hannon (2005) argues that graduate entrepreneurship is likely to have benefits to the economy since there is a need, in a globalised knowledgebased economy, for highly educated entrepreneurial leaders. The next section explores in turn what is known about entrepreneurship intentions and activities among students, graduates and academics.

\section{Students}

Some idea of the scale of student entrepreneurial intention can be gauged from local, regional and national surveys in the UK which indicate that about a third to two thirds of students harbour entrepreneurial ambitions. A national survey conducted among 2,000 university students in $\mathbf{2 0 0 5}$ found that about two thirds would possibly or definitely consider setting up their own business alone or with others in the foreseeable future or at some point in the future (NCGE 2005). Local research conducted at one large university in England came out with a roughly similar statistic, finding that 3 in 5 students intended running a business at some time in their life (Robertson 2002). Regional research found that over the entire duration of a five year longitudinal survey period comprising 4-7 universities in one region, a consistent finding was that over one third of the students intend to become selfemployed (Robertson \& Wilkinson 2006). The authors estimate that "[E]extrapolated out to the whole collaborative student population of the universities, this would equate to over 57,000 students holding a desire for self-employment within the Yorkshire and Humber region" (Robertson \& Wilkinson 2006:3). The study also found that more males than females, and older (those over 21 years) than younger students intended to be self employed. A consistent finding over five years of regional research was that, of those who intend to become self-employed, about a third definitely or probably expect to start a business within 2 years of graduation (Robertson \& Wilkinson 2006). The extent to which these findings can be generalised across the country is a matter for further research but are indicative of the significant level of interest in entrepreneurship among students. 
The same study also compared non-White and White students in the seven universities in one region (Robertson \& Wilkinson 2006). It found that non-White students had a more positive attitude towards entrepreneurship. Of those students who intended to become selfemployed, $16 \%$ were Asian or Asian British. Non-White students believe more strongly that universities support and encourage enterprise and that their families have influence on their self-employment goals. However, they appear to be more risk averse than White students. The interest in entrepreneurship among non-White students in one region is also supported by data on other regions and nationally. National level data indicate a high level of interest in entrepreneurship among non-White students: about a third of those who engage in enterprise education in UK universities are non-White (NCGE 2007). In some regions such as those covered by the East Midlands RDA and East of England RDA, the proportion of non-Whites engaging in enterprise education rises to $57 \%$ and $44 \%$ respectively (NCGE 2007). ${ }^{26}$

The national scale of actual student entrepreneurship is not known but some attempts to estimate this have been made. ${ }^{27}$ Research conducted in seven universities in one region (Robertson \& Wilkinson 2006) found that $2 \%$ of the current student population were already self-employed. Over the period 2003/04 to 2005/06 there was an average of 192 selfemployed students within the universities in the region. According to Robertson \& Wilkinson, if this figure was extrapolated across all universities in the UK, this could equate to over 2,000 existing student businesses. Almost half of the currently self-employed students surveyed had been operating their business for at least a year; approximately the same proportion also operated their business locally within the Yorkshire region. In terms of discipline studied, those who were currently self-employed at the universities surveyed tend to be enrolled on programmes of study in Business (22\%), Engineering (22\%) or Social Sciences (17\%). Two thirds were males, over half have parents who run their own business, more than two fifths were aged 18-21 and about three quarters were in the first or second year of their programme of study. The finding that a large proportion of self-employed students follow in the footsteps of their parents is in keeping with other research which has found that graduate entrepreneurs are more likely to have parents who are self-employed (Tackey \& Perryman 1999, Greene \& Saradakis 2007).

\section{Graduates}

Entrepreneurial intention among graduates varies among cohorts. A comparison of those who graduated before 2000 and those who graduated after 2000 (Harding 2007) found that the expectations of future start up activity were significantly higher in the population that graduated after 2000 . The figures for men increase from $14 \%$ before 2000 to $18 \%$ after 2000 and for women, increase from $9 \%$ before 2000 to $10 \%$ after 2000 . Furthermore, the perception of seeing business as a good career choice also improved from two fifths of those who graduated before 2000 to a half of those who graduated after 2000. Culture is regarded by the 2008 Enterprise Strategy Paper as an enabler of enterprise and it is interesting to note that the level of fear of failure is lower amongst those who graduated more recently, irrespective of gender, although it is less evident among women. The rate for men has declined from $35 \%$ before 2000 to $30 \%$ after 2000 . For women, the rate has also declined

\footnotetext{
${ }^{26}$ These statistics need to be treated with caution and regarded as indicative only as the figures include both those with and without UK domiciliary status so the non-Whites do not refer specifically to UK ethnic minority students.

${ }^{27}$ For instance, a longitudinal survey of students in a region has been undertaken since 2003. Its questionnaire administered in 2005-06 obtained the views of a broad range of 7012 students enrolled on programmes of study with the seven partner institutions of Leeds Metropolitan University, Leeds University, the University of Huddersfield, Bradford University, the University of Hull, Sheffield Hallam University and Trinity and All Saints College. The 2003-04 survey was restricted to the original partner institutions of Leeds, Leeds Metropolitan, Bradford and Huddersfield universities.
} 
from 38\% before 2000 to $36 \%$ after 2000 (Harding 2007). However, despite these favourable dispositions, the actual rates of business formation are lower among the recently graduated. This may be the result of a number of factors, but may be related to the lower rate of perception of having the skills to start a business among the recently graduated (Harding 2007).

The scale of actual graduate entrepreneurship can be gained from GEM. In the UK the total early stage (TEA) ${ }^{28}$ entrepreneurial activity according to GEM 2006 is higher for graduates than non-graduates and furthermore, the higher the qualification, the higher the rate: those with a doctorate $(10 \%)$, Masters degree or equivalent $(9 \%)$, Bachelors degree or equivalent (7\%), GCSE or equivalent(4\%), UK average (6\%) (Harding 2006). The TEA rates also vary across the nine different regions in England with London having the highest rate and the North East the lowest (Harding 2007). Gender differences are also significant. For graduates, men (9\%) are more likely than women (7\%) to be TEA active (Harding 2007). An examination of graduate entrepreneurship over a four year period between 1999 and 2003 also found that men were more likely than women to be entrepreneurs (Greene \& Saradakis 2007) and a similar male bias was evident among those who graduated in 2005 (HECSU 2007). It will be recalled that a gender bias in favour of males was noted earlier for HE students. Students and graduates are not unusual: the male bias towards entrepreneurship is also evident in the wider population irrespective of educational qualifications: in 2006 the TEA for men was $8 \%$ compared to $4 \%$ for women (Harding 2006). However, the gender gap is smaller between male and female graduates for social entrepreneurial activity compared to mainstream entrepreneurial activity (Harding 2007). It is interesting to note that around a quarter of self-employed women hold a degree or equivalent compared with a lower level of 18 per cent of self-employment men (BERR 2008a).

Some idea of the disciplinary background of the self-employed is provided by an analysis of 2005 graduating cohort six months following graduation. Self-employment was highest among design students (12\%) followed by music students (7\%) (HECSU 2007). ${ }^{29}$ This finding is also endorsed by other research that showed that graduate entrepreneurs were more likely to come from Arts disciplines (Greene \& Saradakis 2007). Mode of study is also significant as those who studied part-time at university are more likely to be self-employed than those who engaged in full-time study (HECSU 2007, Greene \& Saradakis 2007). Graduate entrepreneurs are also more likely to be older than those in paid employment (Greene \& Saradakis 2007). For instance, two in five self-employed graduates were aged 30 and over, compared with just over one in four of the whole 2005 working graduate cohort (HECSU 2007). An examination of graduate entrepreneurship over a four year period found that the self-employment rate increased steadily as graduates build up labour market experience (Greene \& Saradakis 2007).

We saw earlier that in 2001 the self-employment rate among all Indian and Chinese is higher than Whites. However, if we look at UK born Indian and Chinese graduates, the pattern is reversed. Thus for the second generation, Indian and Chinese male and female graduates have a lower self-employment rate than White British graduates. As the data is restricted to the UK born it does not cover all those subsumed under the term $\mathrm{BI}$ and $\mathrm{BC}$ in this report (which also includes those born overseas who have acquired domiciliary rights) but nevertheless it is indicative of changing patterns (Jones \& Ram 2003). A more detailed examination of the relationship between education, ethnicity and self-employment is in chapter 2.

\footnotetext{
${ }^{28}$ GEM calculation of the TEA is based on businesses under 42 months old.

29 HESA 2004/05 Destinations of Leavers from Higher Education (DLHE) survey cited in Graduate Entrepreneurship 2007 (HECSU 2007). These figures include those who work freelance
} 


\section{Academics}

The scale of academic entrepreneurship can be gauged from national surveys of higher education institutions, although this data does not have information on the ethnicity or nationality of the academics engaged in such activity. Annual surveys conducted by HEFCE which captures higher education-business and community interaction testify to the sector's continued relative success in forming new spin-off companies from third stream activity compared with other institutions, for instance, in the US. ${ }^{30}$ Higher Education Institutions reported that their graduates formed 1,172 new companies in 2005-06 while academic staff started around 58. "However, the annual turnover of all active staff start-ups is nearly £27 million, suggesting such companies have a greater relative economic impact than those set up by graduates, which are reported to turn over around £85 million" (HEFCE 2007b:12). However, the comparative lower contribution of graduates to staff in terms of turnover should be treated with caution because it could reflect the difficulties in obtaining data on alumni. Graduate entrepreneurs from a specific university are usually dispersed around the country and can be difficult to trace because of the lack of good quality tracking data on alumni activities.

Apart from spin-outs from university research, there has also been a growing increase in the number of disclosures, active patents protecting intellectual property both within and outside the UK, as well as an increase in licences granted to commercial companies and noncommercial partners to exploit intellectual property generated by UK HEls both within the UK and overseas (HEFCE 2007b). The proportion of universities able to seek out licensing opportunities has increased from about two thirds in 2002 to about four fifths in 2007 (HEFCE 2007b). These activities attest to the increase in academic entrepreneurship.

\subsection{Driver of Productivity: Skills}

Skills play a key role in supporting productivity. Higher skills levels ${ }^{31}$ allow knowledge workers to generate new ideas, adapt to the changing economic environment and facilitate the implementation of new technology. As noted earlier, Leitch argues that in the 21st century, people are the natural resources whose potential has to be mobilised and "[S]kills will unlock that potential" (2006:1). The Government has aimed in recent years to increase the proportion of the population with higher level skills through widening and expanding participation policies as well as graduate employability policies which aim to equip adults with the skills required by employers. These policies have helped to introduce flexible modes or study and increase the number of mature students, part-time students, female students and ethnic minority students in $\mathrm{HE}$.

What higher level skills do $\mathrm{BI}$ and $\mathrm{BC}$ bring to the economy? Qualifications are taken as a proxy for skills and an analysis of the Labour Force Survey 2006 shows that almost similar proportions of non-White ethnic minorities (29\%) and White (28\%) have level 4-8 qualifications. ${ }^{32}$ However, a greater proportion of BC and BI compared to Whites have level 4-8 qualifications. Ethnic minorities represent a higher proportion of the graduate output compared to their share of the working population (Connor et al. 2004). The groups most likely to have degrees were Chinese (31 per cent), Indian (25 per cent) and this compares with 17 per cent of WB people. ${ }^{33}$ Further details on educational attainment of Indian and Chinese can be found in Chapter 2.

As noted earlier, higher level skills allow workers to generate new ideas and adapt to the changing economic environment. However, the UK has a long term weakness in the level of

\footnotetext{
${ }^{30}$ See annual reports by HEFCE on Surveys of Higher education business and community international survey.

${ }^{31}$ Higher level skills 4-8 are higher education qualifications.

32 Level 5 is a first degree and level 8 a doctorate.

${ }^{33}$ ONS 2006 Focus on Ethnicity \& Identity: Education.
} 
human capital (DTI 2003b), but as the foregoing has shown, this weakness is less apparent among $\mathrm{BI}$ and $\mathrm{BC}$. The factors that account for this high level of human capital among $\mathrm{BI}$ and $\mathrm{BC}$ are discussed in more detail in chapter 2. The possession of higher level skills creates opportunities to engage in knowledge-based entrepreneurial activities where knowledge is a primary asset and a source of competitive advantage. Furthermore, the possession of higher level skills by a comparatively greater proportion of $\mathrm{BI}$ and $\mathrm{BC}$ suggests that they are likely to be more innovative. Although there is no specific data on $\mathrm{BI}$ and $\mathrm{BC}$ knowledge-based businesses, as we shall see below (section 1.10.1), in England, ethnic minority businesses compared to WB business are more innovative and regard innovation more favourably.

To help develop the high value businesses that the UK requires to increase productivity, not only is this facilitated by higher level disciplinary knowledge skills, but also by enterprise knowledge and skills which is one of the five enablers of enterprise identified by the 2008 Enterprise Strategy Paper. GEM 2006 shows that among the 18-44 year old age group, for both men and women, if they have undertaken any type of enterprise training at school, college or university, it tends to approximately double the likelihood that they will be expecting to start a business. Furthermore, it increases the likelihood that they will be entrepreneurially active. Voluntary training appears to be more effective than compulsory training (Harding 2006).

Such evidence indicates the merit of Government policy in recent years which has been to develop skills in enterprise in all tiers of education. The policy aims to develop future entrepreneurs as well as enterprising employees and social enterprise. In the 2007 Budget the Government allocated a further $£ 60$ m per year until 2010/11 to sustain and extend this policy. From autumn 2008 , the Government will commit a further $£ 30 \mathrm{~m}$ to extend enterprise education from secondary schools into primary and tertiary education (BERR 2008a). Specialist organisations funded by the Government, such as Enterprise Insight, have been set up to raise awareness of enterprise among 14-30 year olds through various activities including Enterprise Week. Since the launch of Enterprise Week in 2004, the UK's annual Enterprise Week has involved over 11,000 events and more than 1.5 million participants. Survey evidence suggests that enterprise interest is over $50 \%$ higher among participants compared to non-participants (BERR 2008a). The success of Enterprise Week in the UK has inspired the first Global Enterprise Week to be held in November 2008. Some of Enterprise Insight's initiatives have been targeted at ethnic minorities. For instance, a young $\mathrm{BI}$ female graduate Akira, who has previously owned businesses while an undergraduate student, is leading an enterprise awareness campaign targeted at 14-30 year old ethnic minorities. It uses young ethnic minority entrepreneurs as role models. For instance, Dhiren, a successful young $\mathrm{BI}$ graduate entrepreneur who has signed highly profitable deals with major supermarket chains to market Halal chocolate confectionery, serves as an ambassador for the campaign and is involved in various workshops and lecture programmes.

University enterprise education can build on pre-university activity. The value of preuniversity enterprise awareness is apparent as some students with entrepreneurial ambitions at university report that they "...did something at school/college that ignited their entrepreneurial appetite. Their interest in entrepreneurship was first aroused in school/college" (Robertson \& Wilkinson 2006: 8). As noted earlier, in 2004, the National Council for Graduate entrepreneurship (NCGE) was established by Government. It aims to increase the number and sustainability of graduate start ups, increase the number of students and graduates giving serious thought to setting up a business, and developing and promoting a culture of entrepreneurship within Higher Education. These developments are encouraging as the provision of entrepreneurship education and take up varies across the university sector (NCGE 2007). A recent innovation is a two year programme funded by the Higher Education Innovation Fund (HEIF) designed to build closer ties between business 
and universities. The programme called SPEED (Student Placement for Entrepreneurs in EDucation) has thirteen partner universities in the scheme providing a total target of 750 placements. In the first year, applications were received from a broad spectrum of disciplines and demand outstripped supply, ${ }^{34}$ thus testifying to the entrepreneurial ambitions of students. Ten students from this programme and five staff from the central and local teams were interviewed for this research. The wide range of enterprise awareness and skills development which is available at university, both in-curricula and extra-curricula, is discussed in more detail in chapter 8 . This is based on interviews with enterprise educators, the NCGE, students and student enterprise clubs.

Enterprise knowledge and skills can also be developed through external support which can help with various stages of the business life cycle. Start-ups that seek professional external advice are more likely to build turnover faster and are 20 per cent more likely to survive than those that do not (Barclays 2002). ${ }^{35}$ Ethnic minority compared to WB businesses are less likely to seek advice about starting up the business (Ram 1998, Ram et al. 2002, DTI $2006 \mathrm{~d}$ ). Private, public and third sector organisations involved in providing business support were interviewed for this research to explore their engagement with students, graduates and academics, as well as the provision of support for international entrepreneurship. The findings are examined in chapter 9.

Entrepreneurship skills can be acquired not only through formal methods, but also tacitly through helping existing businesses. Children whose parents or close relatives have a business are likely to have many opportunities to learn about entrepreneurship. As we saw earlier, a greater proportion of Indian and Chinese have businesses and it is likely that a greater proportion of children of who help with the family business informally receive enterprise training. The socialisation into entrepreneurship that may be tacitly acquired through assisting the family business may help explain why graduates whose parents were self-employed are more likely to enter self-employment themselves (Tackey \& Perryman 1999, Greene \& Saradakis 2007). Mature and part-time students are likely to have employment experience as do the increasing number of traditional students who have to work to financially support their studies (Finch et al. 2006). Thus many recent and current students and graduates are more likely than earlier generations of traditional students to have enterprise and enterprise-related skills. ${ }^{36}$

\subsection{Driver of Productivity: Innovation}

Innovation - the successful exploitation of new ideas - is one of the main engines for long term economic growth. It is vital to maintaining a competitive advantage in the global economy (DTI 2003c). The latest position on its significance is expressed in the 2008 Innovation White Paper which states:

"Innovation is essential to the UK's future economic prosperity and quality of life. To raise productivity, foster competitive businesses, meet the challenges of globalisation and to live within our environmental and demographic limits, the UK must excel at all types of innovation" (DIUS 2008: 4)

A pre-eminent role is given to science in the Sainsbury Review which argues that the

"best way for the UK to compete, in an era of globalisation, is to move into high-value goods, services and industries. An effective science and innovation system is vital to achieve this objective" (Sainsbury 2007:3)

\footnotetext{
${ }^{34}$ End of year 1 report to HEFCE.

${ }^{35}$ cited in DTI 2004b.

36 'Traditional students' are normally White middle class students who have undertaken ' $A$ ' levels and proceeded directly to full time university study at the age of $18 / 19$ years.
} 
Regular innovation surveys (DTI 2006c) in the UK are conducted by the Government to understand the complex interplay of market forces, institutional arrangements and the stocks and flows of knowledge. This fosters and supports business innovation as well as producing indicators that can be applied in setting policy objectives and in monitoring out-turns. A range of concepts fall under the umbrella term innovation and these include product innovation (both tangible goods and the provision of services); process innovation (significant changes into the way that goods or services are produced); research and development (R\&D) and design activities; and softer or wider innovation which is usually management related such as strategic changes to the organisation of business or its functions. A distinction is also made between products or processes new solely to the business, or which are also new to the market (DTI 2006c).

Students and graduates, as entrepreneurs and intrapreneurs, and academics, play an important role in promoting innovation. Innovation policies in the UK to date have largely centred on encouraging universities to commercialise new knowledge generated by their academic researchers and also promoting more R\&D activities in existing businesses. The boundary between the two has become blurred. Since the Lambert Review (2003) of university-business collaboration, HEls have been increasingly positioned as agents for regional and national economic growth (DIUS 2008). Traditionally, these institutions

“...have been important in improving the skill base of the economy. But a shift in the way research and development $(R \& D)$ is organised is now also strengthening their role in commercial $R \& D$. In the past, universities did basic science, while companies worked separately on applications for commercial use. Today, these boundaries have blurred, and successful R\&D often involves cooperation throughout the innovation process" (Porter \& Ketels 2003:30)

Notwithstanding this blurring of boundaries, business innovation and university innovation are discussed separately below.

\subsubsection{Business Innovation}

Business innovation is one of the enablers of enterprise identified in the 2008 Enterprise Strategy Paper. In terms of R\&D, the British Government spent £3.2 bn. on R\&D in 2006. In the UK, the Government has encouraged R\&D among businesses through grants and tax credits (which provide enhanced tax relief), as well as initiatives, such as the Small Business Research Initiative (SBRI) which helps SMEs to gain greater access to publicly funded R\&D contracts. R\&D tax credits encourage greater R\&D by providing a tax credit for qualifying R\&D spend. These measures have had a positive impact: for instance, since their introduction in 2000, R\&D tax credits have successfully delivered more than $£ 2.3$ bn of support to innovative UK companies, through almost 30,000 claims. As a further boost to business innovation, in 2007 the Technology Strategy Board (TSB) was created to manage the Government's support for such innovation. It funds innovation through activities such as the Collaborative R\&D programme, Knowledge Transfer Partnerships, Knowledge Transfer Networks and Innovation platforms. During 2008-2011, the TSB will invest over $£ 720$ million in innovation (BERR 2008a). Successful initiatives, such as the Knowledge Transfer Partnerships will be expanded and also made more flexible in terms of duration to meet more varied demand (DIUS 2008).

Levels of innovations vary across businesses. There are different levels of innovation in ethnic minority businesses (EMB) and WB businesses. Data from the Government national Annual Survey of Small Businesses 2003, which had an ethnic minority boost, shows that innovation is more evident among EMBs in England (DTI 2006d). ${ }^{37}$ This is particularly the

\footnotetext{
${ }^{37}$ ASBS 2003 ethnic boost report. No details are available for Chinese and Indian businesses as sample sizes are too small. Hence the data is only available for ethnic minority businesses as a whole. The data is only available for businesses with employees.
} 
case with process innovation. For businesses with employees, among EMBs, 45\% had introduced product innovation, and $47 \%$ process innovation compared to $39 \%$ and $32 \%$ respectively for WB (DTI 2006d). This supports the findings from GEM 2005 that EMBs tend to be more innovative. Not only are EMBs more innovative but, furthermore, they have a higher regard for the value of innovations. Thus, among businesses with employees, a higher proportion of EMBs (39\%) compared to WB businesses (32\%) saw product/service innovation as very important. They had a similar view of process innovation with $30 \%$ of EMBs compared to $24 \%$ of WB businesses regarding this as very important (DTI 2006d).

\subsubsection{University third stream activity}

Various barriers to the transfer of knowledge from university to industry have been identified (Agrawal 2001). Some of the impetus to increasing the contribution of higher education to the economy and society has, therefore, come from Government policy initiatives designed to enhance universities' third stream activity. Third stream activity is manifested in a number of ways including disclosures, patenting, licensing, joint ventures of universities with businesses and spin-off companies from universities. Universities have benefited from the DfES/DTI jointly sponsored knowledge transfer schemes and business interaction schemes across the HE sector including the Higher Education Innovation Fund (HEIF), Science Enterprise Centres, the University Challenge Fund and Cambridge-MIT which have stimulated capacity building and spin-off companies (SQW 2005). A range of other Government programmes to facilitate knowledge transfer such as the SMART, LINK and TCS programmes have all been found to be successful (DTI 2003b) ${ }^{38}$ Funding for some successful initiatives, such as HEIF, have been augmented (DIUS 2008). ${ }^{39}$

The core of innovation activities promoted by the Government has emphasised science innovation. The Government launched the 2004-2014 which highlights the important role the higher education knowledge base plays as a source of the country's global competitiveness (DTI 2004c). The Government has funded RDAs to set up high-technology incubators which have had a catalysing effect on the number of science parks and incubator facilities built over the past decade. In 1996 there were about 25 incubators for high-technology firms in the country and by 2007 it is estimated that there were over 270 (Sainsbury 2007). Science parks have also grown: In 1998 there were 39; by 2007 there are nearly 100, with almost 1,700 tenant businesses (Sainsbury 2007). A number of incubators and science parks, including one in China, were visited during this research project, and the facilities offered by them and their involvement in internationalisation are discussed in chapter 8.

Links between SMEs and universities have been facilitated by Research Councils and RDAs. For instance, the Economic and Social Research Council in collaboration with Advantage West Midlands and the Engineering and Physical Sciences Research Council launched an SME Innovation Voucher scheme. This invited SMEs to apply for an innovation voucher that could be used to purchase academic advice and support to generate real innovation for a particular business project. The success of pilot schemes such as these has led to an injection of funds into the scheme by Government and its extension across the country (DIUS 2008).

Another way of promoting university-business links and increasing the competitiveness of knowledge-based clusters is through the development of science cities. Science cities are based on the notion that in the global economy, the UK's future prosperity depends, first, on

\footnotetext{
${ }^{38}$ SMART, which has now been superseded by an R\&D grant, provided grants to individuals and SMEs to develop technologies leading to commercial products. LINK aims to develop partnerships between UK industry and research organisations by supporting programmes of pre-competitive science and technology research. TCS has now been superseded by Knowledge Transfer Partnerships which stimulates innovation in industry through collaborative partnerships between the science base and business through industrial placements.

${ }^{39} 2008$ Innovation White Paper. The HEIF fund, now a permanent part of the university funding landscape, will increase to $£ 150 \mathrm{~m}$ per year by $2010 / 11$. Funding will be allocated entirely through a formula and the benefits distributed more widely in line with the recommendation of the Sainsbury Review (2007).
} 
the capacity to expand knowledge through science and translate it into innovative products and services and, second, on achieving this by building critical mass in clusters based around world-class universities. There are various examples of this such as Science City York (SCY) which is a partnership between the City of York Council, the University of York and the regional development agency, Yorkshire Forward. SCY works through three main clusters: bioscience and health, IT and digital, and the creative industries. Various facilities are available to entrepreneurs, usually graduates and academics, such as special funds, mentoring and other business support, incubation and science park space. Since its inception over 60 new companies have been created.

The Government's intention is not only to stimulate the commercial exploitation of the HE knowledge base within the UK but also internationally. The Global Science \& Innovation Forum (GSIF) is a vehicle for cross-Government exchanges of information and ideas to improve co-ordination of the UK effort in international science and innovation collaboration and to help raise the UK's reputation as a global leader in science and innovation. Chapter 5 contains further information on strategies for collaboration with Europe and internationally.

The emphasis in all policy documents has been on the innovation capacity of research students and staff, and on scientific research. There is no doubt that scientific research undertaken by research students and academic staff play an important role in the innovation process and in facilitating international competitiveness. Philip, in example 2 above, illustrates the role that BC scientific researchers play in innovation. However, to date far less attention has focused on non-research undergraduate students and taught masters students' innovation capacity and their aspirations to set up businesses while students or to consider other progression paths to commercialisation. Are non-research students, both undergraduates and taught masters students, from science as well as other disciplines, not capable of innovation? Clearly as Lincoln and his colleagues in example 3 above testify, as do other examples in chapter 3 , this is not the case.

Not only has there been a lack of sufficient and widespread recognition of non-research students' innovation capability, but traditionally innovation has been conceptualised by Government more narrowly as science and technological innovation, hence the emphasis on the development of scientific and technological research. However, in the 2008 Innovation White Paper, the Government has broadened the concept to embrace a wider range of disciplines and sectors. This is particularly appropriate within a knowledge economy (Brinkley 2008). The Government has recognised the innovation capability of the creative industries, management studies, public sector, and a range of other sectors where innovation is hidden and not captured by existing metrics (DCMS 2008, NESTA 2007a, DTI 2006c, 2007a, Varney 2006). The 2008 Innovation White Paper emphasises that the Government will maintain the growing investment in UK science but will also broaden knowledge exchange between businesses and the research base in arts and humanities and service sectors such as creative industries. The existing measures of innovation are now seen to be inadequate, particularly in the light of a broader conception of innovation, and the Government has commissioned the National Endowment for Science, Technology and the Arts (NESTA) to develop a new Innovation Index to measure the UK's performance as an Innovation Nation (DIUS 2008). This broader concept of innovation is applauded as the examples of student, graduate and academic entrepreneurship provided in chapter 3 testify to the wide range of innovative ideas generated from a cross-section of disciplines.

\subsection{Driver of Productivity: Competition}

Competition can refer to both national and international competition. As this research is focused on international entrepreneurship, our interest is primarily in international competition. The 2004 Trade \& Investment White Paper states: 
"Greater internationalisation strengthens the existing drivers of productivity innovation and competition - and provides access to new technologies. The most successful businesses will be those that understand and embrace this, to enhance their own competitiveness. These businesses are likely to be - or aspire to become - both exporters and importers, investors in the UK and overseas. For individual companies, these activities are complementary and part of doing business internationally. As a nation, we need to recognise that we benefit from overseas investments as much as from inward investors. The challenge for Government is to help more businesses to globalise; to help them become internationally competitive, and make the case to companies for basing high value-added activities in the UK" (DTI 2004d:8)

The Government recognises that the benefits to UK prosperity from increased international trade and investment are potentially large, and are articulated through direct and indirect productivity effects on UK firms, competition effects and innovation effects (DTI 2006b). International trade and investment adds to the competitive intensity of an economy through, for instance, the provision of access to larger markets or niche markets, lower production and labour costs and there are also wider benefits to the economy through knowledge spillovers (DTI 2003b). Businesses which trade internationally are more productive than those that do not, they spend more on innovation, are more capital-intensive and their labour productivity is higher (Girma et al. 2002). Such firms also stimulate competition among domestic firms and are strong conduits for the transfer of ideas and knowledge (DTI 2006b). SMEs reap benefits by participating in outsourcing and global value chains which have risen in importance with the global fragmentation of production and service delivery across multiple countries and enterprises (OECD 2007). However, an international project report notes that "[A]though SMEs are a major source of growth and job creation, they appear to be under-represented in the international economy relative to their contribution to national and regional economies" (Lloyd-Reason \& Mughan 2006:5). In the UK there are variations in participation in international trade among different groups: The Household Survey of Entrepreneurship 2005 found that among entrepreneurs in England, Black (34\%) and Asian $(25 \%)$ entrepreneurs are more likely to trade internationally compared to WB $(17 \%)$. The reasons for this have not been systematically investigated but this report will try and throw some light on factors affecting international entrepreneurship engagement among $\mathrm{BI}$ and $\mathrm{BC}$ students, graduates and academics.

Extending competitive markets to include markets in Europe and overseas is one of the Government's key priorities (DTI 2003a) to help raise productivity and hence prosperity. The choice of overseas countries entrepreneurs engage with depends on a number of factors, including psychic distance. Psychic distance is defined in various ways. According to one definition, it is defined as the distance between the home market and a foreign market resulting from the perception and understanding of cultural and business differences. Cultural distance relates to national culture, while business distance incorporates economic, legal and political structures, business practices, industry structure and language differences (Evans \& Movado 2000).

In some cases of internationalisation, such as trade and investment between UK and some parts of Europe, psychic distance and physical distance may not be that far apart. With other countries, both the psychic and physical distance is large which suggests that trading with countries physically and psychically far away is less attractive. This can be a barrier when the countries with which it is lucrative to do business are the emerging economies of India and China. ${ }^{40}$ It could be hypothesised that for all or some $\mathrm{BI}$ and $\mathrm{BC}$, international entrepreneurial activities are less of a barrier with India and China respectively because of cultural familiarity, an issue explored in this research.

\footnotetext{
${ }^{40}$ The term 'China' is used to cover both mainland China and Hong Kong.
} 


\subsubsection{China and India}

India and China are two international destination points focused on in this report. This is because, first, the economic balance of power is shifting towards Asia (BERR 2007a). Second, these are the two emerging economies with which the British Government is keen to develop links as part of its globalisation strategy. It has set up various mechanisms to facilitate this, such as the Asia Task Force in 2004. Commitment to strengthening economic relations with China was most recently evident at the UK-China summit in 2008 which also announced the establishment of an office of the London Stock Exchange in Beijing to help Chinese companies raise capital in UK finance markets. ${ }^{41}$ There was also a UK-India summit in 2008 which focussed on strengthening economic ties with India. ${ }^{42}$ Third, they are the ancestral countries of the $\mathrm{BI}$ and $\mathrm{BC}$ students, graduates and academics this study focuses on. Both countries have experienced rapid growth, including the development of infrastructure, human capital, and science and engineering focused entrepreneurship. A closer look at China and India illustrates this.

China is the fourth largest economy in the world with a growth rate in 2006 of about $11 \%$ while India had a growth rate of around $9 \%$, both of which are considerably higher than the UK growth rate of about $2.5 \% .{ }^{43}$ Hong Kong is now part of China, under the one country two systems model. ${ }^{44}$ Hong Kong, with its legacy of British colonialism, can be viewed as a stepping stone to China. Hong Kong has the advantage of following the English legal system including IP protection, many of its population speak English, and several have British university qualifications through study in the UK and/or through transnational education programmes delivered through local universities. It is an international financial centre, and many of its businesses use western management models. It recently opened a large, state-of-the art science park which also has links to local universities, such as the University for Science and Technology in Hong Kong. The science park is actively seeking collaboration with UK universities and businesses. Furthermore, Hong Kong is less than an hour's train journey across the Chinese border to the recently developed town of Shenzhen which is home to science parks, a local university, IT and financial businesses, many with international links. One of England's regional development agencies has an office in Shenzhen which was visited for this research and findings are reported in chapter 9.

China is currently considered the 'workshop of the world' as it is cheap to manufacture goods there. However, this is not the position it wants to retain and there are indications that it has ambitions to be the next science superpower with a Nobel Prize winner (Wilsdon \& Keeley 2007). Its ambition is manifested in various ways and a few relevant examples are provided here. By 2006, China's R\&D intensity had more than doubled from $0.6 \%$ in 1995 to $1.3 \%$ of GDP (OECD 2006). There are a growing number of science parks and incubators, one of which was visited in this research and the findings reported in chapter 8 . Apart from building science facilities in the country, China is setting up science parks overseas, including in the UK. It is also investing a great deal in trying to improve the skills of its people by expanding the number of universities. For instance, in 2004 it had 15 million enrolments in tertiary education and awarded $23,500 \mathrm{PhDs}$, with $70 \%$ in science and technology (Wilsdon \& Keeley 2007). The Chinese are not only studying in home universities but a significant number study overseas. In 2006/07, there were about 50,000 students from China studying in the UK at undergraduate and postgraduate levels. ${ }^{45}$ The

\footnotetext{
${ }^{41}$ Prime Minister Gordon Brown's speech at the UK-China business summit in Beijing January 2008.

${ }^{42}$ Prime Minister Gordon Brown's speech at the UK-India business summit in Delhi January 2008.

43 BERR 2007b: Annual growth in GDP averaged just over $2.8 \%$ of UK over the period 1996 and 2006 . For India and China see CIA World Fact Book. As it is generally considered difficult to get reliable estimates of GDP in India and China, these figures need to be treated with caution and regarded as indicative only.

${ }^{44}$ To facilitate integration, Mandarin, the lingua franca of China, is now being taught in Hong Kong schools. The Chinese language most commonly spoken in Hong Kong is Cantonese.

${ }^{45}$ Source: DIUS HE analysis team.
} 
British Government is keen to increase the number of Chinese students studying in the UK and is planning on offering more scholarships and work experience programmes. ${ }^{46}$

India has also invested in developing a skilled workforce. It has a large number of educational institutions offering higher level skills training, including the world renowned Indian Institutes of Technology which rank second in the world in the field of engineering. The Indian Institutes of Management also have a global reputation. Alumni from these institutions hold prestigious professional positions or run businesses in India and worldwide, particularly the USA (Saxenian 1999). India has a large pool of university graduates estimated to be one and a half times that of China and double that of the USA, and it is constantly replenished by $2.5 \mathrm{~m}$ new graduates in science, engineering and IT every year. ${ }^{47}$ India also produces between $5,000-7,000 \mathrm{PhDs}$ every year. ${ }^{48}$ The availability of a skilled workforce at low costs constitutes one of the attractions for multinationals and other companies who are now undertaking R\&D in India. The availability both of high calibre personnel and lower costs for R\&D in India and China is gradually beginning to provide competition for UK universities, thus potentially affecting levels of academic entrepreneurship or possibly opening up more opportunities for international collaboration (Leadbeater \& Wilsdon 2007). This is explored in more detail in chapter 5.

\subsubsection{Social and Cultural Barriers to International entrepreneurship}

There are many barriers to international entrepreneurship. A recent worldwide survey of SMEs' perceptions of barriers to access to international markets found there were both internal barriers (lack of knowledge and a shortage of both financial resources and human resources within the firm) and external barriers (government fiscal policies, regulatory policies and their enforcement, quality of support programmes and political stability) (LloydReason \& Mughan 2006). Other studies have also noted language and cultural barriers (Szabo 2002) and social network and intermediation failures (DTI 2006b).

Survey evidence of UK businesses of all sizes on the barriers to selling into overseas markets show that social network barriers are the second most frequently cited barrier, relating both "...to identifying initial contacts and establishing a dialogue, and to building relationships once initial contact has been established" (DTI 2006b:54). ${ }^{49}$ Research on SMEs in the UK found that between a fifth and almost a third of SMEs which used UK Trade \& Industry (UKTI) services said they encountered language and culture barriers, a half encountered barriers identifying initial contacts, establishing initial dialogue and building relationships, and about 1 in 10 barriers to obtaining information. ${ }^{50}$

While this evidence related to internationalisation with any country outside of the UK, a recent qualitative study for UKTI on barriers to doing business in India, China, Russia and Brazil found that these included "...culture, language, contacts and relationships, product/service suitability, cost barriers in terms of the investment required and/or the need for local presence" (DTI 2006b:55). ${ }^{51}$ Networks appear to be more crucially important in dealing with China and the Chinese. The term quanxi captures this, but this oft used term needs to be better understood in relation of how contacts are developed, how they are used, their negative and positive sides and the kind of reciprocity they entail. This is beyond the scope of this research but the significance of different approaches for dealing with different countries needs to be borne in mind in developing any kind of international activity.

\footnotetext{
${ }^{46}$ Prime Minister Gordon Brown's speech at the UK-China business summit in Beijing January 2008.

${ }^{47}$ Cited in Bound 2007.

${ }^{48}$ Cited in Bound 2007.

49 Based on research undertaken by UKTI 2006, OMB Research 2005, 2006a.

${ }^{50}$ cited in DTI 2006b.

${ }^{51}$ Based on research undertaken by OMB Research 2006b and cited in DTI 2006b.
} 
Networks play an important role in facilitating internationalisation (Casson et al. 2006). For small, knowledge-intensive firms, networks accelerate the internationalisation process and help, for instance, to identify new market opportunities, mode of entry, potential partners, product development and market diversification (Coveillo \& Munro 1995, 1997). In a study of small knowledge-intensive firms in the software industry in India, Prashantham demonstrates how these firms "...develop and leverage network relationships and thereby the resourcefulness with which entrepreneurial firms can (and do) internationalise" (2008: xi). Local networks afforded by the development of knowledge-based clusters such as in Bangaluru in India and Cambridge in the UK can also provide the springboard to the development of international networks as firms get involved, for instance, in supply chain activities. Hence, access to a wider range of networks can substantially improve the internationalisation opportunities open to individuals and a business.

That social networks play a critical role in internationalisation is recognised by Government:

"[T]he UK business community's response to opportunities in the fastest-growing emerging markets, and sectors of growing overseas demand, will depend crucially on the strength of social networks underpinning bilateral trade and investment relationships with those markets, and on the ability of innovative UK businesses to gain access to these networks. If these networks are weak, or relatively closed to new companies, the UK economy's ability to respond to these opportunities may be weak or sluggish, with adverse effects on prosperity" (DTI 2006b:65)

What can be done to mitigate the market failure of limited or no social networks? Various strategies can be adopted including, first, using formal institutions, second, intermediary organisations and third, personal networks. First, Government intervention has led to the establishment or strengthening of embassies, consulates and other agencies overseas and in the UK to provide access to information and influence. Institutional networks are important and those set up by Government, which expects to act as a trusted, impartial intermediary, play a significant role. For instance, a study by Rose (2005) found that bilateral exports rose by approximately $6-10 \%$ for each additional consulate abroad, and the strength of the effect varied by exporter country. UKTI's surveys do not generally identify commercial private sector alternatives to the organisation's information and advisory services, but instead strongly points to the role of private social networks as by far the most frequently cited alternative (DTI 2006b). Staff in the UK and China from UKTI, overseas consulates, regional development agencies with offices overseas and private sector business consultancies were interviewed for this research and the findings are discussed in chapter 9.

Second, institutions for collaboration serve as intermediary organisations and can "...have a significant effect on competitiveness. These entities are neither firms, Government entities, nor universities. They include, for example, chambers of commerce, industry associations, professional associations, trade unions, technology transfer organisations, quality centres, think tanks, university alumni associations, and others" (Porter \& Ketels 2003: 31). Staff from some of the institutions located in the UK and in China were interviewed for this research and the findings are discussed in chapter 9 specifically in terms of their relevance to student, graduate and academic entrepreneurship.

Third, personal networks provide important conduits for internationalisation. Rauch (1999) notes that colonial ties and common language help international trade between countries (cited in DTI 2006b). This is specifically illustrated by Gould (1994) who notes that immigration to the US increased bilateral trade between the US and the immigrant's country of origin (cited in DTI 2006b). A study in the UK found that bilateral trade effects depends on whether immigrants are from Commonwealth or non-Commonwealth countries, with the latter showing a more positive impact on imports and exports (Girma \& Yu 2002). Specifically in terms of knowledge-based entrepreneurship, Saxenian (2006) has 
demonstrated how graduate Indians and Chinese who have gained employment or established businesses in Silicon Valley in the USA, often after a period of postgraduate study at US universities, have also established successful new businesses or international businesses in India, China and Taiwan. These 'New Argonauts' have spearheaded the emergence of important clusters, such as the IT cluster in Bengaluru, India, and contribute to brain circulation between India, China, Taiwan and the US.

Some ethnic minority entrepreneurs in the UK have used their personal networks and cultural capital to penetrate international markets and to engage in transnational businesses (Smallbone et al. 2005, McEwen et al. 2005, Hayer \& Ibeh 2006, Ram \& Theodorakopoulos 2007). In the USA a number of studies have been conducted on ethnic minority transnational business (Portes et al. 2002) and on the contribution of immigrant entrepreneurs to the economy (Saxenian 1999, 2002, 2006, Zhou 2004, Anderson \& Platzer 2006, Wadhwa et al. 2007). In Australia there is growing awareness by Government and financial institutions of the potential benefits of exploiting the international social capital of diaspora communities, including the networks of overseas Australians. ${ }^{52}$ In England, for instance, in the region of Yorkshire and Humber, UKTI personnel are involved in initiatives to identify the competitive advantage of having an ethnically diverse workforce in SMEs.

The three sets of networks are not mutually exclusive and those intending to engage in the internationalisation of their entrepreneurial activities can leverage any combination of all three. This report will explore, particularly in chapter 6, the types of networks student, graduate and academic $\mathrm{BI}$ and $\mathrm{BC}$ use to engage in international entrepreneurial activities and how, and for what purposes, these are mobilised.

\subsection{The Impact of the drivers of productivity and enablers of enterprise}

An analysis of the five drivers of productivity leads the DTI to conclude that "[T]here is no single factor holding back UK productivity performance. The productivity gap is the cumulative result of a series of historic weaknesses. The result has been a failure to make the most of high value added business opportunities. If productivity is to improve, then the UK has to be more adept at seizing those opportunities" (DTI 2003b:10). What opportunities and missed opportunities are evident among students, graduates and academics, particularly $\mathrm{BI}$ and $\mathrm{BC}$, not only for high value added business but entrepreneurship more generally? How can they be seized and developed? This concern is pertinent given the cumulative positive evidence for $\mathrm{BI}$ and $\mathrm{BC}$ in relation to the drivers of productivity, that is, in comparison to WB, a greater proportion of Bls and BCs overall have: higher level skills 4-8; higher levels of self-employment; are more likely to be engaged in international trade; are more innovative and regard innovation positively, and seem to experience less barriers to accessing finance. To what extent do these positive indicators about $\mathrm{BI}$ and $\mathrm{BC}$ entrepreneurship as a whole, evident from previous research, apply also to students, graduates and academics from these two communities? Do they face any barriers either specifically as $\mathrm{BI}$ and $\mathrm{BC}$, or generally as highly skilled people, and if so, what can be done to overcome these?

\subsection{Structure of the Report}

Following this introductory chapter, Chapter 2 looks at the demographic profile of $\mathrm{BI}$ and $\mathrm{BC}$ in the UK, their high level skills attainment and patterns of self-employment. Chapter 3 describes the research methods used in this study. As this report is based on qualitative research, it illuminates patterns and processes of entrepreneurial development, particularly international entrepreneurial development. While it makes no claims as to the representative

\footnotetext{
52 In June 2006 a conference was held in Melbourne, partly sponsored by Government on The role of ethnic diaspora communities in promoting export activity. This included research reports from academics as well as Bending Bank.
} 
nature of the sample of respondents interviewed for the study, strenuous attempts were made to collect data from a very broad cross-section of people using sociological and social anthropological techniques. A profile of the thirty three core case studies of the entrepreneurial activities of students, graduates and academics, mainly $\mathrm{BI}$ and $\mathrm{BC}$, but also including some White British (WB) are included in this chapter. These case studies are categorised under science, engineering, computer services, professional services and creative industries. The case studies also include overseas Chinese and Indians with links to the UK who are engaged in entrepreneurial activities. Chapter 4 focuses on student and graduate entrepreneurship, and informed by the drivers of skills and entrepreneurship, examines the motivation to entrepreneurship, the scale of entrepreneurial activities, the timing of entrepreneurship engagement and the relevance of HE skills to entrepreneurship activities. Chapter 5 is informed by the driver of innovation and focuses mainly on academic entrepreneurship. It examines types of entrepreneurship and the barriers to becoming an Innovation Nation. Chapter 6 is informed by the driver of competition, specifically looking at the competitive advantage to international entrepreneurship offered by $\mathrm{BI}$ and $\mathrm{BC}$. As networks play a crucial role in international entrepreneurship development and maintenance, chapter 6 explores the networks of BI and BC students, graduates and academics and how they are leveraged in international entrepreneurial activities. Chapters 7, 8, and 9 focus on the enablers of enterprise. Chapter 7 explores issues of access to finance, including student debt and the range of sources used to finance entrepreneurial activities. Chapter 8 looks at the enabler of knowledge and skills and focuses on entrepreneurship support provided by universities including entrepreneurship education, student enterprise clubs, the NCGE and incubators. Chapter 9 looks at entrepreneurship support provided by the private sector, the third sector, especially ethnic minority organisations, and the public sector at central, regional and local levels and their links to universities.

In chapters 5-9, a range of barriers are identified under the drivers of productivity and enablers of enterprise. Possible solutions are proposed for what more we might do but they require further consideration of impact, feasibility, cost and affordability. They are presented as a basis for discussion. This report has $\mathrm{BI}$ and $\mathrm{BC}$ as its focus. However, the qualitative research findings on the sample of respondents from these two communities as well as WB, suggest barriers and solutions that are probably generalisable to the whole population of students, graduates and academics. Consequently, the report also identifies the barriers that all entrepreneurs face, irrespective of ethnicity but where $\mathrm{BI}$ and $\mathrm{BC}$ may face additional barriers or the same barrier to a greater extent, these are highlighted. Furthermore, some of the barriers discussed apply equally to national and international entrepreneurship, but where there are additional barriers or the same barrier to a greater degree applying to international entrepreneurship, these are identified. Chapter 10 concludes the report. 


\section{CHAPTER 2: BRITISH INDIAN AND BRITISH CHINESE: DEMOGRAPHY. SKILLS ATTAINMENT AND ENTREPRENEURSHIP}

\section{$2.1 \quad$ Introduction}

As mentioned in chapter 1 , in the decade between 1999 and 2009, it is estimated that ethnic minorities will account for half the growth in the working-age population (Cabinet Office 2003). Non-White population groups have a younger age structure than White groups. Ethnic minorities will offset the impending demographic time bomb: declining numbers of young people and the large numbers of skilled White workers who will be retiring in the next decade. The National Employment Panel (NEP) ${ }^{53}$ report Enterprising People, Enterprising Places states that "... the inclusion of ethnic minorities at every level of our workforce is not simply an issue of fairness or social justice: it is central to our future prosperity" (2005:9). Ethnic minorities include British Indians and British Chinese. Out of the population of 60 million in the UK, non-White ethnic minorities accounted for $4.6 \mathrm{~m}$ or $8 \%$ of the population. Indian make up $2 \%$, and Chinese $0.4 \%$ of the total population (ONS 2005a). The pattern of primary and secondary migration patterns of $\mathrm{BI}$ and $\mathrm{BC}$ are described in this chapter. Some $\mathrm{BI}$ and $\mathrm{BC}$ are second and third generation and are the focus of this report. Secondary and tertiary education patterns and levels of attainment are analysed, highlighting the preference for certain subjects at undergraduate, masters and doctoral levels. Rates of selfemployment among $\mathrm{BI}$ and $\mathrm{BC}$ are examined, contrasting them with WB and with each other. Generational, gender and educational differences are highlighted in this chapter.

\section{$2.2 \quad$ Migration and settlement}

In the UK, Indians constitute the largest ethnic minority group while the Chinese are among the smaller groups. For the purposes of this report, among the UK domiciled, the first generation is defined as those over 16 who were born overseas and the second generation ${ }^{54}$ as those who were born in the UK or came to live here between the ages of 6-16 years (sometimes referred to as the 1.5 generation). There are more second generation Indians compared to Chinese in the UK: almost 1 in 2 Indian but 1 in 3 Chinese are born in the UK. Non-White ethnic minority groups are considerably more likely to live in England than the other countries of the UK. In 2001 they made up 9\% of the total population in England compared to only $2 \%$ in both Scotland and Wales and less than $1 \%$ in Northern Ireland (ONS 2005a). Four in ten Indians live in London, but there are also substantial populations in the West Midlands (17\%) and East Midlands (12\%). About a third of Chinese live in London, 14\% in the South East and 11\% in the North West (CRE 2007).

The Indian and Chinese populations are not homogeneous groups as there is considerable internal diversity among them. One characteristic of this diversity is migration background. The pattern of Indian and Chinese settlement in the UK reflects both primary and secondary migration, as well as independent and associational migration patterns. Indians and Chinese migrated to the UK in substantial numbers from around the 1950s. The majority came directly from India and Hong Kong respectively. Initial migration was of single males but later there was family migration. In the late 1960 s and 1970 s, a substantial number of Indians migrated from former British colonies in East Africa to UK (Owen 2003). Migrants from Africa are usually referred to as 'African Asian' of which over 9 in 10 are Indian (Modood 1997). The UK census category of Indian includes those who have come directly

\footnotetext{
${ }^{53}$ The National Employment Panel is an employer-led body that provides independent advice to Ministers on the design, delivery and performance of the UK Government's labour market policies and programmes.

${ }^{54}$ Some Indians and Chinese are third generation but numbers are small. The term second generation is used for convenience to cover second and subsequent generations.
} 
from India, or via Africa, or born in the UK. The vast majority of first generation Indians were employed in manual jobs, with a smaller proportion in white collar and professional work as well as self-employment (Smith 1974, 1976, Mascarenhas-Keyes 1977, Bachu 1985, Metcalf et al. 1996). Second generation Indian graduates engaged in entrepreneurial activities in this study are the children of the immigrants from India and Africa. For instance, the mother of Kumar (chapter 3, Case Study 12) came from Kenya while his father migrated directly from India.

Hong Kong was part of imperial China until 1842 when it came under British rule. The Chinese in the UK comprise those who have come directly from Hong Kong around the 1950s and also in the 1990s before its 'handover' from Britain to China in 1997. The children of Chinese civil servants in Hong Kong who were born there up to 1996 have the right to paid education in the UK. They usually attend independent schools with boarding facilities and after completing ' $A$ ' levels go to university in the UK. As some of their parents have domiciliary rights in the UK under the handover of Hong Kong agreement, they have purchased flats and houses in the UK in which they live for some time and where their children can spend their holidays. Their children are counted in HESA records as UK domiciled. The UK Chinese population also includes refugees from Vietnam in the 1970s (CRE 1983). Chinese from mainland China came to UK from around the late 1980s, with a few of them via Hong Kong. Chinese people have also migrated from Taiwan, Malaysia, Singapore and other South East Asian countries. Chinese of Hong Kong origin comprised the majority of Chinese in the UK in the 1980s (Shang 1988) and this still appears to be the case at present although there is a rising population from mainland China.

The majority of those in the UK from Hong Kong came from the New Territories, with only few from Hong Kong city and Kowloon. People from the New Territories were of rural backgrounds and less exposed to western culture. They were channelled into the family oriented catering trade in the UK, while the western educated from urban Hong Kong, normally professionals, joined the booming post-war British service industry (Watson 1975, 1977, Cheng 1994). Second generation BC students and graduates are mainly the children of Hong Kong Chinese as illustrated by the example of Tony (chapter 3, Case Study 26) whose parents ran a take-away business. The most common Chinese dialect spoken by Hong Kong Chinese in Britain is Cantonese while Chinese from mainland China speak Mandarin. Those who come from Malaysia and Singapore may speak a range of languages. For instance, Miriam from Malaysia, speaks Mandarin as she attended a Mandarin-medium primary school. She also speaks Cantonese and Hakka because her grandmother originated from Hong Kong. Her multi-linguistic repertoire also includes Malay and English.

UK domiciled Indian and Chinese also include those who have the rights to long term residence although they may not have citizenship. In most cases these $\mathrm{BI}$ and $\mathrm{BC}$ have come here as undergraduate or postgraduate students, sometimes as academic staff, and then remained in the country. Philip, mentioned in chapter 1 , exemplifies this. While some Indians and Chinese have been living in the UK on this basis for almost 20 years or so, others are more recent, the result of UK universities attempts to attract international students as mentioned in chapter 1.

\subsection{Educational attainment}

Most early primary migrants from India and Hong Kong were poorly educated but many secondary Indian migrants from Africa, Chinese migrants from Singapore and Malaysia, and recent primary migrants from mainland China are usually better educated. This section will explore the human capital development among the second generation looking at achievements at secondary and higher levels. 


\subsubsection{Secondary education attainment}

There are differences in the educational attainment of first and second generation ethnic minorities. The second generation (aged 25-44 year olds) who would have had all or the most part of their schooling in the UK, is much more qualified that the first generation: those with no or below $\mathrm{O}$ level qualifications have been halved; those with $\mathrm{O}$ level or equivalent qualification have nearly doubled and those with higher qualifications have grown by more than 50\% (Modood1997). Although there are graduates in both generations, among both male and female Indian and Chinese, there is a higher proportion in the second generation than in the first with degree qualifications (Modood 1997). The second generation have obtained these qualifications in the UK, while among the first generation many obtained their qualifications overseas particularly those who migrated after the age of 20 years. ${ }^{55}$

The increase in qualification levels among the younger population, which comprises second generation and also some third generation, is likely to be sustained or even increased if we look at secondary school attainment and post-compulsory education attendance levels. In the 2007 public examinations undertaken at the school leaving age of 16 , Chinese pupils were the most likely to achieve five or more GCSE grades $A^{*}-C$ in England: $85 \%$ of Chinese girls and $82 \%$ of Chinese boys. Indian pupils had the next highest achievement levels: $80 \%$ of Indian girls and $70 \%$ of Indian boys. The equivalent rates for WB are $64 \%$ for girls and and 55\% for boys (National Statistics 2007). In 2002, 9 in 10 Indian and Chinese ${ }^{56}$ aged 16 were in full-time education compared to 7 in 10 Whites (Bhattacharyya et al. 2003). This pattern of higher staying on rate after compulsory education echoes the findings of an earlier survey of ethnic minorities carried out in 1995 (Modood 1997). The higher retention in education continues among 18-24 year olds as the table below shows.

Table 1: Staying on rates in education among 18-24 year olds Indian, Chinese and White

\begin{tabular}{|c|c|c|}
\hline Ethnicity & Male students \% & Female students \% \\
\hline Indian & 38 & 33 \\
\hline Chinese $^{*}$ & 46 & 47 \\
\hline White & 15 & 15 \\
\hline
\end{tabular}

Source: Quarterly Labour Force Survey ${ }^{57}$

* includes Other Asian

The above table shows that both Indian and Chinese young second generation have a higher staying on rate than White with the Chinese having the highest staying on rate.

\subsubsection{Participation in Higher Education}

Given the greater retention in education post-16, it is not surprising that the Higher Education Initial Entry Rate (HEIPR) is higher for Indian and Chinese: Indian (71\%), and Chinese (49\%); ethnic minorities (56\%) and White (38\%). Levels of participation for female $\mathrm{BI}(72 \%)$ and $\mathrm{BC}(50 \%)$ are slightly higher than for male $\mathrm{BI}(70 \%)$ and $\mathrm{BC}(47 \%)$ (Connor et al. 2004). Given the higher attainment at secondary school and staying on rate, the HEIPR figures for the Chinese have to be treated with caution as they are likely to be an under-

\footnotetext{
${ }^{55}$ This applies even in the case of those who hold British qualifications as British educational provision was available in India, Africa and Hong Kong (Modood 1997). It is still possible at present to obtain a British degree in some overseas countries without ever having stepped foot into the UK.

56 In the analysis of the Youth Cohort study from which the evidence is drawn, the Indian category includes African Asians, and the Chinese includes Other Asian but not Pakistani and Bangladeshi.

${ }^{57}$ Taken from Leslie, D. \& Drinkwater, S (1999) and cited in Cabinet Office 2001.
} 
representation as a result of difficulties with data sources. ${ }^{58}$ Ethnic minorities represent a higher proportion of the graduate output compared to their share of the working population (Connor et al. 2004). However, the picture is not uniform across ethnic groups and the groups most likely to have degrees are Chinese (31\%), Indian (25\%) and this compares with $17 \%$ of WB people (ONS 2006). Furthermore, British ethnic minorities are proportionately more likely than WB to undertake additional study: BC $(27 \%)$ and $\mathrm{BI}(23 \%)$ compared to White $(17 \%)$ go on to further study or training after they have completed their full-time degree (Connor et al. 2004). The Labour Force Survey 2006 shows that almost similar proportions of non-White ethnic minorities $(29 \%)$ and White $(28 \%)$ have level $4-8$ qualifications. ${ }^{59}$ However, there is variation by ethnic group and, as the table below shows, a greater proportion of Chinese and Indian compared to White British have higher level qualifications.

Table 2: Higher Level Qualifications by ethnicity 2006

\begin{tabular}{|c|c|c|c|}
\hline Ethnic group & Level 4-6 \% & Level 7-8 \% & Level 4-8 \% \\
\hline Chinese & 31 & 19 & 50 \\
\hline Indian & 24 & 9 & 33 \\
\hline White British & 22 & 6 & 28 \\
\hline
\end{tabular}

Source: Labour Force Survey $2006^{60}$

Some indication of the size of the $\mathrm{BI}$ and $\mathrm{BC}$ population studying at these levels is given in the table below which also demonstrates the increase over six years not only for full-time students, but also part-time and mature students.

Table 3: British Indian and Chinese Enrolments by Level and Mode of Study at UK HEls 2000-2006

\begin{tabular}{|c|c|c|c|c|c|c|c|}
\hline \multirow{2}{*}{$\begin{array}{c}\text { Ethnic } \\
\text { group }\end{array}$} & \multirow{2}{*}{$\begin{array}{c}\text { Academic } \\
\text { year }\end{array}$} & \multicolumn{3}{|c|}{ Undergraduate } & \multicolumn{3}{c|}{ Postgraduate } \\
\cline { 3 - 8 } & & Full-time & Part-time & Mature & Full-time & Part-time & Mature \\
\hline \multirow{2}{*}{ Indian } & $\mathbf{2 0 0 0 / 0 1}$ & 39,800 & 5,250 & 17,450 & 2,595 & 3,730 & 4,025 \\
\cline { 2 - 8 } & $\mathbf{2 0 0 6 / 0 7}$ & 45,415 & 8,140 & 22,235 & 3,735 & 6,975 & 7,530 \\
\hline \multirow{2}{*}{ Chinese } & $\mathbf{2 0 0 0 / 0 1}$ & 9,385 & 1,545 & 4,845 & 1,255 & 1,260 & 1,660 \\
\cline { 2 - 8 } & $\mathbf{2 0 0 6 / 0 7}$ & 11,175 & 1,880 & 5,820 & 2,060 & 1,955 & 2,535 \\
\hline
\end{tabular}

Source: Higher Education Statistics Agency (HESA). ${ }^{61}$

Notes: Figures are based on a HESA standard registration population and have been rounded to the nearest five. Figures exclude the Open University.

Undergraduate mature students are aged 21 and over.

Postgraduate mature students are aged 25 and over.

\footnotetext{
${ }^{58}$ For an explanation see Connor et al. 2004.

${ }^{59}$ Level 4 - 8 qualifications are all higher education qualifications, with level 5 being a first degree and level 8 a doctorate.

${ }^{60}$ DIUS HE analysis team.

${ }^{61}$ DIUS HE analysis team.
} 


\subsubsection{Subject Choice}

There are variations in ethnic minority participation in HE by institution and subject. Ethnic minorities are concentrated in post-92 universities. They are also concentrated in a limited range of subjects. At undergraduate level, considerably higher representations of ethnic minority students at university are in medicine/dentistry, computer science and law (over 30 percent in each, double the average). Other subjects which have high concentrations of ethnic minorities are business and admin studies, engineering and technology, and mathematical sciences. This contrasts with under $10 \%$ in physical sciences, languages, art and design, humanities, education, veterinary science and agriculture (Connor et al. 2004).

Data analysed by Jones \& Elias (2005) gives a more detailed picture of participation in SET (science, engineering and technology) subjects and occupations. ${ }^{62}$ Data for 2002-3 shows that $8 \%$ of the Chinese population and $5 \%$ of the Indian population hold SET-related degrees compared to $3 \%$ of the White population. The detailed analysis of 2001-2 data shows the patterns of participation at undergraduate, masters and doctoral levels. Indian and Chinese, at undergraduate level, are over-represented compared to White, in SET subjects. Indian students make up 5.5\% of the student body taking SET degrees but only $2.5 \%$ of the Indian population aged $18-25$ years. For Chinese, they make up $1.5 \%$ of the student body taking SET degrees but only $0.7 \%$ of the Chinese population aged $18-25$. On the other hand, Whites are under-represented in SET. Thus they comprise $82 \%$ of the student body taking SET degrees but $88 \%$ of the population aged $18-25$ years. This picture is broadly the same at Masters Level with over-representation of Indian and Chinese students and under-representation of White students. However, the picture changes at doctoral level. Only the Chinese and White population are over-represented in SET subjects at doctoral level while Indians are not. It is not surprising, therefore, that Chinese people are seven times more prevalent among SET academic staff than would be expected based on working population data. In contrast, all other ethnic minority groups are under-represented, while the White population is represented among SET academics more or less in line with population numbers (Jones \& Elias 2005). Research funding data suggests that non-White ethnic minorities are biased towards engineering and technology and away from pure science. The Chinese are particularly successful in winning research funding in all areas, but particularly in engineering and technology (Jones \& Elias 2005). ${ }^{63}$

\subsubsection{Education values and occupational aspirations}

The high level of participation in HE reflects the fact that educational attainment is held in very high regard among $\mathrm{BI}$ and $\mathrm{BC}$, irrespective of socio-economic position. For instance, while $25 \%$ of accepted applicants from England to full-time degree courses in 2000 were Whites from lower socio-economic groups, it is $44 \%$ for Indian, $37 \%$ for Chinese and $40 \%$ for all ethnic minorities (Connor et al. 2003). BI and BC children are drawn not only from comprehensive schools, but a significant proportion have also secured places at the small number of grammar and independent schools which select children on the basis of prior academic attainment (Connor et al. 2003). Many parents will work hard to give their children the best educational chances possible. This is illustrated in the example of Gulab and Bindi, both of whom came from India as adults and only had a primary education. They ran a small grocery shop but sent their children to fee paying schools "to give them the best educational opportunities" and feel this has been rewarded as both the children obtained degrees and are in professional employment. Kim and Lee from Hong Kong, who run a small Chinese restaurant and have no qualifications, encouraged their children to study hard to enter university, and supplemented their local state education with private tuition. Their three children are all graduates.

\footnotetext{
${ }^{62}$ SET includes computer analysts and programmers, ICT, architects, town planners and surveyors (Elias \& Jones 2005).

${ }^{63}$ The data in Elias \& Jones 2005 for those with degrees is for UK domiciled. The data for masters and doctoral level, and for academic staff, appears to combine UK domiciled Chinese and overseas Chinese.
} 
Parental interest and pressures may continue even after children have reached the statutory age of independence at 18 and left home. BI Kumar (see chapter 3, Case Study 12) was studying for a degree in computer science and simultaneously running a successful part-time business which he had started when aged 17 years and further developed during his gap year. Having graduated with an upper second class degree at the age of 21, he said that at several times during his undergraduate years, he wanted to give up his studies as his business was doing well and he wanted to run it full-time. However, his parents kept up a relentless pressure on him to complete his studies, even though he lived in another city several miles away from home. He said his parents told him “... after you get your degree you can do whatever you want but you must get your degree first". The degree was seen as an insurance against the risk of entrepreneurship which Kumar now acknowledges.

Although frustrated at the time by his parents "interference in my life", he now appreciates their foresight and also feels the degree enhances his credentials which will benefit his business.

Research undertaken into the aspirations of BC youth in the 1980s showed that they disliked working in the catering industry where their parents ran restaurants and take-aways. They aspired to professional jobs, particularly in medicine, law and accountancy, and these aspirations were encouraged by parents (Chan 1986). ${ }^{64}$ A later study found that while there were $\mathrm{BC}$ still employed in the catering trade, among the young adults there was a greater diversification of occupations and sectors (Pang 1999). Such diversification is the result of the rise in human capital among second generation $\mathrm{BC}$ and the desire to achieve material success, job prestige and social status.

The next sections of this chapter examine various characteristics of self-employment among Indians and Chinese.

\section{$2.4 \quad$ Self-employment patterns}

To provide a context for examining entrepreneurship among $\mathrm{BI}$ and $\mathrm{BC}$ students, graduates and academics, it is useful to have a picture of some of the characteristics of selfemployment among the communities they come from. As noted in chapter 1, overall, in 2001, a greater proportion of Chinese and Indian compared to Whites were self-employed. Self-employment was highest among the Chinese: among males, it was $17 \%$ compared to $14 \%$ for Indians and $12 \%$ for Whites. For Chinese females, the self-employment rate was $9 \%$ compared to 5\% each for Indians and Whites (Mascarenhas-Keyes 2006). ${ }^{65}$ However, recent evidence suggests that the pattern of higher self-employment among Indians and Chinese compared to Whites has changed. In the Labour Force Survey 2007, BC now show no statistically significant difference and $\mathrm{BI}$ have a slightly lower rate than WB. ${ }^{66}$

A greater proportion of Indian and Chinese compared to WB are self employed with employees (Li 2006). The table below shows the distribution by size of workforce.

\footnotetext{
${ }^{64}$ Cited in Cheng 1994.

${ }^{65}$ Self-employment rate out of all economically active aged 16-74, England and Wales. The figure for Indian females is $5.2 \%$ and White females is $4.5 \%$.

${ }^{66}$ Analysis by BERR statistics team 2008. The Labour Force survey for 2007 shows that the rate for White British is $9.4 \%$, while that for Chinese is $8.3 \%$ and Indian $8.1 \%$. The pattern by gender is: for males WB $13.2 \%$, Indian $11.8 \%$ and Chinese $11.4 \%$. Among females the pattern is mixed: WB $5.2 \%$, Indian $3.9 \%$ and Chinese $5.6 \%$. Note that the data for the Labour Force Survey is for UK, and for the working age population i.e.16-65 for males and 16-59 for females. The census data is for England and Wales and all economically active aged 16-74. While there are differences in geographical and age coverage between the two sources, they are unlikely to have a significant impact on the patterns. Robust statistics are not available from the LFS for graduates and for different generations of Indian and Chinese hence census statistics are used in this chapter.
} 
Table 4: Indian, Chinese and WB businesses by number of employees 2003

\begin{tabular}{|c|c|c|c|}
\hline Ethnicity & Micros 1-9 \% & Small 10-49 \% & Medium 50-250 \% \\
\hline Indian & 87 & 11 & 2 \\
\hline Chinese & 95 & 4 & 3 \\
\hline White British & 82 & 15 & 1 \\
\hline
\end{tabular}

Source: Annual Small Business Survey 2003 Ethnic boost report

The above table shows that among businesses with employees, more Chinese (95\%) and Indian (87\%) compared to WB (82\%) businesses are micro businesses (1-9 employees) (DTI 2006d). ${ }^{67}$ On the other hand, while Chinese businesses are more likely than Indian businesses to be micros, Indian businesses are almost 3 times more likely (11\%) than Chinese businesses (4\%) to have 10-49 employees, and twice as likely $(2 \%)$ than Chinese businesses (1\%) to have 50-250 employees (DTI 2006d).

Another indicator of size of business is financial turnover. In the Annual Small Business Survey 2003 which had an ethnic minority boost, only half of Indian and Chinese businesses compared to a third of WB businesses disclosed their turnover so there is only a partial picture. This picture reveals that ethnic minority businesses as a whole (12\%) and Indian $(10 \%)$ and Chinese (11\%) businesses are more likely than WB businesses $(7 \%)$ to have turnovers of under $£ 56 \mathrm{k}$. Chinese businesses $(33 \%)$ are twice as likely as Indian businesses $(15 \%)$ and more likely than WB businesses (19\%) to have a turnover of $£ 56-250 \mathrm{k}$, but Indian businesses (20\%) are ten times more likely than Chinese businesses (2\%) but less than WB businesses (30\%) to have a turnover of $£ 259 \mathrm{k}-£ 1.5 \mathrm{~m}$ (DTI 2006d).

The comparatively greater proportion of larger businesses and higher turnover among Indian and WB businesses may be related to the age of the business and the sector. Chinese businesses (31\%) are more than twice as likely as Indian businesses (13\%) and WB businesses $(14 \%)$ to have been trading for three years or less. Two fifths of Chinese businesses compared to a half of Indian and two thirds of WB businesses have been trading for more than 10 years (DTI 2006d). If we look at industrial sector of business, in 2003, there was less diversification among Indian and Chinese businesses compared to WB (DTI 2006d). ${ }^{68}$ Almost all Chinese business were in the service sector, mainly restaurants and retail, compared to Indian (86\%) and WB (70\%). On the other hand, $17 \%$ of WB and $10 \%$ of Indian businesses were in the production sector, and $11 \%$ of WB and $4 \%$ Indian were in the construction sector. While $3 \%$ of WB businesses were in the primary sector, there was nil percentage of Indian or Chinese businesses in this sector (DTI 2006d).

Further evidence that the Chinese are more likely to have younger businesses is derived from the rate of engagement in early stage entrepreneurial activity. In the GEM surveys, the Total Early Stage Entrepreneurial Activity index (TEA) identifies the proportion of adults of

\footnotetext{
${ }^{67}$ ASBS 2003 ethnic boost report (DTI 2006d). The report does not have a category White British but uses the term 'non-ethnic minority'. However, as the overwhelming majority of the category 'non-ethnic minority' are White British, for convenience, this term is used.

${ }^{68}$ Primary sector (agriculture, hunting, forestry, fishing; production (mining and quarrying, manufacturing, electricity, gas and water supply; Construction; services (include retail, hotels and restaurants, transport and communication, financial services, business services, education, health and social work.
} 
working age who are either setting up or have been running a business for less than 42 months. By this measure, Chinese (7\%) are more likely than WB (5\%) and Indian (5\%) to be entrepreneurial. Moreover, a greater proportion of Chinese (9\%) and a similar proportion of WB, compared to Indian (6\%) expect to start a business in the next three years. However, compared to WB (48\%) and Indian (46\%), Chinese (41\%) are least likely to think that they have the skills to start a business. They are also most likely (43\% compared to $36 \%$ WB and $34 \%$ Indian) to be deterred from starting a business because of a fear of failure (Harding 2006).

Having looked at some overall features of Indian and Chinese businesses, as this study is focused on the second generation, I now briefly explore the pattern of self-employment across the first and second generation.

\subsection{Self-employment among first and second generation Indian and Chinese}

In the following table, the pattern of self-employment between the first and second generation is compared. The table also highlights the differences between males and females. Furthermore, the table also disaggregates the self-employment rate in terms of businesses with and without employees.

Table 5: Inter-generation comparison of the rate of self-employment among Indian and Chinese in Great Britain in 2001

\begin{tabular}{|l|l|l|l|l|}
\hline Generation & Ethnic group & $\begin{array}{l}\text { SE with } \\
\text { employees \% }\end{array}$ & $\begin{array}{l}\text { SE no } \\
\text { employees \% }\end{array}$ & $\begin{array}{l}\text { Total self } \\
\text { employed \% }\end{array}$ \\
\hline \multicolumn{5}{|c|}{ Men } \\
\hline \multirow{2}{*}{ First generation } & Indian & 11 & 9 & 20 \\
\cline { 2 - 5 } & Chinese & 18 & 8 & 26 \\
\hline \multirow{2}{S}{$\begin{array}{l}\text { Second } \\
\text { generation }\end{array}$} & Indian & 5 & 6 & 11 \\
\hline \multicolumn{5}{|l|}{ Women } \\
\hline \multirow{2}{*}{ First generation } & Chinese & 7 & 5 & 12 \\
\hline \multirow{2}{*}{$\begin{array}{l}\text { Second } \\
\text { generation }\end{array}$} & Indian & 4 & 4 & 13 \\
\cline { 2 - 5 } & Chinese & 8 & 5 & 4 \\
\cline { 2 - 5 }
\end{tabular}

Source: The $20013 \%$ SAR (Samples of Anonymised Records from the 2001 Census)

Men aged 20-64 and women aged 20-59

Li 2007: personal communication

From the above table we can see that for both generations, from a gender perspective, for both Indian and Chinese, women are less likely to be in self-employment than men. From a generation perspective, for both Indian and Chinese, there has been a decline in selfemployment among the second generation, and for men as well as women. The decline is most evident among the self employed with employees. Comparing Indian and Chinese, in each generation for both men and women, Chinese have an overall higher self-employment rate than Indian and this is particularly the case among the self employed with employees. However, if we look at the magnitude of decline from first to second generation, the decline has been greater among the Chinese than the Indian second generation.

The above analysis, however, does not control for age. As has been found in the general population, many people start a business after a period of employment, even those under 30 years old (Botham 2004). Thus, it is possible that the decline in self-employment among the second generation may be a temporary phase as future self-employment may be preceded by a period of employment. Hence, as the second generation get older, their profile may 
change. There is a general pattern, however, among South Asians but particularly in the case of Indians, to retreat from self-employment in more recent years (Jones \& Ram 2003).

The second generation is better educated than the first generation. As noted in chapter 1 , there is a link between education and self-employment with those with higher qualifications more likely to be involved in early stage entrepreneurial activity. The next section explores this.

\subsection{Self-employment and Education}

GEM 2006 shows that for the UK, total entrepreneurial activity (TEA) increases with qualifications (Harding 2006). As we saw earlier in this chapter, a higher proportion of $\mathrm{BI}$ and $B C$ compared to WB have degrees. Furthermore, as noted earlier, they are also more likely to participate in postgraduate study, and BC are more likely than $\mathrm{BI}$ to undertake doctoral study. Inter-generational data on Indian and Chinese who are self-employed shows that a substantial proportion in both generations has degrees.

Table 6: Proportion of self-employed Indian and Chinese in first and second generation who have degrees in Great Britain in 2001

\begin{tabular}{|l|c|c|c|c|}
\hline Generation & \multicolumn{2}{|c|}{ Indian } & \multicolumn{2}{c|}{ Chinese } \\
\hline & Male \% & Female \% & Male \% & Female \% \\
\hline First generation & 39 & 36 & 24 & 21 \\
\hline Second generation & 40 & 44 & 47 & 24 \\
\hline
\end{tabular}

Source: The 2001 3\% SAR (Samples of Anonymised Records from the 2001 Census) Men aged 20-64 and women aged 20-59 Li 2007: personal communication

The above table shows that among those who are self-employed in each generation, for both Indian and Chinese, a greater proportion in the second generation have degrees compared to the first generation. While in the first generation a greater proportion of Indian males compared to Chinese males have a degree, in the second generation this pattern is reversed. A higher proportion of self-employed Indian females compared to Chinese females in both generations have a degree.

Although a substantial proportion of the self-employed in both generations have degrees, there is a question about the quality of the businesses that they run. For instance, a survey of South Asians self-employed in 1995, the vast majority of whom were first generation, indicated that $15 \%$ of Indian and $28 \%$ of African Asians had a degree (Metcalf et al. 1996). ${ }^{69}$ Yet, a very small proportion of Indians (3\% of African Asians and $0 \%$ Indians) had a professional business, (e.g. dentist, accountant) for which a degree is a prerequisite. The overwhelming majority of businesses were largely in retail (grocery/off licence, newsagents, clothes retailer), restaurants, artisan-based services (e.g. carpentry, car repair, building) and clothing manufacture, for which a degree level qualification is not a prerequisite (Metcalf et al. 1996). This pattern of entrepreneurship in which degree level skills are not being used directly in the type of business set up is also found among other new migrants groups. For instance, a recent study of Somali entrepreneurs in England found graduates running low grade businesses (Ram \& Theodorakopoulos 2007).

\footnotetext{
${ }^{69}$ This study did not include Chinese. For South Asians, a distinction was made between those who migrated directly from India and those of Asian origin who migrated from Africa, the latter called African Asians. The majority of African Asians are of Indian origin.
} 
A comparison of self-employment rates of graduate WB, Indian and Chinese with the selfemployment rate of the total population of these three groups reveals interesting patterns by gender and ethnicity.

Table 7: Rate of self-employment by ethnicity and gender among graduates and total population in Great Britain in 2001

\begin{tabular}{|c|c|c|c|c|c|c|}
\hline Ethnicity & \multicolumn{2}{|c|}{ Total population } & \multicolumn{2}{c|}{ All Graduates } & \multicolumn{2}{c|}{ UK born Graduates } \\
\hline & Males & Females & Males & Females & Males & Females \\
\hline $\begin{array}{c}\text { White } \\
\text { British }\end{array}$ & 14.5 & 5.4 & 13.3 & 7.0 & 13.2 & 7.0 \\
\hline Indian & 18.1 & 7.2 & 17.4 & 7.9 & 11.5 & 4.6 \\
\hline Chinese & 24.8 & 13.1 & 14.5 & 6.5 & 10.3 & 4.1 \\
\hline
\end{tabular}

Source: 3\% SAR from census 2001; Men aged 20-64 and women aged 20-59

Li 2008: personal communication

The above table shows that overall in 2001 the self-employment rate among Indian and Chinese males and females is higher than for all WB male and female and this pattern is maintained among all graduate Indian and Chinese males and all graduate Indian females. However, it is only all graduate Chinese females who are lower than WB females. However, for UK born graduates, it is both Indian and Chinese male and female graduates who have a lower self-employment rate than WB male and female graduates. Furthermore, while it is only the self-employment rate for UK born WB graduate males that is lower than for all WB, in the case of Indian and Chinese UK born graduates, it is both male and female graduates who have a lower self-employment rate than all Indian and Chinese, and all graduate Indian and Chinese. This last finding concurs with the finding noted earlier that self-employment in the second generation Indian and Chinese is much lower than that for the first generation. It also supports the pattern found in the Labour Force Survey 2007 that there has been a decline in the overall self-employment rate of Indians and Chinese such that BC show no statistically significant difference and that BI have a slightly lower rate than WB. Further research is necessary to ascertain why this is the case but it is likely that the second generation graduates are exposed to different opportunity structures and are able to take up graduate level paid employment and, therefore, prefer this option to self-employment.

This pattern of self-employment among graduates cited above was evident in 2001 and whether it still persists at present is a matter for further research. Some indication of future trends is evident from small scale surveys of entrepreneurial intentions of students in a few universities in one English region from 2003 to 2006 (Robertson, Price \& Wilkinson 2004, Wilkinson 2005, Robertson \& Wilkinson 2006). These suggest that non-White students, including $\mathrm{BI}$ and $\mathrm{BC}$, have a more positive attitude to entrepreneurship than their White counterparts; that a higher proportion of non-Whites compared to White students intend to become self-employed after graduation; and a higher proportion of non-White students than White students were currently self-employed. As the surveys included both UK domiciled and international students, the findings should be regarded as indicative only of the intentions and activities of UK domiciled students. Further research is necessary to assess the extent to which these findings are representative of non-White, including $\mathrm{BI}$ and $\mathrm{BC}$ students, at all British universities but they can be regarded as indicative of possible future trends.

\subsection{Conclusion}

This chapter has noted that in the decade between 1999 and 2009, it is estimated that ethnic minorities, including $\mathrm{BI}$ and $\mathrm{BC}$, will account for half the growth in the working-age population. This chapter has traced the migration and settlement pattern of $\mathrm{BI}$ and $\mathrm{BC}$. It highlighted the value placed on education in these communities, the high secondary school 
attainment by $\mathrm{BI}$ and $\mathrm{BC}$, both male and female, and the resultant higher participation in higher education up to postgraduate level. While there is take-up across the whole crosssection of subjects offered by $\mathrm{HEls}, \mathrm{BI}$ and $\mathrm{BC}$ are concentrated in a narrow range of subjects, particularly medicine, science and technology, engineering, mathematics, business studies and law. With regard to SET subjects, a greater proportion of the $\mathrm{BI}$ and BC population compared to the White population have SET-related degrees. While this pattern is mirrored at masters' level, it is the Chinese, and to a lesser extent, Whites, who are overrepresented at doctoral level. The Chinese are also more prevalent among SET academic staff. $^{70}$

Self employment rates vary by education, gender and generation. Overall self-employment rates according to the 2001 census for both Indian and Chinese were higher than WB. However, the rate among $\mathrm{BI}$ and $\mathrm{BC}$ was lower in the second generation compared to the first generation. Furthermore, in 2001 among UK born graduates the rate among $\mathrm{BI}$ and BC was lower than it was for WB graduates. Evidence from the Labour Force Survey for 2007 has shown that the pattern of decline in self employment rates is now evident in the total $\mathrm{BI}$ and $\mathrm{BC}$ population. Rates of self-employment do not tell us about the quality of businesses. First generation $\mathrm{BI}$ and $\mathrm{BC}$, including many graduates, generally run low-value added businesses such as corner shops, newsagents, take-aways and restaurants. However, while there is no robust national quantitative data on the quality of self-employment among second generation $\mathrm{BI}$ and $\mathrm{BC}$ student, graduates and academics, this report provides qualitative data on their knowledge-based entrepreneurial activities in a wide range of sectors. The high level of skills of the BI and BC graduates, particularly in SET subjects, equips them with disciplinary knowledge to engage in knowledge-based entrepreneurial and intrapreneurial activities. SET based innovation has been strongly promoted by the British Government and a comparatively high proportion of BI and BC, epitomised by Satinder and Philip referred to in chapter 1 , have the skills to contribute to this driver of productivity. This is in terms of licensing, start-ups and growing the business, the last contributing to business innovation, one of the enablers of enterprise identified by the 2008 Enterprise Strategy Paper.

The next chapter describes the research methods used to obtain qualitative data to illustrate this. A range of entrepreneurial activities engaged in by $\mathrm{BI}$ and $\mathrm{BC}$, as well as WB, students, graduates and academics are described in the next chapter, chapter 3 , and the motivations to entrepreneurship and different characteristics of the businesses are analysed in subsequent chapters.

${ }^{70}$ The secondary data available combines UK domiciled Chinese and overseas Chinese. 


\section{CHAPTER 3: RESEARCH METHODS}

\subsection{Introduction}

This chapter focuses predominantly on the range of qualitative methods used in this research. Qualitative research has been undertaken in England, supplemented by a two week field trip to mainland China and Hong Kong. Although originally there were plans to undertake research in India as well, resource constraints precluded this. One hundred and fifty formal interviews have been undertaken with: BI, BC and WB as well as overseas Chinese students, graduates and academics involved in entrepreneurial activities; a crosssection of local, regional, national and China-based British Government officials; intermediary organisations and university staff. As there is no sampling frame, individuals have been randomly selected for semi-structured interviews by multiple chain referral sampling techniques. ${ }^{71}$ This approach is a more sophisticated form of the snowballing technique as multiple networks are used to generate the sample as discussed below. There are 33 case studies which form the core entrepreneurial activities on which this report is based. From the case studies, 15 graduate entrepreneurs who had already been interviewed were sent a brief self-completion questionnaire seeking quantitative data. Complementing formal interviews, social anthropological research techniques of participant observation, informal interviews, and reflexivity have been used to generate issues for discussion in formal interviews, and to test out more widely themes identified in formal interviews. Details of these methods are provided below.

\subsection{Multiple chain referral sampling}

The methods used to identify the different categories of the sample are discussed below. This is not a comprehensive account of how everyone in the sample was obtained but is illustrative of the techniques used. Mobilising networks and credible contacts was crucially important for research in China and among the Chinese where quanxi (networks) and trust are crucial to inter-personal relationships.

British Indian and British Chinese: As noted in chapter 1, the focus of this research is on UK domiciled Indian and Chinese, referred to as $\mathrm{BI}$ and $\mathrm{BC}$. Referrals were made by a range of different people (university staff, government officials, various agencies and personal contacts). Often those making the referrals for interview were unsure whether the person they referred was British born or had UK citizenship or domiciliary rights. This was particularly the case with the Chinese. British passports facilitate foreign travel - as one Chinese academic said "I have got a British passport because I travel a lot in my work and it makes it easier". Questions about nationality and citizenship status can be sensitive so diplomatic approaches were used to ascertain this. Formal interviews in England were restricted to those Indian and Chinese who were UK domiciled. ${ }^{72}$ Most respondents were UK born but some were overseas born but had acquired domiciliary rights. In most cases $\mathrm{BI}$ and $\mathrm{BC}$ had British citizenship.

Events attended by Indian and Chinese were also a source for identifying respondents. A large conference in June 2007 organised by the Indo-British Partnership Network which was

\footnotetext{
${ }_{71}^{71}$ In entrepreneurship and employment research this technique has been used for example by Ram et al. (2007).

72 On 20 February 2008 the Home Office Border and Immigration Agency published the Government's Green Paper. In this document it outlined proposals for changing the way that someone can become a British citizen or remain here as a permanent resident. Notwithstanding all these potential changes and the introduction of new terminology, the term 'UK domiciled' is used in this report to refer to those who are British citizen as well as those who are citizens of another country but have acquired rights to long term residence in the UK. It does not refer to those who have temporary student or work visas.
} 
attended by Indians from UK and India, as well as WB, helped to identify graduate Bls who had first set up their business in India. Attendance at events organised by The Indus Entrepreneur (TiE), a global entrepreneur network, provided opportunities to identify more graduate Bls and BC.

Students: Attendance at student business competitions at three universities provided opportunities to identify students for the sample. In addition, a cross-section of students from a range of universities who were on the SPEED programme had exhibition stalls at the Festival of Innovation in Birmingham in November 2007. A number were interviewed at the event.

Academic researchers: Attendance at research conferences, including those organised by Chinese scholars associations, provided opportunities to identify appropriate people for interview.

University staff: Key people in charge of specific programmes were identified for interview.

Intermediary organisations: Contacts were gained through a university department which has a long history of working with such organisations, supplemented by other referrals.

Government officials: As a Government social researcher, I had easy access to staff at different levels of seniority in a cross-section of Government departments both in the UK and overseas.

\subsection{Formal Interviews}

A total of 150 interviews were undertaken and 123 interviews were conducted in England as follows:

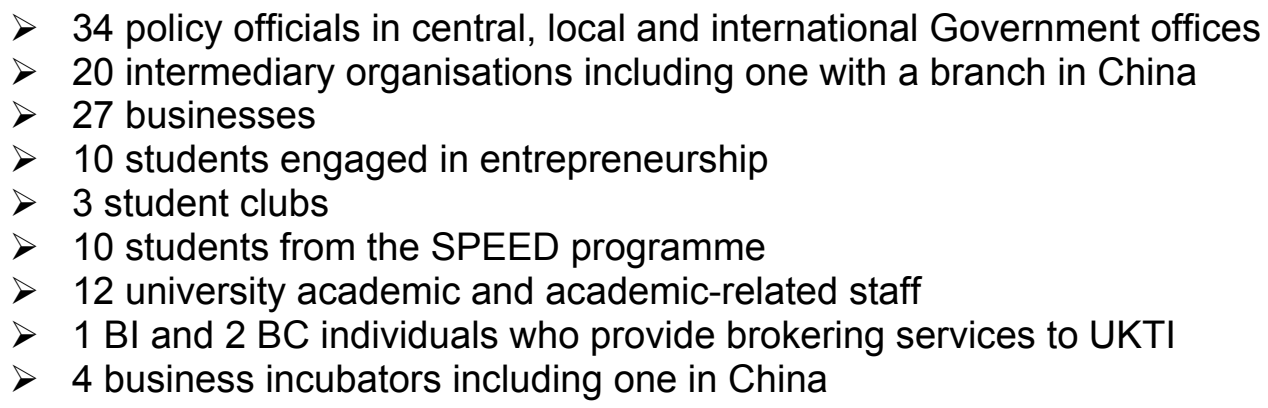

One overseas field trip lasting fifteen days was undertaken in China. This field trip covered the cities of Shanghai, Beijing, Shenzhen and Hong Kong. Twenty nine formal interviews were held with: 11 British Government officials, 9 businesses, 5 support agencies and 4 Chinese academics/professionals.

\subsection{Conducting formal interviews}

The formal interviews in the UK and China followed topic guides and the interviews were usually tape recorded, apart from those held in China where I felt it was not appropriate to record the interviews as it made respondents uncomfortable. This discomfort was apparent to some extent when interviewing Chinese overseas but it was also evident when the subject of recording was broached among WB living in China. For instance, a senior WB official working for the British Government was extremely reluctant to be tape recorded and said "I shall now have to be careful what I say". Consequently no tape recordings of interviews 
were undertaken in China although notes were made during the interviews and transcribed later. ${ }^{73}$

\subsection{Informal Interviews}

Complementing the formal interviews in the UK and China were a range of informal techniques for gathering data. In China, informal 'interviews' were held with 8 businesses, 30 Chinese/Indian/UK academics, 4 UK university careers staff, HR staff of 12 national and multi-national companies, 20 UK university alumni and 12 Chinese university students. A large number of informal interviews were also conducted in the UK. These interviews were undertaken at various events where there was a large gathering of people, such as conferences. On these occasions, individuals and occasionally pairs or threesomes, would be informally interviewed as part of a conversation. A topic guide of questions would be prepared in advance, remembered mentally, and the questions introduced into the conversations at appropriate times. To illustrate this technique, a couple of examples may be cited. First, while attending a Life Sciences conference organised by a Chinese scholars and students association in England, during periods available for networking, such as tea, lunch and dinner breaks, informal interviews were conducted. Another event attended was a 'milk round' in Hong Kong for alumni from British universities. This event provided the opportunity not only to talk to almost two dozen Chinese alumni but also to representatives from about a dozen multinational companies (including British companies) seeking to recruit UK educated Chinese graduates. The careers guidance staff from four elite UK universities who had travelled overseas to host the event were also informally interviewed at the event. Organisers of events were usually informed in advance that I was undertaking research.

\subsection{Informal focus groups}

Informal focus groups were held whenever opportunities arose when a group of people were gathered together. The most frequent opportunities were provided when small groups of people at conferences and other related events were sitting round a table having coffee/lunch/dinner. One or two issues for discussion were introduced as part of the general conversation of the group.

\subsection{Attendance at Events}

A number of conferences and workshops were attended to gather information and exchange views. These included the launch of the ICUK project, conferences on the knowledge economy and innovation organised by the World Bank as well as UKBI, and an OECD conference on Asian entrepreneurship in Shanghai. Attendance at various professional and community events provided opportunities not only to expand my substantive knowledge of topics but also to meet a cross-section of people and to observe behaviour. For instance, attendance at two science conference of Chinese students and scholars in England provided opportunities to observe group dynamics, the use of English, Mandarin and Cantonese languages, and to develop general cultural awareness. I was also able to attend a Business to Business event in China as part of a conference on Asian entrepreneurship. The audience for this event included British and European business angels, venture capitalists, business consultants and academics. Some businesses in the university incubator gave presentations on their business at the event.

\footnotetext{
${ }^{73}$ Notes were made using Pitmans shorthand.
} 


\subsection{Self as Informant}

The technique of Self as Informant (Mascarenhas-Keyes 1987) was also used whereby my reactions to field situations were noted as were those of respondents to me. I recorded 40 incidents of knowledge transfer during the course of the research. Throughout the research, largely because I was a government official, I was often asked by interviewees and other people I met at conferences and various events for information about government policies and thoughts on various issues, as well as access to contacts in government. In some cases the knowledge transfer was initiated by me when it was obvious that sharing knowledge would benefit the recipient. All these incidents of knowledge transfer were systematically recorded, analysed and the insights drawn from them are used in this report. In engaging in such minutiae of informal knowledge transfer, it was crucially important to maintain professional integrity, protect the confidentiality of sources and obtain informed consent where required. In some cases, the names of individuals and information were in the public domain and it was a question of pointing people in the right direction. All these examples of knowledge transfer made it evident where there were market failures of information and networks and the insights gleaned from these are used in this report. Some examples of knowledge transfer are highlighted in the footnotes.

\subsection{Value of informal techniques}

The above informal techniques are an adaptation of ethnographic methods of participant observation and reflexivity and are derived from training and experience as a social anthropologist (Mascarenhas-Keyes 1987). While conventionally, participant observation is conducted over a long period of time, its succinct use in the ways described above, can allow a trained and experienced researcher to capitalise on the opportunity to meet a large number of people in a short space of time and to glean information that would take longer and be more expensive to obtain. Good networking, interpersonal skills and memory are critical to success, as is the discipline of making notes privately as soon as it is possible, so as to capture vital information. Such information can indicate dynamics, patterns and themes that can then be explored more systematically in formal interviews. Conversely, a pattern or theme identified in a formal interview or through other sources, can be tested out with a greater cross-section of people through informal means.

As the analysis is based on the triangulation of data from a variety of sources, data gained through informal techniques is triangulated with that obtained from formal interviews, quantitative data sources, documentary analysis and literature reviews. This adds to the richness and depth of data obtained. Data gained in this informal way is weaved into the analysis and used to highlight multiple patterns, themes and issues.

\subsection{Case Studies}

This section provides information on the criteria used to select the case studies followed by pen portraits of the 33 core case studies used in this report.

\subsubsection{Selection criteria}

In selecting the case studies, the factors taken into account are described below with the results obtained.

Cross-section of entrepreneurial activities: undertaken by students, by graduates and by academics to gain insights into a range of entrepreneurial activities. Student entrepreneurship covers entrepreneurial activities that students engage in while on undergraduate and taught masters programmes. They can be part of the degree programmes, or external to it. There are 7 case studies of students, which include 4 which 
comprise groups of students. Graduate entrepreneurs (21) are those who have left university and set up their business either immediately after graduating or some time later. The entrepreneurship activities of academics (4) include those of existing academics or research postgraduate students or those with doctorates who worked as academics and then left the university to set up a business.

Diversity of ethnic and national backgrounds: to enable comparisons to be drawn: 9 British Indian, 8 British Chinese, 6 White British, 4 overseas Chinese, 1 overseas Indian, 4 groups of students, 2 of which are a mixture of UK domiciled and international students and 2 which comprises solely of international students.

National and existing or potential international activities: to allow issues generic to all entrepreneurial activities and those specific to international ones to be identified. The case studies selected include businesses that are national (8), born global (11), become global (4) and thinking of becoming global (11). Some overseas businesses in China (3) with links or anticipated links with UK, including 2 run by alumni from British universities were also selected as was a multi-national with headquarters in India and branches in China and UK. Also included is an example of a Chinese academic running a joint laboratory with a BC in UK. One UK-India business is also included.

Range of sectors: The case studies selected are categorised as follows: science based (5), engineering (5), computer services (8), professional services (10) and creative industries (5).

Range of ownership patterns: Existing family business (1), new family business (2), sole trader (7), Partners (1), international joint venture (4), wholly foreign owned enterprise (7), patent holder/licensor (4), foreign business (4), potential businesses (3).

Gender: The case studies comprise 27 males and 10 females. This reflects research evidence that shows a higher rate of entrepreneurship of graduate males compared to females (Harding 2007).

Wide age range: The case studies comprise: equal to or less than 20 years old (3); $20-30$ years old (13); 30-40 years old (7); 40-50 years old (7) and 50+ (3).

Regional spread: In England: North East (3), North West (2), Yorkshire \& Humber (3); East Midlands (5), West Midlands (2), East of England (2), London (3), South East (2), South West (2). British citizens who established the business overseas first: in India (2), in USA (1), in China (1). Chinese nationals located in China (3), Indian multi-national business located in India, China and UK (1) and joint BI and Indian national (1).

\subsubsection{Profile of case studies}

Brief profiles of the case studies are provided below. A brief questionnaire survey was used to collect quantitative data from some $\mathrm{BI}, \mathrm{BC}$ and WB businesses who had already been interviewed for the research and some of the data is included in the relevant case studies below. It covered age of owner, age of the business, level of start up finance, source of finance, turnover and growth aspirations. The questions used were either the same or slightly modified ones as those asked in the Annual Small Business Survey 2005 conducted by BERR. The questionnaire was sent to 15 entrepreneurs and 14 responded. The data obtained is incorporated into the profile of relevant case studies.

Each case study has a number so that it can be identified throughout the report when reference is made to it. The names of all individuals and universities have been changed to protect confidentiality. Furthermore, as some of the information is commercially sensitive, specific details have been changed while still retaining key characteristics of the profile of the entrepreneurship activity. 


\subsubsection{Science-based}

Case Study 1: Satinder and Sunita, a married second generation BI couple are in their late twenties. Their 5 year old health care business provides both conventional and complementary medical products and services. It has a turnover of between $£ 250,000$ $£ 499,999.74$ They employ 15 staff, 2 of whom work overseas, and 13 in the UK. Their parents were first generation immigrants from India. Satinder's parents ran a corner shop and Sunita's parents a newsagents and post office. Satinder graduated in Pharmacy from Leeds University and is completing a doctorate at Warwick University focussing on the demand for, and value of, a holistic approach to healthcare. Sunita graduated in sociology from Leeds University. They are planning to expand in the UK and are also currently exploring setting up franchises in India, Dubai and USA.

Case Study 2: Philip is in the 40-50 year old age group. He is first generation BC from mainland China who came to UK to do his Ph.D in the Life Sciences twenty years ago. He works at a British university where he runs a laboratory with 15 staff and research students. He has invented a medical device which provides early diagnosis of a fatal disease and he has a patent for this. He plans to undertake clinical trials in either China or India and manufacture the device in China. He plans to either start a spin off company in the UK or overseas or licence the device to a multinational company. He is exploring various options with his university's technology transfer office.

Case Study 3: Suresh, a first generation BI in the 40-50 year old group, runs his own chemistry-based business. He came to Britain directly from India to undertake postgraduate studies. After completing his doctorate, he moved to another university to take up a lectureship and continue with postdoctoral research in chemistry. After several years, he relocated again and now works as an associate lecturer at a university in North England, delivering a few lectures a year. When he moved to the north, he opened up a chemistry based business. He has a staff team of four scientists, one of whom is British Indian. He does chemistry based research for a large number of clients who do not have their own R\&D capability or if they have such capability, outsource work to him because it is too specialised for them to do it or they are short of staff resources. He has started exploring the possibility of opening a branch of his business in India or establishing a joint laboratory with academic entrepreneurs in India or with a university.

Case Study 4: A group of four international postgraduate students in the 20-30 age group, on a Bioscience and Enterprise masters degree comprising: Chandra, an overseas male Indian post-doctoral researcher from Thailand; Anwar, an overseas male Indian doctor from South Africa; Leela, an overseas female Indian engineer from USA and Christof, a Polish male engineer. They plan to extract polymers from food waste which can then be used for multiple purposes, including in the development of pharmaceutical products. They had won a student business plan competition and were keen to set up an international business but were unsure about next steps. They had not heard of Business Link or of UKTI's business support programmes or of their international trade advisers.

\subsubsection{Engineering}

Case Study 5: Andrew, a first generation BC professor of software engineering in the age group 40-45 years, has been working in a computing department for many years as a software engineer. During this time, he has developed many software products, which have

\footnotetext{
${ }^{74}$ Turnover figures use the range provided in the survey questionnaire, which was based on that used in the Annual Small business Survey 2005 (DTI 2006e). The categories were: Less than $£ 64,000 ; £ 65,000-£ 99,000$; $£ 100,000$ - £249,999; £250,000 - £499,999; £500,000 - £999,999; £1m - £1.49m; £1.5m - £2.8m; More than $£ 2.8 \mathrm{~m}$; Don't know. Note $£ 64,000$ is the VAT threshold level.
} 
been commercialised through licensing arrangements organised through his university's technology transfer office.

Case Study 6: Lincoln, Morley, and Norman are WB males, and Ashok is an overseas Indian student. They are all 20 years old and studying for an undergraduate degree in automobile engineering. They have set up jointly a bio-ethanol business and to exemplify their business idea have converted a standard racing car to run on bio- ethanol. With the help of Ashok's social networks, they intend to promote their business in India.

Case Study 7: Matthew, a WB male in over 55 years old and has a Higher National Diploma (HND) in Engineering. He runs a business providing products and services that reduce environmental pollution. He has been trading for $20+$ years and recently decided to set up a wholly owned enterprise in China and bought a former state owned enterprise. He employs 45 staff in the UK and 65 overseas. His turnover is more than $£ 2.8$ million.

Case Study 8: A group of four undergraduate students aged around 20 years old on an engineering course comprised Arun, a BI male, Avinash, an overseas Indian male, Gerard, a WB male and Elizabeth, a WB female. The students have developed a prototype of their innovative product, a patent has been applied for, a UK market has been identified, and the potential for obtaining and assembling the technology components from overseas is being explored.

Case Study 9: Patrick is a first generation BC in the 35-39 age group and has a degree in engineering from Durham University. He has been trading for around 15 years in the production of automotive components. His company is based in China, but he has offices in England, USA and Japan. He has 13,000 staff, 4 of whom are based in the UK. His turnover is more than $£ 2.8$ million.

\subsubsection{Computer Services}

Case Study 10: Jay is a second generation $\mathrm{BI}$ graduate in Law and Raj is a second generation $\mathrm{BI}$ graduate in Politics, Philosophy and Economics, both from Oxford Unviersity. They are in the age group 20-24 years old. They ran an internet based social enterprise while students and a year ago set up an e-commerce business in Silicon Valley, USA. They employ 4 staff in the USA and their turnover is less than $£ 64,000$.

Case Study 11: Hugh is a 20 year old WB male student reading for a degree in web design. $\mathrm{He}$ has a web-based business which initially operated as a social enterprise but he subsequently went commercial. He creates websites and also uses on-line maps to plan routes for hikers.

Case Study 12: Kumar is in the 20-24 age group and a second generation BI graduate in computer studies from Bradford University. His business is 4 years old and he started his computer hardware engineering business when he was 17 years old and continued throughout his university studies on a part-time basis. He now runs the business full-time. He employs 14 staff all UK based. He has a turnover between $£ 100,000-£ 249,000$.

Case Study 13: Kenneth is in the 30-35 age group and is first generation BC from mainland China who graduated in computer science from Sheffield University having initially started a science degree at Oxford University. While an undergraduate, he was actively involved in the student enterprise club. He is employed as a management consultant but has developed a portfolio of businesses. This includes a two year old international telecommunications business which helps mobile data services and network operators generate revenues by enabling applications and devices to authenticate seamlessly across the wireless broadband network. He has a turnover of between $£ 100,000-£ 249,999$ and employs 14 staff, 12 of whom are based in China. Charles, his Chinese business partner and CEO of the China office, holds a degree in Arabic and an MBA from Beijing University. 
Case Study 14: John is a second generation BC in the 40-44 year old age group and his international business is a year old. He graduated in computer studies from Birmingham University. His company provides software solutions and consultancy. He employs 30 staff, 5 of whom work overseas. His turnover is less than $£ 64,000$ but this is expected to rise as he is developing new products and markets.

\subsubsection{Professional Services}

Case Study 15: Michael is first generation BC in the 45-49 year age group. He has a doctorate in science from a British university. His international business has been trading for 6-10 years and provides a range of consultancy services including advisory services to Chinese parents who want to educate their children abroad. More recently, he has expanded his business to provide business advice to scientists from UK and China who want to set up an international business. His turnover is between $£ 55,000-£ 99,000$. He has offices in the UK and China, with 15 staff working in China and 5 in the UK.

Case Study 16: Clinton is a 21 year old WB male who graduated in Business and IT. He has set up a business while a student which is providing furniture and furnishings for students from all over the UK, particularly those coming from overseas. He takes orders from the students while they are overseas and delivers to their UK address when they arrive.

Case Study 17: Alcar is a second generation $\mathrm{BI}$ graduate in accountancy from London Metropolitan University and is in the 35-39 age group. She set up with her husband an accountancy educational materials business in India two years ago and recently established a UK office. She employs 43 staff, 40 of whom work in India and 3 in the UK. Her turnover is between $£ 100,000-£ 249,000$.

Case Study 18: David, a 24 year old second generation BC graduate from London University, runs a media business with 3 WB partners. He manages the China base of the business while his partners run the UK base. His parents originated from Hong Kong. $\mathrm{He}$ originally planned to set up the business in Hong Kong but found there were better commercial opportunities in mainland China.

Case Study 19: Sunil is a second generation $\mathrm{BI}$ in the $50-54$ age group. He is a graduate of accountancy and worked for several years as an accountant before he set up his own practice with his WB wife which has been trading for 6-10 years. He employs 4 staff and has a turnover of between $£ 250,000-£ 499,000$. He is seeking to grow by expanding into overseas markets.

Case Study 20: Carla is a WB woman in the 45-49 age group and is a graduate in Business Studies. She has set up a joint venture with Henry, who is in his late 50 s, and is a Chinese portfolio entrepreneur living in Hong Kong. She has been trading for 4 years and has a turnover of between $£ 100,000$ - $£ 249,999$. She employs 5 staff, 3 in the UK and 2 in Hong Kong. The business provides consultancy services for UK entrepreneurs wishing to internationalise their business in Hong Kong and possibly mainland China.

Case Study 21: Dominic is a WB male in the 35-39 years age group who graduated in Oriental Studies from Hull University. He is a fluent Mandarin speaker and worked for several years in China. He has now established a consultancy service with branches in both UK and China. He employs two staff who work in his China office while he manages the business from UK. His has been trading for 2 years and his turnover is between $£ 65,000$ $£ 99,000$. He offers advice to UK businesses who wish to internationalise in China.

Case Study 22: Shanti is a second generation BI female in the $20-25$ years age group. She graduated in Business Management from Leeds Metropolitan University. Her father, who came from East Africa to UK in the 1960s, has several businesses. He is now in his seventies and his children, all graduates, help to run the businesses. Shanti manages the 
international travel agency family business and has helped to expand the clientele from mainly Asian to include WB who seeks advice on holiday travel, particularly to the Indian sub-continent.

\subsubsection{Creative Industries}

Case Study 23: Abigail is a WB female in the 25-30 age group. She graduated in Design Studies as a mature student at Sheffield Hallam University. She has a business designing costume jewellery. She markets some of her products through the catalogues of international charities such as Oxfam.

Case Study 24: Kalavanti, a second generation BI woman in the 20-30 age group, is a mature Business Studies student who is doing her degree on a part-time basis. Prior to starting her degree, she had her own business selling jewellery which she imports from India.

Case Study 25: Sita is second generation BI and graduated in law from Leicester University. She is aged between 30-40 years. After working for several years, about two years ago, she set up a designer lingerie retail business in India and an internet based business in the UK. She employs 6 staff, 5 in India and 1 in the UK. Her turnover is between $£ 100,000$ $£ 249,000$.

Case Study 26: Tony is second generation BC while his business partner Omar is second generation Irish-Iraqi. They are both in the 20-30 year age group. Tony graduated from Liverpool John Moore's University in business information systems while Omar graduated from Coventry University in Textile Design. They won a prize at a business plan competition run by the Innovation Centre at Coventry University. They have been running their own designer clothes retail business for two years. Both work on the business part-time and they employ 1 person. They currently source the raw products from Thailand but transform them into designer goods in the UK using Omar's design skills. These value added activities bring them a turnover of less than $£ 64,000$. They are thinking of switching suppliers to Turkey to cut costs.

Case Study 27: Harry and Alfie are mature overseas Chinese students from Taiwan in the 20-30 age group. They are studying for a masters degree in Design Innovation at the university of West England. They were shortlisted out of 60 applicants for a business plan competition. They have designed a device that will hold a large number of music records. They plan to set up the business in Bristol as they are familiar with the environment and Alfie will head up the UK base. They will also have a base in Taiwan which Harry will run. The manufacture of the devices will take place in China where Harry has strong links as he worked there for several years.

\section{China and Indian overseas entrepreneurship activities with links to UK}

The following examples indicate some of the range of businesses which have links with the UK. There are more examples from China than India because it was only possible to do fieldwork in China for this project. 


\section{China}

Four formal interviews were held with Chinese residents in China who already had prior links with the UK. Interviews were also held with a multinational IT company based in India, with many overseas branches including in China and the UK.

\subsubsection{Professional Services}

Case Study 28: Janet, in the 25-29 age group, has an English-Chinese interpreting business. She lived in the UK for a number of years, initially learning English and then undertaking a post-graduate degree in Business Studies at Southampton University. She maintains on-going links with her former UK academic tutors and friends and is thinking of internationalising her business by setting up a branch in the UK.

\subsubsection{Computer Services}

Case Study 29: Francis who has an IT business in an incubator in China is keen to set up a business in the UK where he has pre-existing links. After a B.Sc in China in Mechanical Electronics, he went to Newcastle University to read for an MBA, followed by an M.Sc in IT at Sheffield University. He wanted to study for a doctorate but the scholarship offered by Sheffield University was insufficient so he returned to China. His dream is to study for a doctorate at Cambridge University and set up a UK base for his existing business.

Case Study 30: Mark, in the 35-39 age group holds a degree in computing from a Chinese university. He owns an IT business in Beijing. He wants to develop clients in the UK and he is working closely with his former classmate, Kenneth (Case Study 13), to identify clients and finance.

Case Study 31: Simcar is a multi-national Indian IT outsourcing company which has its headquarters in India and also has branches worldwide including China and the UK. The company is establishing links with a large number of universities in China as well as with one in the UK whereby students from a cross-section of disciplines can do placements on the company's international projects or use their IT platform to develop their own business. Prakesh, the Indian CEO of the company, Gabriel, the Chinese Director of the China office, and Anand, the BI senior academic from the UK University were interviewed.

\subsubsection{Science-based}

Case Study 32: Malcolm is a Chinese professor in his mid-50s working at an elite university in China. He runs a joint laboratory at the university in China with a BC professor Sandy based at an equivalent elite university in the UK. He developed links with Sandy when he was working in the UK prior to returning to China. Malcolm completed all his studies up to doctoral level in China. He was recommended by his supervisor for the Royal Society Fellowship to the UK under the young outstanding scientists' scheme. He worked as a postdoctoral researcher in Scotland and then at an elite London institution. On his return to China he worked as a researcher but also spent almost eight years working for a Chinese national company which operates as an arm of Government. He left his Government post to take up his academic post, but still serves as an advisor to the Government. He and Sandy hope to commercialise their research in China or UK or both.

\section{India}

\subsubsection{Professional services}

Case Study 33: Namaste, a business consultancy service, which provides advice to students, graduates and academics who wish to establish businesses in India and the UK. It is partly run by $\mathrm{BI}$ Ramesh, a senior academic at a British university business school in a university town which has a very large technology cluster. The India office is run by Vishnu, who was a former overseas Indian student at the university. The business has links to the university student entrepreneurship club as well as a number of public sector agencies in India and UK. 


\subsection{Secondary data}

Various national quantitative surveys are undertaken by central Government on a regular basis and the data is used to monitor national PSA targets. However, these national Government surveys have faced various challenges in researching ethnicity. The surveys of particular relevance to this report are the Annual Small Business Survey (ASBS) and Household Survey of Entrepreneurship (HSE) and the Global Entrepreneurship Monitor (GEM). As would be expected with general surveys of businesses, households and individuals using probability sampling methodologies and overall samples of under 10,000, large enough samples of even the main ethnic groups are not obtained to enable robust analysis of different ethnic groups. Consequently the strategy of using ethnic minority boosts to the main surveys has been adopted, following the recommendation of the National Employment Panel report into ethnic minority entrepreneurship (NEP 2005).

However, because this is expensive, they have so far been one-off. The Annual Small Business Survey (ASBS) had an ethnic minority boost in 2003 and included samples of Indians and Chinese. The House Survey of Entrepreneurship ethnic minority boost in 2005 also included Indians and Chinese and a separate report on this data analysis is forthcoming. The Access to Finance Survey 2005 also had an ethnic boost but excluded Chinese. The annual Global Entrepreneurship Monitor (GEM) surveys a large number of countries including the UK and looks at the difference in the level of entrepreneurial activity between countries, uncovers factors that underpin these differences, and identifies policies that may enhance levels of entrepreneurial activity. The UK sample is approximately 43,000. In 2005 and 2006 it also had an ethnic boost which has enabled data on a fairly large sample of ethnic minorities, including Indian and Chinese, to be collected. Furthermore, the surveys asked questions about higher education qualifications and enterprise training. Detailed analysis of this data by ethnicity is not yet available.

There are a number of issues that have arisen with the methodology of ethnic boosts such as finding a suitable sampling frame, cost-effective choice of ethnic groups, and defining an 'ethnic minority business' (Mascarenhas-Keyes 2006). Furthermore, these surveys are cross-sectional and thus only provide a snap shot at a given time. While these can generate some time series data, it has been suggested that longitudinal surveys would yield more robust and reliable data (Li 2006).

A further problem is that the surveys do not collect data that allows desegregations and analysis by generation and education. For instance, the ASBS 2003 ethnic minority boost comprises businesses of first, second and subsequent generation ethnic minorities. However, the sample size for Indian and Chinese businesses is too small to enable a robust and comparative analysis of businesses run by the UK born, and by graduates. This survey did not ask about the qualifications levels of the respondents so quantitative data is not available to enable a comparative analysis of businesses run by graduate and nongraduates. The ASBS 2005 did ask for qualification level but the survey did not have an ethnic minority boost and, hence, only has a small sample of Indian and Chinese businesses. Thus, comparative quantitative analysis is not possible of graduate and nongraduate Indian and Chinese businesses. A survey of Asian self-employment in 1995 (Metcalf et al. 1996) does contain some analysis by generation but the sample does not include the Chinese.

A range of statistics on university students, alumni and staff do not always have data on ethnicity and nationality. For instance, records kept on higher education students attending university extra-curricula enterprise education activities do not distinguish between UK domiciled Chinese and Indian and overseas Chinese and Indian. Academic staff and even student peers are not always aware of nationality or domiciliary status of individuals. The HEFCE business-community surveys usually conducted annually do not collect data on the 
gender and ethnicity or nationality of those involved in graduate or academic entrepreneurship.

It is also difficult to obtain data on student entrepreneurship activity. The HEFCE businesscommunity surveys do not collect data on self-employment. The regular national surveys on student income and expenditure (SIES) which asks questions on student employment does not ask about entrepreneurial activity so there is no national data available on the scale of such activity, the contribution it makes to student finance and the amount of time spent on such activity. On graduates, the DHLE only covers destinations after 6 months of graduation and although there has been follow up research through the Moving on studies (HECSU 1999, Purcell et al. 1999, Purcell \& Elias 2004), sample sizes on ethnic minorities, including $\mathrm{BI}$ and $\mathrm{BC}$, have not been large enough to enable robust analysis by ethnicity. The longitudinal DHLE which followed students from the 2003 DHLE census three years later is awaiting further analysis in terms of self-employment/entrepreneurship.

Entrepreneurship rallies run by the NCGE do not keep ethnicity and nationality data on attendees so it is not possible to analyse attendance to assess the extent to which $\mathrm{BI}$ and $B C$ attend these events. However, the year long programmes that the NCGE offers to those who have British citizenship do hold some ethnicity data. Data from a survey of the Flying Start programme for women is provided in this report. Various analysis of secondary data sets were commissioned for this report but, unfortunately, resource constraints faced by analysts familiar with these datasets resulted in the analysis not being undertaken within the short time frame of a one year project.

\subsection{Literature and policy review}

A review was undertaken, focussing particularly on the examination of various Government documents relevant either directly or indirectly to student, graduate and academic entrepreneurship. Some contribution to the development of the 2008 Enterprise Strategy Paper was facilitated by attending meetings with policy and analyst colleagues and also a seminar to which key academics engaged in research on entrepreneurship were invited.

\subsection{Web-based research}

An examination was undertaken of the websites of a cross-section of universities, regional development agencies, business support agencies and ethnic minority organisations to collect data on their range of activities.

\subsection{Conclusion}

A range of qualitative techniques were used in this research, supplemented by quantitative techniques, further analysis of secondary datasets, literature and policy review and webbased research. Some 150 formal interviews were conducted, predominantly in the UK but also in China. A broad spectrum of people were interviewed including those involved in entrepreneurship activities (providing 33 core case studies), local, regional and central Government officials, staff from intermediary organisations and a range of university staff. Interviewees were identified through multiple chain referral sampling which ensured a diversity of respondents from a cross-section of regions, universities, sectors, age range and both genders. The formal interviews were supplemented by social anthropological techniques of informal interviews, participant observation and reflexivity. Quantitative data was obtained via a self-completion questionnaire completed by almost half of the case studies. The multiplicity of methods used and the triangulation of data obtained through them add to the robustness of the study. They help to identify patterns, themes and dynamics, and provide rich insights into a wide range of issues. 
It would have been very useful to complement this research with research among those who have entrepreneurial ambition but have not yet been able to realise this. An obvious group of potential interviewees are those students who had applied for the SPEED programme but were not successful. However, it was felt that there was a great deal of sensitivity among unsuccessful student applicants about their rejection and it was, therefore, not an ideal time to conduct interviews. Similarly, it would have useful to interview unsuccessful applicants to the NCGE programmes for graduates but time constraints of a one year project made this impossible. Future research could redress this. 


\section{CHAPTER 4: CHARACTERISTICS OF BUSINESSES OF STUDENTS \& GRADUATES}

\subsection{Introduction}

In this chapter I analyse the business activity of non-research students and graduates in greater detail under the themes of two drivers of productivity: Skills and Enterprise. The following chapter, chapter 5, focuses on the driver of innovation which examines the entrepreneurial activity mainly of research based academics. The first section focuses on skills, examining the relevance of discipline based and enterprise skills to the business. The second section looks at various aspects of entrepreneurship including motivation, timing of business set up, types of business formation and staff recruitment and deployment. Although this chapter has a specific focus on $\mathrm{BI}$ and $\mathrm{BC}$, data on WB is also used. The data is drawn predominantly from the 33 case studies, but is supplemented by data collected from a broader range of students, graduates and academics encountered through the informal techniques described in chapter 3.

\section{DRIVER OF PRODUCTIVITY: SKILLS}

Students and graduates engaged in entrepreneurial activities can utilise both degree related skills as well as enterprise skills. The way such skills are acquired and used in their entrepreneurial activities is discussed in this section.

\subsection{Relevance of the Degree}

The students, graduates and academics interviewed for this research report covered a broad spectrum of disciplines. Depending on the type of entrepreneurial activity engaged in, university acquired knowledge and skills can be of relevance in about five different ways. First, it is directly relevant. In the case of those with research expertise, it is the substantive content of their research which forms the basis of their entrepreneurial activity whether it is licensing as in the case of BC Andrew (Case Study 5) or a spin out company. In the case of the undergraduate student groups of BI Arun (Case Study 8 ) and WB Lincoln (Case Study 6 ), they used their engineering knowledge to design innovative products for commercialisation. For WB Matthew (Case Study 7), his HND in engineering enabled him to see the limitations of existing pollution control technology devices and to redesign them to achieve greater effectiveness. BI Alcar (Case Study 17) and BI Sunil (Case Study 19) used their accountancy degree knowledge to establish their accountancy businesses. Those who have studied Business Studies are able to apply their knowledge to setting up a vast range of businesses as epitomised by Clinton (Case Study 16). The NCGE survey of graduate women applicants to the Flying Start Programme found that 7 in 10 respondents said their business idea was related to their degree. The disciplines most closely correlated with the business idea were Art/Design, Arts, Education and Health, with Computing and Law being the least relevant to the business idea. ${ }^{75}$

Second, disciplinary knowledge may form a part of the knowledge resources of the business. As BI Satinder (Case Study 1) was setting up a holistic health centre, he augmented his pharmacy degree with further training in complementary medicine. When BC Michael, who has a doctorate in science first left his academic post to set up a business, he did not use his disciplinary knowledge although the context in which he acquired it provided the knowledge to advise parents about the UK higher education system. However, as he is now expanding his business, he will draw on his scientific knowledge to provide consultancy services to UK

\footnotetext{
${ }^{75}$ NCGE personal communication.
} 
academics and entrepreneurs who want to develop science based entrepreneurship in China. Third, portfolio entrepreneurs have the choice as to whether and when to use disciplinary knowledge. Undergraduate WB student Lincoln (Case Study 6), for instance, has already set up a memorabilia business based on his hobby, but as seen in the last chapter, he is also part of a team of students developing a bio-diesel business in which his disciplinary knowledge plays a major role.

Fourth, qualifications can serve as a credentialising factor. BI Kumar says that his degree in computer studies at present does not contribute to the operational side of his computer services business, although with expansion in the future it will do so. However, at a strategic level, particularly because of his youth, he feels that the fact he has a degree testifies to his professional status and is particularly effective "when negotiating contracts with town hall officials in pinstripe suits". A similar view is expressed by undergraduate WB Hugh studying web design who says he could run his web-based business without a degree but "...it may come in handy when negotiating with graduate clients because you are on par with them". The qualification enhances self-efficacy and serves as a passport providing entry into the professional business world.

Finally, university education may play a generic rather than a substantive role in entrepreneurship. BI Kumar feels that his degree has facilitated human capital recruitment and management. It has enabled him to identify, recruit and work with the right people. He is able to recognise other "bright, creative people who will challenge what I tell them because this is what university has trained them to do, and they come up with innovative solutions to business problems".

According to BI Jay (Case Study 10) who has an e-business in Silicon Valley, it was the stimulation provided by other students at university and the higher level cognitive skills of his degree which contributed to his personal development. As he said

"What I am doing now really doesn't involve any law. For me the value of my law degree was just the skills I learned in the sense of just the discipline it takes to absorb information in a short space of time. And also being able to present arguments well and debate, those skills are useful in pretty much anything. But not any specific knowledge that I took from that degree has helped the business. I think it was more a case for me of the peer group and the people I was around that was more useful than anything of the degree itself"

\subsection{Entrepreneurship skills}

Knowledge-based entrepreneurs make use not only of disciplinary and generic graduate skills but also entrepreneurship skills. A culture of entrepreneurship and entrepreneurship knowledge and skills, two of the enablers of enterprise identified by the 2008 Enterprise Strategy Paper, can be obtained during childhood and adolescence. This can be obtained both tacitly through exposure to a culture of entrepreneurship and explicitly from working in the family business. Graduates who come from a family background of self-employment are more likely to enter self-employment themselves (Tackey \& Perryman 1999; Greene \& Saradakis 2007). From the case studies, three of the BI and one of the BC came from such backgrounds. The parents of Satinder (Case Study 1) owned a corner shop and Sunita's parents ran a post office, businesses which were typical of first generation Indians. In the case of Tony (Case Study 26), the foregrounding of his 'spur of the moment' decision to engage in entrepreneurial activity rests on an experiential background in entrepreneurship. The business run by Tony's parents epitomised the ubiquitous Chinese take-aways that characterised first generation BC from Hong Kong. Tony said that he "was kind of brought up on it and worked there. So entrepreneurship is in my blood". 
Sita's (Case Study 25) parents ran their own retail business, selling school uniforms. Sita helped out while a school girl:

"I used to run it. When we were kids our mum used to go off to India for 2 weeks. We used to tell the school we were taking a week off and go and help in the shop. I was responsible for doing the window displays and ordering the stock. It was very simple; there were four children and we had to come home every night and do the cooking and all the work because my mum and dad both worked. So I had a choice, I either had to go home and help out in the kitchen or I could go to the store and help out in the store, so I used to go and help out in the store. And that is where my kind of love for retail began. I would say in a way that is where my natural ability or a natural relationship with retail began really"

Even for those whose parents are not entrepreneurs themselves, there can be a peripheral exposure to entrepreneurship because other members of the extended family and community are involved in business. As BI Jay (Case Study 10) said "there were always uncles, aunts, and cousins around who were involved in business so you were just aware of it". Ashok (Case Study 6), an overseas Indian undergraduate student draws on entrepreneurship support from his aunt, a lawyer involved in negotiating business deals for national and international clients: "I never had much contact with her before but now that I am setting up my business with my colleagues (WB students) in England I talk to her a lot and she gives me lots of advice".

Entrepreneurship skills can also be acquired through in-curricula and extra-curricula university activities and through business support programmes. These are explored in more detail in chapters 8 and 9.

\section{DRIVER OF PRODUCTIVITY: ENTERPRISE}

Under this driver of productivity, a number of themes are examined. First, the push and pull motivations to start a business, both nationally and internationally, are explored. The second section looks at the timing in a student and graduate's life cycle when the business is set up. This is followed by an examination of the different types of business formation, particularly the forms that have been used for international activity. The final section examines staff recruitment and deployment strategies, particularly for international businesses.

\subsection{Motivation to start a business}

There is a range of reasons that motivate people to become entrepreneurs. They can be divided into 'push' factors and 'pull' factors. 'Necessity entrepreneurship' is linked to push factors, while 'opportunity entrepreneurship' is linked to pull factors. Necessity and opportunity entrepreneurship are analysed separately below.

\subsubsection{Necessity entrepreneurship}

An analysis of 2004 GEM data found that $0.9 \%$ of all graduate entrepreneurs in the UK perceive they have no choice but to enter into entrepreneurial activity as compared to $0.5 \%$ of non-graduates (Brooksbank \& Jones-Evans 2005). There is no quantitative data on $\mathrm{BI}$ and $\mathrm{BC}$ graduates. However, there is national data available for England which gives a general idea of the motivations of ethnic minorities as a whole, irrespective of educational background. The Annual Small Business Survey 2003 Ethnic Minority boost found a higher proportion of ethnic minority businesses (EMBs) compared to WB businesses cited difficulties in finding either the right job ( $7 \%$ compared to $2 \%$ ) or any job ( $9 \%$ compared to $7 \%$ ) as a reason for going into business (DTI 2006d). This finding is also endorsed by the 
Household Survey for Entrepreneurship 2005 (DTI 2007b) ${ }^{76}$ which found, among the unemployed, that a greater proportion of Asian Thinkers compared to White Thinkers said they would like to start a business because they were unable to obtain regular employment. Furthermore, a higher proportion of Asian Thinkers compared to White Thinkers said they wanted to get away from discrimination that occurred at their current place of employment. Unfortunately, because of the absence of data in this survey and the small sample sizes, it is not possible to quantify the level of necessity entrepreneurship among the second generation, or specifically among graduates in the second generation.

Of those interviewed for the current research, two could be classified as necessity entrepreneurs. BI Sunil (Case Study 19) felt he had reached the glass ceiling in his paid accountancy employment. Although he had held senior positions in the private and public sector, he felt that covert racial discrimination was precluding him from advancing further. The only option was to set up his own accountancy business. WB Dominic (Case Study 21) found on his return from working in China that he could not obtain employment commensurate with his skills, abilities and income expectations, so he set up his own consultancy business.

\subsubsection{Opportunity entrepreneurship}

An analysis of 2004 GEM data showed that $8.1 \%$ of UK graduates engage in opportunity entrepreneurship compared to $4.7 \%$ of non-graduates (Brooksbank \& Jones-Evans 2005). Greene \& Saradakis found that the "...general orientation of graduate entrepreneurs was not pecuniary. Instead, of more importance to the entrepreneur is their own personal development and job satisfaction, mixed in with a relatively greater concern for social issues" (2007: 8).

For ethnic minorities, irrespective of educational background, among pull factors, three important ones can be identified. The first and most significant is the desire for independence. The Household Survey of Entrepreneurship 2005 (DTI 2007b) found that among Asian Thinkers, there was a higher proportion compared to WB who wanted to start their own business because they wanted to be their own boss. Second, as noted in chapter 1, EMBs tend to be more innovative and the opportunity to develop an idea or innovation is a more important motivator for Asian Thinkers compared to WB. Finally, Asians are more likely than WB to be motivated because they want 'to follow the example of someone I admire'. In terms of the motivations to internationalisation among all business (irrespective of ethnicity or educational background), it appears that the opportunity to sell to a wider and larger customer base through selling into overseas markets is the predominant motivation, while access to knowledge and ideas, and keeping abreast of developments are also very important motivations for entrepreneurs (DTI 2006b). These pull factors and others were apparent among the respondents to the current research as discussed below.

Opportunity entrepreneurship characterised all the respondents apart from Sunil and Dominic mentioned above. BI Kumar (Case Study 12) and WB Lincoln (Case Study 6) turned a hobby into a business: installing computer systems and selling memorabilia respectively. Lincoln and his student colleagues, including overseas Indian Ashok, are acutely aware of the commercial opportunities of bio-diesel in the context of international concerns about environmental pollution and, hence, they have set up a business in this sector. Capitalising on new opportunities in this sector is also a key motivation for mature

\footnotetext{
76 Household Survey of Entrepreneurship 2005 uses three categories: Thinkers, Doers and Avoiders. Doers are those who are self-employed or own a business (fully or partly), either as their main activity or as a sideline to their normal employment activities; Thinkers are those who are not currently Doers, but have recently thought about starting a business, buying into an existing business or becoming self-employed and Avoiders are those who are neither Doers nor Thinkers. Detailed analysis of the HSE in terms of Indians and Chinese is not yet available. As an alternative, where the evidence exists for Asians this is provided, and if this is not available, evidence on ethnic minorities is used as indicative.
} 
chemical engineering undergraduate British Pakistani Akbar who has set up a business providing bio-fuels for domestic purposes.

The motivation for independence and seeking new challenges can be combined with seeking new international markets. As BI Sita (Case Study 25) said about the factors that motivated her:

"There were a couple of things, I was tired of working for somebody., I felt I was working very hard and it was for somebody else's gain which is one thing. The other big thing was I wanted to test my own mettle and see whether I was cut out for an entrepreneurial life, or whether I was just cut out for being somebody's senior employee. And the third thing was I felt the UK market in retail was very depressed because there had been so much deflation in retail due to the supermarkets and discounts and it was very difficult to compete. I just thought, oh my God, can I be bothered to sit here. And it literally got to a point where we were fighting over peanuts; we were selling a bra for $£ 14$ and M\&S would go to $£ 13$ and we would go $£ 12.50$ and it was all a bit ridiculous. And I thought I am bored with this now. I want to work in a market that wants products, that enjoys products. I was thinking of going overseas. Well there were two big countries I thought would be interesting and one was China, which I had never fancied, and one was India which I thought was going to be an easier transition because I am Indian. And India at the same time was hugely inspirational and I thought it was quite a good time. There is a growing market among the expanding middle class and upper middle class"

India was also the overseas country of choice for BI Alcar (Case Study 17) for both economic and ideological reasons.

"India is just the place to be, it really is; anybody who has got any business sense is going to be in India at the moment. We (she and her husband) wanted to go back to India and we wanted to do something that would make a difference to India..... And I think people like us who are of Indian origin have got to do something with India because by 2020 -2030 it is going to be the third largest economy. 539 million people less than 25 years old - you have got to be there, you have got to be doing something there"

For Jay \& Raj (Case Study 10) the size of the US market was a factor as "... it is 10 times bigger than the UK market and it makes sense to attack it".

BC Kenneth (Case Study 13) was already familiar with China. He had spent his childhood and part of his teenage years there and had paid several visits subsequently. Moreover, he had friends there who were interested in becoming business partners, and as there were considerable market opportunities to start and grow a business, it seemed a logical choice to him.

BC Tony (Case Study 26) had always had an interest in business as his parents had a takeaway but the idea for his own business came unexpectedly.

"I was travelling in Thailand and there is this particular type of clothing over there, I thought this would be an excellent item to market in the UK. So I bought some samples back and I proposed it to my friend who is my business partner now. And we were looking into it, we saw that it was too expensive to bring over, and then we were looking at producing it over there but that was getting too expensive because starting up there is a lot of money needed and cotton was really expensive. So we went from there, importing basic $T$ shirts from Thailand but we are looking at suppliers from Turkey too as it is cheaper there. I have always had an idea of a clothing brand in my head anyway... That has always been in my head - it has never 
had a logo or a brand image or anything like that. But then when I got my friend on board he designed the first $t$-shirt, the print for the T-shirt, and then we just went from there"

To conclude, the student and graduate respondents to this research entered entrepreneurship to capitalise on opportunities in the UK and overseas.

\subsection{Timing of Entrepreneurial Activity}

The timing of the start up of entrepreneurial activities varies among students and graduates.

\section{Students}

The patterns found among students in this research exemplifies those in other research mentioned in chapter 1 . Some students, as in the case of Kumar (Case Study 12) and Hugh (Case Study 11) started their business before university as they were based on a hobby and they started as social entrepreneurs. Kumar helped out friends and Hugh his local Scout group. Part-time students, like BI Kalavanti (Case Study 24), was already running a business before she started her degree and she continued with the business during her studies. In the case of mature students, the businesses they are running while students may not be their first business venture. This is the case with a British Iranian married couple Amin and Farah. They are both Business Studies students who have a retail designer business selling goods in England which have been imported from overseas. Amin had run two businesses in the USA which he sold off when he came to live in England on marriage to Farah whom he met on holiday in Iran and who was UK domiciled. Students on specialised entrepreneurship support programmes, such as SPEED (see chapter 8) usually set up the business in the second year of their undergraduate studies. However, as the programme has some flexibility, part-time students or masters level students may set up at a different time during the course of their studies.

\section{Graduates}

The timing of entrepreneurship after graduation varies and can be affected by a number of factors including opportunities to enter existing businesses, having a business start-up idea, the simplicity or complexity of the idea, the type of support needed, the amount of finance required and the ease or difficulty of access to it ((Nabi et al. 2006). The current research highlighted the variety of options taken up by graduates.

First, graduates may decide to take up self-employment immediately after graduation. Some 'eager entrepreneurs' (Roberts 2004) may do so by continuing or starting their own business, taking over an existing one or joining the family business. In some cases where entrepreneurial activity started before graduation, full-time self-employment immediately after graduation is inevitable. Kumar (Case Study 12) was already running his IT business part-time while a student and immediately after he completed his final year exams he began working full-time on the business.

$\mathrm{BI}$ and $\mathrm{BC}$ second generation can benefit from the entrepreneurship of the first generation. As noted in chapter 1, many graduate entrepreneurs come from a family background of entrepreneurship. Data from the Annual Small Business Survey 2003 which had an ethnic boost showed that overall, about $75 \%$ of Chinese businesses and $65 \%$ of Indian businesses are family owned. $80 \%$ of Chinese businesses are controlled by the first generation, $19 \%$ by the first and second or second generation, and $1.3 \%$ by the second and third generation, or the third generation. Among Indian businesses, $74 \%$ were controlled by the first generation, $25 \%$ by the first and second generation or second generation, and less than $1 \%$ by second and third or third generation (DTI 2006d). 
The existence of family owned businesses provides potential opportunities for graduates to join the business. BI Shanti (Case Study 22) joined one of the family businesses immediately after graduating with a degree in Business Management. The one she chose was the international travel agency family business where she had helped previously on an ad hoc basis. As she is able to communicate well with WB people, she is gradually able to expand the clientele of the business which was previously almost exclusively Asian. At present she has not made any changes to business practices as a result of her degree studies, but she may at a later stage when she has acquired more experience. On the other hand, some graduates have been able to introduce innovations informed by their higher education studies. Graduates trained in computer-aided design, for instance, use various forms of technology to design clothes later sold through their parents' shop. Others may extend the commercialisation activities of the family business. Tilak, a BI undergraduate student currently in his second year of a pharmacy degree, plans to use his parents' wholesale business to distribute a new range of products, such as pharmaceutical products, to a worldwide clientele. Some second generation BC who do not want to work on the operational side of their parents' take-aways and restaurants, have taken on a management role and employed others for the day to day running of the business. Others have leased the business, in some cases to new immigrants from mainland China. ${ }^{77}$ The parents of $\mathrm{BI}$ Sita (Case Study 25) owned a retail shop but she did not have the option to join the family business on graduation as her parents had sold it while she was at university, exhausted after working long hours in the business and unable to withstand the competition generated by large chain stores who had begun selling similar merchandise. The factors affecting the closure of Sita's parents business is partly responsible for the pattern of decline in South Asian self-employment (Jones \& Ram 2003).

A second option is to simultaneously take up paid employment and self-employment. BC Tony (Case Study 26) works full-time for a multi-national retailer while simultaneously running his small retail business part-time. Kenneth (Case Study13) has had a more chequered employment history which has involved periods of paid employment in the UK and China, setting up and running a business in China which went bankrupt, and is now working in the UK as a management consultant while maintaining and developing a portfolio of businesses including an IT business which has bases in both UK and China. He hopes to eventually give up his paid employment and concentrate on developing and consolidating his wide range of business interests.

A third option is to switch serially between paid employment and self-employment, that is, to have 'entrepreneurial spells' (Greene \& Saradakis 2007). Stan, a 40 year old BC with a doctorate in engineering from an elite institution, has combined consecutive periods of paid employment with self-employment, selling his engineering business after a few years at a lucrative price after being head-hunted for a senior paid post. He is planning to start another business when his current contract terminates. Rosie, a 50 year old BC originally from Malaysia, who has UK postgraduate qualifications, has intermittently run two businesses and held paid posts, some overseas, in educational and media services.

A fourth option is to work for a while and then leave paid employment permanently. Sita (Case Study 25) had worked for several years after graduation as a buyer for about five large departmental stores, working her way up to director of buying, before she set up her own business. Alcar (Case Study 17) had worked for several years in the UK and Eastern Europe as an accountant and accountancy trainer, including for a blue chip international company, before she set up her own business.

\footnotetext{
${ }^{77}$ X. Chang, personal communication.
} 
Businesses can be national, become global after a period of being national or are born global. Of the case studies, national entrepreneurial activities are exemplified by Hugh (Case Study 11), Kumar (Case Study 12), Clinton (Case Study 16), Sunil (Case Study 19) and Abigail (Case Study 23). Entrepreneurs have the choice of setting up nationally in the UK first and then going overseas as in WB Matthew (Case Study 7), BC John (Case Study 14) and BC Michael (Case Study 15). Born global businesses begin international activities from the outset as in the case of BC Patrick (Case Study 9), BC Kenneth (Case Study 13), BC David (Case Study 18), WB Carla (Case Study 20) and WB Dominic (Case Study 21). In some cases, the businesses have been set up overseas first, as in the case of BI Alcar (Case Study 17) and BI Sita (Case Study 25) and BI Jay \& Raj (Case Study 10). Alcar and Sita set up their businesses first in India and later established a base in the UK. On the other hand, Jay \& Raj have based their business entirely in the USA. National businesses can use a variety of legal statuses such as sole proprietor, partnership, limited liability company, corporation and co-operative. Kumar, Kalavanti, Hugh, and Clinton, for example, operate as sole proprietors. International entrepreneurial activities can be undertaken through a variety of legal entities. The examples below are taken from UK businesses with trade links with China.

First, a UK company can set up representative agents in China. This may be useful for sales distribution. The representatives may be individuals or companies. For instance, Hong Kong Chinese Henry, a portfolio entrepreneur, (who also has a joint venture with Carla, Case Study 20) acts as a distribution agent for some WB businesses which are based in the UK. At the same time, he has distribution agents overseas, including UK, for one of his businesses. An innovative way of using distribution agents is to sell products through an international social enterprise. WB Abigail's products are marketed through a charity's brochure and some of her profits are used to support the organisation's international social development projects. Second, a UK company can set up third party licensing arrangements. This was the case of a company run by WB Adam who has agreements with various sports outlets in China to sell his designer sports shoes. These shoes are designed by a UK university, manufactured in the Philippines, and then distributed through various outlets, including sports outlets in China.

Third, a UK business may open a joint venture in China. This is the case of WB Matthew (Case Study 7) who set up a business in China with a former state owned enterprise.

Fourth, a UK business may become one of the partners in a Chinese company where the equity stake may be limited by Government regulation. Fifth, a UK business may set up an office in China as a wholly owned foreign enterprise. This was the approach adopted by BC Kenneth (Case Study 13). Sixth, a business may engage in global supply chains of services through outsourcing of back office functions to businesses overseas. Some lawyers, such as BI Narendra, have outsourced work to India where the commonality of the legal system means that lawyers in India can deal with some of the legal work. BI Prakesh, provides a variety of IT services, including the transcription of audio tapes of interviews with English speaking interviewees given to him by researchers in UK. He sends these electronically to India for transcription by English speakers which is done at much lower costs than if undertaken in England. The turnaround time is equivalent or less than UK. Sunil (Case Study 19) who has an accountancy practice had considered outsourcing book-keeping functions to India but decided against this as it is at present not a cost-effective option.

\subsection{Businesses with employees: staff recruitment and deployment}

Some businesses are sole traders, but others have employees. Some employees are entirely UK based, while others work for the business overseas. BC Michael (Case Study 15) employs 5 staff in the UK and 15 in China, while BC John (Case Study 14) employs 25 
staff in the UK and 5 in China. Some entrepreneurs had to quickly develop their own expertise as well as engage staff. As Jay (Case Study 10) said:

"Ian, who started working with us at the beginning, had a technical background so he had built the website or the product to begin with. Then when he left it got tough and we hired an out sourcing firm which was ok but it didn't go particularly greatly. And then when we raised more money we basically employed technical staff and that was ok. But what we have learned, we essentially taught ourselves so we can do a lot of this stuff ourselves. And that was just us deciding that if we wanted to be in the technology business we needed to be able to understand the technology, so we just taught ourselves. It was definitely the best decision we made"

Human resource recruitment and management plays an important part in all businesses, but perhaps poses more challenges for international businesses. Various strategies may be adopted as the following examples illustrate. When selecting staff for their business, for second generation graduate $\mathrm{BI}$ and $\mathrm{BC}$ entrepreneurs, professional expertise, rather than ethnic background, is a key factor. Jay \& Raj in due course realised that they needed staff with greater expertise than themselves and recruited a young White graduate, a recipient of prestigious awards and a graduate of MIT who was introduced to them by one of their Silicon Valley investors. BI Kumar (Case Study 12), who has fourteen employees, says ethnicity plays no role in the choice of staff, and it was a coincidence if a $\mathrm{BI}$ joined his staff team.

However, ethnicity can play a more direct role in some knowledge-based businesses as it did for the non-graduate businesses of the first generation. For non-graduate businesses, which involved running corner shops, newsagents, restaurants, take-aways and repair services, co-ethnics including family members were usually employed. For such businesses, employees require 'common sense', in some cases low level craft skills, and some English language fluency. However, graduate $\mathrm{BI}$ and $\mathrm{BC}$ entrepreneurs with knowledge-based businesses, specifically select graduate co-ethnics only if their cultural capital, as well as professional expertise, is relevant to the business. BC Michael (Case Study 15) has a business which serves both an English-speaking and Mandarin-speaking clientele and, furthermore, there is frequent contact between staff in both UK and China. Consequently, he has employed Chinese graduates in China and the UK who are bilingual in English and Mandarin, as he is himself. If the international business has bases in the UK and the ancestral country, then it is very likely that co-ethnics, if they have the relevant expertise, will be employed overseas. For instance, two British Pakistani brothers, Iqbal and Saleem, whose father works as a taxi driver (an occupation typical of this ethnic minority group), graduated with the same IT degree at a British university. They are setting up an international IT business in the UK and Pakistan, and while lqbal will be based in the UK office, Saleem will run the office in Pakistan. They expect to employ in the overseas office a cousin who has graduated from a university in Pakistan in the same field.

Sometimes, the choice of co-ethnics may be a default option. Satinder (Case Study 1) had initially tried to engage WB:

"I always tried to go to the western community first because I thought they would understand what I am trying to do. And every step of the way they will take you all the way and then not take you any further. And now I always end up with Asian people who take the extra mile"

As a result of his failure to successfully recruit WB, he has decided to engage a family member as an accountant who currently works at a senior level for a prestigious accountancy firm in London. Another $\mathrm{BI}$ with franchising background will be brought in to help to roll out the franchise model. 
BC Kenneth (Case Study 13) has adopted an innovative strategic approach to staff recruitment for his international business. He has four business partners in Beijing, one of whom was a former classmate. He employs sixteen Chinese staff in Beijing, some of whom have been educated at British or American universities. In recruiting team members in the UK, he follows a deliberate policy of employing people from different national and cultural backgrounds as he feels they bring complementary skills and attributes as well as provide access to different pools of contacts. For instance, one of them is Jewish American and the other is $\mathrm{BI}$. He feels $\mathrm{BI}$ have very good general communication skills including English language competency. He has also recruited some Chinese into the UK based team.

WB businesses set up in China also adopt strategic approaches as the examples of Carla (Case Study 20) and Matthew (Case Study 7) illustrate. Carla's business partner is Chinese Henry who manages the Hong Kong office on a part-time basis as he is a portfolio businessman. The Hong Kong office also employs two local Chinese graduates. Henry is an ideal choice of partner as he has professional expertise, social capital and cosmopolitan cultural capital. He was born in mainland China and his family then moved to Hong Kong. He studied ' $A$ ' levels and did his first degree in the UK. He undertook postgraduate training in Hong Kong as an external student of a British university. He now works as a tutor for this university in Hong Kong as well as co-running the business with Carla, running his own shipping company, and serving as a distribution agent for some UK businesses. His knowledge of the UK and Hong Kong, as well as of mainland China, coupled with his cosmopolitan cultural capital and extensive social networks, provides him with the expertise to host UK trade missions to Hong Kong and mainland China.

Matthew has employed overseas Chinese graduates from British universities at his UK office whom he will then employ in the China office when they return home. He has also taken on a Chinese postgraduate student for his UK office through the Knowledge Transfer Partnership programme (see chapter 1 ) run by a university in the vicinity of his UK business. His team of Chinese staff in China are managed by an executive who is of mixed Chinese Korean descent. He also ensures his Chinese staff from China spend time at the company's UK base for a couple of months' training so that "they understand how the business works and to give them some wider exposure". His WB UK sales director goes to China to spend a week every 6-8 weeks to develop and help operationalise the sales strategy. This is a fairly difficult task as the Chinese staff who worked for the business when it was a state owned enterprise are not oriented towards profits-driven marketing strategies.

Maintaining regular contact with partners and staff sited at different locations of an international company is essential for strategic planning and operational success. Face to face contact is facilitated by the availability of regular flights. Kenneth travels to China every couple of months, and sometimes more frequently. Technological innovations have been a valuable asset. For instance, BC Michael (Case Study 15) and WB Dominic (Case Study 21 ) engage in regular video and teleconferencing and daily exchange of emails with their partners and staff in China.

None of the businesses interviewed saw themselves as life style businesses and all had growth aspirations which at some stage could involve increasing the number of employees. BI Sita (Case Study 25) planned to grow within India as the market was huge and she felt there was no need to consider at this stage any other location. She had no plans at present to expand her London base which basically services internet sales and is run by her sister. BI Alcar (Case Study 17) sees a huge market both in India and in the UK. In both countries she feels she would be contributing to the human capital formation of Indians as accountancy is a very popular subject of study for Indians in both countries. Her student and tutor educational materials, written in English and available at a cheaper price than her competitors, could be used not only by Indian students and tutors but also by non-Indians. She had begun marketing her materials in the UK by talking to several universities that offer 
degree programmes in accountancy and management. She also plans to distribute her books to Europe and the Caribbean. Her longer term plans include possibly working with her brother, who is a doctor in Australia, on the development of medical text books. BC Kenneth (Case Study 13) is hoping to expand his IT business to India as "India is the next booming market and there is a huge amount of affinities and co-operation between China and India and I am searching for opportunities to work closely with India". If his plans are successful, then he would recruit graduate staff in India as well as BI in the UK so that he can leverage the latter's cultural and social capital.

\subsection{Conclusion}

This chapter has shown that the majority of $\mathrm{BI}$ and $\mathrm{BC}$, as well as WB students and graduates with entrepreneurial ambitions are opportunity entrepreneurs. Family and community background has an important influence in the orientation towards entrepreneurship and joining family-owned businesses provide opportunities for realising entrepreneurial ambitions. Some students have turned their hobbies into a business and credentialised it with a degree which also allows them in the future to expand the business in ways which will make more direct use of their disciplinary knowledge. Others have set up their business from the outset with knowledge derived from their higher education studies. For a few entrepreneurs, the degree is of generic relevance and enhances their self-efficacy. Necessity entrepreneurship was evident among the two graduates who felt they had reached the glass ceiling in paid employment and setting up their own business was the best way to scale greater heights. Timing of start-up varies: some students run an existing or new business while they are students and some graduates start a business immediately on graduation while others work for some time before entering self-employment or combine paid employment with self-employment.

$\mathrm{BI}$ and $\mathrm{BC}$ second generation graduate entrepreneurs who employed staff used different recruitment strategies to the first generation. Unlike the first generation with low valueadded businesses such as corner shops, newsagents, take-aways and restaurants that generally employed co-ethnics and also used family help, $\mathrm{BI}$ and $\mathrm{BC}$ second generation graduate entrepreneurs recruit staff for their knowledge-based businesses on the basis of graduate level expertise rather than ethnicity. However, ethnicity plays a role in staff recruitment when cultural capital is an asset to the business. This is particularly relevant in penetrating overseas markets. BC employ co-ethnics with graduate level expertise in their UK-China international business where multi-linguistic capabilities and other aspects of cultural capital facilitate service delivery. This strategy adopted by $\mathrm{BC}$ and $\mathrm{BI}$ of employing nationals from the country that the company wishes to penetrate can usefully be adopted by WB businesses. Indeed, an example was provided where this has been done by a WB international firm with a China site who used the Knowledge Transfer Partnership to employ an overseas Chinese graduate from a British university at his UK headquarters prior to transfer to the China office. There is considerable scope for expanding this strategy across the British business population who intend to internationalise. 


\section{CHAPTER 5: DRIVER OF PRODUCTIVITY: INNOVATION}

\subsection{Introduction}

This chapter focuses on innovation as a driver of productivity. As mentioned in chapter 1 , Government sponsorship of innovation has been science and innovation focused. Furthermore, it has focused on research based innovation with funds being made available through different sources for research to be conducted, innovations generated and subsequently commercialised. This chapter first briefly highlights various research support initiatives, particularly European and international initiatives. Universities can drive innovation in multiple ways (NESTA 2007b) some of which are explored here by examining different types of academic entrepreneurship and international academic entrepreneurship. The final section focuses on barriers to academic entrepreneurship and how these might be addressed.

\subsection{European and International Research Collaboration Initiatives}

A range of research and innovation activities promoted by the Government have been mentioned in chapter 1 . As this chapter includes looking at international research and collaboration, the attempts by Government to promote this are briefly highlighted here. The Global Science \& Innovation Forum (GSIF) was established as a vehicle for crossGovernment exchanges of information and ideas to improve co-ordination of the UK effort in international science and innovation collaboration. It provides strategic guidance and systematically scans the horizon for new and emerging issues. GSIF is responsible for the design and implementation of the UK's Global Science and Innovation Strategy for international engagement in science and technology. To improve both national and collaborative international research, research budgets have increased in recent years and there has been a greater attempt to link different Government science budgets into the research councils who administer funds, usually through a competitive process.

There are many attempts to foster international collaboration and networking, and examples of some support are provided here. The UK participates in the Seventh Framework Programme (FP7) for Research and Technological Development which is the EU's primary funding mechanism for supporting and encouraging collaborative, trans-national RTD in the European Community. The Technology Strategy Board, which was established in 2007, funds a support service for UK-based organisations interested in exploiting the opportunities provided by FP7. The UK is also involved in the COST (European Cooperation in the field of Science and Technology) scheme. Since 1971, COST has brought together research teams in different countries working on specific topics. It finances networking of nationally funded activities in supporting meetings, conferences, short term scientific exchanges and outreach activities but it does not fund research projects. There are many Indian and Chinese research students and staff in universities in Europe, studying and working there prior to or after a period at UK universities. They are conduits for wider international networks and collaborative projects.

Collaboration with India and China has become increasingly important. Referring to these two countries, a study of the drivers, barriers and benefits of the international engagement in science and innovation predicted that " $[T]$ hese emerging scientific countries will erode the market share of the world's leading economies in terms of scientific output and breakthroughs" (Technopolis 2005:2). To ensure that these emerging superpowers pose opportunities not just threats, the UK Government is keen to foster collaboration between the UK and these countries. There are various initiatives. First, GSIF has developed bilateral engagements through Government-to-Government policy dialogical platforms such as the UK-India Science and Innovation Council and the UK-China Partners in Innovation. These bilateral mechanisms are being used to coordinate and underpin a wide range of UK 
initiatives. Second, the Research Councils UK (RCUK), an umbrella body for all the research councils, has an international science strategy which emphasises that the UK must play a role in world science and the knowledge economy. It opened an office in Beijing, China in 2007 which was visited during the course of this research. It plans to open an office in India in 2008. These offices will help to keep abreast with the development of science policies in these countries, establish better links with government, universities and research institutes and influence the international research agenda. ${ }^{78}$ Third, the Government aims to build sustainable and strategic partnerships between UK universities and colleges and those of other countries including India and China. ${ }^{79}$ For instance, in 2005, the Government announced the UK-India Education Research Initiative (UKIERI). At the end of 2007, the Innovation China UK (ICUK) project was launched. Connecting five UK higher education institutions and over twenty Chinese partner institutions, ICUK supports academic and business partners in forging collaborations, funding proof-of-concept research, and commercialising joint intellectual property across the UK and China. It is a joint initiative between the Higher Education Funding Council for England, the Department of Innovation, Universities and Skills and the Chinese Ministry of Science and Technology. It has received $£ 5 \mathrm{~m}$ from the UK via the HEIF programme, matched by an equivalent amount by the Chinese Government. By March 2008, thirteen Proof-of-Concept fund applications had been received and the project expects shortly to award the first two Partnership Grants to facilitate collaboration between academic institutions in both countries. ${ }^{80}$ More schemes facilitating collaboration have been initiated and others can be expected in the future. For instance, a new round of research funding for collaboration between China and the UK was announced in 2007 by the Engineering and Physical Sciences Research Council. It is likely that collaborative research with China will be applied research which enhances the possibilities of commercialisation. This is because China is very keen to use research to solve its problems, for instance, in health, natural resource constraints and pollution as we shall see shortly.

In the UK, an increasing emphasis is being placed on ensuring that research has wider impact. While the traditional route has been dissemination at conferences and through publications, greater emphasis is now being placed on the commercialisation of research through technology transfer support. There are various ways in which academic entrepreneurship, including international academic entrepreneurship, may be manifested which are discussed next.

\subsection{Types of Academic Entrepreneurship}

Four types of academic entrepreneurship are discussed below: R\&D for external businesses, licensing, spin off companies, and setting up an independent business.

\subsubsection{R\&D for external companies}

First, academic entrepreneurs may undertake innovative commercial work for an external company which either does not have in-house R\&D capacity or its existing capacity lacks expertise or resources to undertake specific research. Sometimes researchers move between university and industry, and in some research areas, the boundaries between the two are fairly porous. Academics may be involved in helping SMEs to internationalise their businesses in various ways. For instance, WB Adam whose business is based in the UK, has established third party agreements with Chinese companies in a couple of cities in China to distribute sports shoes. There is increasing demand for such shoes with the greater interest in sports generated through the forthcoming Beijing Olympics. The R\&D contract for the shoes is being undertaken by academic staff in a university in the East

\footnotetext{
${ }^{78}$ The RCUK currently funds the UK Research Office in Brussels and in 2007 an office was opened in Washington, USA.

${ }^{79}$ Press release Prime Minister launches strategy to make UK leader in international education April 20061

80 ICUK first Newsletter March 2008.
} 
Midlands which is renowned for its expertise in designing sports shoes underpinned by scientific research. Ideally, the company would like to have Chinese researchers working on the project at a British university as they think this may facilitate a better design which would take account of cultural factors. After the shoes have been designed in the UK, they are manufactured in China.

\subsubsection{Licensing}

Second, an academic may maintain a full-time university post but commercialise his innovation through licensing agreements. The first task is to apply for a patent or equivalent to protect his intellectual property (IP) rights and this can either be applied for solely in the UK or in a number of different countries or jurisdictions depending on where it is thought there may be commercial interest. The application process can take a considerable amount of time and often specialist lawyers are engaged. Once a patent has been secured, then a licence to use the invention can be negotiated with existing companies and the IP owners receive a commercial return. Licences can either be exclusive to one company or nonexclusive so that more than one company obtains the rights to the invention. The former is more expensive but some companies, such as pharmaceutical companies, prefer exclusive licenses. The researchers and the universities in which they are employed received royalties from the licence as we will see shortly.

Licensing is an option that commercially savvy researchers who do not want to give up their academic posts may consider. As BC Andrew (Case Study 5) put it "[I] like doing research and inventing new things but I don't want the headache of running a business. I am happy to just get the royalties". This is the approach he has adopted in relation to the numerous IT software products that he and his team of doctoral students and post-doctoral researchers produce. Matt, a BC post-doctoral chemical engineer is working on a large international collaborative research project at a British university which is funded by the European Union. It involves WB researchers, a senior researcher from an Indian university, as well as colleagues from Germany. Their project on solar energy has great commercial potential and the researchers plan to patent the invention initially in India, Germany and UK and licence it to an external company with royalties going to the researchers and their respective home universities in India, Germany and the UK.

\subsubsection{Spin-out companies}

Third, academics may set up a spin-out company which is based on their IP. Many spin-out companies are to be found in university science parks. Various science parks visited during the course of the current research provided ample examples of spin-out companies that emerged from university research. The academic whose invention is being used usually has an equity stake in the business and so does the university. The degree of involvement of the academic in the business varies: some work full-time and others part-time. Sometimes the spin-outs form part of a specialised sector cluster and there are various clusters in different parts of the UK. The rate of spin-out companies launched varies across universities as is the income that accrues to universities and their staff. A spin-out company launched by one of the universities was based largely on the work of BI Ainesh who undertook his doctoral research in Pharmacy at the university. After his first degree at the university, he worked briefly in industry before returning to the same university to undertake doctoral research. The equity of the company is shared with the university and Ainesh was the first employee. The company has grown over the years with the recruitment of more employees and he has remained its CEO. Scientific services are provides to the company's UK and overseas clients.

\subsubsection{Independent business}

Fourth, some academics leave a full-time post in the university and set up their own business in which the university does not have any stake. BI Suresh (Case Study 3), who set up his chemistry-based business, is an example of this. He came to Britain directly from 
India to undertake postgraduate studies. After completing his doctorate, he moved to another university to take up a lectureship and continue with postdoctoral research in Chemistry. After several years, he relocated again and now works as an associate lecturer at a university in the north of England, delivering a few lectures a year. When he moved to the north, he started up a chemistry-based business. He has a staff team of four scientists, one of whom is British Indian. He undertakes chemistry-based research for a large number of clients who do not have their own R\&D capability or if they have such capability, outsource work to him because it is too specialised for them to do it or because they are short on human resources. Some of the work is done in his laboratories but he also uses the laboratory at the university where he has an associate lecturer affiliation. This arrangement works well as he is able to use existing facilities which are cheaper than if he had to establish his own large laboratory. For the university, it is a source of revenue as the work is done when the laboratories are not being used. His university associate status enables him to meet academic colleagues on a regular basis and keep up to date with developments in the field. He is considering expanding his business to India as noted below.

\subsection{International academic entrepreneurship}

International academic entrepreneurship can occur in various forms which are described below.

\subsubsection{Global outsourcing}

First, innovations may be developed in the UK but trialled abroad. This is an example of global outsourcing as part of the research to market process. As noted in chapter 3, BC Philip (Case Study 2) is considering undertaking clinical trials of his innovative product in China. His reasons are twofold: lower costs and possibly quicker turnaround times. Taking innovative products to the market can take time. Sometimes, for example with pharmaceutical products, it may be that the stringent requirements for testing and validation may lead to innovations remaining on the shelf. However, as China and India seem to offer more accessible possibilities to undertake clinical trials under international standards, it is possible that more scientific innovative products and processes may now reach the market, or reach it earlier, than would have been possible if all research processes were undertaken in the West. Ralph, a Chinese scientist who works for a large international pharmaceutical company said "[T]here is an emergent trend for pharmaceutical products to be developed and sold first in China, then in India and finally in the West". In the West, compared to China and India, he said there was great threat of litigation if things went wrong and compensation costs are much higher. Hence, the higher risks, costs and length of time can be mitigated by global outsourcing of some research functions.

\subsubsection{Joint international laboratories}

Second, joint international laboratories may be set up, either privately or between universities. Suresh (Case Study 3 ) is considering internationalising his business in India either by setting up joint private independent laboratories with Indian chemical scientists in India or opening a separate branch of his laboratory in India. The intention is to outsource some R\&D work commissioned in the UK to India as it has a growing importance as a R\&D hub and also has highly skilled labour which is equally competent but less costly than in the UK (as noted in chapter 1). He has made a couple of trips to India to explore this and has made use of his contacts in his alma mater supplemented by contacts that he made at conferences in India and overseas where Indian scientists were present.

Joint international laboratories between universities may be initiated by researchers who have worked together in a British university. This can be illustrated by the case of BC professor, Sandy, from a highly reputable research university in the UK, who is collaborating with an overseas Chinese professor, Malcolm (Case Study 32), at an equally reputable 
university in China. They had previously worked together in the UK. They have established a joint laboratory in IT, aerospace and telecommunications research. Malcolm makes a couple of trips a year to work with Sandy in the UK and this is reciprocated by Sandy returning to China to work with Malcolm. During his time in China, Sandy renews his personal and professional contacts, extends his networks, and keeps abreast with research and other developments in China. They both hope that, in future, some of the joint work may lead to a spin-off company or to licensing agreements with existing companies in the UK or in China, or in both countries.

\subsubsection{Benefits and tensions in international collaboration}

International collaboration can lead to benefits but it can also raise issues. Malcolm is in favour of joint collaboration between China and the UK. After working in UK universities, he returned to China and spent almost eight years working for a Chinese national company which operates as an arm of Government. As a result, he built up extensive and strong relationships with Government officials, and since he left to take up a Chair at the university, he has continued to serve as a Government adviser. These links, and an understanding of changing Government policy, he says are crucial to influencing the Chinese Government which exercises greater central control on science programmes and funding than in the UK. $\mathrm{He}$ is strongly in favour of more collaboration with overseas countries, and as he has worked in the UK and understands the role of science in society and research protocols, he has "a soft spot" for the UK. He also thinks that China will benefit from scientific collaboration with the UK as the UK has a strong science research base which, unlike China, it has had the opportunity to develop over a long period of time. On the other hand, China has a greater focus on applied research as it has to find innovative solutions to major problems such as limited energy resources, pollution, poverty, poor health and rural deprivation. He regards basic research as very important to innovation. In his view, China can operate two models: first, it can do the basic research itself but this will take time and China does not have the luxury of time as it needs to solve its multiple problems in the immediate future. Second, it can engage in collaboration with other countries, such as the UK, which has already undertaken a large part of the basic research. He favours the second model as more cost effective and efficient and will lead to more knowledge transfer from universities to the public and private sector.

Any commercialisation of joint international research is dependent on different regulatory frameworks in the respective countries and can cause tensions if not properly addressed. For instance, academic entrepreneurship that arises from joint collaboration of UK with China, as is expected with the pioneering Innovation China-UK (ICUK) programme launched in 2007, needs to take account of the different approaches in each country. According to Shaun, a UK Government official stationed in China:

"In China there is this issue about spin outs from universities. If the university is State owned or a major funder is the State, the control of the spin out will still remain in the hands of the university. In other words, they are the ones who choose the CEO and they choose the Board. In various ways the university still hangs on to the business. Now the thing that occurs to me is that in the UK, the Government might have a stake in the business, equity in the business, but they have a more hands off approach. Whereas in China, not only is the State an equity in the business but there is a more hands on approach. The implications of these differences is something that might need to be teased out. ICUK is cutting edge: how does collaboration and cooperation of things that have a common potential occur, and how can they be developed in different markets in the UK and China? We know the answers are important but we don't know what they are. ICUK is almost like a pilot and we hope to get an idea about how you can actually work in partnership in taking ideas to different market places, about issues, about differences and nature and scale. And from ICUK we will be able to extract lessons learnt" 
The ICUK programme is being subjected to a formal evaluation and this may reveal the processes, issues and solutions for setting up, with China and other overseas countries, collaborative research programmes with commercial outcomes.

\subsection{Income generated from academic entrepreneurship}

Commercialisation of innovations can be a complex process and university technology transfer offices play an important role. Technology transfer facilities exist at about four fifths of universities (NCGE 2007). BC Philip (Case Study 2) was working with the technology transfer office of his university to explore the commercialisation paths for his invention. Some offices cater only for the IP generated by their own university, while others, like Imperial Innovations, also assist with the commercialisation of IP generated by other universities, including those from overseas.

The way the commercial gains are distributed between the university and the inventors varies. As Joe, the technology transfer legal adviser in a university said:

"Every university has its own policies on how much of a cut it takes and how it distributes the cash. You will find most universities are extraordinarily cagey on what their actual policies are, for obvious reasons - because they don't want their academic staff upping sticks and going to the university down the road if they realise they are missing out on a far larger cut of their invention"

Another issue that can complicate matters is that researchers involved may move to different universities in the world. Collaborative arrangements with overseas universities to jointly commercialise IP can occur if some of the work has been done at an institution in the UK. For instance, Sam, an overseas Chinese scholar who came to work at a leading UK institution via Sydney, went to Hong Kong to continue his research. While in Hong Kong, he worked with British collaborators. The innovation is now being commercialised and both institutions are beneficiaries of this. According to Joe, the technology transfer legal adviser at the UK university:

"We have an agreement with the Hong Kong University that we will split patent costs. Sam is building on work that was done here so in order to commercialise the whole lot he can't do it with just the Hong Kong work - you have got to build on the UK university work. And if you think about it, it is in my interest to come up with an agreement with Hong Kong because I want them to commercialise it. They have built it on our university's technology. We have got as much of a stake in it as they have. Business for us is not a zero sum game. It is very often collaborative. If a university comes forward to us and says, right, we have got one of your ex guys, we need access to some of your IP in order for us to make this license, and this license will make us all $X$ hundreds of thousands of pounds a year, I am very happy to sign that bit of relevant paperwork"

The rise in knowledge nomads which included highly skilled researchers who move to different global locations to pursue research interests and career trajectories will necessitate greater international collaboration of worldwide technology transfer services.

\subsection{Barriers to becoming an Innovation Nation}

The 2008 Innovation White Paper articulates the Government's ambition for the UK to become an Innovation Nation. The above sections have indicated that there is some commercialisation of innovation generated by universities and there are indications of internationalisation activities. However, it is argued that "[C]urrent levels of UK innovation 
are insufficient to drive UK productivity growth and close the UK productivity gap versus key competitors" (Porter \& Ketels 2003:16). One of the reasons for this appears to that although "[T]he UK has a long-standing strength in the generation of new ideas ... However, we have not been effective in turning those ideas into products, services and processes that consumers want to buy" (DTI 2003b:9). Furthermore, "UK universities (are) less active in commercialisation efforts than their peers in other advanced economies" (Porter \& Ketels 2003: 24). Although there are encouraging signs, according to surveys undertaken by HEFCE (2007b), that the situation is improving, nevertheless, some barriers exist or potentially exist and need to be overcome if the UK is to become an Innovation Nation. At least five barriers can be identified: lack of awareness of the commercial potential of research, lack of incentives for academics, potential curtailment of R\&D contracts, lack of recognition of the innovation potential of non-research students, and the lack of a sustainable pool of indigenous researchers. These are discussed in turn below with possible solutions suggested where relevant.

\subsubsection{Lack of awareness of the commercial potential of research}

There is a lack of awareness among many academic researchers of the commercial potential of their research and of the multiple progression pathways to market. The presence of spin out companies in incubators or innovation units in universities and publicity around academic staff who have engaged in commercialising their research, can serve as incentives to younger generations of academics. As Joe, a university technology transfer legal advisor said:

"The younger generation of academics are much more savvy. I find these days Ph.D students and post docs are much more switched on to what the potentials are, largely because of the publicity around things like spin outs. If they walk in here and see all these spin outs and read in the university report all about Professor $X$ for example who did very well from his research - they read about these and think well these guys are making money out of their work, I could do the same and then they come forward"

Publicising success stories is important for influencing not only undergraduate and postgraduate students but also other academics.

\subsubsection{Lack of visibility of research to external intermediaries}

The insufficient commercialisation of academic research is partly related to its lack of visibility to those who could use it commercially. Alfred, the director of a science based incubator (see chapter 8 ) talking about missed opportunities for commercialisation said "[T]here is absolutely tons of it; that is a pretty big issue in terms of literally people working in silos and nobody else finding out about it". Consequently he engages in some outreach work to universities to locate innovations and develop links with tenant businesses in his incubator:

“...we don't do as much as we would like to because again it is a resource issue as much as anything. Which is why the concept of having a one stop shop is a good one, because instead of us having to trawl round 10 universities, times all their different specialist faculties and secret programmes, we can go to a one stop shop in theory. And we have to discipline ourselves to keep apprised of what our tenants are doing and feed that across from the universities and vice versa. So it works pretty well, it is not perfect that's for sure but it is better than it used to be"

More outreach work by the Government and intermediary bodies would help to better capitalise on opportunities to promote knowledge transfer and commercialise research. 


\subsubsection{Lack of sufficient incentives for academics}

Academics can be influenced by different incentives. Some academics are keen for their innovations to be commercially exploited because they have a strong desire to contribute to improving people's lives. Thus BC Philip (Case Study 2) who has developed an innovative disease detection device strongly feels that this should be made available worldwide as it will reduce morbidity and mortality.

Other academics that are aware of commercial potentials may be unwilling to engage in entrepreneurial activities. Part of the problem is a commitment to academic values and ethics and fears that their autonomy and integrity as independent researchers will be compromised by the pursuit of 'filthy lucre'. It is important to deal with actual and perceived incompatible values of the university and the marketplace. It is also important to consider providing incentives for academics. The promotion criteria for academics are strongly biased in terms of research publications in highly reputable journals, conferences and books. Furthermore, a large part of Government funding to universities is based on the RAE (Research Assessment Exercise) which encourages such a bias. However, if the promotion criteria were changed to include recognition of entrepreneurial activity, and if Government funding took better account of departments' and universities' contribution to GDP, then it is likely that academics may become more favourably disposed to actively considering the commercial exploitation of their research. Some academics, such as Gibb (2005), argue that there should be more widespread adoption of university policies which provide incentives and recognition for academics who engage in research and development rather than maintaining the traditional focus on research and publication. There are some changes taking place in universities: for instance, the level of incentives for engagement with business and the community has shown increases over the last seven years (DIUS 2008). Change is also evident, for instance, in one pre-92 University which has revised its promotion criteria to include rewarding entrepreneurial activity and business/community engagement. However, if such a change became standard practice in all the universities, then there is likely to be an increase in academic entrepreneurship which will also span a wider range of disciplines than at present.

\subsubsection{Potential Curtailment of R\&D contracts}

Government policies potentially can create a barrier for large companies to award R\&D contracts to researchers in UK universities. Thus, the scope for academic entrepreneurship may be curtailed if companies engaged in using university personnel for R\&D work decide to relocate overseas on grounds of cost. As universities have to charge full economic costs, there is the danger that they are becoming less able to compete with countries such as China and India where R\&D costs are much less. While this is a threat, nevertheless, some UK Government officials have argued that no one country can have the expertise in all areas and, therefore, if the UK is seen as a centre of expertise in certain topic areas, it will not lose its capacity to do R\&D work for international clients. Furthermore, it is argued that while UK may not be able to compete in terms of cost, it can compete in terms of quality as its research personnel are of a high calibre.

While these arguments may well be true at present, there is a danger of complacency and ethnocentricity in assuming that other countries, particularly non-western countries, will continue to lag behind the UK. For instance, there have been various suggestions that the Chinese in China lack the capacity to innovate. Trevor, a senior British official in China said "[T]his is the legacy of previous political regimes premised on a 'punishment society' where in the past if you did something on your own initiative rather than follow instructions you were punished. Furthermore, teamwork was not encouraged as it was previously not safe to share knowledge as knowledge is power". However, under the current more open political regime, these mental and social barriers appear to be gradually diminishing. More studentcentred rather than the traditional didactic pedagogic approaches are being adopted in universities which are encouraging students to think for themselves. Often these pedagogic 
innovations are being spearheaded by overseas returned scholars who have been exposed to these practices at universities in the UK and elsewhere. For example, Malcolm (Case Study 32) who returned to China after spending several years lecturing and undertaking research at universities in the UK, uses these approaches when teaching science students. Chinese students studying in the UK, including in laboratories run by Chinese scholars, say that they have enhanced their innovative capacity while studying at British universities. There has been ample evidence of this at conferences organised by Chinese scholars in the UK where many doctoral students presented papers on their research. Most of these scholars will return to China, adding to the talent pool of scientists, and will help improve the innovative calibre of Chinese scientists. The rise in quality, the increase in the quantity of scientists with first degrees and doctorates graduating from the expanding higher education sector in China (as noted in chapter 1), its raft of modern science parks and incubators, and the increase in overseas Chinese returnees, are likely to combine with cheaper manufacturing costs to make China increasingly more attractive to large companies wanting to outsource their R\&D to universities. Indeed, one multi-national company that wanted to do this asked a British university with a campus in China to run a special training programme for its science employees, in order to up-skill them so that they could engage in R\&D work. This multi-national company was a major supplier of contracts to this British university who now faced the prospect of curtailment of such contracts in the face of competition from China.

India, like China, is also on the march to raising its innovation profile. It has achieved renown as an R\&D hub and has been attracting large multinational companies, particularly in the pharma industry, to undertake R\&D in the country. India has also witnessed a rapid rise in the number of patents which are under-exploited commercially. Indeed, to help redress this, Imperial Innovations, the technology transfer company of a British university, Imperial College, has now established a base in India, acquiring a 35\% stake in a company called i2India. It will help to create commercial value for the intellectual property developed in India's universities, research institutes and corporations. The associate company will also provide Imperial Innovations' technologies and technology businesses with greater market opportunities in India, enabling them to leverage the low-cost, world-class manufacturing and technology development resources available there. Such activities will promote the international commercial exploitation of UK research and that undertaken overseas, some undertaken on collaborative terms involving WB, BI and BC. Given the advancement of countries like India and China, it may be necessary for the Government to think about strategies to ensure that a substantial proportion of R\&D remains in the UK, and/or to develop collaborative approaches with universities and laboratories overseas which draw on the techniques of integrated global outsourcing used by businesses.

\subsubsection{Lack of sufficient recognition of the innovation potential of non-research students}

As noted earlier, the traditional conception of innovation has been very narrowly focused on science and technology innovation. The 2008 Innovation White Paper went beyond this to recognise that innovation can spring from a much wider range of disciplines and sectors including creative industries, financial services, public services and many more. However, what needs to be made explicit, particularly in a university setting, is the innovation potential of undergraduates and non-research postgraduates. Examples have been provided in chapter 3 of the innovation potential of such students. Hence, more attempts need to be made to capitalise on the innovation potential of non-research students and to consider patenting or other forms of protecting their intellectual property. Patent applications can be expensive, particularly for international patents, and this may deter students who lack funds. Provision of grants from universities, central or local government would help redress this. Driving up patenting of innovations of students, as well as of graduates and academics, will mitigate the lack of volume of patenting in the UK noted in the Sainsbury Review (2007). 
Students need a better understanding of IP protection and issues. Students who have developed IP that could be commercialised, or they think could be commercialised, may be afraid of disclosing this to fellow students, as well as their own tutors, particularly if it has been developed outside disciplinary studies. Even where they know that they would benefit from tutor support, this reluctance is due to fears that tutors "may steal my ideas". This was the view, for instance, of $\mathrm{BI}$ student Bhopal, and this clearly raises the issue of adequate knowledge of IP rights and protection, and of the level of trust between students and tutors. In some cases, students realise that collaboration with their tutor is essential and the ability to negotiate such collaboration is an important skill. These negotiating skills and selfconfidence may be more apparent in mature students. This was the case of WB William who developed a sports device while a mature undergraduate student, and subsequently collaborated with his tutor to produce a prototype, now licensed to a major sports manufacturer. Akbar, a British Pakistani mature student, also developed a very good relationship with his tutor. Akbar said he trusted him and valued his support though the tutor has no equity stake in his business.

Students, their tutors and academics all need awareness training in IP, as occurs in some universities, if all students and academics with innovations that can be commercialised are confident to make disclosures and apply for IP protection. There is evidence that suggests "...that the UK has very strong intellectual property rights protection, providing a good environment for innovation and technology transfer" (Porter \& Ketels 2003:25). The Gowers Review (2006) of the UK's intellectual property framework found it generally fit for purpose, although the report contains various recommendations to deliver a more robust intellectual property framework to promote innovation in a global economy. It is generally assumed that it is the intellectual property of doctoral students, post-doctoral researchers and academics that needs protection. However, more attention needs to be paid to protecting the IP of nonresearch students.

Managing the intellectual property of students can be a complex process because in most cases they solely own the IP, unlike in the case of staff, who as employees of the university, do not solely own the IP. A recent report for the NCGE notes that there has been an unprecedented growth in recent years in undergraduate and non-research postgraduate students' engagement in entrepreneurial activity and new venture creation (Freeman \& Barron 2006). However, “.. at all levels IP issues may arise that may both hinder the development of new ventures and also provide an immediate unsatisfactory experience for the student concerned. In addition the student may develop a negative perception that could affect their relationship with an institution as an alumnus in the longer term" (Freeman \& Barron 2006: 3). A few universities run workshops for students and staff on student IP management but this needs to become standard practice across all universities.

\subsubsection{Lack of a sustainable pool of indigenous talent}

The lack of a sustainable pool of indigenous highly skilled talent can act as a brake on the innovation capability of the UK. This issue, in relation to SET skills, for instance, has been recognised by Government (DTI 2006a). A considerable proportion of students in many subjects, including on SET taught and research postgraduate programmes, are from overseas. A recent report on patterns in HE institutions (UUK 2007) showed that in 2005/06 seven in ten $(71 \%)$ of taught postgraduate enrolments and one in two $(48 \%)$ on research programmes were non-UK. High levels of enrolments from international non-EU students appear particularly in engineering and technology, agricultural sciences and some aspects of biological sciences. The percentage of non-British in SET ${ }^{81}$ occupations has increased over time (1992-2003). For instance, in the period 2002-03, non-British made up 7\% of those in SET occupations, with the highest percentages being among science professionals $(12 \%)$ and ICT professionals (11\%) (Jones \& Elias 2005).

\footnotetext{
${ }^{81}$ This report was on science, engineering and technology (SET) and does not include Mathematics which is included in STEM.
} 
Britain has not been generating a sufficient stream of indigenous young people, including WB, who can take up doctoral studentships, research assistant and research fellow posts. As noted in chapter 2 , there are $\mathrm{BI}$, and particularly $\mathrm{BC}$ scholars working at doctoral and postdoctoral level but because of population size, their numbers are inevitably going to be small. Chinese scientists, both UK and overseas domiciled, are very successful in obtaining grants from UK research councils (Jones \& Elias 2005). The research councils award grants to universities and the nationality and immigration status of the researchers is not relevant. Some of the overseas postgraduate research students from China studying in the UK have been recruited directly in China by UK domiciled Chinese academics on visits to China to attend conferences and to see their parents, family, friends and professional colleagues. For instance, BC academic, Adrian is the supervisor of Penny, a Life Sciences Chinese doctoral student at Bath University. ${ }^{82}$ Adrian was visiting China and met Penny's Chinese professor, Hector, at a conference. Adrian was looking for students to work on a project funded by a UK research council. Hector recommended Penny to Adrian, and following an interview, he selected her and arranged a scholarship. Senior Chinese academic Andrew (Case Study 5) also followed a similar strategy of recruiting students directly from China through his contacts there as he was finding it difficult to recruit doctoral students in the UK. Chinese and Indian students are admired not only for their intelligence but also for their diligence and capacity to work long hours. As Philip (Case Study 2) said "[I]n China you see the lights on in the lab even after 10 o'clock and the students are working on their research. In the UK, the British students leave at $5 \mathrm{pm}$ and go to the pub". While this may be an exaggeration, nevertheless, the lack of an indigenous pool of potential research students, provides an incentive to recruit students with similar work ethics from overseas using personal and professional networks.

The flow of overseas SET personnel to the UK is not only through the student route as it was in the US (Saxenian 1999) but also through proactive steps taken, for instance, by ambitious Chinese scientists in China who keep a look out for jobs advertised at UK universities or they hear of these through word of mouth. Some, particularly a few years ago, sent their CVs 'on spec' to a number of universities. Combining Chinese and overseas degree qualifications and experience enhances job prospects for Chinese scientists when they return to China as often the large companies who have partly sponsored their research in the UK have recently established bases in China. For instance, at a recent conference of Chinese scholars in the UK, a British educated Chinese woman Betty, working for Proctor \& Gamble, Beijing, gave a presentation on their R\&D work in China where it is expanding its research laboratories. The organisation offers lucrative starting salaries and career opportunities for those with a doctorate and international experience. Conference participants comprising doctoral students and young researchers were encouraged to apply and there was a lot of interest judging from the questions raised after the presentation. Sometimes Chinese student associations in the UK host a recruitment event for multinationals or companies in China or UK who wish to employ British educated Chinese to work in China.

The issue of indigenous capacity building has been raised recently and the Government is devising policies to address this. As noted in the Government's document World Class Skills, "[I]n a world of increasing international trade and investment, migrant workers' skills make an important contribution, but we must also continue to develop the skills of our domestic workforce if we are to meet the skills needs of a prosperous economy" (DfES 2007:4) The need to engage in capacity building specifically of UK scientists was recommended most recently by Sainsbury (2007) in his review of science and innovation in the UK. The 2008 Innovation White Paper reiterates the commitment to raise the profile of science in society and to promote greater take up of STEM subjects at school, college and university. There is some work aimed directly at women and ethnic minorities. For instance, there is a scheme called STEM NET which is running programmes in schools to increase the

\footnotetext{
${ }^{82}$ Pseudonym.
} 
engagement in science of ethnic minority students. These attempts at capacity building which already appear to be yielding positive results (DIUS 2008) are to be applauded, endorsed and evaluated for effectiveness. When students are at university, it is also important to try and maintain the science focus in terms of employment as many bright scientists can be lured into lucrative non-science employment which requires numerate graduates. As noted in chapter 2, BI students are over-represented in SET subjects at undergraduate and masters level but not doctoral level and steps could be taken to encourage them, and WB too, to follow the footsteps of the Chinese who are overrepresented at doctoral level.

It is likely that the UK's reliance on overseas scientists, and particularly those from China, cannot be expected to be sustained at the same level over the long term. There are various developments in China which may make it attractive for overseas domiciled Chinese to return and for those on short term contracts not to seek renewal. The expansion of the HE sector in China, as noted in chapter 1, has generated a demand for teachers and academic staff. To help fill these vacancies, Jonathan, a senior Chinese academic interviewed in China, suggested it will be necessary for Chinese working or domiciled overseas, including UK, to return to China. This will also help to develop the innovative capacity of the country as more academic staff mean smaller class sizes and greater opportunities to develop creative thinking using student centred pedagogic approaches. A commonly held view is that, if China provides the right political and socio-economic environment, its innovative capacity will flourish.

BC maintain an awareness of political, economic and social developments in China. They generally maintain strong personal links with China through visits, telephone calls and emails. Frequent visits from overseas also mean they renew contacts and obtain first hand knowledge of latest developments in their country. Some, like Philip (Case Study 2), hold one or more visiting professorships at Chinese universities which provide opportunities for short periods of teaching and collaborative research activity. Many visit their alma mater to see former teachers and give seminars on their work. As Peter, who holds a permanent academic post as a science professor at an elite university in the UK said:

"I go to Beijing twice a year - the main purpose is to see my parents and also for my children to see their grandparents. They study Mandarin at Sunday school in England so they can talk with their grandparents and relatives. But I also make use of the time to talk to academic colleagues at universities in Beijing and elsewhere in China to find out what is happening, to develop international collaborative research projects and identify opportunities to commercialise them. Who knows, I may return to China in the future so it is good to have the contacts if you need a job"

India and China, whose economies as we saw in chapter 1 are rapidly growing, have introduced various schemes to attract their overseas domiciled population back home. The Indian Government has introduced Overseas Indian Citizenship which allows multiple visits to India without visas for each trip as well as rights to purchase property and undertake investments. Global salaries and affluent lifestyles are also on offer in India. Second generation Bls like Alcar (Case Study 17) and Sita (Case Study 25) and others who have made the transition to work in India, and are happy with the decision, serve as ambassadors promoting the idea of relocation to peers in the UK. Returnees, particularly those from the USA, have spearheaded the rise of IT cities such as Bangaluru, ${ }^{83}$ Hyderabad and Pune which have helped to contribute to India's rapid economic growth (Saxenian 1999). Taiwan, Hong Kong and mainland China have also used various incentives to attract returnees (Wilsdon \& Keeley 2007). This has led, for example, to senior posts at the University of Science and Technology in Hong Kong to be headed up by eminent Chinese scientists who

\footnotetext{
${ }^{83}$ Formerly Bangalore.
} 
previously worked for several years in the USA. It is likely that if China is to develop into the next science superpower, and to achieve a Nobel Prize, which is its ambition, it will need to further encourage the return of its overseas Chinese scientists.

In a very competitive global employment market, national retention of scientists, engineers and technologists, as well as those of other disciplinary backgrounds, and irrespective of ethnicity or nationality, will always be a threat. As mobile professionals, they are likely to go, either short term or long term, to countries which offer better conditions. India, as noted earlier, offers global salaries, and China is continuing to develop high quality laboratories and science parks with state of the art facilities. There will probably always be a continuing stream of 'knowledge nomads' spending some time in the UK but their peripatetic nature will not create the sustainable pool of highly skilled talent in UK universities, and in the R\&D units of companies that the UK needs to ensure its innovation capacity and global competitiveness remain leading edge. As noted in chapter 1 , research in the USA (Saxenian 2006) has demonstrated a high level of 'brain circulation' among the 'New Argonauts': highly skilled Indians and Chinese who follow their own international career trajectories which enable them to take advantage of employment and entrepreneurial opportunities in the USA, as well as their home countries of India, China, Taiwan and Hong Kong. Furthermore, such professionals also oscillate between different organisational and institutional structures as they consecutively or simultaneously take up employment or selfemployment or move between working in academia or in industry. The ability to work in both academia and industry, and in a global employment market, is encouraged among Chinese scientists in the UK. For instance, at a science conference organised for and by Chinese students and scholars in the UK, one of the sessions focused on career development. The panel of experienced scientists who had worked in multiple organisational and geographical contexts, exhorted the audience, which included many young doctoral students and postdoctoral researchers, to develop a portfolio of skills and experience which would allow them to take advantage of a wide range of opportunities in the UK and China, as well as elsewhere in the world, and in universities, multinationals and SMEs.

However, the potential loss of UK domiciled scientists and professionals from other countries, or of second generation $\mathrm{BI}$ and $\mathrm{BC}$, should not be over-stated. A range of personal factors need to be taken into account before any decision is made to leave the UK. To take the example of BC. Some BC have considered returning to China permanently but there are various factors which may hold them back. For instance, there are personal factors such as their children being well established in schools in the UK and their concern about the negative effects of uprooting them. Furthermore, although the children usually have attended weekend classes in Mandarin, their level of fluency and written ability are not necessarily sufficiently high to enable them to cope with Mandarin-medium lessons as well as the rigours of the Chinese educational system. As one mother, Anita, a chemical scientist at a British university with a five year old son said "I don't think my son could cope with the pressures of the schools in China. They are very competitive. He is used to the more relaxed system in the UK". Another factor is the uncertainty of jobs they will be able to obtain in China. This is not only in terms of material benefits but also whether they will obtain jobs commensurate with the status of jobs held by their former classmates who have remained in China, or returned from overseas many years ago, and benefited from the expansion in economic opportunities. On the other hand, because of China's one child policy, many UK domiciled Chinese are the only child and many feel both a responsibility, and an emotional need, to live near their parents. In the case of some Chinese, it is unlikely that they will return permanently to China because they have married a WB and expect to continue residing in the UK. Some of these factors may mean that there will still be a core of $\mathrm{BC}$ who will continue to be UK domiciled. 
This chapter has focused on innovation as the driver of productivity. As a result mainly of Government funding strategies, innovation has predominantly been manifested through academic entrepreneurship underpinned mainly by science and technology based research that has commercial potential. Different forms of academic entrepreneurship exist and their attractiveness varies. Licensing of intellectual property generated by research is a viable option for academics whose heart is in research and not running a business. BI and BC academics appear to be in a relatively better position than WB academics to exploit the potential of their ancestral countries, India and China. This can be as locations to establish private or university based joint laboratories or collaborative arrangements with academic counterparts to undertake more cost effective research processes and manufacturing of innovatory devices. Hence, they are able to bring the model of integrated global outsourcing, common among many international businesses, to the process of taking research to the market. This is vastly facilitated because they are able to make use of their cultural capital, including multi-linguistic competence, as well as professional and friendship networks back home among compatriots. These assets are also used by $\mathrm{BC}$ and $\mathrm{BI}$ academic-related and professional personnel to facilitate international research collaboration and commercialisation as well as promoting business formation and innovation in the UK using intellectual property generated in India and China. To emulate the modus operandi of $\mathrm{BI}$ and $\mathrm{BC}$, it is essential that the wider population of academics in the UK build and sustain global research networks. Although there are encouraging signs of international institutional collaboration, this encompasses only some universities and much more could be done by Government and universities to make such collaboration widespread among all universities.

To realise the Government's ambition to become an Innovation Nation, it is essential that the barriers to innovation are removed or mitigated, and missed opportunities curtailed. The development of academic entrepreneurship in the UK is dependent on a talented pool of academics, particularly SET academics, who are also commercially savvy. This requires removing the barriers of ignorance of the commercial potential of research among existing academics, opening the eyes of new university recruits, and providing academics with incentives to value and engage in entrepreneurship. To sustain future academic entrepreneurship, capacity building of an indigenous pool of innovators, particularly SET based, is crucially important. Government attempts to do this are endorsed through the promotion of science in schools, colleges and universities. However, more could be done to encourage postgraduate research take-up, particularly among BI who are over-represented in SET at undergraduate and masters level but not at doctoral level, and WB who are only very slightly over-represented at this level. Potential threats to the curtailment of R\&D also need to be addressed. The low recognition of the innovation and commercialisation potential of non-research undergraduate and postgraduate students has led to missed opportunities and this cannot be allowed to continue. Greater recognition and support of the innovation capacity of non-research students not only from SET disciplines, but a crosssection of disciplines, would dovetail very well with the 2008 Innovation White Paper's wider definition of innovation. If successful, it is hoped that the network of university clusters that the Government has charged NCGE to establish (DIUS 2008, BERR 2008a) will help to address this issue (see chapter 8).

Emerging economies, such as those of India and China, pose threats to the UK (as well as opportunities) which need to be taken seriously. Strategies to boost the quantity and quality of indigenous researchers as well as support mechanisms for greater collaborative schemes between the UK and emerging economies need to continue. More global collaborations linking universities with investors and businesses would be welcome. Some thought could be given to considering how schemes, such as the Science Bridges scheme, could be modified or new schemes developed for non-research students to link with entrepreneurs, investors and businesses. It is important for the UK to support 'brain circulation' of its 
indigenous talent pool as this will generate wider social networks, familiarity with a wider knowledge base, experience of working with researchers from different countries in their home territory and understanding of their research protocols. However, it is also necessary to guard against brain drain which will deplete the indigenous talent pool. 


\section{CHAPTER 6: DRIVER OF PRODUCTIVITY: COMPETITION - THE VALUE OF CULTURAL AND SOCIAL CAPITAL}

\subsection{Introduction}

This chapter focuses on competition as a driver of productivity. In particular, it looks at the competitive advantage of $\mathrm{BI}$ and $\mathrm{BC}$ in helping to penetrate the markets of the emerging economies of their ancestral countries of India and China. In chapter one, we noted that for UK businesses to internationalise in overseas markets they need to overcome both physical and psychic distances, and these are likely to be more significant when countries like India and China are involved because of their physical and psychic distance from the UK. For British people, setting up international businesses in India is relatively easier than in many other countries because, as a former British colony, it possesses features which are similar to Britain, such as democracy and the legal system. The same applies to Hong Kong where, for instance, the Intellectual Property laws are the same as in the UK. Furthermore, English is widely spoken in these two countries. In Hong Kong, British business transaction approaches and management practices are more commonly found. Mainland China, on the other hand, has a different political regime, different approaches to business, a different language, Mandarin, is the lingua franca, English is not so widely spoken, and it has a greater degree of heterogeneity because of its vastness. These factors help make mainland China a more difficult country for entrepreneurs to penetrate, particularly those with no previous exposure to the country or with contacts there.

In this chapter, I explore how student, graduate and academic $\mathrm{BI}$ and $\mathrm{BC}$ are able to use both their cultural capital and social capital to provide a competitive advantage in developing and sustaining entrepreneurial, and particularly international, entrepreneurial activities. The chapter starts with a brief discussion of cultural capital. Various aspects of cultural capital are explored, including embodied cultural capital and linguistic competence, and the way they are leveraged to enhance the international capability of $\mathrm{BI}$ and $\mathrm{BC}$. We noted in chapter one, that networks play a critical role in the development of international entrepreneurship and the rest of this chapter focuses on networks. Three types of social capital are identified and discussed: bonding (networks within communities), bridging (networks between different communities) and linking (networks to institutions and individuals in positions of power and influence). The ways in which different types of social capital are developed, enhanced and sustained through the use of a variety of social and cultural practices by $\mathrm{BI}$ and $\mathrm{BC}$ are explored. An endowment of networks is not sufficient: their value lies in knowing how and when to leverage different networks for different purposes. The way $\mathrm{BI}$ and $\mathrm{BC}$ do this for internationalisation purposes is examined, including provision of overseas hospitality, acquiring information and market intelligence, business partner and staff recruitment, accessing finance, negotiating with Government officials and university senior management, and developing collaborative research. Finally, I examine the kinds of mechanisms that can be used to facilitate the extrapolation to the wider population of the principles underpinning competitive advantage that networks give $\mathrm{BI}$ and $\mathrm{BC}$.

\subsection{Cultural Capital}

Cultural capital has been defined in various ways but as used here it refers to the possession by individuals of physical and cultural attributes and tacit and/or explicit knowledge of cultural mores and dispositions. This section briefly examines different types of cultural capital, such as linguistic and embodied cultural capital (Bourdieu 1997) and cosmopolitan cultural capital.

Linguistic cultural capital can take different forms. BC Kenneth (Case Study 13) and Michael (Case Study 15) speak and write Mandarin fluently. They are thus able to deal with 
business regulations and other bureaucratic procedures without interpreters. While knowledge of the official language in China is a distinct advantage, on the other hand in India and Hong Kong, competency in the major languages of Hindi and Cantonese respectively is not essential as English is widely used for communication with professionals, civil servants and business people. However, linguistic cultural capital can play a role in everyday life. BI Sita (Case Study 25) and Alcar (Case Study 17) possessed only a rudimentary knowledge of Indian languages when they first set up their businesses in India but this was still an asset as they could converse with shopkeepers, taxi drivers, domestic staff and the general public which facilitated their settlement in India.

Embodied cultural capital is the cultural capital that resides within individuals by virtue of having a particular skin colour, facial features, mannerisms, ways of thinking and manner of participating in commensality and other social activities. Such individuals can fit more easily into the wider social fabric of their society both at home and in its diaspora manifestations. Where they may be lacking in certain facets of cultural capital, steps can be taken to acquire this. For instance, BC David (Case Study 18) is a Cantonese speaker as his parents originated from Hong Kong. However, as he runs the China office in Beijing of his China-UK business, he has started taking lessons in Mandarin to fit in more easily with mainland Chinese both domestically and professionally. As he said:

"When Chinese people in Beijing see my face they know I am Chinese but when I start to talk they realise that Mandarin in not my mother tongue and it creates a distance between us. So I am trying to become like a native speaker of Mandarin. When I write it is OK because nowadays we use the same script for Cantonese and Mandarin"

Thus cultural capital is not static and can be augmented over time and leveraged to provide competitive advantage.

$\mathrm{BI}$ and $\mathrm{BC}$ students, graduates and academics also possess cosmopolitan cultural capital. As a result of residence in the UK, and in some cases, other parts of the West, they have acquired cosmopolitan cultural capital. They speak English fluently and sometimes other western languages too. They are comfortable wearing western attire, are at ease with British and other westerners, and familiar with the food and alcohol culture. The ability to operate in multiple environments gives them a competitive advantage as they are able to establish empathy with a wider range of people than most WB. They are able to engage in the strategic manipulation of identity to enhance their business ambitions. BC David (Case Study 18), for instance, says that in Beijing when he has business dealings with Chinese businessmen, Government officials and other Chinese people, he draws on his Chinese cultural capital to achieve rapport with them. On the other hand, when he is on business trips to the UK, or has to deal with British clients in China, he draws on his cosmopolitan cultural capital to smooth face-to-face interactions. This versatility enables him to make use of the "best of both worlds". There are also other forms of cultural capital which are not based on ethnicity. BI Jay \& Raj (Case Study 10) who are graduates of an elite, worldrenown university use the university brand as a way of drawing on its reputational benefits to enhance their credibility in the USA.

Penetration of overseas markets is aided by the possession of appropriate cultural capital. BC Kenneth (Case Study 13) and BC Michael (Case Study 15) had considerably less difficulty establishing their businesses in China as they are fluent Mandarin speakers, have multiple contacts, and have a general familiarity with the country where they were born. A different degree of familiarity is evident in the case of Sita and Alcar who had visited India often as children and teenagers to see family members. Such familiarity can mean that they are also aware of the 'red tape' and working practices evident in their country. While BI, BC and WB experience frustration with the bureaucracy of India and China, the threshold of tolerance among many $\mathrm{BI}$ and $\mathrm{BC}$ appear higher than WB and they are less likely to give up 
fulfilling their entrepreneurial aspirations. WB Matthew (Case Study 7), an experienced entrepreneur in England, found it very difficult to penetrate the Chinese market as he possessed no relevant cultural capital. He attributes his eventual success after several years mainly to resilience and determination to capitalise on a new lucrative market for his product. On the other hand, WB Dominic (Case Study 21) had less difficulty with setting up his international business as he could leverage his international cultural capital: he was a graduate in South East Asian Studies so was familiar with the history and cultural traditions of China, and he had worked in China for several years and could read, write and speak Mandarin fluently. Hence, while the appropriate international cultural capital can be acquired by WB entrepreneurs themselves to penetrate overseas markets, those who originate from these countries are usually a step ahead.

\subsection{Social Capital: Concepts}

The concept of social capital has been subject to much debate and discussion, but as used in this chapter and this report, it refers to networks. Putnam states that:

"Whereas physical capital refers to physical objects and human capital refers to the properties of individuals, social capital refers to connections among individuals social networks and the norms of reciprocity and trustworthiness that arise from them." (2000:19)

Putnam (2000) distinguishes between bonding social capital (networks between homogenous groups) and bridging social capital (networks between heterogeneous groups). In this chapter, bonding social capital is used to refer to networks within the $\mathrm{BI}$ community and the networks within the $\mathrm{BC}$ community. Bridging social capital is used to refer to networks between Bls and wider WB society and BC and the wider WB society, as well as the networks between $\mathrm{BI}$ and $\mathrm{BC}$ and other ethnic minorities.

A third form of social capital, discussed in this chapter, is referred to as linking social capital. According to Woolcock:

"Linking social capital, which reaches out to unlike people in dissimilar situations, such as those who are entirely outside of the community, thus enabling members to leverage a far wider range of resources than are available in the community" (2001:13-14)

Thus, those who fall in the category of linking social capital would typically be Government officials, bank managers, venture capitalists, senior managers of universities and equivalent who hold positions of power and influence over a wider range of resources. Trust is a key characteristic of all the networks, particularly bonding and bridging social capital. BI and BC communities have social capital with considerable range and depth. These three types of capital are discussed in more detail below, followed by a discussion illustrating their application in the context of international entrepreneurship.

\subsection{Bonding Social Capital}

$\mathrm{BI}$ and $\mathrm{BC}$ have networks not only among their communities in the UK, but also bonding bilateral networks with family and friends in India and China respectively. Furthermore, as part of diaspora communities, they also have multilateral bonding kinship and friendship networks with family and community friends in Europe, the USA and South America, Australia, the Gulf States, Africa, - indeed virtually every country in the world.

The structure of social relations within Asian families, including $\mathrm{BI}$ and $\mathrm{BC}$, provide multiple opportunities for family members and friends to get together, thus providing opportunities for bonding and for information exchange. Technological advancements allow information 
exchange through email, MSN and telephone, both nationally and internationally. Asian cultural practices, which include frequent celebrations of domestic rituals, religious activities and community events, provide an ample playground to renew old networks and build new ones. The cultural expectation of attendance by extended families living in different parts of the world at marriages, funerals and other important social events, creates a wider range of opportunities for extending networks and providing conduits for informal information exchange. Visits to the ancestral homeland, and to family and friends in diaspora communities located in different parts of the world, provide opportunities for developing contacts across the globe. For students, graduates and academics with entrepreneurial ambitions, such events can provide information, for instance, on the emerging middle classes in India and China, regarding their changing tastes in fashion and consumption, and expectations of health and well being. Observing the items relatives buy when they come to UK open eyes as to what is not obtainable or not easily obtainable in India and China and, therefore, can provide information on potential opportunities in developing niche markets overseas. Awareness of the medical and health problems, and of diagnostic and treatment protocols and regimes, may raise awareness of the potential wider benefits of life science and medical research. These events can be used to provide mini ethnographies that the business savvy can use to gain information which could lead to more formal market research. It can be the first step in the business idea to start-up trajectory, as exemplified in the case of Sita (Case Study 25) who eventually opened a luxury lingerie business in India for the expanding group of middle class women.

Universities provide opportunities for developing bonding social capital among students, graduates and academics as exemplified in the case of the Chinese. There are opportunities for academics from the same ethnic background to work together. Thus BC academic Sandy worked with overseas Chinese Malcolm (Case Study 32) for several years in a UK university on joint research projects. Their collaboration is still continuing through the setting up of a joint laboratory as noted in chapter 5 . There are extensive Chinese students and scholars networks in the UK. Some are partly funded by the Chinese Embassy in the UK. There are also other specialist discipline based networks such as for Life Sciences and another for Chemistry. These networks hold regular events, including conferences, some of which are partly funded by the Chinese embassy. These networks are dominated by overseas students and academic staff from mainland China but many BC students and scholars who originated from mainland China are involved in these networks. On the other hand, $\mathrm{BC}$ who have originated from Hong Kong are less involved. Part of the explanation appears to be language. As noted in chapter 2, one of the main languages spoken in Hong Kong is Cantonese and few speak Mandarin although very recently it has become incorporated into the mainstream curricula of schools in Hong Kong. British born Chinese students, graduates and academics may have learnt Cantonese when speaking to parents and relatives and through attendance at special classes organised by the community. Unless they also attended Mandarin classes in the UK, the provision of which is a more recent phenomenon, it is unlikely that they have fluency in this language as exemplified by David (Case Study 18) who, as we saw earlier, is now learning Mandarin in Beijing. Some of the events organised by the Chinese networks use English as a medium of communication and this is certainly the case for formal presentation at conferences.

However, Mandarin is also used: for instance, at a Life Science conference, a speech by an official from the education department of the Chinese Embassy was in Mandarin. The conversations during tea, lunch and dinner breaks was in Mandarin. English, as a common language, is used in mixed groups of Hong Kong and mainland Chinese but it is evident that many of these conversations are more stilted.

These student and scholars' networks help to create strong social and professional bonds. As the students and scholars originate from different parts of the vast country of China, these events help to establish bonding social capital. Bonding networks established as students often persist over time. Thus, current academics maintain strong bonding links with 
the former tutors of their undergraduate alma mater in China. For instance, BC scientist Edward had recently been promoted to a professorship at an elite British university. His former Chinese tutor, Gavin, now in his 70s, came to England with his wife to attend Edward's inaugural professorial lecture, a long-standing tradition of British universities. BC links with their alma mater both in China and in the UK are important nodes in their networks that can be leveraged when necessary.

\subsection{Bridging Social Capital}

First generation $\mathrm{BI}$ and $\mathrm{BC}$ have extensive bonding capital but more limited bridging and linking capital, except in the case of those working as professionals. Lack of English language fluency and lack of familiarity with a cross-section of British society are some factors which account for less bridging and linking social capital. This is, however, less true of the highly educated first generation professionals such as BI Suresh (Case Study 3) and BC Philip (Case Study 2). Unlike others from the first generation, these first generation professionals, as well as second generation $\mathrm{BI}$ and BC students, graduates and academics, have a wider repertoire of networks. High level English language fluency skills is an important factor. For the second generation, participation from a young age in schools, colleges and universities in the UK with WB, and those from other ethnic origins, has meant that they have grown up and been educated in multi-ethnic environments.

While there is individual variation in the range and depth of their networks, nevertheless, on the whole, in addition to bonding social capital, BI and BC students, graduates and academics also have substantial bridging as well as linking social capital. University attendance provides an arena to develop contacts. The institutional infrastructure of universities has an impact on the development of social networks. Collegiate based universities such as Oxford, Cambridge, Durham and Kent provide more opportunities for contact between members of the college through co-residence, commensality practices, social events and informal socialising in the college bar. These opportunities also facilitate the development of multi-disciplinary networks. These complement the networks created within discipline-based departments. Universities which do not have a collegiate system provide different, but possibly fewer opportunities for the creation of networks. Participation in student clubs, associations and sports events also provide multiple opportunities for developing networks.

Pedagogic approaches used by academic tutors can also facilitate networking. As will be seen in chapter 7 , some undergraduate and postgraduate courses include entrepreneurship in their programmes and require students to work in groups to develop a business plan. Two examples of multi-ethnic student entrepreneurship teams that emerged from different pedagogic approaches are: Case Study 8 with undergraduates Arun, Avinash, Gerard and Elizabeth and Case Study 4 with postgraduates Chandra, Anwar, Leela and Christof. With Case Study 4, the students were asked by their tutor to form teams on a voluntary basis from within their cohort. Various factors affected team formation including interest in the business idea, compatibility of personalities and complementarity of skills. With case Study 8 , the course tutor had a deliberate policy of allocating students to teams to ensure heterogeneity in terms of gender, ethnicity, aptitudes and skills. The undergraduate student entrepreneurship team of Lincoln, Martin, Morley and Ashok (Case Study 6) emerged organically through a different process but facilitated by common disciplinary interests and informal tutor support. They were studying on the same degree programme, although Morley was based at another university. However, he was a school friend of Lincoln and they maintained their relationship while at different universities. Lincoln and Ashok were also involved in the student enterprise club and this augmented the link they already had as costudents on the same degree programme. The interest of the four students in the same business idea, which would make use of their disciplinary skills, brought them together. These mechanisms provided opportunities for students, including $\mathrm{BI}$ and $\mathrm{BC}$, to begin the 
process of collaboration while still at university, across ethnic boundaries and between UK and overseas students.

With postgraduate research students and academics, there are various ways in which bridging social capital can be developed. A significant amount of university based research, particularly science based research, is conducted in teams which include doctoral research students, post-doctoral researchers and academics. Such research structures provide opportunities for intra and inter-departmental, inter-institutional and international collaboration. As we saw in chapter 5, there are also Government sponsored studentships and fellowships, and international programmes like ICUK and UKIERI, which promote international collaboration. Researchers are expected to disseminate their findings via publications and presentations at academic events. Thus they have opportunities to develop wider national and international bridging networks through participation in national and international seminars and conferences. These create opportunities to meet other researchers in the same field working in different parts of the world. For instance, BC Philip (Case Study 2) has developed links with scientists from India working in the same topic area whom he met at conferences in India and elsewhere.

The contacts developed at university can be sustained through friendship and membership of professional associations, as well as alumni networks, social and other events, providing access over the life course to peers and other contacts that have been developing their professional careers not only in the UK but in the global labour market.

\subsection{Linking Social Capital}

Contacts which facilitate access to a wider range of resources are important in entrepreneurship development, particularly international entrepreneurship. Linking social networks can be developed by individuals and institutions. BI and BC can make strategic alliances with their countries of origin via institutional links with universities. For instance, some BC academics retain visiting professorship status with universities in China, sometimes their undergraduate alma mater or also other universities they have developed contacts with through their academic work. BC Philip (Case Study 2), as noted earlier in chapter 5 , holds visiting professorships at a number of universities in different parts of China. Other ways through which links may be maintained with universities is through scholars giving invited seminars on their current work while on holiday in China. Thus, Hannah, a BC social scientist working as a researcher at a British university, has given seminars at various universities in China whenever she returns to visit family. The Chinese Government often provides financial incentives to overseas scholars to maintain links in this way, for instance, by providing an honorarium or help with air fares.

As graduates and academics progress through the life course and take up senior positions in local and central government, international government institutions and agencies, multinational companies and universities, these form the basis of linking social capital. Thus BC Sandy had links to government officials in China via Malcolm (Case Study 32) who, on his return to China after working with Sandy and colleagues, worked for a few years as a senior civil servant. As noted in chapter 5 , Malcolm visits the UK on a regular basis to work with Sandy as they run a joint UK/China laboratory. His links in China have also been shared with other BC and WB at Sandy's university and have been instrumental in developing further international collaboration at individual, institutional and government levels. To complement personal networks, there are wider institutional networks. For instance, some universities are members of a World Universities Network which has 24 institutions which include universities in India and China. The global Network has an enterprise forum whose activities are in the early stages of development.

Apart from personal and institutional mechanisms for generating networks, technological advancements have created other conduits for networking. There are also a host of online 
networks. These include on line social networking sites such as FACEBOOK and also business ones such as LINKEDIN which can be used by entrepreneurs who want to develop their business, including internationalising it. The younger generations of graduates are familiar with new forms of technology based social media which is one of the reasons why the National Council for Graduate Entrepreneurs, as will be seen in chapter 8, is developing its social networking site for students and graduates.

\subsection{Leveraging Social Capital}

In order to effectively leverage social capital, it is important to mitigate problems with networks. There can be a market failure of network path dependence, that is, a single network can lead to the concentration of knowledge and information sharing, for instance, of a particular overseas market, or a geographical section of it or particular sector. Furthermore, over-reliance on a small network can result in groupthink (lack of critical thinking) and lack of radical innovation (Prashantham 2008). Hence, the wider the networks, the more advantages they can potentially offer. With Indians, it has been suggested that their networks may be constrained by caste boundaries. There was no evidence of this among the $\mathrm{Bl}$ interviewed, and it may be that with second generation graduates, the norms that traditionally govern ascribed status relationships have been attenuated. At university, it appears that $\mathrm{BI}$ students are less aware or even concerned about the caste background of fellow $\mathrm{BI}$ or overseas Indian students so the networks they establish are more likely to transcend caste, region and religious boundaries. From the previous sections, it can be seen that $\mathrm{BI}$ and $\mathrm{BC}$ have a large endowment of bonding, bridging and linking social networks. Some of these networks are bilateral between UK and the ancestral country: India, China/Hong Kong. These networks, for many $\mathrm{BI}$ and $\mathrm{BC}$, are augmented by multilateral links between UK and other countries in the world. Such networks are usually the result of being members of diaspora communities established in different parts of the world. The high value placed on education, noted in chapter 2 , has resulted in a growing, educated middle class, with family, kinship, friendship and professional contacts, including with entrepreneurs, in different parts of the world and the motherland. Such diversity ensures that multiple conduits exist for information on a range of different markets and different sectors thus potentially allowing for a dynamic response to emerging new opportunities.

The rich endowment of social capital is not of much value unless it is sustained and proactively leveraged. As noted by Prashantham:

“...more social capital is not necessarily better. Thus, discernment in leveraging network relationships is required. This includes wisdom in judging which network relationships to leverage and to what extent" (2008: 87 emphasis in original)

Studies of ethnic minorities, including Asians, have demonstrated the value of networks to entrepreneurship in local, national and international contexts (e.g. Ram 1994, Ram \& Theodorapoulos 2007, Janjuha-Jivraj 2003, Hayer \& Ibeh 2006, Saxenian 1999, 2006, Rindoks et al. 2006). These indicate that social capital plays a key role in helping to overcome one of the key areas of market failure in relation to national and international entrepreneurship - information problems and market entry. The next section demonstrates how networks have been leveraged by $\mathrm{BI}$ and $\mathrm{BC}$ for various purposes including as a general resource, for accessing finance, partner and staff recruitment, undertaking collaborative research, commercialising research and stakeholder engagement. 


\subsubsection{General Resource}

Social capital can be used as a general resource to provide hospitality and infrastructure support. A network of family and friends can, at a basic hospitality level, help cater for the entrepreneur's psychological and social needs. Setting up a business in a foreign country can be a lonely affair, particularly during the initial phase of reconnaissance. However, a network of contacts can ease the isolation and provide a ready-made social circle, familiar family and religious rituals, food and drink as well as companionship. BC Kenneth (Case Study 13) who is currently trying to extend his business out of Beijing to other cities in China said on his return to England from a trip to China: "I am tired of staying in hotels. It is boring and lonely in the evenings. In future I am going to stay with a family and I will arrange this through my contacts". If these are the feelings of someone who is Chinese, knows the language and makes frequent trips to the country, then one can imagine that they must be magnified in the case of non-Chinese, unfamiliar with the country, people and language.

Family and friends may provide other forms of infrastructure support which free the entrepreneur or potential entrepreneur to pursue their business interests. Thus when Alcar (Case Study 17) wanted to set up a branch of her business in the UK, she travelled from India and cut down on accommodation costs by living with her UK based parents and relatives. Alcar, who describes herself as a "very hands-on mother" did not want to leave her two young children behind in India although she has a live-in nanny. She often takes them abroad with her. In the UK, she knows that her parents can provide reliable and culturally sensitive childcare while she attends business meetings. As she said "[I] feel relaxed knowing that my kids are in good hands and my parents like looking after the children and enjoying their company". Thus, even if family and friends are unable to provide information, market intelligence and business contacts of direct relevance to the $\mathrm{BI}$ or BC entrepreneur, they are, nevertheless, able to provide infrastructure support (accommodation, childcare) and hospitality that facilitate the official activities that the entrepreneur has to engage in when trying to start up or grow the business globally.

\subsubsection{Partner and Staff Recruitment}

A wide range of contacts provide graduate $\mathrm{BI}$ and $\mathrm{BC}$ entrepreneurs with greater flexibility in the choice of business partners, employees and members of boards. Among the first generation, $\mathrm{BI}$ and $\mathrm{BC}$ business partners were drawn from the same community, often family and friends (Watson 1977, Ram \& Jones 1998, Ram \& Jones 2002). However, among students, graduates and academics, their partners can be drawn not only from their own community but from a much wider pool that reflect their wider repertoire of bonding, bridging and linking social networks. The use of bonding social capital is evident in the case of Jay \& Raj (Case Study 10) who are cousins, grew up in the same neighbourhood in England and attended the same university. They were business partners while at university and continued this relationship after graduation to set up a new business. However, they drew on bridging social capital to recruit one of their employees, a White European, who was recommended to them by White American professional contacts in Silicon Valley. Bridging social capital can be drawn on to recruit business partners too. BI Sunil (Case Study 19), a chartered accountant, set up a business with his WB wife, also a chartered accountant. BC David (Case Study 18) is a partner in a media business with three WB. One of the WB partners ran a media business in London and David, while an undergraduate student, built up this contact as he used to work for the business.

Bridging social capital with other ethnic minority groups can also be drawn upon in addition to that with WB or Whites. BC Tony (Case Study 26) set up his business with his British Iraqi friend Omar whom he had known since his school days when they were classmates. Cad, a BI student and James, a Black South African overseas student, have worked together on a range of small entrepreneurial activities as undergraduates and intend to continue the collaboration after graduation with plans to establish international businesses. Sachin, a postgraduate BI student in the process of setting up his own business, has formed 
a partnership with two other students: a BI male and a BC female, thus using both bonding and bridging social capital. He got to know his two partners as they worked closely on the committee of a university student enterprise club. He said: "I know the calibre of these two people: they are bright, very hard working, trustworthy, reliable, and ambitious and have great personalities." He had been impressed by their attributes when they served under his presidency of the student committee.

The value of multilateral diaspora connections is particularly significant for those overseas countries that have a requirement that international businesses must be co-owned by an indigenous partner. Thus, a $\mathrm{BI}$ entrepreneur in the UK trying to establish a business in Dubai may be able to identify an Arab partner through his Indian relatives working in Dubai. Such multilateral international contacts are also useful in identifying potential skilled people who may be able to staff the overseas operation. Finding an indigenous partner is also an issue for BC who want to set up a business in some sectors in China. Those BC who have British passports are treated as foreigners and, therefore, are subject to all the restrictions and regulations that normally apply to those without a Chinese passport. However, as they have family members and other contacts in China, these can be used for the purposes of setting up and acting as a front for the business in China. This is one strategy adopted by Chinese living overseas in countries whose nationality they have adopted but who want to capitalise on the growing entrepreneurial opportunities in China.

The strategic appointment of members to the Board of a business can be an important way of leveraging social capital, particularly bridging and linking social capital. Board members are usually not selected through open recruitment as employment legislation demands in the case of staff recruitment. Rather, they are invited to join a Board and can receive some financial remuneration. Kenneth (Case Study 10) is complementing the core operational staff with a broader cross-section of people on his Executive Board. The Board will set the strategic objectives of the company and he has leveraged his networks to recruit people of different national and cultural backgrounds who also have specific expertise. He has recruited a range of influential WB and Chinese to his Board and in the process of trying to recruit an Indian as he wants to expand his business into India. The people on the Board and the staff provide not only their expertise but also access to their national and international networks as well as cultural capital. In Kenneth's case, it is evident that he has adopted a strategic approach to using bonding, bridging and linking social capital to sustain and grow his business thus demonstrating his managerial capability to engage in softer or wider innovation.

\subsubsection{Location of the Business}

In deciding to establish a business overseas, bridging and linking social capital can play a vital role. For instance, both Jay \& Raj (Case Study 10) already had connections with people in Silicon Valley which inspired and sustained their ambition to locate the business there. As Jay said:

"It was through a fantastic event that the Oxford Business School organised every year called Silicon Valley comes to Oxford. It is an awesome event because it gets some really high profile people from Silicon Valley down to Oxford. And that is where Raj and I met some of the Silicon Valley people and hung out with them for a bit and just kept the connections going every year. So when we came out here we already had a few connections. The other thing was... we got funding from the most prestigious early stage investment fund in the world right now, so that instantly gave us credibility and a massive network to tap into. We actually came over here with a good network behind us" 
While in the first instance, their networks were not drawn from their own ethnic community, nevertheless, the ubiquitous presence of entrepreneurs and employees of Indian origin in Silicon Valley who have businesses and family connections with India (Saxenian 1999) has meant that inevitably they have also made connections with compatriots.

\subsubsection{Accessing Finance}

National and international networks can be leveraged to access funding streams in different parts of the world. BC Kenneth (Case Study 13), as we will see in chapter 7, has obtained funds from friends in China. He is also playing a brokerage role for his Chinese friend Mark (Case Study 30) who is based in Beijing but wants to set up in the UK too. Kenneth is helping him to access finance in the UK, and also to access market information and to find clients in the UK.

Business planning competitions and events where entrepreneurs can make a pitch can provide access to national and international finance, particularly equity finance. The student teams of Arun (Case Study 8) and Chandra (Case Study 4) were successful in business plan competitions. Successful performance in such competitions provides opportunities to build and expand linking social capital as it is possible to forge contacts with potential mentors, venture capitalists and business angels and other people with power and influence who serve as sponsors and judges on selection panels. Overseas Chinese students, Harry and Alfie (Case Study 27) developed linking social capital with a senior manager from the local city council. BI, Kapoor, is a senior manager in charge of inward investment at the enterprise unit of the local council. He was in the audience of a university business plan competition and was impressed by the pitch made by Harry and Alfie. The contact with Kapoor is a a crucial one for Harry and Alfie and is likely to leverage business support and finance and provide linking social capital to other influential people not only in the council but more widely in the city and region as the council has links to the chamber of commerce, regional development agency, Business Link and other organisations.

Business events overseas, as well as in the UK, provide opportunities for accessing linking social capital. For instance, in China, a business-to-business event associated with a conference on Asian entrepreneurship was held at a university incubator. ${ }^{84}$ The event showcased Chinese graduate entrepreneurs from the incubator who gave presentations on their businesses and their growth plans to an audience which included business angels and venture capitalists from UK and elsewhere in Europe. These business angels and venture capitalists were part of the bridging and linking networks of the event organisers which included a BI Anand (Case Study 31) who is a professor of entrepreneurship from a British university, and some BC. Through the organisers, the young Chinese entrepreneurs had an opportunity to meet people with access to finance from outside of China. For the business angels and venture capitalists, the event provided an opportunity to consider investing in a country with a high growth rate and, therefore, likely to give them a good return on their investment.

\subsubsection{Collaborative activities including research}

The development of international research and business collaboration can be facilitated by $\mathrm{BI}$ and $\mathrm{BC}$ academic staff. Within universities, $\mathrm{BI}$ and $\mathrm{BC}$ staff may be used to help identify contacts in India and China. For instance, a BI senior academic, Ramesh, who works at a university business school (Case Study 33), has been instrumental in fostering links with India. As he said:

"I am an Indian from Bangaluru. I see the changes that have been taking place there and elsewhere in India and I am able to identify the opportunities for my university to capitalise on this through joint collaboration. I use my contacts in India as well as my

\footnotetext{
${ }^{84}$ This is incubator D discussed in chapter 8
} 
knowledge of how systems and bureaucracies work in India, to facilitate collaboration"

In his case, his linguistic fluency in Indian languages was not significant as English is widely spoken in India. In China however, the Chinese linguistic skills of Chinese students and academic staff play an important role in facilitating collaboration.

Networks of students, alumni and scholars from different universities in the UK and different countries can all facilitate the development of national and international research collaborations that can lead to different routes to commercialise knowledge. For instance, a software engineering research group led by BC John (Case Study 14) originally from mainland China includes scholars from different universities in the UK, some of whom are BC and others overseas Chinese working in the UK universities. Some research projects have involved collaboration with researchers in China, facilitated by the contacts of BC academics and their knowledge of "how things work in China". Commercial routes being considered are licensing and national and international spin out companies.

Collaborative international projects between UK and overseas countries may be set up through joint laboratories founded by researchers who may have worked together initially in a British university. This was the case of overseas Chinese Malcolm (Case Study 32) who had worked with BC Sandy mentioned in chapter 5. Sainsbury (2007) recommended that the Science Bridges scheme which was piloted with UK-USA bridges should be extended to China and India and to other key high technology innovative countries. The Science Bridges scheme helped develop entrepreneurial skills among researchers and supported the commercial development of technology and expertise in spin-outs.

\subsubsection{Commercialising Research}

Social capital also can be leveraged to help commercialise research products. Philip (Case Study 2) as noted in chapter 5 is planning to manufacture his diagnostic machine in China. $\mathrm{He}$ also plans to undertake clinical trials in China. Manufacturing in the UK is a less viable option because of high costs. He could choose a number of low cost countries but his preference is China because not only are costs lower, but he has a large network of people whom he can mobilise to identify a suitable manufacturer and maintain oversight of the work. If he undertakes clinical trials in China, he can use his academic and clinical contacts to undertake the work. He has sustained his links with Chinese academics over several years, visiting them when he is in China to see his family. Furthermore, as noted earlier, he also has formal links with some universities where he has the status of Visiting Professor. India is his second option for manufacturing the device, if for any reason he is unable to manufacture his machine or undertake the clinical trials in China or if he wants to extend his clinical trials to another country. He has contacts with a number of Indian scholars, many of whom he met at international conferences, and he says "I trust Indians". Trust is an important factor in relationships which is taken into account when considering relinquishing control over the development of innovative products and processes to colleagues and other professionals overseas.

Developing large scale international projects with commercial potential requires skill in leveraging different types of networks. This can be illustrated with a project involving institutional and government collaboration with universities and governments in the UK and China. The project took considerable time to be developed and a large part of the success in bringing it to fruition can be attributed to the leveraging of social capital. The scheme has been spearheaded by a partnership of two women working at a research university: Hilary who is WB and Marianne who is first generation BC from mainland China. Marianne had worked in a large city in China for six years before coming to the UK for higher education studies. Later she worked in joint venture companies, and although she was based in the UK, she travelled frequently to China to deal with the Chinese end of these businesses. She has lived in the UK for 10 years and now works in the technology transfer office of the lead 
university in the programme. Her cultural capital (Chinese ethnicity, up-to-date knowledge of China, cultural affinity and linguistic fluency in Mandarin) and social capital (wide range of contacts in China and UK, within Government, universities and industry) have helped to facilitate the development of the programme. Hilary had worked previously at another British university where she organised several trade missions to China. As a result, she had also developed extensive contacts in China and an awareness of business and cultural practices. She had a strong belief in the viability and value of collaborating with China in taking knowledge generated in British and Chinese universities to the market. This belief has sustained her during difficult periods of protracted negotiation with Chinese and British Government officials. Both women were able to forge a partnership and use their respective cultural and social capital to develop the programme and bring it to fruition.

The above has demonstrated the various ways in which $\mathrm{BI}$ and $\mathrm{BC}$ used bilateral and multilateral bonding, bridging and linking social capital to gain competitive advantage in initiating, developing and sustaining international entrepreneurship. The next section examines how the lessons learnt from $\mathrm{BI}$ and $\mathrm{BC}$ can be extrapolated to the wider population of students, graduates and academics to mitigate market failures of networks and mediation for international entrepreneurship. To do this requires taking advantage of opportunities for developing networks that exist 'right under our noses' in the UK.

\subsection{Opportunities for developing networks for internationalisation}

To develop and sustain international entrepreneurship, effective international networks need to be developed and there are currently a lot of missed opportunities There are at least five arenas which provide opportunities for developing international networks that are discussed in turn below.

\subsubsection{Research and industry networks}

There is scope for the development of research and industry networks. We saw in chapters 1 and 5 that various attempts are being made by Government to establish bilateral research networks, including with India and China. These need to be enhanced and, furthermore, it is important for these networks to be multi-disciplinary. Research training may need to be revised to facilitate the development of networks. BI Ramesh, a senior academic involved in entrepreneurship education said:

"The Ph.D in the UK is too short, it is only 3 years, and there is not enough time to develop links with the local area, particularly in the case of overseas students, but even local, British students who go to different universities to study, and therefore do not have enough time to develop their local connections, all of which helps with knowledge transfer and commercialisation of knowledge. Whereas in the USA, the $P h . D$ is 5 years which gives far more time to develop local links and besides includes internships which again promote the development of links. The USA doctorates are far broader based, and because of the nature of the programme, students acquire a greater degree of knowledge of the workings of businesses in different parts of the world, as well as their local area, and this can be quite useful when they want to set up their own business"

Two way traffic needs to be developed so that more UK students and researchers go overseas. While some of this is occurring, it is only a trickle at present. Consequently, there is a need to create more opportunities to develop collaboration between UK and India and China. To strengthen collaboration, the UK needs to send more students and academics to work at Chinese universities but this has to be made attractive. Scientists who want to develop their research careers through international experience do not at present see Chinese universities as places to spend part of their working life compared to Ivy League universities in the USA. However, as noted in chapter 1, Chinese universities are being heavily supported financially by the Government to raise standards and some of them are 
now listed in the top 100 world universities. ${ }^{85}$ The Government plan is to develop more universities to world class status. If this ambition is realised, then China may become an attractive location for young British scientists. It also seems likely that British scientists see barriers to working in China which may be based on myths. According to Sean, a WB UK Government official who has worked for a few years in China:

"One of the resistances to coming to China is, of course, the question of the Mandarin language. You don't need Mandarin language that much. In fact, people are delighted to have an English speaker as this is a way they can practice their English. But I think this kind of exchange is mutually beneficially. Those who come across from the UK have got to be courageous. There is no big ex pat academic community here. But there is a lot of heterogeneity in Chinese labs and some of the scientists have studied and worked abroad"

Some attempts to break down these resistances are taking place which may bear fruit in the future. For instance, the British Council is sponsoring summer schools in China for secondary school British students who are learning Mandarin. While in China, they attend lessons in Mandarin and engage in activities which promote cultural understanding.

\subsubsection{Public and Private Sector Networks}

It would be useful for British universities to forge strategic and operational alliances with incubators and science parks in universities worldwide to provide reciprocal 'soft landings' to grow international businesses. Opportunities are available to develop more links with public and private institutions which would facilitate international activities. For instance, the China Council for the Promotion of International Trade (CCPIT) and China Chamber of International Commerce (CCOIC) organised match-making discussions in 2007. This was promoted by the UK Science Park Association as it could provide opportunities for links to be established between science parks in the UK and those in China. This is a step in the right direction and will augment the collaborations that already exist between UK science parks and those in Europe. A few examples of multiple worldwide linkages are evident. For instance, the UK Soft Landing Zone programme has been set up by Coventry University Enterprise Limited in partnership with UKTI in order to establish a network of British incubator offices around the globe. ${ }^{86}$ The offices, located on key university science parks including in India, China and Hong Kong, is open to UK companies who are either considering or are at the early stages of undertaking international business. As well asdesk space in a dedicated office - complete with IT services, telephone answering and post forwarding - businesses signing up to the programme will also be able to take advantage of a number of support services. Each company will be allocated a dedicated business support officer to advise or call in expertise on all legal, financial, cultural and practical issues of doing business in a particular country. In addition, the partnership with UKTI will give participants the opportunity to benefit from subsidies on travel and accommodation.

While such initiatives are very welcome, collaboration needs to be evident in all universities and mainstreamed across the HE sector. For this to be realised, investment of time and energy is required. As the director of a well known science park at a British university said "[W]e have tried to establish links with a science park in Shanghai but it was very time consuming and in the end we gave up". It may be necessary to recruit staff that have a particular role in establishing and sustaining such links. For students and graduates, access to incubator facilities in different parts of the world with reciprocal arrangements, would be very useful. As will be seen in chapter 8 , such reciprocal arrangements would provide 'soft landings' for entrepreneurs wishing to internationalise their business in another country and

\footnotetext{
${ }^{85}$ See for instance THES - QS World University Rankings.

${ }^{86}$ See http://www.coventry.ac.uk/cutp/latest-news/a/531/\$/tab/
} 
would benefit from starting off in an incubator in that country with which their university had prior links. Francis (Case Study 29), an alumnus of three British universities is currently in a university based incubator in China. He wants to expand to UK and said it would be very helpful if his current incubator had a 'soft landings' link with incubators at any of his former three British alma maters.

Another possibility is to find British businesses overseas who are prepared to offer their business as a 'live incubator'. BI Sita (Case Study 25) who has designer business in India, for instance, is prepared to host student entrepreneurs who wish to set up a designer business in India. BI Alcar (Case Study 17) has made a similar offer to an incubator at a British university. Equivalent possibilities could be explored with alumni who have businesses overseas. These suggestions can be built into, and build upon, the Government's plans (BERR 2008a) to support the pan-European pilot programme (currently known as Erasmus for young entrepreneurs) to offer cross-border mentoring and work placements in SMEs. This scheme could be extended to encompass India, China and other countries.

Sufficient links with intermediary organisations are also lacking. Greater encouragement and support could be given to organisations such as The Indus Entrepreneur (TiE) to establish links with universities. As will be seen in chapter 9, it has international chapters and offers mentoring programmes. Although there are links to some universities, these need to be extended to encompass all universities. It is encouraging to note that the 2008 Enterprise Strategy Paper indicates that the Government plans to work with this organisation. The RDAs, Business Link and UKTI could be more engaged in supporting student and graduate entrepreneurship. British and international students, for instance, could be provided with ring-fenced places on trade missions and trade fairs.

\subsubsection{Networks with current international students, staff and parents}

As noted in chapter 1 , UK universities are now host to a very significant number of international students with around 50,000 students from China and about 24,000 from India in 2006/07. ${ }^{87}$ Yet research among Chinese students shows that while there are individual differences, on the whole, there is a lack of socialisation between them and British students and they remain relatively insular, socialising instead with co-nationals and other international students. Indeed, a survey conducted by the UK Council for Overseas Student Affairs found that only $15 \%$ of Chinese students said that they had UK friends (UKCOSA 2004). ${ }^{88}$ Academic interaction between students needs to be enhanced through the widespread development of formal and informal curricula and pedagogic approaches. There are also a large number of overseas academic staff and it is possible, although this needs to be researched, that there is some degree of insularity among them too. This insularity needs to be addressed as it creates a barrier to the cultivation of networks. Furthermore, strategies should be developed to capitalise on the networks offered by the parents of the overseas students, including Indian and Chinese students. Attempts can be made to network with them when they come to visit their children studying in the UK. Most of these parents are likely to be middle income and of professional backgrounds who are able to pay the high fees charged to international students. They are likely to be in prominent positions and will have their own networks in the public and private sectors back home. Those with businesses or entrepreneurial ambitions, as well as those with intrapreneurial ambitions, may be encouraged to consider the UK as a possible location if they have received good hospitality from universities, RDAs etc. during their visit to this country. These personal networks are not only important in themselves as they may contain some future entrepreneurs, but may also contain people in professional positions such as lawyers and

\footnotetext{
${ }^{87}$ Source: DIUS Higher Education analysis team.

88 This finding was also substantiated by various presentations based on qualitative research at London University, Institute of Education Conference Learning Together: Reshaping Higher Education in a Global Age, July 2007.
} 
accountants needed by entrepreneurs, as well as future civil servants and executive managers of large firms. Thus building and sustaining networks with students and their parents provides access to the networks of the older generation as well as to contemporaries.

\subsubsection{Alumni networks}

Alumni networks of international students and staff who have attended British universities need to be developed and maintained. Alumni networks can be used to promote British universities overseas. Thus, Janet (Case Study 28) an alumnus from a business school of a British university has been asked to promote the school in China, stressing the specific opportunities available for international entrepreneurship development. Another university, through its international office, keeps a database of all the interactions that the university has with China including via students, post-doctoral and academic researchers and those involved in any collaborative research. This database will be used when particular contacts are required in China. Some regional development agencies are also engaged in alumni development activity. One RDA which has a base in South China is creating a database of alumni from universities in its region which it hopes to mobilise for facilitating international entrepreneurial activities. The British Council in China is also developing an alumni database as is a British chamber of commerce overseas. Alumni networks are crucially important in countries such as China where, as mentioned in chapter 1 , there is a heavy dependency on 'quanxi' or networks to facilitate entrepreneurial and other activities. For alumni network development international relationship management to become standard practice in the HE sector, sustained institutional commitment and support is necessary.

\subsubsection{Employment of overseas students and graduates}

We saw earlier how $\mathrm{BI}$ and $\mathrm{BC}$ businesses are ae to use the cultural and social capital of the owners as well as their staff to gain competitive advantage in penetrating overseas markets. British companies can try to emulate this by employing people from the countries which they are trying to penetrate internationally. Overseas students and graduates provide a valuable pool of resources. Matthew (Case Study 7) who has a wholly owned subsidiary in China (as noted in chapter 4) has begun employing overseas Chinese graduates from British universities in his UK business. He has recruited one graduate, Billy, under the Knowledge Transfer Partnership which he has found works very well. Billy has gained an understanding of the substantive nature of the business while working at the headquarters in the UK. Moreover, he has learnt western management practices which Matthew is keen to introduce in the China office. Billy is familiar with both UK and China, and has English language and Mandarin language competencies. He also has social networks in China which can be used to the advantage of Matthew's company. We saw earlier that Matthew had considerable difficulty in penetrating the Chinese market to set up the business, and should there be further difficulties if he wants to expand the company, he anticipates that Billy will help to ameliorate these. Thus, many companies that are thinking of penetrating the Chinese, Indian and other overseas markets could take advantage of the presence of international students from those countries at British universities and employ them with the aim of facilitating entry into the markets of their countries. The increase in the amount of time that overseas graduates can work in England from one to two years, which takes effect in 2008, will facilitate such an internationalisation strategy.

\subsection{Possible curtailment of networking opportunities}

While there are a large number of students in UK universities at present who provide networking opportunities, it is a mistake to think that the 'golden cow' will continue and the UK must anticipate that numbers will decline. Apart from competition from other countries for overseas students, the need to study overseas may gradually decline. Let us take the example of China. The cache of an overseas degree is slowly diminishing as the take up of overseas education has become more widespread, educated returnees have increased in 
number and they have lost some of their original competitive advantage when only a small contingent could afford to study overseas. In addition, China's investment in its universities means that some are achieving world class status and can provide high quality education thus encouraging students to study at home, even at postgraduate level (Wilsdon \& Keeley 2007). Furthermore, the lack of work experience in China has been a disadvantage for some job seekers who have returned from overseas. This is not to say that the overseas educated are not still in high demand, particularly those educated at elite institutions overseas. This was evident at alumni events in Hong Kong, Beijing and Shanghai, organised by the careers officers from Oxford, Cambridge, Imperial College and LSE for their graduates of Hong Kong and China domicile. These events simulated the 'milk rounds' which are commonplace in UK universities as mechanisms for companies to recruit new staff. At the events in Hong Kong and mainland China, the companies represented included large firms such as HSBC, Royal Bank of Scotland and Ernst \& Young who were keen to recruit bright people with international education and experience but who were also familiar with China and Hong Kong and had Chinese linguistic skills. The enhanced possibility that an overseas education provides of acquiring lucrative posts with blue chip companies suggests that there will continue to be a demand for overseas education but the scale of the demand may change with less students coming to the UK in due course.

Another factor which may lead to a decrease in demand for British higher education and, therefore, reduce the networking opportunities, is the likelihood of the growth of transnational educational programmes in Hong Kong. Such growth is facilitated by a number of factors. First, the closer links developed between Hong Kong and China since the handover in 1997 has meant that mainland Chinese students are better able to take advantage of tertiary level opportunities in Hong Kong. Hong Kong has historically had a large number of transnational education programmes which have allowed students to acquire British degrees without going overseas. Alumni from British universities, such as Chinese Henry (Carla's business partner in Hong Kong - Case Study 20) tutor on these programmes run at universities in Hong Kong. These programmes have the potential to be used as a spring board to China to aid the swifter and greater penetration of transnational education programmes.

Second, there are financial incentives. Overseas education in UK is very expensive. ${ }^{89}$ Chinese parents of more limited financial means, but with aspirations for their children to have a university education, are sending their children to Hong Kong where the costs of education are considerably less. Another strategy is to reduce the time spent overseas by taking advantage of split site provision. For instance, British universities are continuing to develop innovative transnational educational programmes such as $2+2$ degrees where students spend two years in Hong Kong/China and two in the UK, obtaining a British degree at the end. New, on line course modules have been developed in collaboration with counterparts in China. These may, of course, increase the attraction of study in Britain, as might the offer of more scholarships and work experience opportunities, ${ }^{90}$ but it is debatable whether they can ever be sufficient.

Third, learning support is available. While the university programmes available in Hong Kong are delivered in the English language medium, there is also back up tutoring in Cantonese and Mandarin which is not readily available in the UK. This means that students who have a lower command of English for academic purposes can still achieve high level success because they can supplement their learning in English with learning in Cantonese or Mandarin. Fourth, social and psychological needs can be better met in Hong Kong. Proximity facilitates the frequent exchange of visits between children and parents and reduces parental anxiety. This is particularly relevant if there is an only child in the family

\footnotetext{
${ }^{89}$ Universities UK undertakes an annual survey of tuition fees for international (non-EU) students - see http://www.universitiesuk.ac.uk/statistics/fees/survey07-08.asp. There are also living costs on top of fees ${ }^{90}$ Prime Minister Gordon Brown's speech at the UK-China business summit in Beijing January 2008 http://www.number-10.gov.uk/output/Page14312.asp
} 
due to various factors, including China's one child policy. Furthermore, students are in a more familiar cultural environment with easy access to Chinese food which many miss while studying overseas.

Some UK universities have already recognised the potential danger of a drop in overseas student numbers and have established a campus in China or accelerated twinning arrangements with Chinese universities. Nevertheless, the dynamic environment of changing supply of and demand for western style education mean that opportunities for networking need to be seized now while there are still sizeable numbers of international students currently in UK universities.

\subsection{Conclusion}

This chapter has focused on competition as the driver of productivity. In particular, it has examined how cultural and social capital is used by $\mathrm{BI}$ and $\mathrm{BC}$ to help penetrate markets in their ancestral countries. This is vitally important as these are fast growing economies and any assets that people in the UK possess should be capitalised to facilitate international entrepreneurship. $\mathrm{BI}$ and $\mathrm{BC}$, like other ethnic minorities in the UK, can make a valuable contribution to the UK economy and to internationalisation. However, there are generational and class differences. While both the first and second generation possess cultural capital, graduates in the second generation have a richer stock of such capital. For instance, they have high level linguistic competence in English which complements mother tongue competencies and they are also cognisant of the cultural mores of the British and their compatriots. Such cosmopolitanism allows them to engage in the strategic manipulation of identity to foster and grow international entrepreneurship. Unlike most first generation BI and BC who had a smaller endowment of social networks, students, graduates and academics of the second generation have a richer endowment. Not only does this comprise bonding, bridging and linking social capital, but as members of diaspora communities, such networks transcend geographical boundaries. Such diverse bilateral and multilateral networks create a veritable spider's web which can be leveraged in different ways to enhance the competitive advantage of $\mathrm{BI}$ and $\mathrm{BC}$.

There are extensive opportunities 'right under our noses' to emulate the $\mathrm{BI}$ and $\mathrm{BC}$ in the development and leveraging of networks. All universities in the UK, and more recently further education colleges, have benefited from Government initiatives to increase their intake of international students. The magnitude of increase varies between universities and regions but, nevertheless, there is a widespread dispersal of international students, particularly Chinese and Indian, across the country. While the bonding social capital within these groups is enhanced through co-location in the UK, bridging and linking social capital which can be engineered to the advantage of the British economy, and also for mutual intercountry benefit, is only minimally occurring. Various strategies need to be adopted to mitigate the loss of missed opportunities. These include the adoption of pedagogic approaches which encourage British students to collaborate with international students; the provision of social events which take account of the commensality and other cultural practices of different groups of international students rather than adopt an ethnocentric approach of the 'British way of doing things'; capitalising on the loyalty to the alma mater that overseas Chinese and Indian students have, through the development, sustaining and strategic use of alumni networks for international entrepreneurship; and seeking opportunities to develop networks with the parents of international students particularly by making links when they come to visit their university children in the UK. The large number of overseas academic staff, particularly Chinese in SET university departments, offer opportunities for intensifying networks which can be leveraged when the academic staff return home, to develop, for instance, collaborative research projects, joint laboratories and outsourcing of parts of the research process. British firms wishing to internationalise can be encouraged to employ international students and graduates from British universities who 
originate from the countries they are trying to penetrate. This could perhaps be facilitated through ring-fenced Knowledge Transfer Partnerships. Opportunities for developing networks with students and staff from overseas need to be seized now as there are no guarantees that the current volume of students and staff from overseas will be sustained in the future. 


\section{CHAPTER 7: ENABLER OF ENTERPRISE: ACCESS TO FINANCE}

\subsection{Introduction}

Access to Finance is one of the enablers of enterprise. As stated in the Enterprise Strategy Paper 2008:

"The Government's vision is for more UK entrepreneurs and businesses to be able to access the finance they need to enable greater levels of enterprise, whether expressed through start-up or growth" (BERR 2008a:47).

In this chapter, various aspects relating to access to finance for students, graduates and academics, including $\mathrm{BI}$ and $\mathrm{BC}$, are examined. The chapter starts by looking at the secondary evidence on access to finance for graduates and ethnic minorities before examining the empirical data collected through the current research. It examines the levels of start up finance and the sources from which it was obtained from 14 graduate entrepreneurs from the case studies who responded to a brief questionnaire. The chapter then briefly considers access to finance for academic entrepreneurs before moving to examine issues relating to students. One of the issues facing recent graduates, current and future students, is student debt which has been rising over time. The impact of this for entrepreneurship is examined, followed by suggestions for dealing with market failures in access to finance and information asymmetries. The multiple advantages of providing financial and other support to students are then explored. Finally, access to finance is discussed within the broader context of Government policy.

\subsection{Graduate businesses: levels of start up finance and sources of finance}

At all stages in the business life cycle, appropriate finance is essential to invest in starting or growing a business or engaging in other forms of entrepreneurial activity. Finances can be obtained from a number of sources: personal resources, gifts and loans from family and friends, and from external sources such as banks, other financial institutions, business angels and venture capitalists. Most SMEs have been enjoying favourable access to external finance (Fraser 2005). Indeed, in the last five years, around three-quarters of businesses report no problems accessing finance. However, it is estimated that around 25,000 businesses, with viable propositions, are unable to access finance a year (BERR 2008a). It is not known what proportion of these belong to $\mathrm{BI}$ and $\mathrm{BC}$ as well as WB students, graduates and academics, or the proportion from these groups with aspirations to entrepreneurship who were stymied because of lack of access to finance. The impact of the recent credit crunch also needs further investigation. The following section examines prior evidence on access to finance for graduates, and Indians and Chinese.

\subsubsection{Graduates}

The amount of finance required to start up a business can vary considerably and is dependent on a number of factors, including the nature of the business. The median level of start-up finance is estimated by the Global Entrepreneurship Monitor (GEM) to be approximately $£ 10,000$ (Harding 2006), although in the e-commerce sector this figure is lower (FreshMinds 2006). Research based on the GEM 2005 adult population survey of 32,500 adults of working age in the UK reveals that obtaining finance for the business is the single largest issue preventing recent graduates from thinking of starting a business. Four in ten $(40 \%)$ of pre-2000 graduates reported that this was the case, rising to six in ten $(56 \%)$ for those who graduated after 2000 (Harding 2007). A similar issue is a barrier for students.

Students from one university surveyed in 2004, who planned to set up a business within 2 years of graduation, cited obtaining finance as the principal barrier for not starting up (Robertson \& Collins et al. 2004). Of the many reasons graduate entrepreneurs gave for not 
getting finance, fear of debt was one of them. The level of fear of debt has risen over the last few years: $35 \%$ of those who graduated after 2000 compared to $23 \%$ who graduated before 2000 (Harding 2007).

Finance can be obtained from various sources and those selected can change over time. Comparing those who graduated before 2000 with those who graduated after 2000, the GEM survey found that business finance sourced from financial institutions (unsecured bank loan, bank overdraft, non-bank unsecured loan, mortgage or secured loan and venture capital) dropped from $80 \%$ to $63 \%$ whereas those sourced from private decisions (friends and family, individual investor and credit cards) have increased from 35\% to 57\% (Harding 2007). The most popular source of finance has changed from a bank overdraft before 2000 to friends and family after 2000 . Thus "..recent graduates are more likely to raise finance from private decisions, such as friends and family, individual investors or credit cards to finance their businesses" (Harding 2007:10). The level of Government grants as a financial source has increased slightly from $16 \%$ to $17 \%$ (Harding 2007).

\subsubsection{Ethnic minority businesses, including Indian and Chinese}

For ethnic minority businesses as a whole, research evidence suggests that they seem to have more difficulty accessing finance than WB businesses (DTI 2006d) but after controlling for various factors such as size, sector, age of business etc., ethnicity does not appear to be the issue (Fraser 2006). However, there is considerable variation among the different ethnic minority groups (Smallbone et al. 2003, Fraser 2006). Of the ethnic minority groups researched (Indian, Pakistani, Bangladeshi, Black African and Black Caribbean) Indians seem to have the least difficulty in accessing external finance (Fraser 2006). Furthermore, like other South Asians, Indians are better able to obtain finance from family and friends compared to other ethnic minority businesses and White businesses (Ram et al. 2002). These studies do not include Chinese who appear to have no more difficulty than Whites in accessing finance. For instance, when businesses with employees were asked about the obstacles to the success of business, Chinese business were as likely as WB businesses (14\%) to cite obtaining finance as an obstacle (DTI 2006d).

There is very limited evidence on ethnic minority graduates. A small scale study of ethnic minority graduate enterprises (EMGE) reports that:

"[I]n comparison with non-graduate ethnic start-ups, EMGEs appear not to encounter finance constraints and are able to provide sufficient collateral. There is excessive reliance on personal savings and family finance, at the start-up and long after the start-up stage, which has implications for the optimal capital structure. EMGEs have much less external finance in their capital structure compared with general graduate start-ups" (Hussain \& Scott 2007: 4).

Further research with a larger sample is required to establish the extent to which the findings are generalisable and to identify specific patterns among $\mathrm{BI}$ and $\mathrm{BC}$.

\subsubsection{Levels and sources of start up finance}

This section examines the levels of finance and sources of finance of 14 of the 15 graduate $\mathrm{BI}$ and $\mathrm{BC}$, as well as WB graduate entrepreneurs, who responded to a questionnaire which elicited information on finance. The table below comprises both recent graduates and those who graduated some time ago. 
- Table 8: Amount of Finance required by graduates to start a business

\begin{tabular}{|c|c|c|c|c|}
\hline $\begin{array}{l}\text { Amount } \\
\text { Sought }\end{array}$ & $\begin{array}{l}\text { Name and Case } \\
\text { Study (CS) }\end{array}$ & Ethnicity & Business sector & Source of finance \\
\hline \multirow{2}{*}{$\begin{array}{l}\text { Less than } \\
£ 1,000\end{array}$} & Kumar (CS 12) & $\mathrm{BI}$ & Computer services & O/BP/D \\
\hline & Michael (CS 15) & $\mathrm{BC}$ & Professional services & O/BP/D \\
\hline $\begin{array}{l}£ 1,000 \text { to } \\
£ 4,999\end{array}$ & Tony (CS 26) & $\mathrm{BC}$ & Creative industry & O/BP/D; F/F \\
\hline \multirow{3}{*}{$\begin{array}{l}£ 5,000 \text { to } \\
£ 9,999\end{array}$} & $\begin{array}{l}\text { Dominic } \\
\text { (CS 21) } \\
\end{array}$ & WB & Professional services & O/BP/D \\
\hline & Matthew (CS 7) & WB & Engineering & O/BP/D; F/F; Bank \\
\hline & Carla (CS 20) & WB & Professional services & O/BP/D \\
\hline $\begin{array}{l}£ 10,000 \text { to } \\
£ 24,999\end{array}$ & Sunil (CS 19) & $\mathrm{BI}$ & Professional services & O/BP/D \\
\hline $\begin{array}{l}£ 25,000 \text { to } \\
£ 49,999\end{array}$ & 0 & & & \\
\hline \multirow{2}{*}{$\begin{array}{l}£ 50,000 \text { to } \\
£ 99,999\end{array}$} & Kenneth (CS 13) & $\mathrm{BC}$ & Computer services & O/BP/D \\
\hline & Sita (CS 25) & $\mathrm{BI}$ & Creative industry & Bank \\
\hline \multirow{2}{*}{$\begin{array}{l}£ 100,000 \text { to } \\
£ 249,999\end{array}$} & $\begin{array}{l}\text { Jay \& Raj } \\
\text { (CS 10) }\end{array}$ & $\mathrm{BI}$ & Computer services & Business Angel \\
\hline & Patrick (CS 9) & $\mathrm{BC}$ & Engineering & O/BP/D \\
\hline \multirow{3}{*}{$\begin{array}{l}£ 250,000 \text { to } \\
£ 499,999\end{array}$} & John (CS 14) & $\mathrm{BC}$ & Computer Services & O/BP/D; F/F \\
\hline & $\begin{array}{l}\text { Satinder and } \\
\text { Sunita (CS 1) } \\
\end{array}$ & $\mathrm{BI}$ & Science & O/BP/D; F/F; Bank \\
\hline & Alcar (CS 17) & $\mathrm{BI}$ & Professional services & O/BP/D \\
\hline $\begin{array}{l}\text { More than } \\
£ 500,000\end{array}$ & 0 & & & \\
\hline
\end{tabular}

From the above table it can be seen that the amount of finances required at start-up varied considerably among the 14 entrepreneurs. At the one extreme, Kumar and Michael required less than a $£ 1,000$ whereas John, Satinder and Alcar required between $£ 250,000$ $£ 499,999$. Six of the fourteen entrepreneurs, Kumar, Michael, Tony, Dominic, Matthew and Carla required less than $£ 10,000$. One factor which affects the amount of start up funds required is the nature of the business. Kumar and Tony were able to start up by operating from their bedroom at home which considerably reduced start-up costs. They were able to do this as, in the initial stage of the business, commercial premises were not required. As Kumar's business has expanded and he is now employing staff, he has started renting business premises. At present, he has not sought any external finance as he uses income generated from multiple contracts to pay staff salaries and other expenditure. The high startup costs for Satinder and Sunita were related to three factors: first, they needed large premises in a good location as they relied on footfall during the early stage of building up the clientele. Second, they needed a wide range and sizeable quantities of products. Third, they needed to pay a number of staff, with expertise in a range of complementary medical techniques, to be available to provide health services to clients. 


\subsection{Sources of finance}

A range of financial sources is used by respondents. In only two cases, Sita and Jay \& Raj, was a single source of finance used; debt finance via a bank and equity finance via a business angel respectively. In eight cases, there was recourse to the combined resources of the owner, business partners and directors. In the remaining four cases, in two cases (Tony, John) combinations of internal sources were used, whereas Mathew and Satinder used a combination of internal and external sources. To gain an insight into the reasons behind using various sources, each is discussed below in turn.

\subsubsection{Family and Friends}

Family and friends are often the first port of call in raising finances and we can see that Matthew, Tony, John and Satinder used this source. While Sunita's parents provided some funds, Satinder's parents did not provide any money but helped in kind by giving him free bed and board while he was setting up the business. Friends may help to finance the business in kind. Jay \& Raj ran a social enterprise while at university and according to Jay:

"The biggest cost that businesses have especially in the early days is labour costs. So when you are at university the biggest advantage you have is that students are prepared to work for free because they work to improve their CVs"

Speaking about raising money from friends, Kenneth (Case Study 13) said he received financial help from ".... Chinese friend back home, but I failed to persuade any Chinese friends here to help with the funding but interestingly I managed to persuade WB people and Americans directors of the business to help me finance some of it". Kenneth has accessed funds in China and he epitomises the wider networks of family and friends that members of ethnic minority diaspora communities can leverage as we saw in chapter 6 .

Some entrepreneurs are reluctant to draw on family and friends. As Jay said:

"I think there are two ways of looking at it. The argument for taking money from family and friends is that if you have people you care about, or family and friends investing in your company, then you are extra driven to make your business succeed. The other way of looking at it, for not taking their money, is to say that it is an added pressure especially when it is your family that is putting money up, that is an extra level of stress. And neither of us really wanted that so we never really approached family or friends for money"

\subsubsection{Owner/Business Partners/Directors}

Entrepreneurs often use their own resources and that of their partners and directors. The above table demonstrates that this was the most popular resource with twelve of the fourteen respondents. For four of these, Tony, Matthew, John and Satinder, this was used to supplement family finance. Those who used their own resources had invariably worked in graduate jobs for a number of years. For instance, Alcar and her husband were employed as high earners and used their combined savings, as well as money from family and friends and the bank, to start the business in India.

\subsubsection{Debt finance}

Satinder, Matthew and Sita had used bank finance. As Sita had worked for several years, and towards the latter part of her employment was on a six figure salary, she had considerable savings. She was an owner occupier and used her savings to pay off her mortgage. She then used her flat as collateral to secure a bank loan from the British bank, Lloyds. The money also went further in India as costs of staff and premises were lower than if she had set up in the UK. 
Satinder was not successful in raising bank finance initially because the bank found his business idea too innovative and unproven. He had to rely on family and friends in the community, some of whom acquired an equity stake. He is planning to grow the business in India and will use family connections to raise debt finance: "one of my uncles is a bank manager there so there are lots of contacts he can pull up there". Satinder also illustrates how diaspora connections can be used to leverage finance.

Kenneth had tried to raise bank finance but was not successful. In his view:

"Banks have very little understanding about entrepreneurship and the risk profile; they just blew me out of the meeting on the first occasion. I did talk with them and they were talking in terms of business loans and personal loans, come on, that is not the way to fund businesses. You can talk about a bridging loan - I would be happy with that but to charge me $10 \%$ or $9 \%$ interest rate on the mortgage loan is just ridiculous. I will not go to any high street bank for funding for my business or my friends' business"

Difficulties in raising debt finance in the UK was one of the factors which prompted Jay \& Raj to chose Silicon Valley in USA because it was easier to raise funding for their business there than in the UK. As Jay said:

"It took us a long, long time to raise a small sum of money in London and we were just like, if we need more money further down the line and we had to spend that much time again, it just didn't make sense. While out here it would take far less time and far less effort to raise money. So that was just the biggest reason for starting up in the US"

\subsubsection{Equity finance}

Prior to leaving to set up their business in the USA, Jay \& Raj were very fortunate to obtain business angel finance as a gesture of goodwill from Raj's employer. According to Jay:

"When Raj left his banking job after six months, his boss actually signed us over a cheque for $£ 16,000$. That was the first Angel investment which was great because the money came in really handy. It was really a good luck gesture and see what you can do. So that kept us going for a few months. And then we had a hard slog of approaching Angel investors or professional investors around London and we eventually got a sizeable chunk of money and raised $£ 200,000$ to have a really big go at it. And then we raised more money out here in the States.... There is an incredibly amount of money out in Silicon Valley. If you have a good idea, and you are passionate about it and you come across well, it is actually very easy to raise money to get your business going. It is just the culture out here, there are tons of investors, there are tons of people willing to put money into early stage technology companies"

The relative ease of acquiring Angel finance in the US is attested by GEM which estimated that it amounts to as much as $1 \%$ of the entire country's GDP. ${ }^{91}$

Satinder had also explored accessing equity finance. Southampton University ${ }^{92}$ "wanted to help me out but they wanted to take $40 \%$ of the business". Their interest in the business was because they could "see the potential in terms of health care and also in terms of incubating students and developing new businesses but they wanted pretty much the whole business for it".

As Sita is planning to expand in India she is currently in negotiations with venture capitalists in India. Alcar recently set up a UK office and is planning to list on the UK stock exchange to

\footnotetext{
${ }^{91}$ Quoted in FreshMinds 2006.

92 Peudonym.
} 
raise funds for her expansion in the UK. She is also exploring the possibility of obtaining British Government grants and other facilities such as the R\&D tax credits to fund innovation activities in her international business.

The above indicates that there are some difficulties in accessing different types of finance. The next section highlights various measures used by Government to address market failures although none of these is targeted specifically at student, graduate and academic entrepreneurs.

\subsection{Dealing with market failures}

Changes in the macro-economic environment, such as lowering interest rates and reforms to the tax system, can create a more conducive environment for investment. However, market failures exist and Government has attempted to redress this. There are multiple Government policies to remove the barriers to finance of start ups as well as growth of existing firms. These include, for instance, Early Growth Funds (which make small amounts of equity finance to business start-ups and other businesses in the early stages of growth); Regional Venture Capital Funds (which address market failure in the provision of venture capital); Enterprise Capital Funds (through which the Government supports private sector investment in small businesses); support for Community Development Finance Institutions (CDFIs) which provide funds for individuals and SMEs in deprived areas who cannot obtain funds from mainstream sources, and the Small Firms Loan Guarantee Scheme (SFLG) for SMEs who are unable to obtain a conventional loan because they do not have assets to offer as collateral. The SFLG programme is the Government's principal debt finance instrument and it helps to overcome the lack of collateral in certain circumstances by providing lenders with a Government guarantee against default. Changes to the eligibility criteria of SFLG in 2003 brought a number of new business sectors within the scope of the scheme, in which there is strong representation of ethnic minority businesses e.g. retail and catering. Further changes to the SFLG were announced in the Enterprise Strategy Paper 2008 which includes increasing the banks SFLG lending allocation thus increasing SFLG capacity.

While some businesses are life-style businesses, others wish to grow as in the case of BI Satinder and Sunita and BC Kenneth. As the business owned by Satinder and Sunita is now five years old, from 2008 it will be able to benefit from the revised eligibility criteria for the Small Firms Loan Guarantee scheme which is now accessible to growth oriented firms more than five years old (BERR 2008a). In addition, Government has announced in its 2008 Enterprise Strategy Paper, new or strengthened existing funds for growth, such as the Enterprise Capital Funds, regional capital loans funds, including RDA co-investment funds. It will also continue to support the British Business Angels Association to encourage participation of private investors in UK businesses with growth potential as well as capacity building.

Indian and Chinese graduate entrepreneurs can also take advantage, if eligible, for Government sponsored financial schemes designed to help ethnic minorities and faith groups. Some of these are mentioned here. The Government has provided funds to stimulate private investment in the Bridges Community Development Venture Fund, investing in businesses in deprived wards, which include a sizeable proportion of ethnic minorities. CDFIs (Community Development Financial Initiatives) have been a key vehicle for assisting ethnic minorities. The Phoenix Fund, which includes a CDFI, has been successful in supporting people living in disadvantaged areas and under-represented in enterprise, which had included ethnic minorities (Ramsden 2004). The Government has also provided support for a number of CDFls to provide specialist loans to Muslim businesses owners (which include Indian Muslims), which comply with Islamic Sharia law. ${ }^{93}$

\footnotetext{
${ }^{93}$ In Sharia law, the giving or receiving of interest is prohibited and money must be invested ethically.
} 
The Government introduced the Community Investment Tax Relief to encourage more private investment in CDFls.

None of the businesses in the current research mentioned any of the above Government schemes as sources of finance. Of course, some of these schemes did not exist at the time when some of the entrepreneurs were looking for finance. It is also possible that they were unaware of the schemes or if they were, found they were not eligible. The removal of information asymmetries would be helpful for entrepreneurs looking for funding.

Having explored the access to finance for graduate entrepreneurs, I now turn to academic entrepreneurs and student entrepreneurs. This requires looking at how funds from Government and universities are provided and used.

\subsection{Academic entrepreneurs}

For potential academic entrepreneurs, there are also problems with accessing finance. There is a lack of sufficient post-doctoral fellowships to enable researchers to develop their business ideas and commercialise their research. To take the research developed in universities to the market, it has to pass through a number of phases including the proof of concept phase. Often this is the phase referred to as the 'valley of death' which is the weakest link in the chain of research to market. Funding is required for this stage said Joe, a university technology transfer legal advisor.

"We had a guy in civil engineering who came up with a new way to make a propend; a propend being a product that is used in the oil industry. It is like a little powder and you ram it down an oil well to make it flow better. He reckoned he had come up with a new way to make this; he could make it much harder and much lighter. But he needed some money to actually go to a company and get them to make him a sample of these according to his new process. Now he couldn't do that with the funding he had because it was outside the realms of the grant that he had. But all he needed was about $20 \mathrm{~K}$ and so we were able to scrape together some proof of concept funding"

Some ways that Government could improve the situation were suggested by Joe:

"What Government should do is make as much research funding available as possible at a basic level. And also improve the proof of concept level because there is a funding gap between $50 \mathrm{~K}$ and $250 \mathrm{~K}$. Up to $50 \mathrm{~K}$ you can use research funding to build prototypes of things, crude ones. And at 250K and upwards you can get seed funding. But in the middle to build say a large scale working prototype there is nothing - there is no available funding. So I would urge the Government to make some money available there - it has to be completely at risk and on a proof of concept basis. Other than that, the Government should just get out the way and let the market adjust. In the US they are so much better at commercialising research than we are here and part of the reason for that is that US venture capitalists are far less risk averse. In the US it is not seen as a problem if your first couple of ventures fail, hey ho, just carry on - there is always more money sloshing around. If that one fails pick yourself up and get a new idea and carry on. Here in the UK, people are very risk averse and if the Government attempts to micro manage the process of technology commercialisation, then it will fail. You have to let the market react. I would say the best role for Government would be putting aside a pot of Government backed cash for proof of concept between $50 \mathrm{~K}$ and 250K"

The Government has taken up the Sainsbury Review's recommendation to develop a national Proof of Concept specification to be delivered by the RDAs, which will provide access to facilities and have a strong focus on investor readiness (BERR 2008a). As the 
Sainsbury Review focused on science and innovation, this Government strategy may be more relevant to potential and existing science based academic entrepreneurs. However, in line with the wider concept of innovation proposed by the 2008 Innovation White Paper, such funding needs to be extended to a wider cross-section of disciplines. Furthermore, it would be also very helpful for proof of concept funds to be made available, albeit in smaller amounts ranging from $£ 1,000$ to $£ 50,000$, for non-research students and graduates as has been introduced successfully already in some universities (Robertson \& Wilkinson 2006). However, this needs to be sustained not only in the few universities that already provide it, but also extended so that it becomes a standard practice across all universities. To foster international entrepreneurship, ring fenced funds could be made specifically available.

The newly launched Innovation China UK (ICUK) programme is a step in the right direction. As noted in chapter 5 , the UK Government has provided $£ 5 \mathrm{~m}$ over two years and this has been match funded by the Chinese Government. The ICUK Collaboration Development Fund aims to support staff exchange, feasibility studies, proof-of-concept research and joint commercial research and development projects. Scientists from partner institutions and their Chinese collaborators, with the help of ICUK project managers, will jointly identify market-led research and development opportunities and make applications to the ICUK Collaboration Development Fund. Research and development to be carried out in China will also be funded by the Chinese Ministry of Science Technology. The first calls for proposals are currently being processed. This initiative provides not only funding but also infrastructure support which are helpful ingredients to project success.

Finally, having considered issues relevant to graduate and academic entrepreneurs, I now turn to access to funds for student entrepreneurs.

\subsection{Students}

Just over half of universities in England (56\%) have start up funds for students, although in Wales this figure is $92 \%$ (NCGE 2007). There is considerable variation among universities in the different regions in England, with all the universities in Yorkshire and Humber and four fifths in the North East providing such funds, but only one fifth in the East Midlands region (NCGE 2007). Apart from this, there may be specific programmes using Government grants targeted at students. For instance, there is the SPEED programme mentioned in chapter 1 which involves thirteen universities and is funded under the Higher Education Innovation Fund administered by HEFCE. Student entrepreneurs on the programme have access to around $£ 4,500$ each which can be used in various ways depending on the needs of the business and their personal development needs. The grant has been spent on accessing equipment, raw materials, finished products for personal branding, paying for mentoring support and as working capital. It has also been used for marketing, including in the case of British Asian student Akbar, exhibiting at trade fairs overseas. All the students interviewed said that it would have been impossible or very difficult to get their businesses started without the grant.

The students on the SPEED programme who were interviewed were all concerned about how they would continue the business after the grant ran out. Survival of the business is an issue not only for these students, but for graduate entrepreneurs as a whole. The exit rate among graduate business is high and according to one study it is $70 \%$ (Greene \& Saradakis 2007). Exiting a business does not necessarily imply failure, but it may be that financial worries are part of the decision to exit. Some of SPEED students interviewed had begun exploring various options. Abigail (Case Study 23), who had recently graduated, had managed to secure European funding for a year as she met the eligibility criteria of European Structural Development Funds. Other equally worthy students and graduates may not be so fortunate because they fail to meet the eligibility criteria. Hugh (Case study 11) needs $£ 40,000$ to expand his business. He was planning to have an initial meeting with a 
Business Angel/Venture Capitalist - he was not sure of the status of the person who had approached him at a business exhibition where he had a stand. However, he had reservations about going down this route as he was afraid of losing control of his business.

Anxiety about being able to continue the business may be exacerbated if the student has other financial commitments as in the case of mature students. Mature students with families have the additional difficulty of meeting the financial commitments of maintaining a family. As Akbar, a 26 year old mature third year undergraduate student who had set up his bio-diesel company said:

"I started the business using some of my own savings and money from the SPEED programme. Now I need a lot more money to expand as my exhibition at the Trade Fair in Italy was successful and now I have potential clients in Italy and Africa. But I don't know where to get it from. My wife and I and two children are living in rented accommodation and I need to get a mortgage to buy a house. I also have a lot of student debt. I don't think I will be able to get a bank loan easily and so I may have to take up the offer from a venture capitalist and lose control of my business"

Programmes such as SPEED which are funded for limited periods raise the spectre of the dangers of short-termism. As Oliver, a senior academic who works in enterprise education said:

"My problem is at the moment I look across the UK and I don't see much sustainability because we keep throwing public money at it but that money is project based. It is the same old problem, project based. Universities do it for the project period, everybody is on temporary contracts, and it comes to an end. So how do you embed that sustainability into the institution? So that might be through funding streams that require that, it might be linked to HEIF for example, which is sort of starting to work because HEIF has gone into a third leg of sustainable funding but it still has that project element. Thus all the people who are on HEIF contracts here are still on temporary contracts. So we don't have any real sustainability in terms of the support infrastructure for graduates in enterprise education. I think that is a major issue"

Programmes such as SPEED have to explore alternative methods to sustain them when grant funding runs out. Various options are being explored such as securing funding from RDAs, European programmes and from individual universities. Entrepreneurial universities may decide to embed programmes such as this in their standard curriculum portfolio, while others may not. This means that students in some HEls may have access to realising their entrepreneurial ambitions while others may not.

Current students may have more difficulty accessing finance to start or continue their businesses because, unlike earlier generations of students, they are more likely to have considerable debts mainly because of Government reforms to the funding of higher education since the late 1990s. This issue is explored in the next section.

\subsection{Student debt and its implications for entrepreneurship}

A study of national and international evidence of student debt concluded:

"Debt and fear of lack of funding are definitely contributing factors to graduates delaying the creation of a business, and as such, this report must conclude that perception of student debt is one of the most significant factors to consider." (FreshMinds 2006: 107). 
It is estimated that about three quarters of all full-time students in UK universities in 2004 studying for diplomas, degrees and postgraduate qualifications have debts and these mount up throughout the years of study (UNITE 2005). ${ }^{94}$ Figures on student actual or anticipated debt around 2004 seem to vary according to different surveys ${ }^{95}$ but they all find it has been rising over time. Debt appears to range between around $£ 8,000$ to $£ 12,000$, although it is higher among students in South West England, and from poorer families. ${ }^{96}$ Ethnic minority students, according to the student income and expenditure survey $2004 / 5$, have lower average levels of debt as do those students who live at home (Finch et al. 2006). One reason for the lower level of debts among ethnic minority students may be because they are more likely to live at home than White students (Connor et al. 2004). Student debt is derived from a number of sources. Leaving aside family loans, student debt is largely made up of loans from the Student Loan Company which manages the Government financial support package for students, as well as credit cards and overdrafts (UNITE 2005).

The effect of student debt on actual entrepreneurship of graduates and the career plans of students has been examined by various studies. A study which examined data on the class of 1999 , followed up four years later, found that:

"Student debt did not appear to markedly impact on labour market options, save that for those who had managed to pay off their student debt it does dampen their future propensity towards entrepreneurship. Such findings may suggest that there is little in the way of a finance gap for graduate entrepreneurs. Nonetheless, student debt levels continue to grow and there is a need to continue to monitor the impact of increasing levels of student indebtedness by financial providers and support organisations interested in obviating any market failure in this area" (Greene \& Saradakis 2007:7 emphasis in the original).

Such monitoring and evaluation of the impact on entrepreneurship is important because of changes to the financing of higher education which included the introduction of tuition fees for the cohort starting in 1998 and the abolition of grants for most students. It may change further in different ways following the Government review in 2009 of the 2006 student financial support reforms (Chester \& Bekhradnia 2008). It is important to assess the specific impact in the UK as international comparisons with countries that have a longer history of substantial student debt should be treated with caution as "the issues involved are complex, and a factor that has a certain effect in one country may well have the opposite result in a different scenario" (FreshMinds 2006:99).

It is useful to explore the impact of actual and anticipated debt on the perceptions and behaviour of current students. The impact of debt is not likely to affect all students and graduates in the same way. A study by Barclays Bank (NCGE 2005) of students in 2005 found that around a third of all students feel that student debt would have some impact on their ability to borrow money to set up in business; slightly fewer feel student debt would make it difficult to borrow money for other reasons. Of those students who wanted to set up a business immediately on graduating or some time in the future, and who had or anticipated having debts, the same study found that for a quarter of students, debt had no impact and they would carry on with their business plans regardless. Such personality types are not risk averse. The existence of a 'hard-core' of entrepreneurs who are undeterred by various barriers and who enjoy taking risks appear to exist in a wide range of countries (FreshMinds

\footnotetext{
94 This study includes international students.

95 The samples for the surveys vary considerably: some like the UNITE survey is a sample of UK students, fulltime, both undergraduate and postgraduate, and includes UK domiciled and overseas students while other surveys include only some categories of students.

${ }^{96}$ See various surveys, analysis and overview by Barclays, Nat West, UNITE, AGCAS, NIESR (Metcalf 2005) and Student Income \& Expenditure Survey 2004/5 and HECSU 2008. Hence a range is given as the sampling methodology varies between the surveys.
} 
2006). Among students, 'eager entrepreneurs' (Roberts 2004) were epitomised by students in the SPEED programme. In particular, 20 year old undergraduate Lincoln (Case study 6) exhibited great entrepreneurial drive and passion and said he enjoyed taking risks. At the age of 19, he was already a portfolio entrepreneur commercialising his hobbies and was now starting up another business with other students which would directly use the knowledge he was gaining from his automobile engineering degree. He appeared to be unlikely to be deterred by anything that would potentially stand in the way of the immediate realisation of his entrepreneurial ambitions. He was actively involved in the university student enterprise club and his infectious enthusiasm is likely to inspire a lot of students.

On the other hand, many students are far more cautious. The Barclays Bank study (NCGE 2005) also found that, of the students with entrepreneurial ambitions and actual or anticipated debts, more than half $(57 \%)$ said that they would defer their plans until the debt was paid off, while a fifth (18\%) said they would scale back their plans but still start up. The length of time graduates will take to repay their student debts will depend on the type of debt. Student Loans Company loans are non-repayable until a certain income threshold has been crossed (currently $£ 15,000$ ). Thereafter, they are income contingent and have an effective zero interest rate in real terms. The FreshMinds report argues that "[W]hether students perceive their debt as being that lenient is, however, another matter, and it is ultimately the perception of debt that is important to graduates when they are considering establishing a business" (2006:5).

Overdraft and credit card debt are, of course, more problematic because commercial terms would apply. The report argues:

"There is little conclusive evidence that student debt in the form of specialised loans affects a graduate's likelihood of becoming an entrepreneur, but it would seem reasonable to suggest that credit card debt must make it considerably harder for a would-be entrepreneur to choose to set up their business rather than find highpaying, secure employment. Any graduate in such a situation would face difficulties if for no other reason than with that amount of outstanding debt they are likely to have difficulties obtaining further loans from other sources" (FreshMinds 2006: 101).

In considering the impact of student debt, it is important not only to monitor the views of students, but also of those who provide business support as this may influence potential entrepreneurs. For instance, Mark, the director of a regional chamber of commerce was vociferous in his condemnation of student loans and its impact on entrepreneurship: "I am absolutely against student loans, because you are bringing people into a labour market with debt ... as a liability. That is exactly how a bank will look at it. So your chances of getting finance now are probably far less". A senior academic, Duncan, also saw student debt as "a particular albatross hanging round their neck and with $£ 20,000$ of debt, who in their right minds would want to take the risk of starting a business?"

This risk has to be set alongside the possibility of taking up secure, paid employment. Gerard, an academic engaged in enterprise education, noted that:

"if they are getting a firm offer of a job in their final year which is going to pay off their loans etc, why go for the uncertainty of starting a business? It is a strong factor that is now driving students down the conventional route. So it is the exceptions we are looking at."

Student debt, and the other potentially adverse characteristics of students and young graduates, such as lack of their own accumulated funds, collateral, favourable credit history and sufficient employment experience, may lead to the perception of them as a greater risk by external financial institutions. This could possibly be mitigated in various ways which are 
discussed below, in turn, in terms of the sources of finance: family and friends, debt finance, equity finance and Government subsidies.

\subsection{Dealing with student finance difficulties}

\subsubsection{Family and friends}

Family and friends provide what has been called 'love money' (FreshMinds 2006). We saw earlier in this chapter how some graduate entrepreneurs had managed to secure 'love money' from family and friends. Students may also follow this option. However, the disposable income of families may be depleted as parents provide loans to their children (UNITE 2005) and possibly support them financially in various small and ad hoc ways. Furthermore, students from lower socio-economic groups may find 'love money' to be a less viable option because of the more restricted availability of disposable income among their parents. This barrier may be particularly accentuated in the case of $\mathrm{BI}$ and $\mathrm{BC}$. We saw in chapter 2 that a greater proportion of $\mathrm{BI}$ and $\mathrm{BC}$ compared to WB higher education students came from lower socio-economic groups. Furthermore, there is evidence to suggest that some may also have considerable debts (Furlong \& Cartmel 2005) even though a number may be eligible for Government subsidy. Middle income families may also have less disposable income if resources have been depleted by financially supporting their children through higher education. Given the larger family sizes and aspirations for all children to attend university, $\mathrm{BI}$ and $\mathrm{BC}$ family resources are likely to be stretched even further. Consequently, the amount of disposable income likely to be available to provide 'love money' to help finance potential student and graduate entrepreneurs is likely to be curtailed. Lower availability of family finance may be coupled with greater pressure to get a job. Paid employment offers regular and secure income and also facilitates adhering to Asian family values of supporting the family, including helping to pay for the education of younger family members. Clearly, various factors such as socio-economic conditions, size of family, nature of family obligations and values, all play a role and need to be investigated through further research.

However, even if parents are able to provide finance, it is possible that students and young graduates may not wish to avail themselves of this, as we saw earlier in this chapter, in the case of Jay \& Raj (Case Study 10). Nevertheless, the idea of family and friends being a source of funds should not be lost sight of, but the concept could be broaden to embrace a wider community. One possible solution is to ensure that the Government's commitment in the 2008 Enterprise Strategy Paper to build Business Angel capacity incorporates working with ethnic minority business organisations who can potentially serve as an extended family. Successful members of these organisations could be encouraged to provide Angel finance to promising $\mathrm{BI}$ and $\mathrm{BC}$ students and graduates who become members of the organisation. This may require outreach work being undertaken by these organisations to universities but they could potentially hold the promise of providing more accessible routes to equity finance.

\subsubsection{Debt finance}

Debt finance is mainly acquired through banks but also other financial institutions. The way in which banks treat student debt may vary between banks and is an issue that needs to be explored further. Some may regard Student Loan company debt as a 'good debt' and ignore it when potential students or graduates apply for a loan. Some thought needs to be given to developing a modified SFLG scheme. This scheme is particularly suitable for those students, graduates and academics that lack collateral and have businesses less than 5 years old. ${ }^{97}$ The scheme, for instance, could be modified to take account of student debt and also consider whether the Government guarantee to lenders for $75 \%$ of the loan could be increased in the case of students and young graduates. Irrespective of modifications,

\footnotetext{
97 The 2008 Enterprise Strategy paper extended the scheme to businesses over 5 years old who had growth plans.
} 
banks, other financial institutions and agencies involved in the scheme, at national and regional levels, need to work more closely with universities to raise awareness of the scheme which appears to be not well known judging from the people interviewed for the current research.

A ring-fenced micro-finance loan scheme could be developed specifically for students and graduates. Barry, an experienced director of an incubator with a lot of experience of working in the business sector prior to joining the university, said:

"What would be useful is a micro-finance scheme for students and graduates through which they could apply for small loans of up to $£ 5000$ on which they pay a favourable interest rate"

A mechanism for doing so may be to provide loans via the Student Loan Company as suggested by the FreshMinds report. It notes that:

"[A]s of 2006, the Student Loan Company will already be accustomed to opening a second account per student to cover their fees which will be charged in arrears. The possibility of allowing further student loan-style borrowing for the purposes of a business start-up therefore seems a realistic possible solution to fears of lack of funding amongst recent graduates" (Freshminds 2006: 106).

Another approach may be to develop a micro-finance self help bank linkage scheme. Such an approach is used to develop financial literacy and generate funds among the poor in India to enable them to undertake a variety of activities, including starting up or growing a business (Kropp \& Suran 2002). Like the poor in India, most British students have no collateral or personal savings, but have debts and generally low levels of financial literacy. The scheme involves a group of people who save an agreed amount on a regular basis to create a corpus of funds which is loaned, on mutually agreed terms, to members of the group. Once financial discipline has been established and a corpus of funds accumulated, banks match the funds saved by the group, thus increasing the corpus of funds at their disposal. If established in the UK, British students involved in such a scheme could, as a collective rather than individuals, have more success in accessing debt finance and could use the funds to help start their own business. All the banks in India are involved in this scheme and the branches of some of these banks which are located in the UK (such as $\mathrm{ICICl}$, Bank of Baroda) could be mobilised to pilot the scheme among students in the UK.

\subsubsection{Equity finance}

Equity finance is another option but this type of funding is not well understood by students. Hugh, a WB student with a web-based business, who needs $£ 40,000$ to expand, was potentially offered funds by a venture capitalist which he reluctantly may have to resort to, although worried about loss of sole control of his business. Philip (Case Study 2) said that a large number of venture capitalists had approached him but he was reluctant to relinquish control. Raising awareness of equity finance, its advantages and disadvantages, needs to take place in universities so that students, graduates and academics, including BI and BC, have a better understanding of what it entails.

\subsubsection{Government subsidies}

Grant funding via the Government can occur at national, regional, sub-regional and local levels. The SPEED programme is financed by national funds and student entrepreneurs interviewed were unanimous that this played a key role in translating their business ideas into a start-up. While some students eventually may have become entrepreneurs anyway the 'hardcore entrepreneurs', it seems likely that many would probably not have done so, resulting in missed opportunities for increasing innovations and business start ups. The fact that there was heavy demand for places in the SPEED programme, and many start ups have been generated, has led to suggestions that such programmes should have long term 
funding (as mentioned earlier) and be made available to students at all universities rather than the very small number at present.

We noted in chapter 1 that a lot of Government funding has gone into developing enterprise among science students. However, it is suggested that such funding has not gone far enough to achieve better levels of outcomes. As Ben, a senior lecturer who works in a Science Enterprise Centre said:

"What would be nice is the Government have put all this money up to start all these science enterprise centres to get more of an entrepreneurial spirit and to generate these students with their ideas. But a lot of them will come through the year; they have a very good idea, and then will almost fall at the end because they haven't got the funding in place. And it is almost like saying the Government should have said, right, we will provide all these entrepreneurial courses and we will also put some money into a pot to fund the best $10 \%$ just to get something going. I think that is what is missing because we tell students where to go to look for money but we can't guarantee they are going to be given it"

A suggestion made by Oliver, a senior lecturer who has been working in enterprise education for several years at different universities is that there should be Government provision for "seed capital funds targeted at universities, so each university should have its own seed capital fund for graduate entrepreneurship. We have to have better sustainability for enterprise education activities." Such funds could also be used to help pay for patent applications from students in all universities, not only in a few as at present.

Another option proposed by some university staff is Government interventions similar to the 'golden hellos', debt cancellation or reduction, and other schemes designed, for instance, to attract graduates to work in geographical areas or subjects experiencing recruitment difficulties. Oliver had a hypothesis about the result of such potential financial incentives:

"I wonder what the impact would be if Gordon Brown said that the best way to kick start businesses in this country is that for every single graduate that leaves a British university who wants to start up their own business the Government will wipe out $50 \%$ of their debt. I wonder what that would do...and...I would bet my cotton socks that the business start up rates would catapult"

As noted earlier in this chapter, several sources of Government supported grant and loan funding exist. These are not specifically targeted at students or graduates and, furthermore, they have their own eligibility criteria. Identifying and applying for them is time consuming which can deter students who need time to study, work part-time to finance their studies, and also attend to family commitments as in the case of mature students. Support from Intermediary organisations can make a difference. For instance, Terry a WB graduate who now owns a thriving beauty salon, obtained start up funds through an intermediary organisation. Vincent, one of organisation's staff, spent a considerable amount of time reading extensive documentation on various British and European funding streams, preparing appropriate proposals and negotiating deals. He also helped to secure premises. During this period, Terry concentrated on successfully completing his studies as the certificates he attained were crucial to establishing the credentials of the business. Without Vincent's help, Terry doubted whether his business would have got off the ground, or if it had, there would be none or fewer certificates on the walls of his beauty salon.

Besides financial packages, students need other forms of support which I will now turn to. 
There is a need to deal with information asymmetries. Students, graduates and academics may not be fully aware of the range of funding sources available. Even if they are aware of the sources, they may not be finance and investment ready so that they understand the full range of financing options available to them and the implications of this for the business. They need to be able to balance the fear of losing control of the business if they accept equity finance, and not starting up at all, or not taking advantage of the potential to grow. They also need to have financial management skills. This may be particularly important as many SMEs, particularly sole traders and partnerships, do not have their finances managed by someone with a financial qualification (Fraser 2005).

Innovative ways need to be found to provide students with information about funding and help develop investment readiness skills so that they can take full advantage of the supply of finance available. At present all universities have 'milk rounds' where potential employers talk about the opportunities available for graduate employment with their organisations. An equivalent could be held by the university careers service for student, graduate and academic entrepreneurs where banks, business angels and venture capitalists come to the university and market their services. It would also be useful to have present a range of organisations which provide business support (see chapter 9) such as UKTI, RDAs, Business Link, chambers of commerce, ethnic minority business organisations and TiE. Precursors to this idea are various enterprise fests (Price et al. 2004) but while these were evident at only at a few universities and were generally one-off, it is important to have the self-employment 'milk round' as a regular annual feature of all universities. This would help to elevate the status of self-employment as a career option. It would also help to increase the career services events for entrepreneurship which at present account for a mere $5 \%$ of events (NCGE 2007). The Association of Graduate Career Advisory Services is planning to have a new task group on entrepreneurship which hopes to involve those providing entrepreneurial advice at universities. This may help to raise the profile of self-employment as a labour market option.

Besides helping to generate more start-ups and improve the survival rate of existing ones, there are other advantages of financial and other support of student and graduate entrepreneurship which I will now turn to.

\subsection{Advantages of improved access to finance}

At least five advantages can be identified.

\subsubsection{Potential increase in volume of start-ups}

There has been far less financial and other support for student and graduate entrepreneurship from Government compared to its support for academic entrepreneurship as it is expected that research generated innovation will have a greater economic impact on the country. Yet, investment in student and graduate entrepreneurship could lead potentially to higher and better outcomes. This is for two reasons; first, the actual volume of nonresearch undergraduate and postgraduates is considerably higher than research students and staff. In 2006/7, there were about 2,362,800 higher education students in the UK comprising WB and British ethnic minorities $(2,011,300)$, EU $(112,300)$ and non-EU overseas students $(239,200)$. The overwhelming majority of HE students are non-research students: $97 \%$ of UK domiciled students, $86 \%$ of EU students and $85 \%$ of non-EU students. Second, academic entrepreneurship based on extensive research takes longer to materialise whereas there is a greater probability that investment in student and graduate entrepreneurship may yield earlier returns. Hence, more businesses could be generated leading to enhanced cumulative wealth, job creation and knowledge transfer. Furthermore, it 
would lead to the better capture of the innovation potential of non-research students, the absence of which, as mentioned in chapter 5 , has led to missed opportunities.

\subsubsection{Capitalising on the dynamism of young people}

Young people are likely to be more dynamic. This is the view of Amanda, a Student Enterprise Adviser working at a university that placed a great deal of value on student and graduate entrepreneurship. This university had the hallmarks of an entrepreneurial university (Gibb 2006) and included a specific cadre of staff and support facilities. Her motto was "Don't delay, build on student dynamism now". She and her team of staff work to turn viable business ambitions into reality while the students are still at the university. Among the many possible dangers of delaying entrepreneurship plans is that these may be completely jettisoned as graduates become engrossed in new jobs as well as family and other commitments. The attraction of secure, graduate level jobs is a strong one, particularly for some students with large debts and family pressures to secure stable employment. Hence, capitalising on student dynamism, youth and limited encumbrances, together with mobilising the financial packages mentioned above, may lead to increased firm formation.

\subsubsection{Helping To Remove Regional Disparities}

Financial and other support packages may keep students in the region where they studied as undergraduates or postgraduates. As Oliver, a senior academic who supported Government financial packages for students with viable business ideas said:

"There are all sorts of very good rationales for doing it because, you know, they tend to set up locally so you have economic retention in terms of them not going to London or whatever. They are more likely to employ their own friends or graduates coming from the university, and obviously if they are successful, they are more likely to put something back into the university providing that you have got the alumni networks set up"

Lack of support for start-ups before or immediately after graduation may thus fail to help ameliorate disparities in regional economies as graduates move to richer areas like London with more employment opportunities. Alternatively, as there are no standard entrepreneurship support packages available throughout the country, the RDA which offers the best package is able to lure students away from the region where they did their studies. Amanda, the Student Enterprise Adviser, whose university is located in a region which suffers a high level of deprivation, gave the example of a group of new graduates with a very viable business started when they were students at the university. They moved away from the region in which their university is based to another more prosperous one as the latter's RDA offered them funding and other facilities. She said that if her university and/or the local regional development agency had provided financial and other support for the students, then they would have retained them. Strengthening regional economies and removing the disparity between them is one of the key aims of Government. Therefore, some consideration should be given to providing equitable financial and other support in each and every region rather than leaving it to the vagaries of a 'postcode lottery'.

\subsubsection{Reducing unemployment or under-employment}

Support for moving into entrepreneurship may help to reduce unemployment or underemployment of students who may find it less easy to get good jobs. There is some suggestion that students who study at more reputable institutions, such as the Russell Group universities, are less likely to consider going into entrepreneurship, particularly soon after graduation, because they get attractive offers from blue chip employers. According to Oliver, a senior academic at a Russell group university:

"If you are a very qualified, top class student in a Russell Group University and you have got 10 different companies, all blue chips, wanting to offer you a job, then are you going to do that or are you going to set up a business? In the US, more of those 
people would probably set up businesses. In the UK, well I think the cultural issue would be still to take the job and then you set the business up 3 or 4 years down the road if that is what you want to do"

The 'war for talent' among blue chip and other companies to the detriment of entrepreneurial ambitions was amply evident among Chinese graduates from elite British universities interviewed in Hong Kong at a 'mini milk-round'. ${ }^{98}$ The companies offered lucrative employment prospects. A few graduates who had considered setting up a business after a couple of years of work experience said they would regard themselves, and be regarded by peers and family, as "foolish to give up the prospect of good career, good security and money for the risk of starting a business". It is likely that similar views are also evident in the UK among students and graduates, particularly those from BC and BI backgrounds.

It is suggested that students who graduate from some post-92 universities, who appear to have less attractive job opportunities, are more inclined to consider starting a business. This is an interesting observation because there is research evidence to suggest that there is no correlation between institution attended and entrepreneurship (Greene \& Saradakis 2007). However, that research focussed on the cohort who graduated in 1999, followed up four years later, and it is possible that institutional affiliation may now have some impact. Ethnic minorities, including $\mathrm{BI}$ and $\mathrm{BC}$, are more likely to study at post-92 institutions (Shiner \& Modood 2002, Connor et al. 2003) so there is a greater likelihood that they would need support into entrepreneurship.

\subsubsection{Stopping the dispersal of student groups of nascent entrepreneurs}

Another advantage of providing financial and other support services to students, while they are students or immediately on graduation, is that student groups who have developed an innovation are less likely to disperse on graduation. Some of these groups, as with Arun and his colleagues (Case Study 8) and Chandra and his colleagues (Case Study 4), comprise British and international students or international students only. The likelihood of international students dispersing and returning home overseas is even greater than home students although some may take advantage of immigration regulations which (from 2008) allow them to stay in this country for two years after graduation. Funding would enable students with good ideas, such as Arun and Chandra and their colleagues to stay together rather than disperse immediately after graduation. While contacts can still be maintained by telephone and email, nevertheless, physical proximity would facilitate face-to-face meetings which are probably crucially important in the setting up phase of the business.

\subsection{Wider Government policy}

Finally, I turn to the wider issue of Government policy under which enablers of enterprise are subsumed. The 2008 Enterprise Strategy Paper states that the Government's ambition is to make the UK the most enterprising economy in the world. To do this requires co-ordination and integration of policies at different levels: central, regional, sub-regional, local and university levels. In formulating and delivering these policies, the Government's ambition to engage fully in the global economy has to be always taken into account. Interviewees were critical of Government policy on many counts, two of which are mentioned here by way of illustration: risk averse enterprise policy and the lack of holistic approach to universitygenerated entrepreneurship. Each will be examined in turn.

\subsubsection{Lack of sustained and comprehensive policy on investment}

Government policy is said to err on the side of caution and to measure outcomes in terms of failure or survival of the business rather than, or as well as, successful processes and

\footnotetext{
${ }^{98}$ The careers officers from four elite British universities in collaboration with the British Council offered a 'mini milk round' in Hong Kong, Beijing and Shanghai where blue chip multinational companies tried to recruit alumni from these universities.
} 
learning. BI Jay (Case Study 10) who found it difficult to set up his business in the UK and is now in Silicon Valley, notes the loss to the UK economy because he did not set up his business here:

"I think what Government needs to realise is that it is the old sort of thing that to make money you need to lose money. So the Government needs to be prepared to make investments in young people like me, for example, when I left university. The Government needs to invest in people like me knowing that the first thing we do may very well fail It is probably more likely to fail than it is to succeed. But the point is that the experiences that are learned from that first venture I will put into my second venture and then I will be more likely to succeed in that. So there is a long term reward coming in to the economy as opposed to thinking really short term. I think that is the big attitude that needs to be changed. A lot of people in the UK don't understand that, if they want to get to a position where they have got an economy as strong as the Silicon Valley entrepreneurship scheme, then in the short term that is going to cost money, and that money could be lost in the hope of securing longer term rewards. I don't think there are two ways about it. Whether we are successful or not there is still a net loss to the UK, because the experience we are learning is being learnt out here and not back in the UK where it could have been fed back into the system. Personally for the internet industry that is how it is going to be until there is some dramatic change in the UK mentality towards early stage businesses and early stage entrepreneurship"

BC Kenneth (Case Study 13) also supports this point of view. He points out that his current success as a portfolio international entrepreneur is the result of failure at his first start up attempt. However, he says it was "a great learning experience and helped me with businesses I set up later. I won't make the same mistakes again". Encouragement to "have a go' and the removal of the fear of failure are important cultural changes that are necessary if the ambition for the UK to become the most enterprising economy in the world is to be achieved.

\subsubsection{Lack of a holistic approach to university entrepreneurship}

This chapter has so far looked at student, graduate and academic entrepreneurship in separate sections. This is partly a reflection of the compartmentalisation of policy as there is a lack of a holistic approach to university generated entrepreneurial activity. According to Oliver, a senior academic who teaches entrepreneurship, runs an enterprise support centre and has an equity stake in a business set up by one of his students on graduation:

"There is a failure of technology transfer across the UK and it is partly a failure of policy because policy has driven us down this direction. We concentrate on academic spin outs so the establishment of actual businesses rather than licensing technologies and making available technologies and things to other people to commercialise. It will still generate a return to the university. So in technology transfer we are trying to pull everything into spin out ventures because the policy framework and the funding pushes us down that road but actually what you want is a wider spectrum of stuff going on. So you have some graduate entrepreneurs setting up service based businesses, some graduates setting up spin outs that are linked to licensed technology, some external entrepreneurs buying into the university to use that licence for technology, and then some real genuine academic entrepreneurship where the academics are leaving the university to set up a business with a new technological whatever. So I think policy tends to drive us towards one at the moment. Policy tends to be in boxes, trying to influence bits, whereas actually on the ground it is all linked together. The danger is that when you get the policy over here that is in that box, it pulls this string that takes the institutions in this direction but then it neglects the interactions between the key things which are crucial for a more holistic approach to enterprise and activities" 
Integration of funding streams and the development of strategic Government and institutional plans may help to reduce the level of current fragmentation.

\subsection{Conclusion}

This chapter has examined issues relating to access to finance for students, graduates and academics who wish to engage in or grow their entrepreneurial activities. Students and recent graduates including $\mathrm{BI}$ and $\mathrm{BC}$ merit targeted interventions as most enter the labour market with sizeable student debt, in addition to little or no personal savings or collateral. Graduates who enter paid employment have the security of knowing that they will have a steady income from which to pay their debts while those entering entrepreneurship do not have such an assured trajectory. While this may not deter the hard core or eager entrepreneurs, it may be a sufficient deterrent for those who are ambivalent about the wisdom of taking a risk with entrepreneurship. As a greater proportion of $\mathrm{BI}$ and $\mathrm{BC}$ compared to WB students and graduates come from lower socio-economic backgrounds, family and friends may have less disposable income to channel into supporting student and graduate entrepreneurial ambitions. However, wealthier members of Indian and Chinese ethnic minority businesses and social organisations could be mobilised as extended family to provide business angel finance. As the Government is planning to work with the Business Angel Association to develop Angel finance, this could be extended to working with ethnic minority organisations to identify the support they require to provide Angel finance for student and graduate entrepreneurs from their community.

Access to debt finance could be enhanced in at least three ways. First, providing ringfenced, clearly visible loans for the target group; second, modifying the SFLG scheme so that Government guarantees a higher proportion of the loan than the current $75 \%$ and third, developing micro-finance schemes, including a micro-finance self help bank linkage scheme. Grant finance could be made available for students to help sustain initiatives such as SPEED, to pay for patent applications, and to provide proof of concept funds for academics interested in taking innovations to market. Targeted interventions are needed to deal with a range of market failures including information asymmetries, lack of sufficient financial literacy and discipline and lack of investment readiness.

The provision of financial packages and support is likely to have multiple benefits including an increased volume of start-ups and other entrepreneurial activities, amelioration of regional disparities, and facilitation of international entrepreneurship by maintaining the physical proximity of British and international student groups. Holistic strategies dealing with a wide range of university-generated entrepreneurship would provide better services to students, graduates and academics and remove the current 'postcode lottery'. 


\section{CHAPTER 8: ENABLER OF ENTERPRISE: KNOWLEDGE AND SKILLS PROVISION BY UNIVERSITIES}

\subsection{Introduction}

The 2008 Enterprise Strategy Paper states that:

"The Government's vision is for many more people in the UK to have the enterprise skills to successfully start and grow a business" (BERR 2008a:33).

Enterprise knowledge and skills is one of the five enablers of enterprise identified in the 2008 Enterprise Strategy Paper. The need to raise aspirations towards entrepreneurship and acquire enterprise skills has been recognised by Government for some time with the launch of the Enterprise in Higher Education initiative in the early 1980s. This chapter looks at support provided to students, graduates and academic staff including BI and BC, within the university. Some attention is also given to another enabler of enterprise - the culture of enterprise. The first part focuses on enterprise education, both in-curricula and extracurricula in universities. It suggests some of the ways in which this could be improved, particularly to foster international entrepreneurship. The second section focuses on the activities of the National Council for Graduate Entrepreneurship (NCGE), particularly its programmes for recent graduates. To provide support to early stage businesses, there are incubators (a generic term which appears to cover incubators, innovation centres and science parks) in, or attached, to many universities. The third section looks at four incubators, including one in China. It also looks at the extent to which they do, or potentially can, foster international entrepreneurship.

\subsection{Entrepreneurship education: in-curricula and extra-curricula}

As mentioned in chapter 1 , various forms of enterprise education are now provided in universities, about a third in-curricula and the remainder extra-curricula (NCGE 2007). However, enterprise education provision does not fully cater for all students. For instance, $80 \%$ of provision is at undergraduate level and $87 \%$ is for full-time students (NCGE 2007). Entrepreneurship education provision by business and management schools has always existed and this is still continuing, accounting for almost two thirds of existing provision (NCGE 2007). Different institutional models exist (Pittaway \& Hannon 2007) and some enterprise education is now delivered centrally (potential cross-curricula but in practice the emphasis remains in business studies, science and technology) while in other cases provision is decentralised so that each department can decide on the scope of activities and delivery mechanisms (Price et al. 2004, Botham \& Mason 2007). The NCGE has been working with some Higher Education Academy Subject Centres such as engineering, dance and bio-science to identify enterprise education provision and help embed it in disciplinary curricula and pedagogy (Hughes 2007). NESTA has been working with a Higher Education Academy Subject Centre to examine enterprise education for the creative industries. ${ }^{99}$ There is considerable on-going debate about the nature and scope of enterprise education including institutional ethos, concepts of entrepreneurship, curricula, pedagogy, intended outcomes and the nature of entrepreneurial universities (Gibb 2005).

\subsection{Examples of enterprise education}

The following examples of enterprise education were elicited during the empirical research and illustrate some of the patterns mentioned above. This section is not designed to give a comprehensive account of the range of provision available (see Price et al. 2004, NCGE

\footnotetext{
${ }^{99}$ See HEA Art Design Media Subject Centre \& NESTA report 2007.
} 
2007) but to provide a flavour of the range available, including international entrepreneurship education.

\subsubsection{Core curricula provision}

Some entrepreneurship education provision is incorporated as part of the degree programmes at undergraduate, taught masters and doctorate levels. This is exemplified by the two case studies involving student teams mentioned in chapter 3. Case Study 8 involved Arun, Avinash, Gerard and Elizabeth who were on an undergraduate engineering degree programme and undertook an enterprise module as part of the core curricula. Case Study 4 involved Chandra, Anwar, Leela and Christof who were on a taught Masters programme in Enterprise and Biotechnology. Students in both these programmes were encouraged to develop their ideas in teams to a standard that can be presented at business plan competitions run at their universities. A science enterprise centre was offering in 2007/8 a Doctorate in Enterprise where the student works on a R\&D project funded by an external business so it has an inherent commercial dimension.

These three examples from science and engineering testify to attempts in the last few years to increase entrepreneurship education in these disciplines. The Lambert Review of Business-University collaboration (2003) emphasised that "[I]t is also important for students - particularly science students - to develop entrepreneurial skills to allow them to exploit their innovations and develop the commercial potential of their work" (2003: 111). This has led to the setting up of 13 science enterprise centres involving over 60 universities nationwide. Apart from enterprise education, these centres have helped to start new businesses and put budding entrepreneurs in touch with a range of opportunities like seedcorn funds, venture capitalists and business angels, and science park accommodation, as well as establishing various links to industry. Evaluation of attempts to embed enterprise within the science and engineering department core curricula has shown them to be successful, with positive views evident not only among students but also the academics involved in teaching enterprise. Furthermore, such attempts enhanced the likelihood of sustaining discipline-based enterprise education (Handscombe et al. 2007).

\subsubsection{Self-employment placements}

The SPEED programme, as mentioned in chapter 1 , is a very recent innovation funded by the Higher Education Innovation Fund which has led to businesses being set up by Lincoln (Case Study 6), Hugh (Case study 11), Clinton (Case Study 16) and Abigail (Case Study 23). Instead of doing a year in industry as a placement, these students have received a comprehensive support package including business funding, advice, training and mentoring. Although overseas Indian Ashok is part of Lincoln's team, he is unable to benefit directly from the SPEED programme because overseas students are not eligible. This is a source of great frustration to him as he said "[T]his is not fair. We are paying such high fees as overseas students and yet we don't have equal treatment as UK students". He had arranged a meeting with the vice-chancellor to air his grievance and to seek some form of redress.

\subsubsection{Electives}

A university business school is planning to offer entrepreneurship education electives to students from life sciences, law and computing intelligence to enable them to become "more business savvy and to consider business opportunities". Another business school offered this to students of any discipline. One area of business opportunities that is mushrooming is computer games which benefits from multi-disciplinary collaboration as it brings together science, art and design. While there may be slight differences in approach in various universities, basically the students are organised into small groups and guided through the planning and establishment of a new company. The experience gained from the forming and running of a new business counts towards their final degree. 


\subsubsection{Business Plan submissions}

Existing programmes may develop innovative approaches which encourage entrepreneurial development. For instance, in a Masters programme, instead of the students doing the conventional dissertation, they are offered the opportunity instead to prepare a comprehensive business plan covering all the typical elements of marketing, HR, product development, finance etc, and these approaches are expected to have a theoretical underpinning. It is anticipated that some of these will develop into start-ups. The programme provides easier access to financial capital and other expertise through business angels, venture capitalists and business consultants who are linked to the university as Enterprise Fellows. Some of these Fellows are from India and Europe while another is WB with strong links to China. These Fellows can provide not only information about those countries but also provide vital conduits to networks in India, China and Europe for the students.

\subsubsection{Extra-curricula provision}

While some institutional structures or degree programmes are better able to incorporate entrepreneurship education, in other cases, particularly in some non-modular degree programmes, the accreditation may take the form of a specific certificate. For instance, one university is introducing a University Certificate of Professional Development and is designing a diploma as well. This will allow students across all faculties to study for this certificate as an extra-curricula option. It is anticipated that students in the creative industries, who are more likely to go into self-employment as a career option because of limited prospects of working as employees, will be better prepared for this by undertaking the certificate. In some universities, some enterprise education provision is on a self-help basis with students having access to CD Rom, DVD and other interactive material.

\section{International entrepreneurship}

\subsubsection{Involvement of multi-national companies}

Case Study 31 (Simcar) represents direct engagement by a university with a multi-national company to deliver enterprise education, with a strong international entrepreneurship element. A British university has signed a contract with Simcar, a major Indian multinational software company which is headquartered in India but has bases worldwide including in China and the UK. This company employs graduates to deliver software solutions to clients worldwide. As IT solutions can be used in any type of business to improve its effectiveness, students from any disciplinary background can undertake a placement in this company and work on existing projects. As the company has clients worldwide, it gives UK students the opportunity to work with international clients. Simcar has a joint venture with a Chinese IT company in China. It has also signed contracts with a number of universities in China to open Centres of Excellence for the same purposes as it has with the British university. According to Prakesh, the Indian CEO of Simcar:

"[T]he relationship is mutually beneficial. Students gain practical experience by working on international projects and student and graduate entrepreneurs can also use our IT platform to launch their own businesses, nationally or worldwide. We gain by proactive engagement in the 'war on talent' as we can take advantage of multiple opportunities to select future young employees in both UK and China"

The relationship between the university and Simcar is a good example of providing internationalisation skills thus addressing an important market failure in the supply of internationalisation skills (DTI 2006b). Simcar's relationship with the British university was engineered by $\mathrm{BI}$ Anand who had known Prakesh personally for some time. 


\subsubsection{Summer courses}

While many universities offer extra-curricula activities during the academic year, some offer intensive courses in the summer (Price et al. 2004). Ramesh, a senior BI academic who directs such courses at his university, has set up a collaborative arrangement with India whereby overseas Indian students and graduates can come to the UK to take up especially reserved places on the university's summer schools in England. Such programmes, which bring together British students and graduates with those from overseas, can provide a conducive environment for developing international businesses. Ramesh has noticed an emergent trend in international collaboration that would benefit from further development.

\subsection{Staff background and pedagogic approaches}

The academic and commercial background of staff can affect the value placed on entrepreneurship education. Some university staff have experience of working outside the university. Thus Darren, who works as a lecturer in the engineering department of a pre-92 university, had considerable experience of non-academic work. He said:

"I came to this university 3 years ago. I had worked in higher education but doing consultancy work with small companies. I had spent my entire existence doing consultancy with companies, forming ideas, taking prototypes forward, that side of things. So my background is in product development, product design, engineering design and engineering production"

As a result of this background, he encourages students to think about applied engineering and entrepreneurship. Another colleague, Ben, in the same department, was trained as a biologist but had previously worked at a university which encouraged academic entrepreneurship:

"I am a biologist by background but I spent 10 years there (previous university post) and got more into science management the last 5 years in the department of biology. And a lot of my colleagues were doing little start-up spin outs and that really caught my imagination and sent me off in this direction of enterprise and entrepreneurship. So I use both my biology background and my business background to help develop science entrepreneurs"

The pedagogic approaches used by university staff can encourage or discourage the development of entrepreneurial skills. As Darren from the Science enterprise centre commented:

"Some are very much a stick of chalk and teach very old fashioned development that you have got to learn all these physical formula and we will test you on that. Others, for example in the textiles section, will get the textile students to form groups and they are told to go and make some money, start something up. For example, a group of girls set up last year selling sweets. They went to a wholesaler and bought sweets, repackaged them in nice packages, took a stall at the student market each week and I think they sold $£ 1,500$ of sweets. And the trademark, the name they came up with, they came to me and said how do we protect the trademark and they sold the name to a sweet company, which is very good. But at the end of that, none of those students wanted to become sweet shop owners or manage a brand. It was done for the purpose of an assessment and it was done very well, and they applied themselves very enthusiastically but they really wanted to do something with textiles... And I think when people are getting marks at undergraduate level they focus"

This is an example of undergraduate non-research students being innovative, and with the support of a business oriented tutor, able to commercialise their IP by protecting it and 
selling the trademark. It is also an example of students using one of the progression pathways to market which does not involve a start-up.

Enterprise education activities can involve alumni who have set up successful businesses and return to pass on their experience to students. Thus, a successful BI entrepreneur regularly returns to his alma mater to lecture and run workshops on entrepreneurship. Jay \& Raj (Case Study 10) returned to their alma mater to participate in an event on employment and entrepreneurship opportunities in Silicon Valley. As ethnic minorities, including Indian and Chinese are more likely to be motivated than WB because they want 'to follow the example of someone I admire' (DTI 2007b), the use of successful role models is a good way to encourage compatriots and others to follow suit.

\subsection{Student Enterprise Clubs and Business Plan Competitions}

About a half of universities in England (and about three quarters in Wales) have student enterprise clubs (NCGE 2007). Four case study entrepreneurs BI Jay \& Raj (Case Study 10), BC Kenneth (Case Study 13) and WB Lincoln (Case Study 6) have been involved actively in these clubs in different universities, including holding prominent positions on the executive committees, such as president. These clubs are run for students by students and provide a range of enterprise awareness activities. Managing the activities of the club can be very time consuming and this has led Oxford University, for instance, to fund a paid sabbatical post for the club president. The 2007 presidents of student enterprise clubs in Oxford and Cambridge are $\mathrm{BI}$, a past president of the Oxford club was a $\mathrm{BI}$ male and the incoming president of the Cambridge club is a BC woman. Such involvement is indicative of $\mathrm{BI}$ and $\mathrm{BC}$ interest in entrepreneurship. Some clubs include 'dragon's den' style business plan competitions. As well as intra-university competitions, there are also inter-university competitions. For instance, two universities held an inter-varsity competition and the winning student team of Arun, Avinash, Gerard and Elizabeth (Case Study 8) went on to compete and win in an international competition. Jay \& Raj (Case Study 10) were successful in a competition which gave them a prize of $£ 500$. Some of the student clubs have been very successful in raising academic and commercial sponsorship and prize money for their competitions.

Business competitions are run not only by students but also incubation or innovation centres, departments of universities, ethnic organisations and professional bodies, sometimes in conjunction with student clubs. Overseas Chinese students Harry and Alfie (Case Study 27) were shortlisted in a competition organised by the Innovation Centre at their university. Some UK-based Chinese associations which comprise both BC and overseas Chinese students and scholars run local, regional, national and international competitions in the UK. According to overseas Chinese postgraduate student Edward who helps to organise these events, "invitations to compete and attend these events are also extended to Chinese students and scholars in Europe". Some of these events are supported by the Chinese embassy as well as other sponsors. Judging panels have included Chinese and British academics, entrepreneurs and representatives from various agencies. Some competitions involve worldwide participation. A business plan competition run by a British university was for Chinese students studying either in the UK or anywhere in the world. The university's collaborators were the China Innovation \& Development Association, UK (CIDA UK) and the British Society of Chinese Entrepreneurs. The intention was to identify those with ideas to develop businesses between China and the UK. Some of the shortlisted applicants were students from universities in China. Professional bodies which cater for the HE sector are also involved in running business plan competitions. For instance, Enterprise Educators UK, ${ }^{100}$ in conjunction with a number of sponsors ran a nationwide business plan competition in 2007, as it has done in previous years, for science and engineering students and

${ }^{100}$ Formerly UKSEC. 
graduates. The NCGE participated in the 2008 HSBC competition to find the student or recent graduate for the title of 'Unipreneur of the Year' which attracted about 400 applicants. The global entrepreneurship organisation, The Indus Entrepreneur (TiE), runs its own competitions.

Participation in the business plan 'dragon's den' style competitions can yield multiple benefits. The participants benefit from the expertise of panels of judges who are usually successful entrepreneurs, venture capitalists, business angels and academics. Prizes for successful participants include cash, offers of equity finance, mentoring and other support. Unsuccessful participants may benefit in other ways. For instance, overseas students Harry and Alfie (Case Study 27), as noted in chapter 6, made a pitch in front of an audience which also included representatives from the local council and regional development agency. Although they did not win the competition, BI Kapoor, the enterprise officer from the local council was impressed by their proposed international business. He immediately arranged a meeting to explore how the business could be supported as it would fit in with the council's inward investment plans. This example illustrates how linking social capital can be developed by students which can be leveraged to mutual advantage.

Enterprise education activities for students and graduates are to be welcomed but there is still more that can be done to improve take up and effectiveness. The limitations of enterprise education policies and practices are discussed below with some suggestions for addressing them.

\subsection{Limitations of enterprise education provision}

\subsubsection{Lack of take up of entrepreneurship education opportunities}

Despite the availability of entrepreneurship education programmes and student enterprise club activities, many students do not take advantage of them. There are many reasons for this. First, some students do not know such provision exists so there is a need for improved marketing. Second, some students do not feel these are useful to them. This was the case with BI Kumar (Case Study 12). He went to one of the enterprise education activities and found "... that the level was so basic that it was not worth wasting my time". Kumar, of course, had already set up his business before entering university. However, he had growth plans and the level of enterprise education that he needed was not available at the university. As pointed out in chapter 1 , some students are already self-employed and there are a number of mature students who already have work experience. Hence, the type of enterprise education they need may be different from that of the 'traditional' students who have come directly to university and lack employment or self-employment experience.

Third, enterprise education may not be seen by students as relevant to their studies. This was recognised by Jeff, the director of one of the COVEs (Centre for Vocational Excellence). In his view, students in the second year of their degree studies in textiles should think about doing project work with the anticipation that it could be commercialised. Thus, he felt that the idea of entrepreneurship should be introduced early on in undergraduate studies rather than towards the end, and this may be more pertinent in the case of those subjects which tend to have higher self-employment outcomes ( HECSU 2007). Part of the challenge he faced was selling this idea to students and their tutors.

Fourth, some students do not have time for extra-curricula activities and this may be the case particularly among part-time students, or full-time students who subsidise their education by paid work, or mature students with family commitments. Sometimes the courses they study, such as medicine, are very time consuming. However, even for students who intend becoming GPs, targeted entrepreneurial education can be very useful in improving the success of the business. Darren from a Science Enterprise Centre lamented the absence of medical students on enterprise programmes. He pointed out that: 
"It is not necessarily a product or a service that is revolutionary. I worked on a programme with GPs; you are running a surgery, a GP practice, and it is turning over several million a year. Your customer facing stuff is all about: are you curing the patients correctly, how do you do your initial triage, is the business process correct, what is the wastage in the process? It is all those kinds of things that you might apply, like a production control environment, to your GP practice. Or you might look at how you are marketing yourself, or you might look at your surgery web site, or you might look at your telephone queuing system at peak times and say here is a model from a call centre, how do we do this?"

Medicine is a subject which has a high representation of BI students (Connor et al. 2003) but unfortunately there is no robust national data to ascertain the extent to which they take up enterprise education.

\subsubsection{Lack of engagement by parents}

As noted in chapter 1 and above, entrepreneurship education is now part of the curriculum in schools, colleges and universities. However, by and large, parents have been left out of the equation at each level of education. Teacher feedback to parents on their children's progress in secondary schools is in terms of core subjects and not on the wider curriculum, including enterprise education, that children and teenagers are now exposed to as a result of Government policy. Parents are usually not aware of in-curricula and extra-curricula entrepreneurship programmes at school. This lack of awareness continues while their children are at university. Yet, parental support for university students' entrepreneurial ambition is important as borne out by a small scale research project. This compared aspirant student entrepreneurs from a UK university with aspirant entrepreneurs in one region. It found that in assessing factors critical to start-up, the university students compared to the regional aspirants gave greater importance and weight to parental support (Robertson \& Collins 2004).

Parental ignorance is likely to make them risk averse and this may strongly influence their children's' attitudes to entrepreneurship. Hence, they are more likely to encourage their children to eschew entrepreneurship in favour of secure, stable, pensionable, salaried employment. This is of particular relevance for Indian and Chinese families. They exert much stronger influence on education decision-making with regard to choice of subject to study at university, choice of university and career plans (Connor et al. 2003, 2004). Parents, particularly immigrant parents who have themselves experienced a great deal of economic hardship, fear that their children will not complete their studies, or if they do complete them, they will "waste their education" and forsake a more secure future for the uncertainties and risks of running a business. This appears to be the case even among some parents who are entrepreneurs themselves, although as noted in chapter 2 , they may be necessity entrepreneurs, operating businesses with marginal returns and long hours labour.

The parents of BI Jay \& Raj (Case Study 10), who started their business within a year of graduation, were initially not pleased. As Jay said:

"They were all very upset, I know Raj's mum was pretty upset when he left the bank, and my parents were pretty upset when I turned down applying my law degree. I think it was more an initial fear of not really knowing what was going to happen. But things have gone really well so now they are all pretty supportive of all we are doing"

The parents of BI Satinder (Case Study 1) were also concerned when he started training in complementary medicine prior to setting up his holistic health care business.

"They did start to become concerned when I left pharmacy locuming because with locuming I could technically bring in about $£ 50,000$ a year and work decent hours. I 
went to work for a company which combined conventional and holistic medicine and I was being paid $£ 19,000$ pro rata, and they said: what have you got educated for? I think they hoped I would take an easier route; if you want to go into business you set up a traditional pharmacy, make a couple of hundred thousand a year and just laugh at it. But the whole mission side of it I don't think they understand. When they came from India they had to turn their back on their own way of life and I think me bringing Indian medicine back up, not in a tiny way but even addressing the issues in my own life, forces them to re-look at it"

BI Kumar had to withstand considerable parental opposition to maintaining his business throughout his undergraduate course as his parents were afraid he would drop out or fail his degree. WB parents may also be ambivalent. As Stephen, a 22 year old WB male graduate who started his insurance service business while an undergraduate said "[M]y parents are providing me with free accommodation and board, as well as office space in their house. They see this as my 'Gap year' and if the business is not sustainable, then I will have to move out and get a graduate level job". As noted in chapter 2, self-employment among WB graduates is higher than the WB population as a whole, whereas for UK born $\mathrm{BI}$ and BC graduates it is much lower than that among the total $\mathrm{BI}$ and $\mathrm{BC}$ population. This pattern among $\mathrm{BI}$ and $\mathrm{BC}$ graduates is reflective of a general pattern among the second generation where the self-employment rate is lower than for the first generation (Mascarenhas-Keyes 2007). Parental views may be one of the factors in this decline.

The 2008 Enterprise Strategy Paper proposes that a culture of enterprise is one of the five enablers of enterprise. Of its six new key policy proposals in this area, three are targeted at young people. While this is to be applauded, parents and those in loco parentis also need to be targeted. Thus, there is a need to raise awareness among parents of the value of entrepreneurship education. Parents can be encouraged to attend specially designed sessions for them at schools and colleges. They can also be exposed to university entrepreneurship facilities during Open Days and equivalent events and given opportunities to meet student and graduate entrepreneurs. The awareness of enterprise of prospective college and university students could also be raised. For instance, during Open days and induction programmes, students from all the disciplines and their parents could be shown round incubator units, innovation centres, science parks and centres for vocational excellence and have the opportunity to meet student, graduate and academic entrepreneurs.

\subsubsection{Lack of engagement of tutors}

Beside parents, university tutors may fear that student engagement in entrepreneurial activities will distract them from their studies and result in dropping out, or if they continue their studies, will lead to the achievement of lower than expected grades. For instance, the staff in one university incubator who had organised a business plan competition complained about the lack of support from academic colleagues who felt students did not have time to run a business while at university. BI Jay (Case Study 10) found there was concern from his tutors about his student entrepreneurial activities but he was able to manage their concerns:

"There was also the worry about my academic work but I was always good at managing my time so it never really affected my work in that sense. And they knew that my passion wasn't really in law but I think they respected the fact that I still gave it the time and attention that it needed. I didn't neglect it. The relationship I had with my tutors I knew I couldn't push it too far. I knew I couldn't stop working on my degree and do entrepreneurship - that would be going too far. But I knew that I had a certain amount of slack and a respect for what I was doing. I had a good relationship with my tutors"

Academic staff would benefit from enterprise awareness raising programmes and enhanced interaction between universities, businesses and social enterprises. While there are specialist university staff who undertake specific training to become entrepreneurship 
educators, nevertheless, these represent only a small fraction of the staff in universities. Often they provide generic rather than discipline specific training although there are examples of partnership working with subject specialists to provide bespoke training. One solution would be to introduce into the initial training of new lecturers, and the continuing professional development of existing academic staff, a basic awareness raising programme in entrepreneurship education that has both generic and discipline-based components. This could help ensure that all staff are in a position to recognise potential entrepreneurial opportunities in their students' activities, provide initial encouragement and signpost them to more specialist help. To allay parental and tutors' anxiety about students' retention and attainment, entrepreneurship education could be embedded into degree programmes and made part of the accreditation process. This has the additional value of making students aware of the ways in which their discipline specific knowledge could be applied to both entrepreneurship and intrapreneurship.

Some enterprise education initiatives in universities are organised by the National Council for Graduate Entrepreneurship (NCGE). The work of the NCGE is discussed below.

\subsection{National Council for Graduate Entrepreneurship}

The NCGE is engaged in a range of enterprise education activities. It is developing social networks within and between universities. It works with the RDAs, university staff and student enterprise clubs, to raise awareness among students and graduates of different progression pathways to commercialisation. It also provides business support programmes. Its range of activities is discussed below.

\subsubsection{Social networks}

The NCGE is in the process of developing a fully connected e-social networking site across regions, across universities, and within universities. Within universities it is expected to serve as a mechanism for facilitating contact between students interested in entrepreneurship and those in the university who are available to facilitate that interest. This is particularly important in large universities where some departments, such as the business school, may be very active in fostering and supporting student entrepreneurial ambitions, but in other departments such support is very weak or non-existent. The creation of networks between universities is important as many students on completion of their studies return to their home area which is often in a different location to where they went to university. It is expected that they will be able to make use of the networks at universities in their home location for entrepreneurial support. The same would apply to postgraduate students who move between universities for different levels of study.

\subsubsection{Rallies, business support programmes and competitions}

The NCGE organises awareness raising rallies at universities as well as business support programmes. Some rallies are themed and, for instance, have focused on the creative industry, digital media, social enterprise, franchising and health care. While the rallies are open to all students, specific business support programmes such as the Kaufman-NCGE Global Fellowships or the Flying Start programme and other schemes which last for about a year, are only open to UK domiciled graduates who are planning to start and base the business in the UK. The Global Fellowship takes the best entrepreneurial talent from UK universities and links them with the entrepreneurial environment in America. The purpose of the Fellowship is to encourage UK graduates to develop scalable high intensity businesses. The Fellowship consists of six months in the UK where Fellows work with their sponsor university to develop their science, technology or engineering business idea and six months in the US as Kauffman Global Scholars where they work with top entrepreneurial universities and intern in leading innovative companies. Fellows are drawn from UK universities and have science, technology and engineering related business ideas. Successful candidates have included British ethnic minorities. The two young male recent graduates who won the 
2008 HSBC Unipreneur of the Year award were NCGE-Kaufmann Entrepreneurship Fellows. The NCGE has helped also to develop discipline-specific programmes. For instance, a new Flying start programme run by NCGE and the Royal Society for Engineers in 2008 targets final year students or recent graduate engineers who want to turn their engineering business idea into a reality. Beside the NCGE, another programme to assist young graduates is provided by NESTA, the National Endowment for Science, Technology and the Arts organisation which was established in 1998. It funds, for instance, the Creative Pioneer Programme which is a funding initiative designed to encourage the growth of a new generation of creative entrepreneurs. It is an opportunity for individuals, typically up to three years after graduation, to access knowledge, training, support and business funding (Price et al. 2004).

\subsubsection{Enhancing female entrepreneurship}

Rates of entrepreneurship among women in the general population are lower than men due to various factors (Carter \& Shaw 2006) and this is also the case for women graduates (Harding 2007). Given the gender gap in entrepreneurship and the Government's intention to raise female entrepreneurship, a new twelve month Flying Start programme launched in 2007 which specifically targeted women graduates is very welcome. This programme will be very helpful in trying to reduce the low rate of self-employment among $\mathrm{BI}$ and $\mathrm{BC}$ graduate women, which at noted earlier in chapter 2, is even lower than WB graduate women. As explained by Anabel, the director of the programme, the rationale for the programme is:

"...trying to assist women in a slightly more targeted way. The rationale behind it is that women don't tend to seek funding to support their business start-ups as often as men do. And also the amount of money they seek to get their business ideas off the ground is lower than men would normally do, that is what the research shows. So the idea is that we would take 60 women and increase their aspiration levels so they can start to think bigger and think broader about how to develop their businesses. And we would work on them from the point of view of trying to provide them with a better skill set to deal with getting the funding to start these businesses"

Data from a survey of applicants to the Women's Flying Start programme conducted by the NCGE indicates considerable interest in the programme. ${ }^{101}$ In the first year of the programme, there were 1145 applications for 60 places. A survey of 700 of the applicants ${ }^{102}$ found that $98 \%$ applied because it was a woman-only programme, indicating the value of a targeted initiative. Forty three per cent of those who applied were current students, the remainder graduates with less than 5 years out of university. ${ }^{103}$ The median age was 23. Two thirds of respondents were at the ideas stage while a quarter proposed to start their business within 12 months. Two fifths of the respondents (43\%) were non-White ethnic minorities. This was highest in the area covered by the London Development Agency where three fifths of the respondents were from non-White ethnic minorities. Women from Asian (including Indian) and Chinese communities (combined) outnumbered Black (African and Caribbean combined) women in all regions apart from areas covered by the South East England Development Agency and the London Development Agency. Notwithstanding interethnic minority group differences, the high rate of interest in the programme testifies to entrepreneurial ambitions of ethnic minority female graduates, including $\mathrm{BI}$ and $\mathrm{BC}$.

Those who attended the programme were asked to participate in a completion survey. Almost all respondents $(96 \%)$ said that the issues that concerned them before the programme had been dealt with, thus testifying to the success of the Flying Start

\footnotetext{
${ }^{101}$ NCGE 2007: a survey was conducted with 700 of the 1145 applicants for the Women's Flying Start programme.

102 The results should be regarded as indicative of patterns only because it has not been possible to establish respondent and sample bias.

${ }^{103}$ This was part of the eligibility criteria: applicants had to be within 5 years of graduating.
} 
Programme. These issues included not knowing enough about business, lack of confidence, uncertainty about the future and whether the business idea was viable, and funding and financial issues. The top reported benefits of the programme were meeting likeminded others (53\%), networking (40\%) and receiving expert advice (28\%).

\subsubsection{Network of university clusters}

In the 2008 Enterprise Strategy Paper, the Government extended the role of the NCGE. It has been given the task and extra resources to build and manage university enterprise networks based on the US Kauffman Foundation experience. The aim is to achieve long term sustainable change and is a step towards the Government's vision of a national network of university clusters that are exemplars in their whole approach to enterprise and entrepreneurship. This will inspire, it is hoped, an enterprising approach among students and graduates alike, and provide them with high quality enterprise and entrepreneurship education that will enable them to compete and succeed in a global environment. A key part of the development of the network will be the involvement of the private sector and the commitment and engagement of the senior management within universities. There are signs already of private sector involvement as Microsoft UK is planning to work with NCGE to support a network promoting enterprise to students studying for a technology-related degree.

To conclude this section, it can be noted that while there are schemes to encourage new graduates to develop their entrepreneurial ambitions and ideas such as the KaufmannNCGE Global Fellowships, NCGE Flying Start programmes, and NESTA programmes, these appear to be insufficient to meet the demand as they are all over-subscribed. Some attention, therefore, needs to be given to extending provision.

\subsection{Incubators}

The boundary between science parks, innovation centres and incubators is generally blurred and often the terms are used interchangeably. The term incubator is used here as a generic term to refer to all three. About a half of universities in England have incubators for students but there is considerable regional variation (NCGE 2007). Incubators can play an important role in nurturing pre-start ups and early stage businesses, and in some case, as in the science parks, they also provide a cluster location for established companies. They can be private or public sector. Public sector ones are exemplified by those linked to universities and usually located in the university campus. In all cases, the incubators are a bridge between the university and the industrial/commercial world. The following section is based on interviews held with personnel working in four incubators, although data from a wider range of facilities which were visited is also drawn upon. Incubators $A$ and $B$ are located in two post-92 universities in the Midlands. Clinton (Case Study 16) who is part of the SPEED programme in located in incubator A while Tony (Case Study 26) attended entrepreneurship events at incubator $B$ and won a prize at a business planning competition run by the incubator. The third, incubator $\mathrm{C}$, is located in the East of England. It is an independent institution, funded by both the private and public sector, and works predominantly with a group of universities that generate relevant, commercial research. Incubator $C$ is selected because of its relevance to research based academic entrepreneurship while the other three are more relevant to non-research students and graduates. The fourth, incubator $D$, is located in China and is attached to a major university. As noted in chapter 1, China is also investing heavily in R\&D and science parks/ incubators. For this reason, the incubator in China is included. Francis (Case Study 29) is located in incubator D. One of the issues explored with the incubators was the extent to which there is support for international entrepreneurship. I shall discuss the incubators under six headings: type of incubator, size of incubator, how funded, its clientele, facilities offered and internationalisation. 


\subsubsection{Type of Incubators}

Incubators can have a generic focus in which case a broad spectrum of business ideas may be supported or they may have a specific focus. Incubator A, like the university in which it is based, tends to focus on fashion and textile product design, media products, software and IT, business consultancy and training. The university does not have a strong science base but this is expected to change as the university is in a city that has been designated a science city. There are possibilities of science and design disciplines collaborating in developing games where interactive digital technology and design features are now coming together. Incubator B is targeted at the creative industries which is one of the strengths of the university. Incubator $C$ is science based with a focus on off shore energy, communications and electronic sectors. Incubator D covers a broad spectrum of businesses within science, engineering and technology.

\subsubsection{Size of Incubators}

The size of the incubator can vary to fairly small to extremely large. This is exemplified by the contrast between incubator $C$ and $D$. Incubator $C$ has about 30 tenant businesses in one building and about 40 virtual tenants. The size of each business varies and some multinationals maintain an operation with about 2-3 people on site who may be responsible for liaising with other SMEs who are doing R\&D for them. The companies that grow from start ups normally get to about $£ 10-15$ million turnover before they are ready to exit. Incubator D in China is very big and has over 200 businesses although not all take up space in the incubator, some being virtual. The physical space of the incubator is currently being extended through the construction of another building.

\subsubsection{Funding of Incubators}

The funding of incubators can be extremely variable. For instance, Incubator B is funded from a variety of sources. The building is provided by the local council and all applications for use of its space have to go through the council process. The council is represented on the management committee of the incubator. Other funding comes from the university and other public sector sources. Some of its activities are funded through the HEIF programme. In the case of incubator $\mathrm{C}$, the RDA funded the capital development of the centre in conjunction with a number of local authorities and also leveraged in European funding. A local enterprise agency manages it and also made some investment. Incubator $D$ is funded by the city municipal government. Each city municipal government in China has its own science and technology bureau which is in charge of its incubators while the Ministry of Science \& Technology develops and oversees central policy formulation.

\subsubsection{Clientele of Incubators}

Incubators in the UK universities have different eligibility criteria. Most incubators give priority to their own students and alumni but also accept graduates from other universities living in the vicinity of the university. Some, for instance, like incubator A, because of the basis on which it was funded, do not accept overseas students as incubatees although they may be allowed to attend open events.

Incubator A was originally a vehicle for the commercialisation of university IT and catered for those who had already graduated. It facilitated 120 business start ups in the last 5 years, $90 \%$ of which are still running. There is now a separate business innovation and creation unit in the university which undertakes the commercialisation of knowledge transfer from staff IP. The incubator has begun to develop an undergraduate focus as it has now become part of the SPEED programme. The students and recent graduates who use Incubator $B$ have usually developed their IP during the course of their undergraduate studies or taught Masters. This 'germ of an idea' is then discussed with the staff at the incubator and developed further, if appropriate, together with mentoring and other support. A lot of the nascent businesses assisted by the incubator emerge from the first and second year modules offered by Business and Law, and Art and Design degree programmes. Omar (partner of Tony, Case Study 26) had studied for an MA in Design Innovation. In the case of 
incubator $\mathrm{C}$ which focuses on academic entrepreneurship, the clientele is drawn from a number of sources: a core group of universities, spin outs from large companies,

recommendations from the local authority, word of mouth and outreach work by the director.

Variations by gender and ethnicity are evident in the incubators. Incubator A has a strong female presence. There also appears to be an over-representation of non-White clients, both as incubates and attendees at open entrepreneurship education events. However, Barry, the director, was unable to say whether the Indian and Chinese students who used the incubator facilities were UK domiciled or from overseas because data on ethnicity and nationality is not kept. Incubator $\mathrm{C}$ is male dominated but in the last ten years there has been a marked improvement in the number of females involved in the industry, mostly at the higher academic level. There are a number of Indians and Chinese, particularly Indian, involved in the activities of incubator $\mathrm{C}$, either as entrepreneurs or employees. Some of the Indian and Chinese staff, as with WB and other staff, may work as employees for a period of time after graduation and then return to the university to undertake a doctorate. There is always the potential that their doctoral studies may lead to research that could be commercialised and they may return to incubator $\mathrm{C}$ to start or grow their business. The director, Alfred, like Barry, was unable to say whether the Indian and Chinese were British Indian and Chinese or overseas Indians and Chinese. The majority of students who participate in incubator B entrepreneurship programmes are non-Whites, including Indian and Chinese. However, Alison, the director (like Barry and Alfred) did not know whether the Indian and Chinese participants were British Indian and Chinese, or overseas Indian and Chinese. While participants in the incubator's programmes are predominantly non-White, this is not reflected in the graduate start-ups which are "quite heavily biased towards White Caucasians. ... It doesn't represent the interaction that we have here. The majority of our participants are non-Caucasians". As Incubator D is linked to one of the major city universities in China, a large proportion of its clientele are graduates from this university. The majority tend to be male, and, as would be expected, of Chinese origin.

\subsubsection{Facilities offered by Incubator}

The range of facilitates offered by incubators varies. Incubator A offers various types of entrepreneurship activities for students. These include open forum meetings which anyone can attend. The director gets alumni from the incubators to come and talk to students. As Barry says, "[T]hey act as role models as they are closer in age to the students and share similar educational experiences and are also very accessible". Incubator A offers the university's PR machine to generate publicity for the incubator businesses so some of the marketing of the business is done with aid from the university. Attendance at incubator A's events are free for all students but once they start to use space in the incubator they incur rental charges. If the businesses are successful, they are expected to pay royalties to the incubator. There is also a virtual component to the incubator.

As incubator B has limited work space to house early stage businesses, it provides the students and graduates with advice and support and access to a range of different entrepreneurship-related activities. In incubator $C$, businesses stay for about an average of three and a half years as technology based businesses can take some time to get established. They have access to well designed office space and equipment.

In Incubator D, the Chinese municipal government has a special fund to help new graduates who have joined the incubator. They also have access to different types of scientific and IT equipment at the incubator, and where more specialist laboratory and other facilities are needed, these are available at the university to which the incubator is linked.

\subsubsection{Internationalisation Activities of Incubators}

Among the four incubators, a diversity of international plans and activities are evident. Some international development has happened organically as exemplified by incubator B. Four Indian students, two of which were British Indians and the other two overseas Indian, started 
developing a business at the incubator. The plan was to start the business in the UK, and when the overseas students returned to India, they would open a base in India. Since there are a lot of Indians in the Gulf States, and the students have family and kinship connections with them, their plan was to involve them as business partners in the Gulf States.

Unfortunately, this business folded up and the students 'disappeared' leaving debts at the incubator. Incubator B is now trying to develop its international links through more formal strategic planning, rather than leave things to chance. Lionel who works at the incubator said:

"That is one area actually that we are trying to work on. This is at very, very early stages but what is happening is that we have tabled a report to senior management that is trying to introduce a soft landing approach which basically offers 6 months incubation for UK based businesses looking to start abroad and vice versa, so foreign based businesses looking to enter the UK market. What we are trying to do is link that in with international student engagement, so student entrepreneurship engagement. So like here they go through a process hopefully where we work on them at pre-start level, then we move them along the chain into another area of incubation and what we want to try and do is move this model that we have here abroad. ... We haven't necessarily outlined the specific targets but it would be looking at India as one of the focused countries. China is one of the focused countries. ...We are also looking at markets in South Africa and the Middle East, Oman and the Gulf States particularly, and a lot of the newer EU Member States"

As India and China are strategic markets for the recruitment of overseas students to the university in which incubator B is located, the development of student entrepreneurship links with these two countries seems to follow naturally. The other countries are tertiary markets for students. The university already has transnational educational links with some HE institutions in India and China and it is possible that these may be used in its soft landings strategy. However, with the Gulf States, the intention is to build up a link only for the international incubation activity and not part of a wider transnational education programme. Incubator B has already had initial discussions with UKTI whom they see as one of the major stakeholders in the soft landings idea and they were encouraged by their positive response.

Personal contacts may be one way of fostering international incubator links. For instance, BI Sita (Case Study 25) and Alcar (Case Study 17) whose businesses are located in India, have been introduced to this incubator as they are interested, as noted in chapter 6 , in offering in-house incubation facilities. ${ }^{104}$ This link is seen a mutually beneficial. Sita is keen to offer placement opportunities to clothes design students from the university. For her, as the university is recognised as a centre of expertise in Arts and Design, one of the benefits would be the creation of links with British academics and designers via the students. It also provides her with the opportunity to keep up to date with cutting edge developments in the design field. Alcar is particularly keen on targeting $\mathrm{BI}$ as she has an ideological commitment to the development of her ancestral country and feels that Indians living overseas can play an important role.

The soft landings approach will help to address market failures affecting the supply of international skills in the economy which can be a barrier to international trade and investment (DTI 2006b) or any form of internationalisation. As Lionel said:

"Part of the international approach incubator $B$ is thinking of developing is to provide facilities for overseas students studying at the university:.. we can support them here whilst they are on their degree and then we can support them back home when they want to start up their business back home, and obviously vice versa. Students

\footnotetext{
${ }^{104}$ This is an example of knowledge transfer that I was involved in as mentioned in chapter 3.
} 
coming from sister universities abroad could then use the highly skilled migrant workers visa regulation to allow them to do this"

Incubator B also has more ambitious plans for internationalisation which has a multilateral dimension. According to Lionel, they are planning

"Joint ventures to increase the collaboration and general trade between the two areas or three or four areas. We wouldn't necessarily look at it as being just reciprocal between, say, India and England. What we would do is we would set up a network for which our city would be the hub but there is no reason why the network shouldn't inter-trade between each other. So if we are setting up one with say India, China, Oman and our city, there is no reason why India and Oman shouldn't be also trading independently"

For incubator $\mathrm{C}$, the nature of their work, off shore energy, has an implicit international element as energy resources are located worldwide and the geographical focus of interest is constantly shifting. Consequently, staff who work in the energy sector tend to originate from different countries and because the location of the work shifts, many of them also acquire international experience. The incubator has collaborative links with USA, Norway, Holland and Brazil but none with India and China at present. However, it is anticipated that because of the growing economic importance of India and China and their particular concerns about energy use and conservation, links with these countries are inevitable.

Incubator D in China is very keen to develop international links. In 2007, an agreement was signed between the incubator and a British university. The British university will offer a Chinese student a doctoral studentship in its Enterprise Education Faculty and this will be reciprocated by the offer of a doctoral studentship to a British student at the Chinese university. The doctorate will be entrepreneurship focused and will involve using the facilities of incubator D. Different types of agreements have already been signed by incubator D with the USA, Netherlands, France and Singapore. These bilateral arrangements are to help overseas graduate businesses who want to enter the Chinese market to start their business in the incubator. Thus if a graduate entrepreneur from these countries wants to set up a business in China, he/she could use the facilities of the incubator at a preferential rate. The agreements carry a reciprocal arrangement whereby Chinese graduate entrepreneurs who want to internationalise their businesses in these overseas countries can use their incubator facilities to do so. Jane, who is in charge of marketing at incubator $D$, gave the example of one of the incubatees who wanted to set up operations in France. A staff member from Incubator $D$ went with him to France and spent a month there with him. However, at the end of this exploratory period, the Chinese entrepreneur decided not to locate his business in France. Another IT business from the incubator had tried to do the same thing in the UK but this did not materialise either. The barriers to executing such international plans need further exploration.

The decision that Chinese graduate entrepreneurs take on where to locate their businesses internationally depends on a number of factors. A significant factor is some prior knowledge of a country. Francis (Case Study 29) has chosen the UK as a location for his business because he has connections with academic staff in three UK universities where he undertook undergraduate and postgraduate studies. Furthermore, he is familiar with the UK environment and has friends here from his student days. He regretted the fact that it was not possible at the time he was studying in the UK for overseas students to obtain employment for two years as it is now. He felt this would have given him important insights into British working practices which would facilitate internationalising his business in the UK. The only opportunity he had was a brief project he undertook for a UK company for his 
M.Sc. ${ }^{105}$ Overseas Chinese students Harry and Alfie (Case Study 27) want to establish a base for their international company in the UK university town that they currently live in because "we know this area". Thus knowledge of the UK as a student can have longer term benefits. It reinforces the value of the new immigration regulations which allow overseas students to work for two years after graduation. ${ }^{106}$ It also reinforces the local implementation of UKTI policy. Thus, in the East Midlands area for instance, local UKTI staff use various strategies to increase the familiarity of overseas students with the area. The rationale for this strategy is the hope that when the students return home, and at some stage want to set up a business overseas themselves or their employers have this ambition, the East Midlands may be considered as a possible location. It may be worth expanding this policy to include academic staff from overseas. Furthermore, it would be useful to capitalise on the opportunities afforded by overseas parents visiting their children at UK universities to also network with them and introduce them to the region.

While some businesses in Incubator $D$ do not wish to internationalise as there is a vast internal market in China, there are other businesses which are keen to do so. Some of the businesses run by Chinese graduates have direct relevance to the West. ${ }^{107}$ For instance, a business dealing with steel was considered by Marie, a European venture capitalist, to be of interest to an Indian steel multinational company headquartered in Luxembourg. A business dealing with hospital IT systems was considered by Terry, a WB business angel, who is also on the Board of an NHS trust in the UK, "to be relevant to solving some of the problems encountered by the NHS in developing an efficient IT system". There were many other similar examples where developments in China had applicability to the UK and beyond. The Chinese graduate owners of these businesses not only possessed good graduate technical, professional and business skills but in many cases, also had very good English language fluency skills. For these businesses trying to find a way of entering the UK market, the contacts made at an international seminar held at the incubator set the basis for further developments. Such spontaneous engagement between China and the UK also testified to the ad hoc nature of engagement with the UK commercial market and indicated the need for better strategic planning for mutual benefit.

\subsection{CONCLUSION}

This chapter has focused on Knowledge and Skills as one of the enablers of enterprise identified in the 2008 Enterprise Strategy Paper. While the inclusion of enterprise education in universities is to be applauded, nevertheless, much more needs to be done to cater for a cross-section of students with different needs. More provision is necessary for postgraduate students, and part-time students, as well as those from overseas, whose numbers have increased with the expansion of higher education. The increasing diversity of student backgrounds and interests means that both basic and advanced enterprise education needs to be provided for. To facilitate better participation in the global economy, international entrepreneurship programmes and activities for British and overseas students, should also be provided.

A culture of enterprise, another of the five enablers of enterprise identified by the 2008 Enterprise Strategy Paper, needs to be developed across all sections of society. A cultural change in the negative or ambivalent perception of entrepreneurship needs to occur among many parents of students and graduates, particularly those of $\mathrm{BI}$ and $\mathrm{BC}$, as parents exert a

\footnotetext{
${ }^{105}$ While I was in Shanghai, I introduced Francis to a British entrepreneur attached to a UK university who was on a business trip to China. Francis was also unaware of UKTI so I gave him contact details.

${ }^{106}$ Changes to immigration regulations from April 2008 allow a two year stay to replace the former one year option.

${ }_{107}$ While in China I attended an event where some graduate businesses from this incubator made presentations to an audience which included business angels, venture capitalises and academics and business support agencies from UK and France.
} 
great deal of influence on their children, even in early adulthood. A cultural change is also necessary among academic tutors who are likely to be the front line contact for students with entrepreneurial ambitions. Basic enterprise awareness training would be useful as part of the CPD of all tutors, which could be supplemented where necessary by interactions with businesses as well as public and third sector organisations. Embedding entrepreneurship education in the curriculum is likely to allay the fears of parents and tutors that students with entrepreneurial ambitions will drop out of their studies or achieve lower than expected grades.

Due to over-subscription, there also needs to be an increase in the number of places available on entrepreneurship support programmes like SPEED for students and for graduates on programmes such as those offered by the NCGE. Opening up such programmes to overseas students and graduates from British universities will provide opportunities for the development of bridging and linking social capital, as well as the potential for the development of collaborative international entrepreneurship or international inter-trading. While there has been an increase in the number of incubators and science parks in or attached to British universities, to facilitate international entrepreneurship, there is more to be done to extend eligibility for incubator facilities to overseas students, and to develop reciprocal soft landings for students and alumni in incubators in this country and overseas. 


\section{CHAPTER 9: ENTREPRENEURSHIP SUPPORT OUTSIDE UNIVERSITIES}

\section{$9.1 \quad$ Introduction}

This section looks at entrepreneurship support available outside of universities. Some of this support is provided by the private sector and the third sector. There is also public sector support which complements that provided by the private and third sector and is particularly able to address market failures and finance gaps as well as deal with social equity issues. This chapter begins with looking at private sector support exemplified by four case studies (Case Study 33,15, 20 and 21), and then examines third sector (ethnic minority organisations) and public sector support (Business Link, UKTI, RDAs, local councils and chambers of commerce). It explores the extent to which such support links with the universities and promotes, or potentially can promote, international entrepreneurship.

\section{$9.2 \quad$ Private sector support}

Private sector support has arisen because of a gap in the market and a demand for reliable and trusted services. Four examples taken from the core case studies illustrate this.

Namaste (Case Study 33), a business consultancy service, is partly run by BI Ramesh, a senior academic at a British university business school in a university town which has a very large technology cluster. Ramesh said "UKTI cannot provide all the support needed by graduates and academic entrepreneurs who want to internationalise so we set up a consultancy service to fill this gap". Ramesh has professional, family and friendship links with India which he renews by frequent visits to India, and as noted in chapter 6, uses to benefit his university activities. He also leverages them for running Namaste. Vishnu runs the India office of the company. He was formerly an overseas student at the university where Ramesh works. Namaste exemplifies how alumni connections can be leveraged to establish an international business with bases in UK and overseas, in this case India. The business has developed targeted services to help UK and Indian companies who want to internationalise across the respective countries for competitive, market and strategic advantage. It is connected to business support organisations in India and the UK-India British Council as well as the university student entrepreneurship club.

The business run by Michael (Case Study 15) provides business support services to graduates and academics in UK who are interested in science-based international entrepreneurship and wish to engage in entrepreneurship activities in China. Such activity represents a growth in his business which started off by offering advice to parents in China who wish to send their children to study overseas. Michael says that although parents can obtain advice via the British Council, consulates and embassies, they trust him more than they do officials from these organisations. While this is partly because of a general distrust of officials, it is also because they are more likely to put their trust in a Chinese compatriot with whom they have shared moral values. The facility to converse in Mandarin enhances interpersonal relationships. Furthermore, Michael's advice is based on experiential knowledge gained through study in China, UK and other parts of Europe and is, therefore, regarded as a more authentic basis for providing guidance on university choice. It is perhaps inevitable that some mistrust of government officials, be they British or Chinese, will exist, thus increasing the likelihood of a demand for private sector support. Trust is an important part of Michael's cultural capital, and in addition, his assets include linguistic competence in both English and Mandarin, links to European universities including UK universities where he obtained his doctorate and worked as an academic researcher, and links to universities in China through family and professional contacts. Furthermore, as he has lived and worked in both countries, he has a cosmopolitan approach as noted in chapter 
6 and can "fit into both cultures quite easily". These assets, together with his education in the sciences, have facilitated the expansion of his business from providing consultancy services to parents in China to providing business services to graduates and academics interested in science-based international entrepreneurship. The latter part of his business is in the early stages but the bulk of enquiries so far have come from the Chinese who perceive their compatriot to provide a more reliable and trustworthy service than non-Chinese. This is not to say that all Chinese or all Indian will only use services provided by compatriots but that those Indian and Chinese who wish to set up a consultancy service providing business advice have the additional competitive advantage of being able to draw on common ethnicity, shared cultural values and language as business assets.

Michael and Ramesh provide illustrations of a pattern, mentioned in chapter 6 , in which BC and $\mathrm{BI}$ use their cultural and social capital as business assets. According to BI Kulip, the director of an ethnic minority business network:

"There are individuals who have set up as consultants to facilitate overseas trade and because they have got a connection with their country of origin, whether it is India, China or Pakistan. They can then help facilitate that because they will have a link in China who they can tap into, and then they can help a particular company to source or to sell or to locate in those particular countries... These could be individuals who have been to China, understand the language, know their way around and come back into the UK, set themselves up as international consultants and go out and sell their services to people over here. But that I believe can only be done because they have got a connection with their country, they can either speak Cantonese, Mandarin or Hindi. And because of that they can come in and develop a business around it"

There are examples where $\mathrm{BI}$ and $\mathrm{BC}$ graduates are not entrepreneurs themselves but as paid employees make use of the cultural and social capital to which Kulip refers to facilitate international entrepreneurship. For instance, two BC, Colin and Daniel, both have science doctorates from British universities although their first degrees are from universities in China. They work for a private UK company, and through their contacts in China, help in identifying and facilitating inward investment from scientists in China. As they said, "[W]e also look for opportunities for scientists from China and UK to collaborate on research that can be commercialised."

It is not only $\mathrm{BI}$ and $\mathrm{BC}$ who have been able to set up international firms providing business support but also WB companies who adopt particular strategies to penetrate overseas countries. Carla (Case Study 20), a WB woman, was able to 'buy in' the cultural and social capital of Hong Kong Chinese Henry when she set up a joint venture company with him to help businesses, including graduate businesses, in the UK who want to trade with Hong Kong and/or mainland China. She arranges frequent trade missions, sometimes accompanying the missions from UK, or Henry manages them in Hong Kong. Henry, who is a portfolio businessman, has extensive knowledge of business opportunities, regulations, access to finance and other business related issues in Hong Kong as well as China. As he speaks Cantonese and Mandarin, as well as fluent English, he is able to provide business brokerage services. Dominic (Case Study 21) a WB male, was able to use cultural and social assets acquired as an employee in China to help set up his business support firm. He acquired his knowledge of China through a degree in South East Asians studies and a long period of working in China. He has a lot of contacts, is fluent in Mandarin and understands the business environment. His clientele are almost exclusively WB. 


\subsection{Third sector business support}

\subsubsection{UK Ethnic Minority Organisations}

There are specialist support agencies for different ethnic minority groups who provide a service better suited to their specific clientele than mainstream business support which is not taken up for various reasons (Ram et al. 2002, Mascarenhas-Keyes 2006). For instance, there is a membership organisation in the north of England serving the Asian community which includes Indians and Chinese. About $90 \%$ of its members are Asian, while the remainder includes WB who are keen to network with Asian businesses. This organisation also supports businesses run by young, second generation Asians, about half of whom are educated to degree level. According to BI Kulip, the director of this organisation:

"The majority of members are well qualified to degree level. Fifty percent of the ones coming through are new businesses qualified at degree level or above. Most of them may have been into employment and then dropped out to set up their own business, or some of them may have just diversified their father's business. In terms of types of businesses they are getting involved with, I had a concern 3 or 4 years ago whether the second generation businesses would continue the entrepreneurial spirit as their forefathers have done. Would there still be this increase in the number of business start ups or would they be settled, integrated, and more comfortable with the UK and operating in the normal fashion as everybody else, and therefore the start up and enterprise figures would be the same as the British community. I have been proved wrong fortunately because we are still seeing a range of businesses coming forward but it is not your usual businesses like you would associate Asians with, your retail and your corner shop. The types of businesses we are getting are around the IT sector, the creativity industries, music, fashion, design, professional services such as financial services, legal services, consultancies, UK call centres, travel businesses. In the 5 or 6 years I have been here, usually you would see the businesses operating in the low value added high volume businesses. Now it is more specialist, more areas of business..."

While, as Kulip says, second generation graduates are setting up businesses, nevertheless as we saw in chapter 2, the rate of self-employment is still below that of WB. This suggests that there may be a role for ethnic minority organisations to develop links with universities to promote entrepreneurship among $\mathrm{BI}$ and $\mathrm{BC}$ students, graduates and academics.

The organisation is mainly a networking organisation and a source of informal business support. Those who offer professional services to entrepreneurs such as solicitors and accountants are also members as they can acquire clients among co-members. The organisation hosts various events for its members, holds exhibitions, breakfast clubs, meet the buyer and other networking events. It holds gala dinners and runs 'dragon's den style' business competitions and gives business awards. It also publishes a directory of members and details of their business. It lobbies local and central Government on behalf of its members on issues which adversely affects them.

\subsubsection{International organisations}

Another membership organisation called The Indus Entrepreneur (TiE) is a global network of entrepreneurs and professionals. TiE has had a branch in London for some time and in 2007 opened another one in the north. BI Satinder and Sunita (Case Study 1) and BC Kenneth (Case Study 13) were recruited for this research at TiE events. As the founding members of the organisation in the USA were of Indian origin, its membership continues to be dominated by Indians. It started in Silicon Valley (Saxenian 1999) and has grown exponentially over the years with increasingly wider global coverage. It has several chapters in India and the US but none in China although one of its members, Kenneth, is hoping to redress this. There is also a global board of trustees which includes a UK trustee. Members are overwhelmingly graduates. Membership is at two levels: ordinary member and charter 
member, the latter being an entrepreneur who has sufficient experience to mentor new members. Members include entrepreneurs, academics engaged in teaching entrepreneurship, and organisations such as major banks, law and accountancy firms that offer professional support services to entrepreneurs. Some are also members of the IndoBritish Partnership Network and conduct consultancy work for UKTI.

Global entrepreneurship organisations like TIE provide informal social and business networks which serve as important conduits for knowledge spillovers as individuals share their experiences of overseas markets. Sometimes such knowledge spillover is shared through formal events with guest speakers, including from overseas, as well as through mentoring. The organisation has a mentoring programme in which chartered members mentor new entrepreneurs including students and young graduates. The Government is planning to work with TiE to learn from the success of its mentoring programme (BERR 2008a). Such programmes help to mitigate some of the main sources of market failure relating to overseas market entry: beneficial knowledge spillovers, information failures, network path dependency and collective information failure (DTI 2006b). TiE works with a few universities, often via the business schools and co-organises business competitions with some of them. It helped sponsor in 2007 a UKSEC ${ }^{108}$ national business plan competition. Links should be established between organisations like TiE and all universities so that students, graduates and academics with international entrepreneurial interests can benefit from its members' expertise and networks. It provides a greater potential to develop international businesses as it has almost fifty chapters worldwide.

\subsection{Public sector support}

\subsubsection{Business Link}

Successive evaluations show that assistance provided by the Government sponsored Business Link can help firms become more productive and to have higher employment growth. ${ }^{109}$ Business Link is now being established as the primary access route for individuals and businesses seeking support and its role has been strengthened under the Business Support Simplification Programme (BSSP). The BSSP is a cross-Government agenda which aims to make it easier for companies and entrepreneurs to understand and access Government funded grants, subsidies and advice with which to start and grow their businesses. ${ }^{110}$ Currently over 3,000 publicly funded business support schemes exist but the Government plans to reduce this to 100 or less by 2010. Rather than Business Link providing all the advice and support, it puts enquirers in touch with a range of expertise from across the private, public and voluntary sectors. It also provides advice on international entrepreneurship and is developing an extensive product portfolio to cover a range of international entrepreneurship topics. To capture the value of innovation, UKTI export and Business Link advisers will receive training from the UK-IPO (UK Intellectual Property Office) in advising businesses on IP management (BERR 2008a). There is unfortunately no robust national quantitative data available on the extent to which students, graduates and academics use Business Link. Under its new remit, Business Link has the potential to develop closer links with universities and the support services they offer to students, graduates and academics. This creates the potential to collect monitoring and evaluation data which can enhance co-ordinated service provision for students, graduates and academics.

\footnotetext{
108 UKSEC has now been rebranded as Enterprise Educators UK.

1091998 PACEC Business Link VFM Evaluation, 2001 Business Link Tracker Study. The impact of Business Link support on assisted Businesses - the Business Link tracker study 2002 (DTI 2002).

${ }_{110}$ See Budget Report 2006 (H.M. Treasury 2006), pre-Budget Report 2007 (H.M. Treasury 2007b), BERR 2008a, 2008d.
} 


\subsubsection{UK Trade and Investment (UKTI)}

UKTI has international trade advisors in all the regions in England. Each is usually responsible for different specialisms. For instance, Deepak, a BI graduate, specialises in IT and medical technology and also has responsibility for developing international businesses with India. Businesses in these sectors, invariably headed up by graduates, are identified through various means such as ethnic networks as well as trade and professional networks, and assisted to become global. Deepak provides information to these potential international companies about the business environment in India, informs them of international trade shows in this field, sponsors tent space at relevant overseas exhibitions, takes them on trade missions to India, and puts them in touch with British embassy personnel in overseas countries who then provide them with relevant contacts. He also arranges access to support programmes such as Passport to Export which is designed for both experienced and less experienced exporters as well as those who are new to export.

The UKTI Trade Missions are not specifically targeted at students, graduates and academics. For instance, overseas Indian student Chandra (Case Study 4) said he had not heard of UKTI and neither had BC Philip (Case Study 2). BC Kenneth (Case Study 13) had contacted UKTI for advice about doing business in China but said he found "the service inadequate and I preferred to use my own resources". He had this option, unlike most potential entrepreneurs, because he had lived in China, was familiar with the environment and had lots of contacts. It seems that BC do not take advantage of trade missions to China organised by UKTI and companies like that of Carla and Dominic, but prefer instead to use their own resources.

To facilitate academic entrepreneurship and international technology transfer from universities, and to take advantage of the growing opportunities for international collaboration, UKTI is implementing a new international R\&D strategy to bring more business R\&D into the UK. It also helps innovative British companies to do business overseas in the expectation of raising their R\&D levels. Its global R\&D team consists of experts specialising in specific technologies and industry areas. One of the indicators of UKTI's performance is the increase in inward investment, $75 \%$ of which is expected to be of knowledge driven companies. Under its global entrepreneurship programme, UKTI have deal makers who look for early stage companies overseas who could be encouraged to set up in the UK. BI and $\mathrm{BC}$ graduates play an important role in facilitating international entrepreneurship. For instance, BI graduate Imran, works as a consultant to UKTI as a dealmaker for India. His father was an entrepreneur in India, he owns a knowledge-based business himself and has previous experience of working on Indo-British partnership initiatives. Complementing his family links with India, he has built a vast repertoire of bridging and linking social capital in India and UK which helped him to acquire the dealmaker post. He visits India every two months: "[I] attend meetings at the elite and world recognised Indian Institutes of Technology (IIT) and other renowned institutions and meet research scientists and early stage technology entrepreneurs". He has also identified research students from the IITs and nominated them for scholarships at UK universities. There is the expectation that these students will generate innovations that can be taken to market in the UK.

Beside the UKTI which has offices overseas, there are other organisations, linked to UKTI, which facilitate international trade. For instance, the China British Business Council has offices in many cities in China. It is involved in helping British businesses set up in China and uses various methods such as assisting in trade missions, identifying Chinese partners, and monitoring social and economic trends so that it can provide up-to-date market advice.

Some of the staff working in the CBBC offices in China were born or educated abroad including in the UK. For instance, Ramsey is British born Chinese. He is in his late 20s and initially came to work in China partly in an attempt to "trace my roots". His grandparents emigrated from Hong Kong to UK in the 1950s and opened a Chinese restaurant. His father grew up in the UK, went to Hong Kong to get married, and returned to the UK where 
Ramsey was born. After graduating from a British university, Ramsey went to work in China as a teacher, before returning to do postgraduate studies in the UK. While doing his postgraduate studies he worked on a placement with CBBC in the UK and was later able to obtain a job with the organisation in China. He has learnt Mandarin although he speaks Cantonese quite well. His advice to any British born Hong Kong Chinese is to learn Mandarin and capitalise on the opportunities in China like he is doing. Mary Ann, a young Chinese woman who works at a CBBC office in another city, is an alumnus from a British university. She enjoyed her time in the UK and due to her self-confidence, English language fluency, good interpersonal skills and determination to broaden her horizons, she undertook a series of work placements and voluntary activities in her university town in the UK. As a result, she feels she can relate to British entrepreneurs very well and help them to set up businesses in China.

\subsubsection{Regional Development Agencies}

All the nine regional development agencies in England and those in the rest of the UK have strategies to boost economic development and regeneration. They include policies and practices to start up and sustain businesses, develop investment opportunities and increase competitiveness. RDAs provide slightly over a tenth of the funds to support enterprise and entrepreneurship education in universities (NCGE 2007). For instance, the RDA, Yorkshire Forward, funds the West Yorkshire Graduate Start Up programme (Price et al. 2004).

Some RDAs are fostering closer links with universities such as developing a network of entrepreneurial universities in their region, or working with a higher education entrepreneurship group, and connecting with schools, FE colleges and universities in the region (BERR 2008a). One example of partnership working between universities and an RDA is the West Yorkshire Universities Partnership. This is a programme of activity devised by Yorkshire Forward and the four West Yorkshire Universities of Leeds, Leeds Metropolitan, Huddersfield and Bradford through the Centre for Graduate Entrepreneurship in Yorkshire (CGEY). The Centre has been funded for the last two years by the Higher Education Funding Council of England (HEFCE) using the Higher Education Innovation Fund (HEIF). The HEIF funding has enabled the partnership to expand and include the Universities of Hull, Sheffield Hallam and Trinity \& All Saints College. This Regional Universities Partnership aimed to convert the maximum number of university students into successful entrepreneurs, operating within Yorkshire and the Humber. It also aims to improve the business skills of student and graduate entrepreneurs and promote the adoption of innovation and technology within new and young business ventures. Partner institutions have been successful in developing a conveyor belt of link activities, ranging from raising business awareness through to business creation and sustainable business growth (Robertson \& Wilkinson 2006).

The 2008 Innovation White Paper states that the Government will sponsor New Partnerships for Innovation "...that will bring together venture capital, universities, business and regional Government to align efforts and develop innovative solutions to local and regional challenges" (DIUS 2008:10). These Partnerships should enhance collaboration between RDAs and universities and help improve the absorptive capacity within local regions of knowledge created locally, regionally, nationally and internationally. Partnership working with universities in all regions, not just a few as exemplified above, will help to capitalise on the innovative potential of all students and graduates which will help to redress the missed opportunities referred to in earlier chapters.

All RDAs are keen to internationalise and the UKTI has a role across all the RDAs to strategically guide their work. Various approaches are used by RDAs to foster internationalisation. Some RDAs have established an office overseas. For example, one RDA opened an office in Beijing in 2006 and also has a representative in Shanghai. It is planning to open two offices in India, located in Mumbai and Delhi. Another RDA has opened 
an office in South China. A Scottish development agency has opened an office in Beijing. If it is not possible to open an office overseas, different mechanisms may be used. For example, one RDA is represented in India through an Indian female graduate from a British university who works for a large international accountancy firm and part of her role is to represent the RDA in India.

There appears to be merit in UK RDAs being involved in setting up links in China. China presents challenges in terms of scope and scale and, hence, it may be a good strategy for RDAs to be involved in different parts of China. The strategy of locating offices overseas is to better capitalise on the opportunities for trade and investment that India and China as fast growing economies offer. To understand this strategy and explore its relevance to student, graduate and academic entrepreneurship, one of the RDAs with an office in China was interviewed. This RDA decided to locate its office in South China as the profile of businesses and industrial sectors in this area corresponds quite closely with the profile of its region in England. The office is located in the Science and Technology Centre where the RDA gets two years free rental, followed by three years half rental. Many overseas organisations are located in this Centre which is regarded as a Science international business platform and such co-location facilitates international linkages. The purpose of the overseas office is to promote the specific English region as a place to study, to invest and to visit. As far as business start up and growth is concerned, the overseas office facilitates Chinese entrepreneurs to set up in the UK. This is an advantage to the businesses as they have access to UK capital markets, can buy a share of a UK company, and also have access to UK technology. UK companies setting up in China have access to cheap manufacturing and new markets and they also benefit China by bringing in advanced technology.

The overseas RDA office acts as a link between its region's universities and research institutes and those in China. It has a higher education network through which it identifies the need of Chinese universities and links them via the RDA office in the UK to appropriate universities. For instance, one university in China, interested in developing collaborative research in marine technology that could be commercialised, has been linked with a British university in the RDA's region. Sometimes, the overseas office is able to leverage Chinese Government funds for some activities. The office in South China is staffed by two fluent English speaking Chinese personnel, both of whom have spent some time overseas as postgraduate students, one at Birmingham University in England and the other at a Canadian university. Since taking up their posts, they have spent some brief periods in the UK with the RDA and have attempted to familiarise themselves with the economy, and the business and university profile of the region. The rationale underlying the RDA's choice of Chinese rather than British staff, according to Alistair, a WB senior RDA manager is that:

“.. particularly with an economy like China, particularly with a political system like China, the best way that one can get an insight into what is going on is to have local people employed. Otherwise you are incredibly alienated particularly in terms of the language. But secondly in terms of how long it takes to penetrate those countries"

Another RDA has been working closely with a local university in UK to support the development of collaborations with China. Shelley, a senior academic based at the university involved in developing international links, said they have campuses in China. The RDA sponsored visits to science parks in China with the potential to link them to the university's own science park. One of the Chinese people who was employed while the university was undertaking its initial scoping work in China has been retained by the university, according to Shelley, "....as our roving person in China looking at increasing the number of research collaborations we have with Chinese universities. So she looks at our existing research collaborations with China and who we were working with and who we weren't. And then armed with a knowledge of our university's expertise she has now been visiting the top universities in China, as well as those we are already working with, to look at 
increasing the extent of existing collaborations and then also engendering new

collaborations". Some of these collaborations are expected to eventually have commercial outcomes.

Some RDAs have specific units focusing on business support for those businesses who want to penetrate specific overseas countries. The head of one unit, BC Natasha from mainland China, came to study at a British university located in a city twinned with her home town. She noted that whereas Chinese businesses in the UK were concentrated in the catering trade, "...there is a growing diversification into a wider range of graduate businesses which includes accountancy practices, engineering companies, and scholars involved in academic research that have the potential to be commercialised". The agency works with universities on innovation, spin out companies and student placements within the spin out companies. A Chinese multi-disciplinary association located in the UK has proposed a joint research project with China and the agency is supporting them. It also organises trade missions to China and runs road shows in the region to make businesses aware of the opportunities in China. Those who join the trade missions could include second generation $\mathrm{BC}$ including graduates who may not be familiar with mainland China. A similar unit established by the same RDA is headed by BI Pankajan to aid international entrepreneurship with India.

\subsubsection{Local government councils}

Local government councils play a role in supporting and developing entrepreneurship. Councils can work in collaboration with universities and a range of other agencies. For instance, the development work for the new science park at Exeter is the result of a partnership of the RDA, the University of Exeter, Devon County Council, Exeter City Council, East Devon District Council and the Met Office. The Incubating Graduate Business project in Leicester is funded by the European Social Fund and is managed by the city council. Councils are also involved in internationalisation activities. WB Martin, the international manager of a city council, works very closely with the two universities in the city. One of the universities has established an overseas campus in China. The presence of Chinese students in the overseas campus together with overseas Chinese studying locally has made the city council "...conscious of the opportunities that this represents in terms of potential entrepreneurs". This potential remains to be exploited in a structured way and the council maintains awareness of Chinese student and graduate entrepreneurial ambitions.

The city council is currently concentrating its attention on building links with China and building relationships with the relevant agencies. A representative office of a company wholly owned by the council is currently being set up in China. This strategy has been adopted because " $(T)$ he legal basis for opening an office in China is quite complicated so the actual position is that we have set up a stand alone company that has a representative office in China". Its remit is not only the area where the UK university has a campus but covers a much wider area. Martin went to China to set up the office and recruit the first staff member who took up his post in 2007 . One of the selection criteria was that the successful candidate should have experience of working in an international business environment, not just the Chinese business environment. This recruitment strategy was to ensure that the candidate was aware of western business culture which is different from the Chinese business culture. Martin said they were fortunate to recruit someone who had had a British university education and has experience of working with UK businesses located in China.

\subsubsection{Chambers of Commerce}

There are numerous accredited chambers of commerce in the UK which allow voluntary membership of businesses. Some of them work closely with other chambers in a region so that they can bid for regional contracts and undertake regional policy support. There are also links with overseas chambers of commerce but according to Clifford, the director of one chamber, the full potential of overseas collaborations has not been exploited to enhance the internationalisation of businesses. One chamber of commerce, for instance, has signed a 
Memorandum of Agreement with the Mumbai Chamber of Commerce in India, and is exploring a similar arrangement with another chamber of commerce in India. The chamber has also helped to establish a China Trade Bureau and an India Trade Bureau.

The links with India and China build on long established twinning relationships that the city has with cities in India and China. Whereas previously such twinning arrangements were seen primarily as civic engagement, increasingly they are seen as vehicles to facilitate international business. Hence, for instance, a number of delegations have come from India and China from the provinces in which the twinned cities are located. The delegations come to look at business opportunities such as setting up new businesses or partnering with UK businesses. For those interested in research activities, the chamber helps to introduce them to relevant university departments and academics. Liaison with chambers of commerce overseas is also a strategy adopted by RDAs. For instance, one RDA hosted the Bollywood Oscars and also co-convened a conference aimed at fostering UK-India trade links. It signed a Memoranda of Understanding with the Indian federal chambers of commerce to which many local chambers of commerce are affiliated.

The presence of a large ethnic minority population in a city can facilitate international business development as there are extensive links between the city and different parts of the world mainly through family connections. According to the director of a chamber of commerce in the Midlands, different approaches are needed for dealing with Indian and Chinese potential entrepreneurs who come on trade missions to the UK. Derek said:

"China is a very, very big place, the chances of them knowing somebody in our city is nil. India is different, very different, because relationships with people here and back in India are very often key, and often those result in people coming backwards and forwards... I think regardless of computers and everything else, people do business with people. The Chinese one is very clinical but they won't do business with you until they trust you... No I just think the way people do business is different but it is still people do business with people. The first thing you have to do when you are dealing with China, you have to get past the political bit because it is still a political State. All these delegations will have somebody from the Party with them, as in the Party Chairman or the General Secretary or somebody. You have got to get past the politicians. When you have got past the politicians you can do the business. India is free; you do what you like.... Now interestingly, delegations that we have in from India nearly always want to see other Indian businesses. I think, dare I say it, an element of that is also talking to people who run a business here and let's hear it from somebody we know. Whereas the Chinese are very clinical, very clinical. A different approach but it is the old sort of thing, you have to understand who you are dealing with"

This quotation demonstrates how the longer presence of $\mathrm{BI}$ in Britain, and the networks maintained with people in India, allows for the access of information which plays a complementary role to the 'official line' articulated by the chamber of commerce and other agencies. People from mainland China have fewer connections with $\mathrm{BC}$ for one main reason. As noted in chapter 2, the majority of $B C$ originated from Hong Kong, not mainland China. The links of Hong Kong Chinese and mainland Chinese are very rudimentary because Hong Kong was a British colony with few links with mainland China which are only now beginning to change under the one country, two systems model.

\section{$9.5 \quad$ Conclusion}

This chapter has focused on the business support dimension of one of the enablers of enterprise, Knowledge and Skills. Private sector support by $\mathrm{BI}$ and $\mathrm{BC}$ as well as WB international businesses have emerged to fill the gap in provision by public and third sector provision. Third sector ethnic minority business support organisations, including TiE, a 
global entrepreneur and professional organisation which is attempting to broaden its base from Indian dominance, have some links with universities. However, such links are patchy and tenuous and primarily articulated through personal contact. Government support to strengthen and sustain these links, as well as to expand them to encompass all universities, could help to support student, graduate and academic international entrepreneurship, not only among $\mathrm{BI}$ and $\mathrm{BC}$, but all those linked to universities.

There is a range of public sector support including that provided by Business Link, UKTI, RDAs, chambers of commerce and city councils. Some of these have direct links to universities in their region. Indeed, a few have also set up overseas offices, for instance in China, to act as conduits for developing international entrepreneurship including international graduate and academic entrepreneurship. However, there is considerable diversity in the strength of links and collaboration between public sector business support organisations and universities in the development of entrepreneurship activities and knowledge transfer of university generated intellectual property. There is a role for Government support to ensure greater parity across the country and to reap the benefits of best practice thus driving up regional and national productivity. The diversity of business support for university generated entrepreneurship, coupled with support provided within universities, needs to be streamlined in accordance with the Government's Business Support Simplification programme. 


\section{CHAPTER 10: CONCLUSION}

\subsection{Introduction}

This chapter draws together the main conclusions and recommendations from qualitative research, organised under four of the five drivers of productivity and three enablers of enterprise as identified in the 2008 Enterprise Strategy Paper. It covers the drivers of skills, innovation, enterprise and competition and the enablers of enterprise: culture of enterprise, knowledge and skills, and access to finance. Some of the conclusions relate to the whole population of students, graduates and academics, while others are specific to BI and BC. Possible solutions are proposed for what more can be done to ameliorate or eradicate barriers to international entrepreneurship but they require further consideration of impact, feasibility, cost and affordability which are beyond the scope of this study. They are suggested here to promote discussion and debate to aid policy and practice formulation and implementation. As this is a qualitative study, illustrating some patterns and processes, the final section of this chapter identifies areas for further quantitative and qualitative research.

\subsection{Drivers: Skills and Innovation}

\subsubsection{Increase people with STEM skills at all levels}

$\mathrm{BI}$ and $\mathrm{BC}$ are over-represented in $\mathrm{HE}$ relative to their proportion in the working age population. They are over-represented in certain subjects, particularly science, engineering and technology (SET) in the case of both males and females. As a significant proportion of undergraduates and particularly postgraduate students in many SET subjects are from overseas, it is essential to encourage this trend among $\mathrm{BI}$ and $\mathrm{BC}$ as it will help to ameliorate the shortage of indigenous SET academics and professionals. While there are various Government interventions designed to promote capacity building in STEM ${ }^{111}$ (science, technology, engineering and mathematics) subjects, nevertheless, more needs to be done to promote take up of doctoral research which underpins academic entrepreneurship. This is particularly important in the case of $\mathrm{BI}$ and $\mathrm{WB}$ as interventions do not appear necessary in the case of $\mathrm{BC}$ as both males and females are over-represented at doctoral level. ${ }^{112}$ While $\mathrm{BI}$ are over-represented in SET at undergraduate and masters' level, they are underrepresented at doctoral level. In the case of Whites, ${ }^{113}$ their representation at doctoral level is only slightly more than would be expected. A steady stream of indigenous doctoral candidates from $\mathrm{BI}$ and $\mathrm{BC}$, as well as other ethnic minorities and $\mathrm{WB}$, is required to provide the SET researchers necessary to produce innovative products for patents, licenses and spin out companies, and to engage in R\&D to promote business innovation. The higher interest and participation in SET among $\mathrm{BI}$ and $\mathrm{BC}$ augurs well for the Government's target to increase STEM personnel.

\subsubsection{Promote multi-disciplinary collaboration}

Innovation often derives from the combination of knowledge and skills from different disciplines, yet sufficient multi-disciplinary activity appears lacking. It is important to foster multi-disciplinary collaboration at all levels within universities in the development of innovations to be taken to market. Of particular benefit to SET-based innovators may be collaboration with business studies and management disciplines. This is because businesses, and perhaps particularly knowledge driven businesses, require a combination of different types of expertise to start and grow. The examples provided in the report of undergraduates Arun et al. (Case Study 8) and postgraduates Chandra et al. (Case Study 4)

\footnotetext{
${ }^{111}$ Note that Government policies are focussed on STEM (science, engineering, technology and mathematics) while the secondary data on subject and ethnicity used in this report is taken from Jones \& Elias (2005) which refers to (SET) (science, engineering and technology) which is why both acronyms are used here.

${ }^{112}$ However, the data on which this is based includes almost $50 \%$ who are not British nationals (Jones \& Elias $2005)$ so the figure could be inflated by those who are overseas Chinese.

${ }^{113}$ The secondary data does not have report separate statistics for White British.
} 
showed that they had many of the ingredients of potential international business formation: a viable product; high level technical expertise; overseas networks and knowledge of overseas product development capability and market interest; but they lacked management knowhow, both in terms of operating in a domestic market and also overseas markets.

Collaboration with students or graduates from the business school would have helped. Such collaboration may lead not only to product and process innovation but also encompass softer or wider innovation (management-related) thus increasing and sustaining the innovative potential of young firms.

\subsubsection{Recognise and support the innovative capability of non-research students}

The 2008 Innovation White Paper states that "The UK's capacity to unlock and harness the talent, energy and imagination of all individuals is crucial to making innovation stronger and more sustainable" (DIUS 2008:8). This report has shown that one category of individuals who have not received as much attention as researchers across the HE sector so far are the non-research students at undergraduate and postgraduate levels, including $\mathrm{BI}$ and $\mathrm{BC}$, who can contribute in multiple ways to the drivers of UK productivity. By participating in higher education, students are increasing their level of discipline-based knowledge and skills, and some are gaining entrepreneurial skills too, thus contributing to up-skilling the UK workforce as advocated by Leitch (2006). Given the comparatively larger size of the non-research student body, they could potentially generate more small business start-ups (including innovative start-ups) and revenue than those generated by the considerably smaller body of research students and academics. This report has provided examples of the innovative capacity of non-research students. Yet non-research students have been the Cinderella of university generated innovative entrepreneurship. This is part of a wider problem of less recognition of student entrepreneurial potential discussed below.

\subsection{Driver: Enterprise}

\subsubsection{Promote more entrepreneurship among $B I$ and $B C$ students and graduates}

We saw in chapter 2 that $\mathrm{BI}$ and $\mathrm{BC}$ UK born graduates have a lower self-employment rate than WB graduates. Yet, a greater proportion of $\mathrm{BI}$ and $\mathrm{BC}$ than WB have higher level skills (levels 4-8) including in SET subjects which are vital to science and technological innovation which, as already noted, is a key plank of Government innovation strategy. Furthermore, as we saw in chapter 2, they come from communities which are more entrepreneurial and innovative. Moreover, as we have seen in chapter $6, \mathrm{BI}$ and $\mathrm{BC}$ have a richer endowment of social networks, including bonding, bridging and linking social networks, many of which transcend geographical boundaries. As shown also in chapter 6 , these networks provide them with a competitive advantage in penetrating overseas markets, particularly India and China, but potentially also Europe, Africa and the USA due to widespread bilateral and multilateral diaspora connections. India and China are of particular significance because, as noted in chapter 1 , they are experiencing rapid growth, including in terms of science and innovation, and the UK is trying to gain a strong foothold in these countries through various means including collaborative research, inward and outward foreign direct investment and access to UK finance markets. To better capitalise on the potent combination of high level skills, entrepreneurial heritage, innovative potential and social networks of graduate $\mathrm{BI}$ and $\mathrm{BC}$, policy interventions may be necessary to encourage more graduate $\mathrm{BI}$ and $\mathrm{BC}$ to engage in knowledge intensive national and international entrepreneurship. BI and BC business support organisations, the Government-sponsored Ethnic Minority Business Task Force, as well as global entrepreneur organisations such as The Indus Entrepreneur (TiE) with its large Asian membership, and Business Link, could be encouraged to engage in outreach work to universities to help stimulate entrepreneurial ambition among $\mathrm{BI}$ and $\mathrm{BC}$ students and help convert it into reality. 


\subsubsection{Capitalise on student ambition}

The vision set out by Government in the 2008 Enterprise Strategy Paper is to make the UK the most enterprising economy in the world. The Government also wants to move towards a knowledge-based economy. This involves, inter alia, unlocking the talent of higher education students, graduates and academics so that they actively engage in knowledgebased intrapreneurship and entrepreneurship. As noted in chapter 1, higher education qualifications are correlated with higher rates of entrepreneurship and those with doctorates having the highest rate of entrepreneurship. For those on the way to obtaining a degree and higher qualifications, national and local survey data indicates that between a third to two thirds of university students have entrepreneurial ambitions. Such ambitions seem to be more evident among non-White students which includes BI and BC. Survey evidence suggests that there are almost 60,000 students, both male and female, and including $\mathrm{BI}$ and $\mathrm{BC}$, in one English region that hold a desire for self-employment. While this same degree of ambition may not exist among the other eight regions in England, and elsewhere in the UK, nevertheless, even with a conservative projection, we can anticipate that there are several thousand students, including $\mathrm{BI}$ and $\mathrm{BC}$, with entrepreneurial ambitions. Furthermore, the entrepreneurial potential of international non-research students should not be underestimated or ignored. High participation by international students in business and management courses including MBAs, as well as on extra-curricula accredited and nonaccredited enterprise education events and business competitions, testify to their keen interest in entrepreneurship. Moreover, some of the international students from entrepreneurial backgrounds are using their time here to try and identify business opportunities such as looking for distribution outlets for goods produced in China by their parents' business.

Many students, including $\mathrm{BI}$ and $\mathrm{BC}$, have work experience in a diversity of organisations as increasingly it has become a trend for young UK domiciled people from, at least the age of 16 , to obtain part-time and vacation work to help finance their tertiary level studies and recreation activities. In addition, many have work experience related to their course of study as work placements have become more common under the Government's employability agenda. Hence, unlike earlier generations of graduates who were likely to have had minimal work experience by the time they graduated, today's students have more experiential knowledge of the world of work. Work experience is often considered to be a useful prerequisite to starting your own business and many of today's graduates, both full-time and part-time, as well as mature students, have acquired already a substantial amount of this by the time they leave university. In addition, those with parents and relatives who have their own businesses, as in the case of many $\mathrm{BI}$ and $\mathrm{BC}$, have tacitly acquired entrepreneurial know-how by helping in the family business. Consequently, there is likely to be a substantial body of students and young graduates who may be ready to start a business while students, or immediately on graduation, than has been fully acknowledged.

To realise the Government's ambition to increase the number of enterprises, particularly knowledge-based enterprises, it is important to capitalise on the magnitude of indigenous and international student entrepreneurial ambitions and dynamism and convert ambitions into the reality of start-ups. Other progression pathways to market, such as licensing of innovations of students, should also be promoted among those who do not wish to start a business. There are also a sizeable number of students, including $\mathrm{BI}$ and $\mathrm{BC}$, who are selfemployed, many of them part-time or mature students with substantial and relevant work experience. Helping existing student businesses to grow and innovate, using the disciplinary knowledge and skills they have acquired at university, will contribute to the Government's business growth and business innovation agenda set out in the 2008 Enterprise Strategy Paper and 2008 Innovation White paper. Promoting female entrepreneurship among students and graduates will contribute to an important goal of Government, articulated through the Women Enterprise Task Force, to increase female entrepreneurship. This currently lags behind male entrepreneurship and is considered to be an important 
component of the enterprise gap between the UK and its comparator country, USA. Students in all universities, both domestic and international, would benefit from access to incubator facilities and entrepreneurship support to capitalise on their ambitions. Such facilities may also provide more opportunities for collaboration between domestic and international students, as we have seen in examples provided in this report, thus promoting international entrepreneurial activities.

Yet a 'postcode lottery' exists in terms of an entrepreneurial culture in universities and regions, in the provision of enterprise knowledge and skills and other business support, student IP management and access to funds for start-ups and business growth. Thus, students, including $\mathrm{BI}$ and $\mathrm{BC}$, are well served in some universities and some regions, while in others this is not the case. There is a range of public sector support including that provided by UKTI, RDAs, chambers of commerce and city councils. However, there is considerable diversity in the strength of links and collaboration between public sector business support organisations and universities in the development of entrepreneurship activities and knowledge transfer of university generated intellectual property. Third sector ethnic minority business support organisations have little or no links with universities.

The diversity of practices is not surprising given the large degree of autonomy which RDAs and universities have been given by central Government. Nevertheless, there is clearly a role for Government strategic intervention to help to convert the ambitions of so many students into actual start-ups and growth businesses. This will help to stimulate economic growth in each region and reduce the disparities in the productivity rates of different regions which is a key Government objective. Hence attention needs to be given as to the levers which Government can utilise to achieve this. As well as parity of provision across regions, better integration and coherence between intra-university and external support services are necessary. The plethora of potentially different sources of advice and guidance appears to create a minefield of confusion for students, graduates and academics. Hence, some attention needs to be given to streamlining intra-university and extra-university business support under the Government's Business Support Simplification programme.

Thus, even if the individual and cumulative financial value of non-research student and young graduate businesses is small, they should not be ignored because the entrepreneurs are young, dynamic and enthusiastic and they come from diverse disciplinary fields and backgrounds which suggests that, if cultivated, they have the potential to contribute a great deal to the dynamism of the UK economy. If helped to grow and internationalise, their contribution to wealth creation could be even greater. Furthermore, these businesses create employment opportunities usually for other graduates and are, therefore, contribute to reducing graduate unemployment and under-employment. At present there is a sub-optimal capitalisation of the potential opportunities afforded by undergraduate students and nonresearch postgraduate students, both indigenous including $\mathrm{BI}$ and $\mathrm{BC}$, and from the $\mathrm{EU}$ and overseas. In the 2008 Enterprise Strategy Paper, the Government extended the role of the NGCE to include the development and management of University Enterprise Networks based on the US Kauffman Foundation experience. These networks have the potential to play a part in reducing the missed opportunities for national and international entrepreneurship offered by non-research students and new graduates.

\subsection{Enablers of Enterprise: Culture, Knowledge \& Skills and Access to Finance}

\subsubsection{Promote a culture of Enterprise}

As advocated in the 2008 Enterprise Strategy Paper, a culture of enterprise needs to be developed across all sections of society. A cultural change in the neutral or negative perception of entrepreneurship needs to occur among many parents of students and graduates. Where negative views are held by $\mathrm{BI}$ and $\mathrm{BC}$ parents, more effort is needed to 
overcome them as parents from these communities exert a great deal of influence on their children, even in early adulthood. A cultural change is also necessary among academic tutors who are likely to be the front line contact for students with entrepreneurial ambitions. To allay parents' and tutors' anxiety about students dropping out or paying less attention to their studies, entrepreneurship education could be embedded into degree programmes, and pedagogic materials and approaches being developed by the Centres of Excellence for the Teaching and Learning of Enterprise could help in this process. All academic staff could be provided with basic familiarisation with topics such as Intellectual Property Rights and the help of the UK-IPO could be sought. Academic staff would also benefit from being made aware of the multiple routes to market so that they can provide first tier support to students.

\subsubsection{Support knowledge and skills acquisition and international entrepreneurship education}

This report has provided a rich seam of examples of enterprise initiatives and programmes, which suggests that work within, or by HEls, is often supported by the activities of mainstream providers. Nevertheless, much more needs to be done to enhance provision at post-graduate level and for part-time students who are under-served at present. As indicated in this report, there are a considerable number of post-graduate students, and parttime students, whose numbers have increased with the expansion and widening of participation in higher education. Hence, there is a need to increase provision targeted at these groups. Business start up and growth are the predominant foci of central and regional Government strategies and enterprise education. While undoubtedly these are core activities, there is a need to broaden the remit to include other progression pathways of taking innovations to market. Students need to be made aware that setting up a business is not the only way to commercialise their innovation and that the licensing route is another option.

Programmes to develop international entrepreneurship particularly among students and graduates do exist but they are minimal. More attention to international entrepreneurship in enterprise education could, in the short or medium term, potentially help to foster more 'born global' businesses and promote collaboration between British and international students which may lead to joint business ventures and supply chain collaborations. Such programmes may increase in the wake of attempts, such as by the NCGE, to engage in dialogue with overseas enterprise educators. This is evidenced by closer liaison with Chinese enterprise educators through the establishment in 2008 of the China/UK Entrepreneurship Educators Network and participation in conferences and workshops.

Programmes such as SPEED (Student Placements for Entrepreneurs in Education) are only available in about one in ten universities in England and this report has provided multiple examples of success. However, the programme, funded by the Higher Education Innovation Fund, is over-subscribed. Similarly, programmes for graduates such as the National Council for Graduate Entrepreneurship Flying Start programmes are over-subscribed. There are, therefore, potential missed opportunities for developing entrepreneurship among failed, but nevertheless, good applicants.

\subsubsection{Improve access to finance}

Actual or perceived difficulties in obtaining finance for starting a business is a barrier to entrepreneurship. Students and recent graduates merit targeted interventions as most enter the labour market with sizeable student debt, in addition to little or no personal savings or collateral, and probably lower levels of requisite financial literacy. Graduates who enter paid employment have the security of knowing that they will have a steady income from which to pay off their debts while those entering entrepreneurship do not have such an assured trajectory. While this may not deter the hard core entrepreneurs, it may be a sufficient 
deterrent for those who are ambivalent about the wisdom of taking a risk with entrepreneurship.

Various sources of funding potentially exist but interventions may be required to make them better fit for purpose. As a greater proportion of $\mathrm{BI}$ and $\mathrm{BC}$ students and graduates compared to WB come from lower socio-economic backgrounds, family and friends may have less disposable income to channel into supporting student and graduate entrepreneurial ambitions. However, wealthier members of Indian and Chinese ethnic minority business and social organisations could be mobilised as extended family to provide business angel finance. As the Government, according to the 2008 Enterprise Strategy Paper, is planning to work with the Business Angel Association to develop Angel finance, this could be extended to working with ethnic minority organisations to identify the support they require to provide Angel finance for students and young graduate entrepreneurs from their community. Access to debt finance for all students, including $\mathrm{BI}$ and $\mathrm{BC}$, could be enhanced in at least three ways. First, providing ring-fenced, clearly visible loans for students and graduates; second, modifying the SFLG scheme so that Government guarantees a higher proportion of the loan than the current $75 \%$ and third, developing microfinance schemes, including a micro-finance self-help bank linkage scheme. Grant finance could be made available for students to help sustain initiatives such as SPEED and to provide proof of concept funds for academics interested in taking innovations to market.

Targeted interventions are needed to deal with a range of market failures including information asymmetries, lack of sufficient financial literacy and discipline, lack of investment readiness, and lack of knowledge of student intellectual property protection. Students, and many academic tutors, seem to be unaware of the full range of finance packages to which they have access to start and grow their business. It would be unrealistic to expect academic tutors to have this knowledge but if they do not have an antipathy to enterprise and have a basic understanding of entrepreneurship, they could, as first line contacts, signpost their students to those in the university or externally who could help. It would also be helpful for students to have additional support to identify and apply for relevant sources of finance. This is because of time constraints as it is essential that students complete their course of studies to the highest standards so that they have the requisite panoply of discipline and enterprise skills under their belt to develop and grow knowledge-based businesses.

\subsection{Driver: Competition}

\subsubsection{Value the competitive advantage provided by $B I$ and $B C$}

We saw in chapter 6 that BI and BC make use of their cultural capital and large endowment of networks to their competitive advantage to develop and sustain international entrepreneurial and research activity. The bonding networks of family and friends are used to provide them with personalised and culturally sensitive hospitality and orientation to new places, thus fulfilling a basic need in a new environment. The bonding and bridging networks also provide them with access to market information, help with the identification of business partners and premises and the recruitment of staff and board members. For academics, these networks are particularly useful for the development of collaborative research projects, development of clinical trials and manufacture of innovative products. Linking networks help, for instance, in accessing finance from business angels and venture capitalists. Furthermore, they help with enlisting the assistance of Government officials, particularly in places like China where the State plays a greater role in managing the economy and bureaucratic processes. $\mathrm{BI}$ and $\mathrm{BC}$ entrepreneurs are able to use their own cultural and social capital as well as that of their staff to gain competitive advantage in penetrating overseas markets. This strategy, with modifications, can be used by British firms. British firms wishing to internationalise can be encouraged to employ international students and graduates from British universities who originate from the countries they are 
trying to penetrate. This could perhaps be facilitated through ring-fenced Knowledge Transfer Partnerships.

\subsubsection{Universities can be the seedbeds of international entrepreneurship}

The good practice identified among $\mathrm{BI}$ and $\mathrm{BC}$ needs to be taken up more widely in the UK. Interventions need to be introduced to make use of the potential for networking that is 'right under our noses'.

\section{Students, academic staff, parents and alumni}

The most potent of these sources are the resources brought in by the Prime Minister's Initiatives 1 and 2 which have led to the exponential growth in the number of international students in HEls and FE colleges, particularly from China and India. While the proportion may vary in different institutions, nevertheless, it is unlikely that any institution does not have some international students. Another source of networks is overseas staff whose numbers have risen exponentially in the last decade. Some of the academic staff are from China and India. Strategies need to be developed to capitalise on the potential students and staff offer for networking. Furthermore, networks with the parents of overseas students need to be cultivated as they offer access to the expertise and networks of people already in professional positions in different parts of the world, including India and China. International students and scholars also have their own networks to further their professional development and career prospects. Support for British students, graduates and academics to organise joint events with these networks would provide opportunities to develop wider international networks.

Attention needs to be given by every university, not just some universities as at present, to develop and sustain alumni networks which can be mobilised for various types of international entrepreneurial activities as well as other purposes. Alumni who are engaged in entrepreneurial activities in India and China may usefully be incorporated into the global supply chains of UK businesses or in international franchising of UK businesses. Furthermore, alumni networking and management could identify those in India and China who wish to internationalise their business and set up bases in the UK or enter into partnership with UK-based businesses and universities as illustrated by examples in this report. In addition, many alumni who may not be entrepreneurs or potential entrepreneurs themselves may be working, as illustrated by examples in this report, in intermediary bodies which support international entrepreneurship development. It is important to appreciate that trust, loyalty, hospitality and reciprocity are key ingredients of relationship building and management, particularly in some communities, such as Indian and Chinese. Investment by the British in developing and sustaining bridging and linking social capital with overseas Indians and Chinese who have links with UK universities is likely to pay rich dividends in fostering international entrepreneurship.

\section{Intermediary bodies}

Personal networks can complement those provided by the various intermediary organisations the Government has established overseas and also via special collaborative schemes like UKIERI and ICUK. These networks are useful but because they operate at an institutional level, potential international entrepreneurs may not hear of them because of a market failure in information communication, or people may bypass them because they do not think they are useful.

Although none of the entrepreneurs interviewed had used UKTI services, either in the UK or abroad, relying instead on their own informal channels, this is not to say that UKTI does not play an important role as an intermediary. Indeed, some BI graduate entrepreneurs established in India have now become involved in UKTI in India and hope to help promote its services to the Indian community both in India and overseas. This does suggest that 
Government intermediary services and other support services need to better promote themselves to different constituencies such as non-research students, research students and staff, student and scholars societies, and ethnic minority community groups. While there may be overlaps between the constituencies, nevertheless, there may be merit in investing in mechanisms to tailor information and support to specific constituencies. With students, and to a lesser extent with staff, this will need to be done on a continual basis as one cohort leaves on graduation and a fresh, un-informed cohort arrives. Furthermore, Government legislation and policies, such as relating to immigration, often change with different impacts on different constituencies. Business support staff and academic advisers need to be fully cognisant of these changes so that they can advise international students, particularly those planning to start a business while students or after they graduate. A closer involvement between the Home Office and universities would help.

Third sector intermediary bodies need to be better linked to students, graduates and academics and their institutions. For example, The Indus Entrepreneur (TiE), a global entrepreneur network, should be supported in establishing links with all universities. While $\mathrm{TiE}$ has links with UKTI, these need to be extended to universities and FE colleges. At present its links are with a very small number of universities, facilitated by personal contacts. These links need to be extended to all universities so that a broad cross-section of students, graduates and academics can benefit from their mentoring programmes, dragon's den style competitions, extensive international networks, and links to support institutions and individuals such as banks, lawyers and accountants. Organisations such as TiE can play an important role in addressing sources of market failure such as communication shortfalls. Thus, they can provide important conduits for knowledge spillovers as members share their experiences of overseas markets with other members and provide reliable information on the costs and benefits of internationalisation. As membership extends worldwide with chapters in many countries, its networks can help overcome dependencies in particular markets because of a lack of up-to date information and, therefore, help lead to diversification of internationalisation and of sectors.

\section{Institutions and businesses overseas}

Networks with institutions and businesses overseas need to be strengthened. Bilateral and multilateral links can be established with overseas incubators and science parks. Particular attention needs to be paid to developing reciprocal 'soft landings' for student and graduate entrepreneurs who wish to internationalise. Networks should also be developed with businesses outside the UK which can provide internships and 'soft landings' in-house incubator facilities. Businesses set up overseas by graduate BI, BC, WB, and international alumni who have returned home, could be the first port of call. This relies on universities developing and maintaining effective alumni tracking mechanisms. The soft landings approach will help to address market failures affecting the supply of international skills in the economy which can be a barrier to international trade and investment or indeed to any form of international entrepreneurship.

\subsubsection{Seize the networking opportunities now}

These opportunities for networking need to be capitalised on now because the UK cannot always rely on a continual supply of a large number of international students and staff. There is always competition from other countries for international students. There is also the growing development of transnational education which means fewer students will come here or the time spent in UK may be shorter. Furthermore, there are incentives available in overseas countries, such as China and India, for overseas domiciled Chinese and Indian to return. Such threats to the sustained large scale presence of international students and staff in UK universities will result in a great reduction in networking opportunities. It is important that collaborative activities begin while international students and staff are at universities in the UK and mechanisms are in place to facilitate sustaining them when they have returned home. 
The practices suggested above in relation to Indian and Chinese could be extrapolated to apply to all EU and overseas people with links to UK universities. Benefits could be reaped in every region in England as well as elsewhere in the UK. While not every part of the UK is fortunate to have a sizeable ethnic minority population whose diaspora networks could be leveraged, nevertheless, every university, albeit to varying degrees, has international students with whom networks could be established. However, it would be a mistake to think that increasing the endowment of networks would in itself be sufficient. Training may be necessary on how to mobilise networks and how to take advantage of them while avoiding the 'dark side' of networks.

Hence, it is important to recognise that universities contain the seedbeds of international entrepreneurship but they need sustained support to cultivate the resources before they bear fruit. While some networking undoubtedly occurs organically through co-location of British and overseas people, nevertheless, some degree of social engineering may be necessary. If this is left to individual institutions, it is likely to be patchy and fragmented and the rewards will be less than if there is a systematic attempt by central Government to take advantage of the resources 'under our nose' for facilitating knowledge-based international entrepreneurship. The mechanisms for implementing such as strategy could involve the NCGE working in collaboration with universities, regional and local government, and third sector organisations.

The Government has introduced various strategies, such as prestigious fellowships, inward investment programmes for high growth entrepreneurs, and favourable immigration regulations, to attract overseas talent to the UK. Retaining such talent will help to improve UK productivity as immigrants make a positive contribution to the economy (BERR 2008b). However, the Government is also committed to the principle of equality. Its various human resource recruitment strategies are laudable if they contribute to 'brain circulation' and not to the 'brain drain' of talent from emerging economies and poorer countries which are in vital need of such human resources.

\subsection{Further Research}

The research suggested here is to aid policy formulation and implementation.

- As this study is qualitative, it is illustrative of patterns and themes. The methodology used in this qualitative study suggests that there is potentially substantial international entrepreneurship ambition and activity that is 'under the radar'. Quantitative research is required to provide robust measures of the scale of these patterns and themes. It is important to establish whether the case studies given of student, graduate and academic international entrepreneurship intention and activities, as well as those of British university alumni, and businesses abroad, are the tip of the iceberg or the activities of a few extraordinary people. Separate surveys would be expensive but it may be possible to include pertinent questions in existing national sample surveys such as SIES, DHLE, Student Satisfaction Survey, Survey of Innovation, Youth Cohort Study, HEFCE Business-Community Survey, Annual Small Business Survey and the Household Survey of Entrepreneurship. BERR has set up a special unit to ensure that entrepreneurship is incorporated across departments. The unit could ensure that data on entrepreneurship is included in administrative data collection and various surveys and subjected to data analysis. Individual universities or groups of universities could undertake their own surveys, as the West Yorkshire Universities Partnership has done for a number of years. If there is a harmonisation of concepts, questions and methods, then the data collected could not only be of value to individual institutions, but, if aggregated, could also inform regional and national policies and practices. It would be important for such surveys to 
capture data on international students to help inform the development of international entrepreneurship at and via universities. The new University Enterprise Networks which Government has asked NCGE to develop could be used to facilitate data collection and analysis.

- Research is needed on the entrepreneurial ambitions of international students and staff and particularly their interest in setting up solo or collaborative international entrepreneurial activities with British peers. Facilitators and barriers should also be identified so that appropriate action can be taken. As this report has strongly recommended that universities should be recognised as the seedbeds of international entrepreneurship, a pilot action research project to test this out could be undertaken involving a couple of universities.

- This study has focused on those students, graduates and academics who are involved in successful or potentially successful entrepreneurial activities. Research is also needed on those with entrepreneurial ambitions such as rejected applicants to the SPEED and NCGE Flying Start programmes to assess deadweight and genuine missed opportunities for promoting entrepreneurship.

- There is a need for research into the barriers to accessing finance by students, graduates and academics, particularly the extent to which the perception and actuality of student debt is a deterrent to entrepreneurship. The forthcoming review of HE student reforms may provide a vehicle to do this.

- This study has focused on British Indian and British Chinese students, graduates and academics but further research among other ethnic minority groups would be useful to ascertain the extent to which the patterns identified for $\mathrm{BI}$ and $\mathrm{BC}$ are replicated, particularly the competitive advantage for international entrepreneurship afforded by their cultural and social capital. 


\section{REFERENCES}

Agrawal, A. 2001. University-to-Industry Knowledge Transfer: Literature Review and Unanswered Questions. International Journal of Management Reviews, vol. 3, no. 4, pp. 285-302

Anderson, S. \& Platzer, M. 2006. American Made: The Impact of Immigrant Entrepreneurs \& Professionals on U.S. Competitiveness. Arlington, Virginia. National Venture Capital Association

Aston, J., Casbourne, J., Ritchie, H. \& Tackey, N. 2006. Barriers to Employment for Pakistanis and Bangladeshis in Britain Norwich. Her Majesty's Stationery Office

Barclays \& National Federation of Enterprise Agencies. 2002. Profiting from Support. London. Barclays Bank

Barclays SME Research Team 2005. Black and Minority Ethnic Business Owners: A Market Research Perspective. London. Barclays Bank

Bachu, P. 1985. Twice Migrants. East African Sikh Settlers in Britain. London. Tavistock

Bhattacharyya, G., Ison, L. \& Blair, M. 2003. Minority Ethnic Attainment and Participation in Education and Training: The Evidence. Nottingham. Department for Education and Skills

Botham, R. 2004. Young People and Enterprise in London. London. London Regional Development Agency

Botham, R. \& Mason, C. 2007. Good Practice in Enterprise Development in UK Higher Education. Birmingham. National Council for Graduate Entrepreneurship

Bound, K. 2007. India, The Uneven Innovator: The Atlas of Ideas: Mapping the New Geography of Science, London. Demos

Bourdieu, P. 1997. The Forms of Capital. In Halsey A., Lauder H., Brown, P. \& Stuart Wells, A. (eds.) Education: Culture, Economy and Society. Oxford. Oxford University Press

Brinkley, I. 2008. The Knowledge Economy: How Knowledge is Reshaping the Economic Life of Nations. London. The Work foundation

Brooksbank, D. \& Jones-Evans, D. 2005. Graduate Entrepreneurship in the UK 2004: A Preliminary Policy Paper based on GEM 2004 Data. Birmingham. National Council for Graduate Entrepreneurship

Cabinet Office Performance and Innovation Unit. 2001. Ethnic Minorities' Economic Performance. London. Cabinet office

Cabinet Office Strategy Unit. 2003. Ethnic Minorities in the Labour Market. London. Cabinet Office

Casson, M.,Burke, S., Pemberton, J. \& Strang, M. 2006. Network Approach to the Design of Case Studies for the Evaluation of Business Support, with Special 
Reference to the Evaluation of UK Trade \& Investment International Sectors Group. Reading. Reading Business Group

Carter, S. \& Shaw, E. 2006. Women's Business Ownership: recent research and policy developments. London. Department of Trade \& Industry, Small Business Service

Chan, A. 1986. Employment Prospects of Chinese Youth in Britain. London. Commission for Racial Equality

Cheng, Y. 1994. Education and Class: Chinese in Britain and the United States. Aldershot. Avebury

Chester, J. \& Bekhradnia, B. 2008. Funding Higher Fees: Some Implications of a Rise in The Fee Cap. London. Higher Education Policy Institute

Commission for Racial Equality. 1983. Vietnamese Refugees in Britain. London. Commission for Racial Equality

Commission for Racial Equality. 2007. Fact File 2 Ethnic Minorities in Great Britain. London. Commission for Racial Equality

Connor, H., Tyers, C., Davis, S., Tackey, N. \& Modood, T. 2003. Minority Ethnic Students in Higher Education: Interim Report. Nottingham. Department for Education and Skills

Connor, H., Tyers, C., Modood, T. \& Hillage, J. 2004. Why the Difference? A Closer Look at Higher Education Minority Ethnic Students and Graduates. Nottingham. Department of Education and Skills

Coviello, N. \& Munro, H. 1995. Growing The Entrepreneurial Firm: Networking for International Market Development. European Journal of Marketing, Vol. 29 No.7, pp. 49-61

Coviello, N. \& Munro, H. 1997. Network Relationships and the Internationalization Process of Small Software Firms. International Business Review, Vol. 6, No. 4, pp 361-386

Deakins, D., Ishaq, M., Smallbone, D., Whittam, G. \& Wyper, J. 2005. Minority Ethnic Enterprise in Scotland: A National Scoping Study. Edinburgh. Scottish Executive Social Research

Department of Business, Enterprise and Regulatory Reform 2007a. Our Commitment to Business. London. BERR

Department of Business, Enterprise and Regulatory Reform. 2007b. National Statistics: Statistical Press Release August 2007

http://stats.berr.gov.uk/ed/sme/smestats2006-ukspr.pdf

Department of Business, Enterprise and Regulatory Reform. 2008a. Strategy Paper. Enterprise: Unlocking the UK's Talent. Norwich. HMSO

Department of Business, Enterprise and Regulatory Reform. 2008b. BERR's Role in Raising Productivity: New Evidence. BERR Economics Paper 1. London. BERR 
Department of Business, Enterprise and Regulatory Reform. 2008c. Globalisation and the Changing UK economy. London. BERR

Department of Business, Enterprise and Regulatory Reform. 2008d. Simple Support, Better Business: Business Support in 2010 London. BERR

Department for Culture, Media and Sport. 2008. Creative Britain: New Talents for the New Economy. London. DCMS

Department of Education \& Skills. 2003. White Paper The Future of Higher Education. Norwich. Her Majesty's Stationery Office

Department for Education and Skills. 2007. World Class Skills: Implementing the Leitch Review of Skills In England. Norwich. Her Majesty's Stationery Office

Department for Innovation, Universities and Skills. 2008. Innovation Nation: Unlocking Talent. Norwich. Her Majesty's Stationery Office

Department for Trade and Industry 2002. The Impact of Business Link Support on Assisted Businesses - The Business Link Tracker Study. London. Small Business Service

Department for Trade and Industry. 2003a. DTI The Strategy. Prosperity for All London. DTI

Department for Trade and Industry. 2003b. DTI Strategy. The Analysis Economics Paper No 5 London. DTI

Department for Trade and Industry. 2003c. Competing in the Global Economy: The Innovation Challenge. Norwich. Her Majesty's Stationery Office

Department for Trade and Industry. 2004a. A Government Action Plan for Small Business 2004. London. Small Business Service

Department for Trade and Industry 2004b. A Government Action-Plan for Small Business: The Evidence Base London. Small Business Service.

Department for Trade and Industry, H.M. Treasury \& Department for Education and Skills. 2004c. Science \& Innovation Investment Framework 2004 - 2014. Norwich. Her Majesty's Stationery Office

Department for Trade and Industry 2004d. Trade and Investment White Paper 2004: Making Globalisation a Force for Good. London. The Stationery Office

Department of Trade and Industry. 2006a. Science, Engineering and Technology Skills in the UK. DTI Economics paper no 16. London. DTI

Department of Trade and Industry. 2006b. International Trade and Investment - The Economic Rationale for Government Support. DTI Economics Paper No. 18. London. DTI

Department of Trade and Industry. 2006c. Innovation in the UK: Indicators and Insights. Occasional Paper No. 6. London. DTI 
Department for Trade and Industry. 2006d. Ethnic Minority Businesses in England: Report of the Annual Small Business Survey 2003 Ethnic Boost. London. Small Business Service

Department for Trade and Industry. 2006e. 2004/05 Annual Small Business Survey. London. Small Business Service

Department of Trade and Industry. 2007a. Innovation in Services. Occasional Paper number 9 London. DTI

Department for Trade and Industry. 2007b. Household Survey of Entrepreneurship 2005 London. Small Business Service

Dhaliwal, S. 2000. Entrepreneurship - a learning process: the experiences of Asian female entrepreneurs and women in business. Education and Training. vol. 42, no. 8, pp. $445-452$

Evans, J. \& Mavondo, F. 2000. The Relationship between Psychic Distance, Adaptation of the Retail Offer and Organisational Performance. In Visionary Marketing for the 21st Century: Facing the Challenge. Australian and New Zealand Marketing Academy Conference (ANZMAC) 2000. Queensland. Gold Coast

Finch S., Jones A., Parfrement J., Cebulla A., Connor H., Hillage J., Pollard E., Tyers C., Hunt, W. \& Loukas, G. 2006. Student Income and Expenditure Survey 2004/5. Nottingham. Department for Education and Skills

Fraser, S. 2005. Finance for Small and Medium Sized Enterprises: A Report on the 2004 UK Survey of SME Finances. London. Department of Trade and Industry

Fraser, S. 2006. Finance for Small and Medium-Sized Businesses: Comparisons of Ethnic Minority and White Owned Businesses, London. Department for Business, Enterprise and Regulatory Reform

Freeman, P. \& Barron, E. 2006. Managing Student Intellectual Property. Birmingham. National Council for Graduate Entrepreneurship

FreshMinds. 2006. Student Debt and Graduate Entrepreneurship: An Examination of The UK Situation and International Experience. Birmingham. National Council for Graduate Entrepreneurship

Furlong, A. \& Cartmel, F. 2005. Graduates from Disadvantaged Families: Early Labour Market Experiences. Bristol. Joseph Rowntree Foundation/The Policy Press

Gibb, A. 2005. Towards the Entrepreneurial University. Birmingham. National Council for Graduate Entrepreneurship

Girma, S. \& Yu, Z. 2002. The Link between Immigration and Trade: Evidence from the United Kingdom. Review of World Economics, Vol.138, No. 1, pp. 115-130

Girma, S., Greenaway, D. \& Kneller, R. 2002. Does Exporting Lead to Better Performance? A Micro-econometric Analysis of Matched Firms. Nottingham. University of Nottingham Leverhulme, Centre for Research on Globalisation and Economic Policy 
Gould, D.M. 1994. Immigrant Links to The Home Country: Empirical Implications for US Bilateral Trade Flows. Review of Economics and Statistics, Vol. 76, pp. 302-316

Gowers Review of Intellectual Property. 2006. Norwich. Her Majesty's Stationery Office

Greene, F. \& Saridakis, G. 2007. Understanding the Factors Influencing Graduate Entrepreneurship. Birmingham. National Council for Graduate Entrepreneurship

Handscombe, R.D., Kothari, S., Rodriguez-Falcon, E. \& Patterson, E. 2007. Embedding Enterprise in Science and Engineering Departments. Birmingham. National Council for Graduate Entrepreneurship

Hannon, P. 2005. Teaching Pigeons to Dance: Sense and Meaning in Entrepreneurship Education. International Small Business and Enterprise 28th Conference, Illuminating Entrepreneurship - The Theory and Practice of Enterprise Creation and Development. Blackpool, 1-3 November, 2005

Harding, R. 2006. GEM UK 2006. London. London Business School

Harding, R. 2007. Graduate Entrepreneurship in the UK: Summary Report from GEM UK data. Birmingham. National Council for Graduate Entrepreneurship

Hayer, J. \& Ibeh, K. 2006. Ethnic Networks and Small Firm Internationalisation: a Study of UK-based Indian Enterprises, International Journal of Entrepreneurship and Innovation Management, vol. 6, no 6 pp 508-525

H.M. Treasury. 2006. Budget Report. A Strong and Strengthening Economy: Investing in Britain's future. Norwich. Her Majesty's Stationery Office

H.M. Treasury. 2007a. PSA Delivery Agreement 1: Raising the Productivity of the UK Economy. Norwich. Her Majesty's Stationery Office

H.M. Treasury. 2007b Pre-Budget Report and Comprehensive Spending Review: Meeting the Aspirations of the British people. Norwich. Her Majesty's Stationery Office

Higher Education Academy Art Design Media Subject Centre and National Endowment for Science, Technology and the Arts . 2007. Creating Entrepreneurship:

Entrepreneurship Education for the Creative Industries. Brighton. HEA ADM Subject Centre

Higher Education Careers Service Unit 1999 Moving On: Graduate Careers Three Years After Graduation. Manchester. Higher Education Careers Service Unit

Higher Education Careers Services Unit 2007 Graduate Entrepreneurship. Summer 2007 Manchester. Graduate Prospects

Higher Education Careers Services Unit 2008. The latest on student finances. Manchester. Graduate Prospects

Higher Education Funding Council for England. 2007a. Staff Employed at HEFCEfunded HEls: Update Trends and Profiles. Bristol. HEFCE

Higher Education Funding Council for England. 2007b. Higher Education-Business and Community Interaction Survey 2004-05 and 2005-06, 2007/17. Bristol. HEFCE 
Higher Education Statistical Agency. 2006. 2004/05 Destinations of Leavers from Higher Education (DLHE). Cheltenham. HESA

Home Office Border and Immigration Agency 2008. Green Paper The Path to Citizenship: Next Steps in Reforming the Immigration System. London. Home Office

Hughes, I. 2007. Enterprise Teaching in Bioscience Units in Higher Education. Leeds. The Higher Education Academy, Centre for Bioscience

Hussain, J. \& Scott, J. 2007. Access to Start-up Finance for Ethnic Minority Graduate Entrepreneurs. Birmingham. National Council for Graduate Entrepreneurship

Janjuha-Jivraj, S. 2003. The Sustainability of Social Capital within Ethnic Networks. Journal of Business Ethics 47, pp. 31-43

Jones, T. \& Ram, M. 2003. South Asian Businesses in Retreat? The Case of UK. Journal of Ethnic and Migration Studies, Vol.29, No.3, pp. 485-500

Jones, P. \& Elias, P. 2005. Science, Engineering and Technology and the UK's Ethnic Minority Population. A Report for the Royal Society. Coventry. Warwick University, Warwick Institute for Employment Research

Kloosterman, R., van der Leun, J. \& Rath, J. 1999. Mixed Embeddedness. (In)formal Economic Activities and Immigrant Businesses in the Netherlands. International Journal of Urban and Regional Research. 23 (92) 253-267

Kropp, E. \& Suran, B.S. 2002. Linking Banks and (Financial) Self Help Groups in India. In: Seminar on SHG-bank Linkage Programme, 25/26 November 2002, New Delhi

Lambert, R. 2003. Lambert Review of Business-University Collaboration. Final Report. Norwich. Her Majesty's Stationery Office

Leadbeater, C. \& Wilsdon, J. 2007. The Atlas of Ideas: How Asian Innovation Can Benefit Us All. London. DEMOS

Leitch, S. 2006. Leitch Review of Skills: Prosperity for All in the Global Economy World Class Skills. Norwich. Her Majesty's Stationery Office

Leslie, D. \& Drinkwater, S. 1999. Staying On In Full-Time Education: Reasons for Higher Participation Rates among Ethnic Minority Males And Females. Economica, 66, 6377

Li, Y. 2006. Assessing Data Needs and Gaps for Studying Ethnic Entrepreneurship in Britain - A Review Paper. Department for Trade \& Industry. Minority Ethnic Business Workshop

Lloyd-Reason, L. \& Mughan, T. 2006. Final background report of the OECD-APEC joint project. In: Removing Barriers to SME Access to International Markets. OECD Conference, 6-8 November 2006. Athens, Greece

London Development Agency 2005. Redefining London's BME-owned Businesses. London. London Development Agency 
Mascarenhas-Keyes, S. 1977. Goans in London: Portrait of a Catholic Asian Community. London. Goan Association (UK)

Mascarenhas-Keyes, S. 1987. The Native Anthropologist: Constraints and Strategies in Research. In Jackson, A. (ed.) Anthropology at Home, London. Tavistock Publications

Mascarenhas-Keyes, S. 2006. Ethnic Minority Small and Medium Enterprises in England: Diversity and Challenges. In: World Conference of the International Council for Small Business, Melbourne, 18-21 June 2006

Mascarenhas-Keyes, S. 2007. Asian Entrepreneurship in the UK: Continuity and Change among First and Second Generation Entrepreneurs. In Asian Entrepreneurship: New Asian Ventures in the Global Community of Enterprise and Innovation $7^{\text {th }}$ International Entrepreneurship Forum (IEF), 30-31 August, 2007, Shanghai

McEwen C., Pollard J. \& Henry N. 2005. The "Global" in the City Economy: Multi-Cultural Economic Development in Birmingham. International Journal of Urban and Regional Research 29, pp 916-33

Metcalf, H., Modood, T. \& Virdee, S. 1996. Asian Self-employment. The Interaction of Culture and Economics in England. London. Policy Studies Institute

Metcalf, H., Rolfe, H., Stevens, P. \& Weale, M. 2005. Recruitment and Retention of Academic Staff in Higher Education. London. Department for Education and Skills

Metcalf, H. 2005. Paying for University: The Impact of Increasing Costs on Student Employment, Debt and Satisfaction. National Institute Economic Review, vol. 191, No. $1,106-117$

Modood, T. 1997. Qualifications and English Language in Modood, T., Berthoud, R., Lakey, J., Nazroo, J., Smith, P., Virdee, S. \& Beishon S. Ethnic Minorities in Britain: Diversity and Disadvantage. London. Policy Studies Institute

Modood, T., Berthoud, R., Lakey, J., Nazroo J., Smith, P., Virdee, S. \& Beishon, S. 1997. Ethnic Minorities in Britain: Diversity and Disadvantage. London. Policy Studies Institute

Nabi, G., Holden, R., Walmsley, A., Harte, V., Jameson, S., Kyriakidou, N. \& Price, A. 2006. Career-making: Graduating into Self-employment. Birmingham. National Council for Graduate Entrepreneurship

National Employment Panel. 2005. Enterprising People, Enterprising Places: Measures to Increase Ethnic Minority Employment and Business Growth. London: National Employment Panel

National Council for Graduate Entrepreneurship \& Barclays Bank. 2005. Nascent Graduate Entrepreneurs. Birmingham. National Council for Graduate Entrepreneurship

National Council for Graduate Entrepreneurship. 2007. Enterprise and Entrepreneurship in Higher Education. Birmingham. National Council for Graduate Entrepreneurship 
National Endowment for Science, Technology and the Arts. 2007a. Hidden Innovation: How Innovation Happens In Six 'Low Innovation' Sectors. London. National Endowment for Science, Technology and the Arts

National Endowment for Science, Technology and the Arts. 2007b. Policy Briefing - Five Ways Universities Drive Innovation. National Endowment for Science, Technology and the Arts

National Statistics First Release. 2007. National Curriculum Assessment, GCSE and Equivalent Attainment and Post-16 Attainment by Pupil Characteristics, in England 2006/07

National Statistics online 2008. International Productivity

Office of National Statistics 2005a: Focus on Ethnicity \& Identity - Population Size. Norwich. Her Majesty's Stationery Office

Office of National Statistics. 2005b. Annual Business Inquiry 2004. London. Office of National Statistics

Office of National Statistics 2006: Focus on Ethnicity \& Identity - Education http://www.statistics.gov.uk

OMB Research. 2005. UKTI Telephone Survey of UK Trade \& Investment's Inward Investment \& Trade Development Customers and Non-Users, Final Report. Kent. OMB Research Ltd

OMB Research. 2006a. UKTI Innovative SMEs and their Internationalisation Capabilities. Kent. OMB Research Ltd

OMB Research. 2006b. UKTI PIMS Qualitative Follow-up Study of Business Needs in Emerging Markets. Report to UKTI. Kent. OMB Research Ltd

Organisation for Economic Co-operation and Development.1998. Fostering Entrepreneurship: A Thematic Review. Paris. OECD

Organisation for Economic Co-Operation and Development 2006. Science, Technology and Industry Outlook 2006 Highlights. Paris. OECD

Organisation for Economic Co-Operation and Development. 2007. Enhancing the Role of SMES In Global Value Chains: Final Synthesis Report. In: OECD Global Conference on Enhancing the Role of SMEs in Global Value Chains, 31 May-1 June 2007, Tokyo

Owen, D. 2003. The Demographic Characteristics of People from Minority Ethnic Groups in Britain. In Explaining Ethnic Differences: Changing Patterns of Disadvantage in Britain, D. Mason (ed.), Bristol. The Policy Press, 21-52

Pang, M. 1999. The Employment Situation of Young Chinese Adults in the British Labour Market in Personnel Review, vol 28, pp 41-57

Pittaway, L. \& Hannon, P. 2007. Institutional Strategies for Developing Enterprise Education, White Rose CETLE Working Paper. In: International Entrepreneurship Stimulating Smarter Successful Small Businesses World-Wide. 30th Institute for Small Business and Entrepreneurship Conference, 7-9 November 2007, Glasgow 
Pollard, E., Sheppard, E., Tamkin, P. \& Barkworth, R. 2004. Researching the Independent Production Sector: A Focus on Minority Ethnic Led Companies. Brighton, Institute for Employment Studies

Porter, M.E. \& Ketels, C.H.M. 2003. UK Competitiveness: Moving to the Next Stage. DTI Economics Paper No 3. London, Department of Trade \& Industry

Portes, A., Haller, W. \& Guarnizo, L.E. 2002. Transnational Entrepreneurs: The Emergence and Determinants of an Alternative Form of Immigrant Economic Adaptation. American Sociological Review, Vol. 67, No. 2, pp. 278-298

Prashantham, S. 2007. The Internationalization of Small Firms: A Strategic Entrepreneurship Perspective. London, Routledge

Price, A., Finlayson, R., Scott, J., Wilkinson, D., Myers, K., Richardson, C., Marston, A. \& Miller, C. 2004. Final Project Report: Mapping Graduate Enterprise. Birmingham. National Council for Graduate Entrepreneurship

Public and Corporate Economic Consultants (PACEC). 1998 Business Link Value for Money Evaluation Cambridge. PACEC

Purcell, K., Pitcher, J. \& Simm, C. 1999. Working out? Graduates Early Experience of the Labour Market. Manchester. Higher Education Careers Service Unit

Purcell, K. \& Elias, P. 2004 Seven years on: Graduate Careers in a Changing Labour Market. Manchester. Higher Education Careers Services Unit

Putnam, R. D. 2000. Bowling Alone. The Collapse and Revival of American Community. New York: Simon and Schuster

Ram, M. 1994. 'Unravelling Social Networks in Ethnic Minority Firms', International Small Business Journal, 12, 3, pp 42-53

Ram, M. 1998. Enterprise Support and Minority Ethnic Firms. Journal of Ethnic and Migration Studies, Vol 24 No 1 pp 143-158

Ram, M. \& Jones, T. 1998. Ethnic Minorities in Business. Milton Keynes. Small Business Research Trust

Ram, M., Abbas, T., Sanghera, B., Barlow, G. \& Jones, T. 2001a. Making the Link: Households and Small Business Activity in a Multi-Ethnic Context. Community, Work and Family, 4, 3, pp 327-348

Ram, M., Smallbone, D., Deakins, D. \& Jones, T. 2001b Banking on Break-Out: Finance and Ethnic Minority Businesses. Paper presented at the 15th Reseach in Entrepreneurship (RENT) conference, 22-23 November, 2001. Turku, Finland

Ram, M. \& Jones, T. 2002. Making the Connection: Ethnic Minority Business and the Family Enterprise in Fletcher, D. (ed.) Understanding the Small Family Business. London. Routledge

Ram, M., Smallbone, D. \& Deakins, D. 2002. Ethnic Minority Businesses in the UK: Access to Finance and Business Support. British Bankers Association 
Ram, M. \& Theodorakopoulos, N. 2007. Forms of Capital, Mixed Embeddedness and Somali Enterprise. In: International Entrepreneurship - Stimulating Smarter Successful Small Businesses World-Wide. 30th Institute for Small Business and Entrepreneurship Conference, 7-9 November 2007, Glasgow

Ram, M., Edwards, P. \& Jones, T. 2007. Staying Underground: Informal Work, Small Firms and Employment Regulation in the UK. Work and Occupations, 34, 3, pp 318344

Ram, M. \& Jones, T. 2008 Ethnic Minority Business: Review of Research Policy. forthcoming Government and Policy

Ramsden, P. 2004 An Evaluation of Phoenix Fund Support for Community Development Finance Institutions. London. Department of Business, Enterprise and Regulatory Reform

Rauch, J., 1999. Networks versus markets in international trade. Journal of International Economics, Elsevier, Vol. 48, No. 1, pp. 7-35

Rindoks, A., Penninx, R. \& Rath, J. 2006. What Works in Networks? Examining Economically Related Benefits Accrued from Greater Economic Linkages, Migration Processes and Diasporas, unpublished ms., Institute of Migration and Ethnic Studies, University of Amsterdam

Roberts, R. 2004. Current \& Future Trends in Graduate Enterprise - A Banking Perspective. ACCA Seminar, June 2004

Robertson, M. 2002. UK Undergraduate Entrepreneurial Cultures, Backgrounds and Career Aspirations. Leeds. Leeds Metropolitan University

Robertson, M. \& Collins, A. et al. 2004. Barriers to Start-Up. Leeds. Leeds Metropolitan University

Robertson, M., Price, A., Wilkinson, D. 2004. West Yorkshire Universities Graduate Start Up Partnership Student Entrepreneurial Intentions Survey 2003-04 - Universities of Leeds Metropolitan, Leeds, Bradford and Huddersfield. Leeds. Leeds Metropolitan University

Robertson, M. \& Wilkinson, D. 2006. Entrepreneurial Intentions Survey 2005-06 Final report. Leeds. Leeds Metropolitan University

Rose, Andrew K. 2005. The Foreign Service and Foreign Trade: Embassies as Export Promotion, Centre for Economic Policy Research Discussion Paper. London. C.E.P.R. Discussion Papers

Sainsbury, D. 2007. The Race to the Top: A Review of Government's Science and Innovation Policies. Norwich. Her Majesty's Stationery Office

Saxenian, A. 1999. Silicon Valley's New Immigrant Entrepreneurs, California: Public Policy Institute of California

Saxenian, A. 2002. Transnational Communities and the Evolution of Global Production Networks: The Cases of Taiwan, China and India. Industry and Innovation, Vol. 9, No. 3, pp. 183-202 
Saxenian, A. 2006. The New Argonauts. Regional Advantage in a Global Economy Cambridge. Mass. Harvard University Press

Shang, A. 1988 The Chinese in Britain London: Batsford Academic \& Educational

Shiner, M. \& Modood, T. 2002. Help or Hindrance? Higher Education and the Route to Ethnic Equality. British Journal of Sociology of Education 23,(2) 209-32

Smallbone, D., Ram, M., Deakins, D. \& Baldock, R. 2003. Access to Finance by Ethnic Minority Businesses in the UK. International Small Business Journal, 21(3), 291-314

Smallbone, D., Bertotti, M. \& Ekanem, I. 2005. Diversification in Ethnic Minority Business: The Case of Asians in London's creative industries. Journal of Small Business and Enterprise Development, Vol 12, No 1 pp 41-56

Smith, D.J. 1974. Racial Disadvantage in Employment. London. Political and Economic Planning

Smith, D.J. 1976. The Facts of Racial Disadvantage: A National Survey. Political and Economic Planning Report, No 560

SQW Limited. 2005. Interim Evaluation of Knowledge Transfer Programmes Funded by the Office of Science and Technology through the Science Budget. Cambridge, SQW Ltd

Strebler, M. Pollard, E., Miller, L. \& Akroyd, K. 2006. Report on recruitment and retention of staff in Higher Education 2005. London. University and Colleges Employers Association

Szabo, A. 2002. Internationalisation of SMEs: The UNECE approach. http://www.unece.org/indust/sme/internat.htm

Tackey, N.D. \& Perryman, S. 1999. Graduates Mean Business: A Study of Graduate Self-employment and Business Start-ups. IES Report 357. Brighton. Institute for Employment Studies

Technopolis Ltd. 2005. Drivers, Barriers, Benefits and Government Support of UK International Engagement in Science and Innovation Final Report. Brighton. Technopolis Ltd

United Kingdom Council for Overseas Student Affairs. 2004. International Students in UK Universities and Colleges. Broadening our Horizons. Report of the UKCOSA survey. London. UKCOSA

UK Trade and Investment. 2006. 2004-2005 Study of the Relative Economic Benefits of UK Trade \& Investment Support for Trade and Inward Investment: Final Synthesis Report. DTI Evaluation Report Series No.9. London. Department for Trade \& Industry

UNITE 2005. The 2005 Student Experience Report. London. UNITE

Universities UK. 2007. Patterns of Higher Education Institutions in the UK, Seventh Report. London. Universities UK 
Varney, D. 2006. Service Transformation: A Better Service for Citizens and Businesses, a Better Deal For The Taxpayer. Norwich. Her Majesty's Stationery Office

Vertovec, S. 2006. The Emergence of Super-Diversity in Britain. University of Oxford Centre on Migration, Policy and Society Working Paper No. 25.

Virdee, S. 2006 'Race', Employment and Social Change: A Critique of Current Orthodoxies' Ethnic and Racial Studies 29 (4), 605-28

Watson, J.L. 1975. Emigration and the Chinese Lineage: The Mans in Hong Kong and London. Berkeley. University of California Press

Watson, J.L. 1977. The Chinese: Hong Kong villagers in the British Catering Trade. In Watson, J. L. (ed) Between Two Cultures: Migrants and Minorities in Britain. Oxford. Blackwell

Wadhwa, V., Saxenian, A., Rissing, B., Gereffi, G. 2007 America's New Immigrant Entrepreneurs. Berkeley. Duke University

Wilkinson, D. 2005. Entrepreneurial Intentions Survey 2004-05 Final report. Leeds Metropolitan University. Leeds

Wilsdon, J. \& Keeley, J. 2007 China: The Next Science Superpower? The Atlas of Ideas: Mapping the New Geography of Science. London. DEMOS

Woolcock, M. 2001. The Place of Social Capital in Understanding Social and Economic Outcomes'. Isuma: Canadian Journal of Policy Research. Vol 2., No.1, pp 1-17

Zhou, M. 2004. Revisiting Ethnic Entrepreneurship: Convergencies, Controversies, and Conceptual Advancements. International Migration Review, Vol. 38, No.3, pp.104074 
Copies of this publication can be obtained from:

DCSF Publications

PO Box 5050

Sherwood Park

Annesley

Nottingham

NG15 ODJ

Tel 08456022260

Fax 08456033360

Email dius@prolog.uk.com

Ref: DIUS Research Report 08-20

(C) Crown Copyright 2008

\section{www.dius.gov.uk/research}

Published by the Department for Innovation,

Universities and Skills

Department for Innovation, Universities \& Skills 